Journal of the Scientific Agricultural Society of Finland

Vol. 53: 391-508, 1981

Maataloustieteellinen Aikakauskirja

\title{
DETERMINATION OF PLANT-AVAILABLE MANGANESE IN FINNISH SOILS
}

Selostus: Kasville käyttökelpoisen maan mangaanin määrittämisestä

\author{
VÄINÖ MÄNTYLAHTI \\ Department of Agricultural Chemistry \\ University of Helsinki \\ SF-00710 Helsinki 71, Finland
}

ACADEMIC DISSERTATION

To be presented, with the permission of the

Faculty of Agriculture and Forestry of the University of Helsinki, for public criticism in Auditorium XII on December 1, 1982, at 12 o'clock.

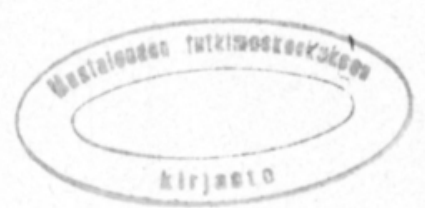


ISBN 951-9041-18-4

ISSN 0024-8835 


\section{Preface}

This study was carried out at the Department of Agricultural Chemistry, University of Helsinki. I owe a debt of gratitude to my teacher, Professor ARMI KAILA, Head of the Department, for the guidance and support she has given me in my work over a long period of time.

I would like to thank Docent antTi jaAkKola Dr. Sc. Agr. and For., and Professor linsa simola for checking my work and giving me valuable constructive criticism.

The Department of Soil Science, Agricultural Research Centre, Tikkurila, has provided me with the opportunity to carry out the experiment concerning effects of microbiological activity and organic matter on the extractability of soil manganese. I would like to thank Professor MIKKO SILLANPĀĀ, Head of the Department of Soil Science, and the staff of the Department for their assistance in helping to make my work a success.

I was assisted at the Department of Agricultural Chemistry, University of Helsinki, by Mrs RIrrTA DAHLSTROM, whom I would like to thank for her skilful work. Also I would like to thank my colleagues and all those persons who have contributed in the preparation of the manuscript.

Mr. JOHN DEROME, M. Sc., translated the manuscript into English, and I would like to thank him for his good and expert work.

I would like to thank the AUGUST JOHANNES and AINO TIURA Agricultural Research Foundation for grants to help finance my research work.

Finally, I am grateful to the Scientific Agricultural Society of Finland for accepting my paper for inclusion in its series of publications.

Helsinki, April 1982

Väinö Mäntylahti 



\section{CONTENTS}

Abstract

ANALYTICAL METHODS …………………………… 399

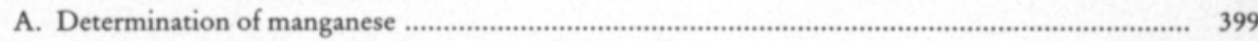

I Determination of extractable manganese in soil ................................................................ 400

1. Determination of exchangeable manganese ….............................................................. 401

a. Extraction apparatus …….................................................................................... 402

b. Development of the resin method ........................................................................ 404

c. Reliability of cation exchange resin extraction in the determination of exchangeable manganese in the soil ............................................................................................ 407

d. Sources of error in the resin method ..................................................................... 408

e. Method for determining the exchangeable manganese in the soil ................................. 409

2. Determination of reducible manganese ………........................................................... 409

a. Properties of the reducing agents ............................................................................ 410

b. Development of the resin method ....................................................................... 412

c. The reliability of resin extraction in determining reducible manganese in the soil .......... 414

d. Method for determining reducible manganese in the soil ............................................. 416

II Determination of total manganese in the soil ...................................................................... 417

III Determination of manganese in plant material ............................................................... 418

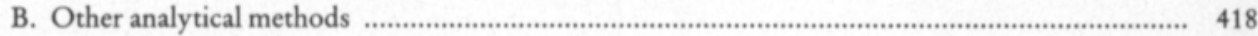

C. Statistical treatment of the results ….................................................................................. 419

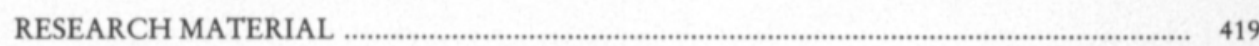

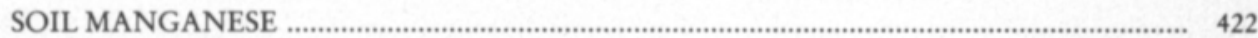

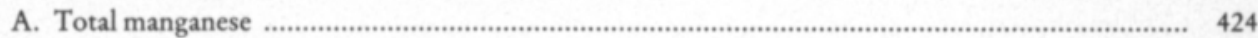

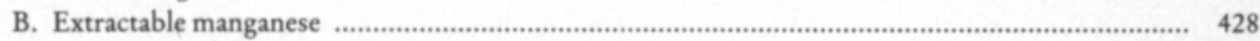

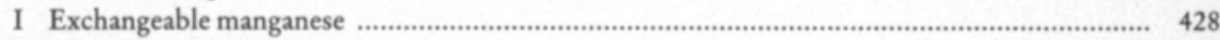

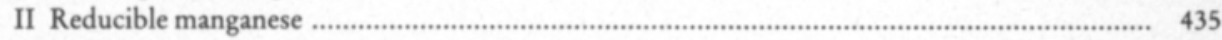

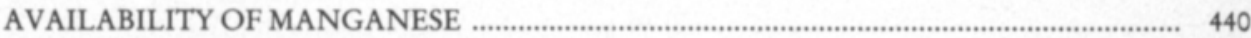

A. Factors affecting the availability of manganese …..................................................................... 441

I Effect of soil moisture and the plant stand ….................................................................. 441

II Effect of organic matter and microbial activity ................................................................. 449

B. Dependence of manganese uptake and manganese content of the yield on different soil properties 452

I Manganese uptake of the yield ...................................................................................... 453

II Manganese content of the yield .................................................................................... 462

III Manganese content of the roots ................................................................................. 471

C. Effect of liming on manganese availability ........................................................................... 474

I Effects of liming material and applied manganese on the content of extractable manganese of the soil

II Effects of liming and manganese fertilization on the manganese uptake and manganese content of the yield

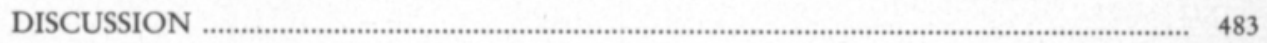

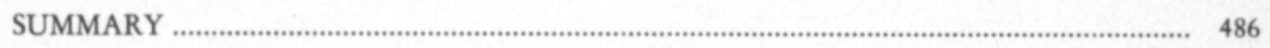

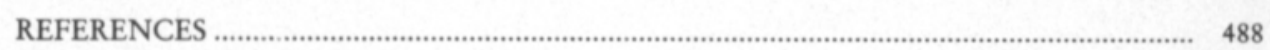

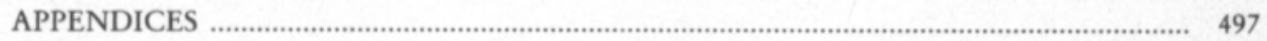





MÄNTYLAHTI, V. 1981. Determination of plant-available manganese in Finnish soil. J. Scient. Agric. Soc. Finl. 53: 391-508.

Abstract. The aim of the study was to determine the plant-available manganese in the soil and to study which factors regulate the plant-available manganese. The material consisted of 193 mineral soils and 17 organogenic soils. Oats (Avena sativa L.), Italian ryegrass (Lolium multiflorum Lam.) and turnip rape (Brassica campestris oleifera L.) were used as the test plants in the pot experiments.

A cation exchange resin method was developed for extracting soil manganese. The method enabled both exchangeable and reducible manganese to be determined. Exchangeable manganese comprised the manganese which was freely present in the soil solution in cationic form, and the manganese in cationic form which could be exchanged from the soil. Reducible manganese was the manganese reducible to the oxidation state, $\mathrm{Mn}^{2+}$, by the action of hydroquinone, hydroxylammonium chloride or ascorbic acid.

The content of exchangeable manganese in the soil explained $33,7 \%$ of the variation in the manganese content of the first yield of ryegrass. The greater the number of yields harvested, the smaller was the significance of the content of exchangeable manganese in the soil as an independent variable. On the other hand, when the content of reducible manganese in the soil was used as the independent variable, then the greater the number of yields harvested, the better it explained the variation in the manganese content of the yield. The content of manganese reduced by hydroxylammonium chloride explained $68,6 \%$ of the variation in the manganese content of the fourth yield. The contents of exchangeable manganese and manganese reducible by ascorbic acid explained $73,4 \%$ of the variation in the manganese content of the roots.

The $\mathrm{pH}$, the organic carbon content and the content of hydroquinone-reducible manganese in the soil explained $67,0 \%$ of the variation in the content of exchangeable manganese in the plough layer of the mineral soils. The content of "total" manganese in the plough layer of the mineral soils explained $27,6 \%$ of the variation in the content of ascorbic acid-reducible manganese.

The plant stands increased the content of exchangeable manganese in the soil and decreased the redox potential of the soil in comparison to the incubated soils. The content of exchangeable manganese started to increase when the redox potential of the soil fell below $0,59 \mathrm{~V}$. Adding glucose promoted the reduction of manganese in the soil, reduction appearing to be both biological and non-biological in origin. Soil moisture increased the content of exchangeable manganese when the moisture was higher than the field capacity.

Liming decreased the content of exchangeable manganese in the soil more than would have been expected on the basis of the change in $\mathrm{pH}$ values. The manganese content and manganese uptake of the crop were also reduced. Adding large amounts of manganese $(\mathrm{Mn} 51,5 \mathrm{~kg} / \mathrm{ha} \cdot 20 \mathrm{~cm}$ ) did not prevent liming (calcite $14 \mathrm{t} / \mathrm{ha} \cdot 20 \mathrm{~cm}$ ) from reducing the manganese content of the yield. 


\section{Introduction}

It has been known for 60 years already that manganese is an essential nutrient for plants (McHARGUE 1922) and it appears, after boron, to be the most extensively studied of the micronutrients (BRANDENBURG et al. 1969). Although the determination of manganese is generally considered to be easy (e.g. RANKAMA and SAHAMA 1950 , p. 640), manganese is, however, known to be a difficult field of soil chemistry. This is mainly due to the fact that manganese occurs in a number of different oxidation states. It has been assumed that it can occur in the oxidation states, $\mathrm{Mn}^{2+}$, $\mathrm{Mn}^{3+}$ and $\mathrm{Mn}^{4+}$, in equilibrium with each other according to the so-called DION and MANN (1946) cycle. In point of fact, it has not yet been possible to show conclusively that manganese would be present in soil in the oxidation state $\mathrm{Mn}^{3+}$ (McKENZIE 1972).

Plants take up manganese from the soil primarily as the divalent cation (CHENG and OUELLETTE 1971), although manganese complexes may be useable in small amounts (GARCIA and SANCHEZ DE LA PUENTE 1977). However, plants are also able to utilize a number of oxides and oxyhydroxides of manganese (LEEPER 1947, JONES and LEEPER 1951 a, 1951 b, HEINTZE 1956, JONES 1957 a, 1957 b, 1957 c). The sum of the exchangeable and easily reducible manganese in the soil has been called the active manganese in the soil (SCHACHTSCHABEL 1957). The oxides and oxyhydroxides of manganese can be classified on the basis of their reducibility into a series of compounds ranging from reducible to inactive ones (LEEPER 1935, 1947, JONES and LEEPER 1951 a, 1951 b). A reduction in the content of manganous manganese does not neccessarily result in a lack of manganese for plants if easily reducible oxides and oxyhydroxides of manganese are simultaneously available. On the other hand, easily reducible manganese may be converted into compounds which the plants cannot utilize. In this case it may be a question of a reduction in the specific surface area of oxides and oxyhydroxides and an increase in crystallization because oxides which have a large specific area and are weakly crystalline, are the most reactive oxides of manganese (MYRRAY et al. 1968, LOGANATHAN and BURAU 1973, LOGANATHAN et al. 1977).

A great number of different extraction methods have been used for the determination of plant-available manganese in the soil. Both strong acids and strong bases have been used as the extractant. Attempts have been made to explain the variation in the content of exchangeable manganese by means of soil $\mathrm{pH}$, organic carbon content, soil texture etc. (BROWMAN et al. 1969, BEYME 1971, DOLAR and KEENEY 1971, RANDALL et al. 1976). The redox potential of the soil (SCHÜTZ 1978, 1980), as well as the microbial activity in the soil (BROMFIELD 1958, 1978, GEERING et al. 1969, BROMFIELD and DAVID 1978), are involved in the oxidation and reduction reactions of manganese.

The aim of this study was to determine the plant-available manganese in the soil. Exchangeable and reducible manganese were extracted from the soil and it was investigated, how they together with other results of soil analyses explained the manganese uptake and content of the yield. In addition, it was studied which are the factors causing changes in the content of extractable soil manganese and how they can be affected. 


\section{Analytical methods}

\section{A. Determination of manganese}

The aim of this investigation was to study the determination of exchangeable manganese and reducible manganese fractions in the soil. Manganese may participate in a very large number of reactions in the soil, depending on the prevailing conditions (LAMM 1964). Thus an attempt was made to extract the manganese under conditions corresponding to the $\mathrm{pH}$ prevailing in the soil so that no changes would occur in the oxidation state of manganese, and manganese would not be transferred from one fraction to another. It was initially estimated that the manganese contents to be determined in the soil solution might vary from 0,01$3,75 \mathrm{ppm}$ ( GEERING et al. 1969, OLOMU et al. 1973) to hundreds of milligrams per kilogram of dry-matter. As the manganese contents would thus be of the order of $10 \mu \mathrm{g} / \mathrm{l}$, a sensitive analytical method would be reguired and interfering factors would have to be removed as effectively as possible.

The manganese concentration was determined in the initial part of the study by spectrophotometry. The manganese in the solution was oxidized to permanganate (WILLARD and GREATHOUSE 1917), and the permanganate concentration then determined by a photometrical method. The reaction takes the following form:

$$
2 \mathrm{Mn}^{2+}+5 \mathrm{IO}_{4}^{-}+3 \mathrm{H}_{2} \mathrm{O} \rightleftharpoons 2 \mathrm{MnO}_{4}^{-}+5 \mathrm{IO}_{3}^{-}+6 \mathrm{H}^{+}
$$

Oxidation requires acidic conditions. Permanganate is stable if excess metaperiodate is used. In addition, the intensity of the permanganate colour developed will remain unchanged in the absence of reducing agents. Colour intensity is measured using a green filter or at a wavelength of $540 \mathrm{~nm}$ (ADAMS 1965).

Turbidity, the presence of other coloured compounds and reducing agents all affect the spectrophotometric determination of manganese. Turbidity is mainly caused by the presence of inorganic material which cannot be removed completely during the filtering stage. The phenomenon is especially problematic if the soil is treated with an extractant which does not contain sufficient cations to flocculate the clay particles. These clay particles pass into the filtrate in amounts depending on the quality of the paper.

The turbidity of the solution can be reduced by repeating the filtration (e.g. SHERMAN et al. 1942). However, this is laborious and time-consuming and the time which the extractant is in contact with the soil varies. Clear solutions can be obtained from coarse mineral soils with one filtration only, while clay soils may require as many as 4-5 filtrations of rather long duration. Clay particles can be removed from a solution by subjecting it to ultracentrifugation. Clear solutions can also be obtained using additives, the particles then being removed at rather low speeds on a centrifuge (SHELDRICK and McKEAGUE 1975).

Colour of the soil filtrate depends on the amount and type of humus in the soil. According to ADAMS (1965), humus can be removed by treating with concentrated nitric acid and hydrogen peroxide. Oxidizing the manganese in the filtrate also presupposes that there are no reducing agents present in the solution. The most 
important of these are organic matter and chloride ions. Organic matter can be removed by treating with hydrogen peroxide, and chlorides by masking (SCHACHTSCHABEL 1957). Chromium, nickel and iron can also cause absorption at the wavelength at which the permanganate is measured. The interfering effect of iron can be counteracted by adding phosphoric acid, which forms a colourless complex with ferric ions (SCHACHTSCHABEL 1957, ADAMS 1965).

The manganese content of the soil filtrate was determined according to ADAMS (1965) as follows:

A $40 \mathrm{ml}$ aliquot of the filtrate was transferred to a $100 \mathrm{ml}$ beaker and $5 \mathrm{ml}$ of concentrated $\mathrm{HNO}_{3}$ and $2 \mathrm{ml}$ of $30 \% \mathrm{H}_{2} \mathrm{O}_{2}$ added. The beaker was covered with a watch glass and placed on a water bath for $30 \mathrm{~min}$. The watch glass was then removed and the sample evaporated to dryness. The beaker was then cooled and $20 \mathrm{ml}$ of deionized water, $2 \mathrm{ml}$ of concentrated $\mathrm{HNO}_{3}, 5 \mathrm{ml}$ of $85 \% \mathrm{H}_{3} \mathrm{PO}_{4}$ and $0,3 \mathrm{~g} \mathrm{KIO}_{4}$ were added. The beaker was covered with a watch glass, placed on a sand bath and then boiled for a further 10 min after the permanganate colour had developed. After cooling the solution was transferred to a $50 \mathrm{ml}$ volumetric flask and filled to the mark with deionized water. The permanganate concentration was determined on a Hitachi PerkinElmer 139 UV-VIS spectrophotometer at a wavelength of $540 \mathrm{~nm}$.

It became possible, later on in the study, to determine the manganese content of the samples by means of atomic absorption spectrophotometry. The ability of atoms in their ground state to absorb radiation of a specific wavelength is utilized in this technique. The effect of factors which interfere with the atomic absorption spectrophotometry of manganese, such as phosphates, perchlorates, iron, nickel and cobalt, is small in an oxidizing air-acetylene flame. They do not normally have to be removed when analysing manganese contents in plant material and soil extracts. Buffers are also unnecessary (ALLAN 1971). The manganese content of plant material, the total manganese content of the soil samples and part of the soil manganese fractions were measured in this study on a Varian Techtron 1000 atomic absorption spectrophotometer at a wavelength of $279,5 \mathrm{~nm}$, using an oxidizing airacetylene flame.

The manganese contents were determined in this study both spectrophotometrically and by atomic absorption spectrophotometry. In principle, determinations, experiments and experimental series were carried out entirely using the same method as was used at the start. This was done in order to avoid having to compare results obtained using different methods. Comparison of manganese determinations carried out by spectrophotometry and by atomic absorption spectrophotometry was not considered to fall within the scope of this study. BORATYNSKI et al. (1973), for instance, consider that both methods give results which are equal to each other.

\section{Determination of extractable manganese in soil}

The amounts of soil manganese extractable with water have been utilized when attempting to determine toxic contents of manganese in the soil. (ADAMS and WEAR 1957, RANDALL et al. 1976). The amounts of manganese available to plants have also been determined from water extracts (PAGE et al. 1962, ROORDA van EYSINGA et al. 1978). In addition, the effect of soil sample treatment, such as sterilization and duration of storage, on the content of extractable manganese has 
been determined by measuring changes in the content of water-extractable manganese (NELSON 1977). Determination of the manganese content of water extracts prepared according to the method of ADAMS (1965) was studied in this paper. Schleicher \& Schüll Selecta Nr 589/3 was used as the filter paper. Preliminary trials showed that the filtrates were turbid. Four parallel series of determinations were made on samples $1 \mathrm{a}-10 \mathrm{~b}$ (Appendix 1 ). The turbidity produced such great variation in the results that the coefficient of variation of the mean varied from 5$120 \%$. The manganese contents determined in this way from water extracts were thus considered to be too unrealiable and the method was discontinued.

\section{Determination of exchangeable manganese}

For extracting exchangeable manganese in the soil the solutions of the following cations have been used: $\mathrm{Na}^{+}, \mathrm{K}^{+}, \mathrm{NH}_{4}{ }^{+}, \mathrm{Ca}^{2+}, \mathrm{Mg}^{2+}, \mathrm{Zn}^{2+}, \mathrm{Cu}^{2+}, \mathrm{Co}^{2+}$, $\mathrm{Ni}^{2+}$ and $\mathrm{Cd}^{2+}$ (e.g. STEENBJERG 1933, HEINTZE and MANN 1949, 1951, JONES and LEEPER 1951 b, SCHACHTSCHABEL 1956, 1957, BROWMAN et al. 1969, SEMB and ØIEN 1970, BEYME 1971, RANDALL et al. 1976, SCHÜTZ 1978, 1980). Inorganic acids have been used, for instance, by BROWMAN et al. (1969), SEMB and ØIEN (1970), MacLEAN and LANGILLE (1976), RANDALL et al. (1976) and DUANGPATRA et al. (1979). Determination of the content of exchangeable manganese of the soil from $0,5 \mathrm{M} \mathrm{MgSO}_{4}$ extracts was studied with soil samples la-4a (Appendix 1). The organic carbon content of these samples varied from $1,0-10,6 \%$. There was considerable variation in the colour of the extracts. For this reason, as much as ten times the amount of hydrogen peroxide given in the analytical method (SCHACHTSCHABEL 1957) had to be used to remove the organic matter. Despite this, it was not possible to obtain completely colourless solutions. It was found when metaperiodate was used to oxidize the manganese, in accordance with the method of ADAMS (1965), that in three of sixteen determinations the absorbance of the control was greater than that of the oxidized sample. It may be that the metaperiodate used to oxidize the manganese also oxidized part of the organic matter in the filtrate and thus negative manganese contents were obtained.

The only available method for determining the manganese content was based on the oxidation of manganese and measurement of the colour intensity of the permanganate ion formed. Therefore it was necessary to find an extraction method which would not be affected by the factors interfering with manganese determination in water and salt extracts or the interfering factors would otherwise be removed. The use of ion exchange resins in conjunction with the extraction of manganese in the soil was considered to be worth studying at this stage.

Ion exchange resins have been used with varying degrees of success in the extraction of a number of macronutrients from soil (e.g. SCHMITZ and PRATT 1953, MacLEAN 1961, WADDY and VIMPAY 1970, SIBBESEN 1977, 1978, 1981, AURA 1978). Ion exchange resins have also been used in the study of the degree of complex formation of micronutrients by, for instance, MILLER and OHLROGGE (1958 a, 1958 b), GEERING et al. (1969), OLOMU et al. (1973) and SIMS and PATRICK (1978). Resins appear to be very suitable for studying organic complexes of micronutrients (RANDHAWA and BROADBENT 1965, 
SCHNITZER and SKINNER 1967, SCHNITZER and HANSEN 1970, STEVENSON 1976, 1977). On the other hand, resins have only occasionally been used in the extraction of micronutrients from soil (ACQUAYE et al. 1972).

The main part of the manganese in the soil is present as secondary minerals, such as oxides and oxyhydroxides. When manganese is liberated from these compounds into the soil solution it can occur as a cation (DION and MANN 1946). As an exchangeable cation (ELLIS and KNEZEK 1972) it may be bound on oxides, oxyhydroxides, organic matter and clay particles in the soil. In the ion exchange processes manganese is liberated as a cation (HEINTZE and MANN 1949, BECKWITH 1955), and in the soil solution it can form both cationic and anionic complexes (GEERING et al. 1969, OLOMU et al. 1973, SIMS and PATRICK 1978). From point of view of the plants the divalent manganese is important, because plants take up manganese mainly as manganous manganese (CHENG and OUELLETTE 1971). According to these points, when the aim is to extract plant-available manganese in the soil the extraction could be carried out with cation exchange resins. As Finnish soils are acidic and the $\mathrm{pH}$ of the extraction conditions can vary from $\mathrm{pH} 3,5-7,5$, the active group of the cation exchange resin should be strongly acidic, so that the ionizing, of the active group would be sufficient. Only strongly acidic cation exchange resin is suitable for this purpose.

Oxide and oxyhydroxide polymers of manganese become negatively charged if the $\mathrm{pH}$ of the soil suspension is higher than the zero point of charge of the oxides and oxyhydroxides. Neutral or negatively-charged polymers of manganese are thus not retained on strongly acidic cation exchange resin. The zero point of charge of oxides and oxyhydroxides of manganese ranges from $\mathrm{pH} \mathrm{1,5}$ to $\mathrm{pH} \mathrm{5,5} \mathrm{(MORGAN}$ and STUMM 1964, HEALY et al. 1966) apart from the oxide $\beta-\mathrm{MnO}_{2}$ which has a zero point of charge at $\mathrm{pH} \mathrm{7,3} \mathrm{(HEALY} \mathrm{et} \mathrm{al.} \mathrm{1966).} \mathrm{Thus} \mathrm{most} \mathrm{of} \mathrm{oxides} \mathrm{and}$ oxyhydroxides of manganese representing the oxidation state $\mathrm{Mn}^{2+}-\mathrm{Mn}^{4+}$ in the extraction suspension, are not retained when a cation exchange resin is used.

Amberlite IR-120 was chosen as the ion exchange resin. Its properties (KUNIN 1974) are as follows:

- polystyrene matrix with $8 \%$ (w/w) DVB (divinylbenzene)

- water content $44-48 \%$

- density of wet resin $1,26 \mathrm{~g} / \mathrm{cm}^{3}$

- particle size $0,47-0,62 \mathrm{~mm}$

- exchange capacity of wet resin $1,9 \mathrm{me} / \mathrm{ml}$

- active group $-\mathrm{SO}_{3} \mathrm{H}$

\section{a. Extraction apparatus}

In studies involving the application of ion exchange resin methods in soil analysis, the soil samples are usually ground so finely that the resin can be removed after the shaking extraction by sieving the suspension (e.g. KALOVOULOS and PAXINOS 1963, ACQUAYE et al. 1972). A method has been developed in which the resin is contained in a nylon netting bag and during the extraction the bag floats in the suspension ( SIBBESEN 1977, 1978, 1981).

In this study, the soil samples were ground only as much as was necessary to pass through a $2 \mathrm{~mm}$ sieve, so as not to break down the primary particles. However, 


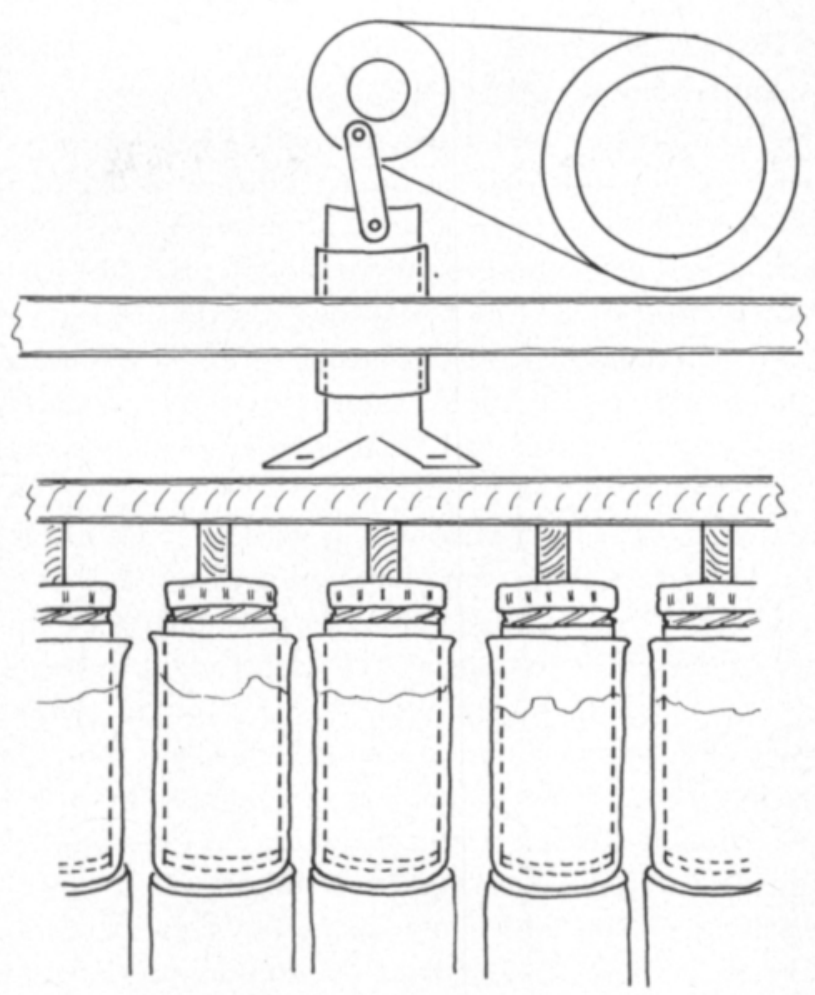

Fig. 1. Schematic diagramme of the shaking apparatus.

as the particle size of the resin was $0,47-0,62 \mathrm{~mm}$ it would not have been possible to separate out the resin by sieving. An extraction cylinder was constructed for shaking the samples with the resin. After a number of preliminary trials, the best construction was found to be a container made from a poly(methyl methacrylate) tube. The diameter of the tube was $70 \mathrm{~mm}$ and the bottom end of the tube was covered with $0,42 \mathrm{~mm}$ mesh nylon netting. The cylinder was $150 \mathrm{~mm}$ long and was fitted at the top with a screw-top cap with a small air hole bored through it. The ion exchange resin was put into the cylinder. The soil sample to be extracted was weighed out into a tall $600 \mathrm{ml}$ beaker which had an internal diameter of $80 \mathrm{~mm}$ and $200 \mathrm{ml}$ of deionized water was added (Fig. 1).

Shaking was carried out on a wet-sieving shaker. A plate, $31 \times 80 \mathrm{~cm}$ in size, was fastened to the shaker in place of the set of sieves. The screw-top caps of the extraction cylinders were fixed to the underside of the plate. The cylinders containing the resin were then screwed into the caps. The beakers containing the soil sample and water were placed under the resin containers. When the machine was started, the up-and-down motion of the resin cylinders was effected and the beakers were kept in place. The length of the stroke was $4 \mathrm{~cm}$ and the speed 55 strokes a minute. The beakers were placed at such a height that the bottom of each resin cylinder was, at the lowest point of each stroke, $3 \mathrm{~mm}$ above the bottom of the beakers. The suspension appeared to be efficiently mixed (Fig. 1). The resin remained inside the resin cylinder throughout the shaking treatment. On the other hand, soil material with a diameter less than that of the nylon netting $(0,42 \mathrm{~mm})$ 
passed into the cylinder as a result of vortices in the liquid. The apparatus was constructed to handle 16 soil samples at a time.

After shaking, the beakers containing the soil suspensions were removed and replaced by beakers of the same size containing $200 \mathrm{ml}$ deionized water. Shaking was then continued for 5 minutes in order to flush out the soil particles from the resin. The resin cylinders were unscrewed from the top plate, the resin rinsed with a little water and then transferred to beakers using a wash bottle. If the soil sample contained a lot of undecomposed organic matter, then it was usually difficult to remove it from the resin during the rinsing stage. However, it was easy to decant the organic matter off after the resin had been transferred to the beakers. The ion exchange resin was then ready to be eluted.

Elution tubes were made from glass tubing with an inner diameter of $17 \mathrm{~mm}$, and length $25 \mathrm{~cm}$. A sieve made from nylon netting (mesh $0,05 \mathrm{~mm}$ ) was fitted at the bottom end. After preliminary trials, it was decided to use an elution technique in which the surface of the eluant remains at a constant height throughout the elution procedure. This was done by running the eluant into the elution tube from a container by means of a syphon. The surface of the liquid in this reservoir was kept at a constant height by means of a 2 liter volumetric flask which was fitted with a one-way stopcock so as to make it easier to invert the flask when full. When the level of the liquid in the reservoir dropped as eluant was drawn off through the syphon system into the elution tube, more eluant was supplied from the volumetric flask (Fig. 2). The elution rate was regulated by adjusting the height of the liquid in the reservoir. This brought about a change in the height of the liquid in the elution tube and a subsequent change in pressure. A $30 \mathrm{~cm}$-long polythene tube, with an inner diameter of $1 \mathrm{~mm}$, was fitted onto the bottom of the elution tube. A $5 \mathrm{~mm}$ long polythene tube, with an internal diameter of $0,5 \mathrm{~mm}$, was attached to the end of the larger tube. This was done in order to constrict the eluant flow sufficiently enough to enable the height of the eluant in the elution tube to be maintained at the desired height. In addition, a polythene disconnector was fitted onto the end of the tube so that the end of the tube could be kept at a constant height in the mouth of the volumetric flask (Fig. 2).

\section{b. Development of the resin method}

Before the ion exchange resin method could be used for routine analyses, it was necessary to study how well the method overcame the problems associated with the water and salt extraction. In addition, the usability of the resin method and the reliability of the analysis results for the extraction of soil exchangeable manganese had to be investigated.

Turbidity and colour of the extract. The turbidity and colour of extracts obtained using the ion exchange resin method were studied. The amount of insoluble matter in the eluate (samples 6a-13b, Appendix 1) was determined gravimetrically and the absorption at the wavelength used for measuring the manganese content was determined on a spectrophotometer. The extracts did not contain measurable amounts of insoluble inorganic material. The absorbance of the blank solutions without the metaperiodate was at a level corresponding to that for the zero of the standards. 


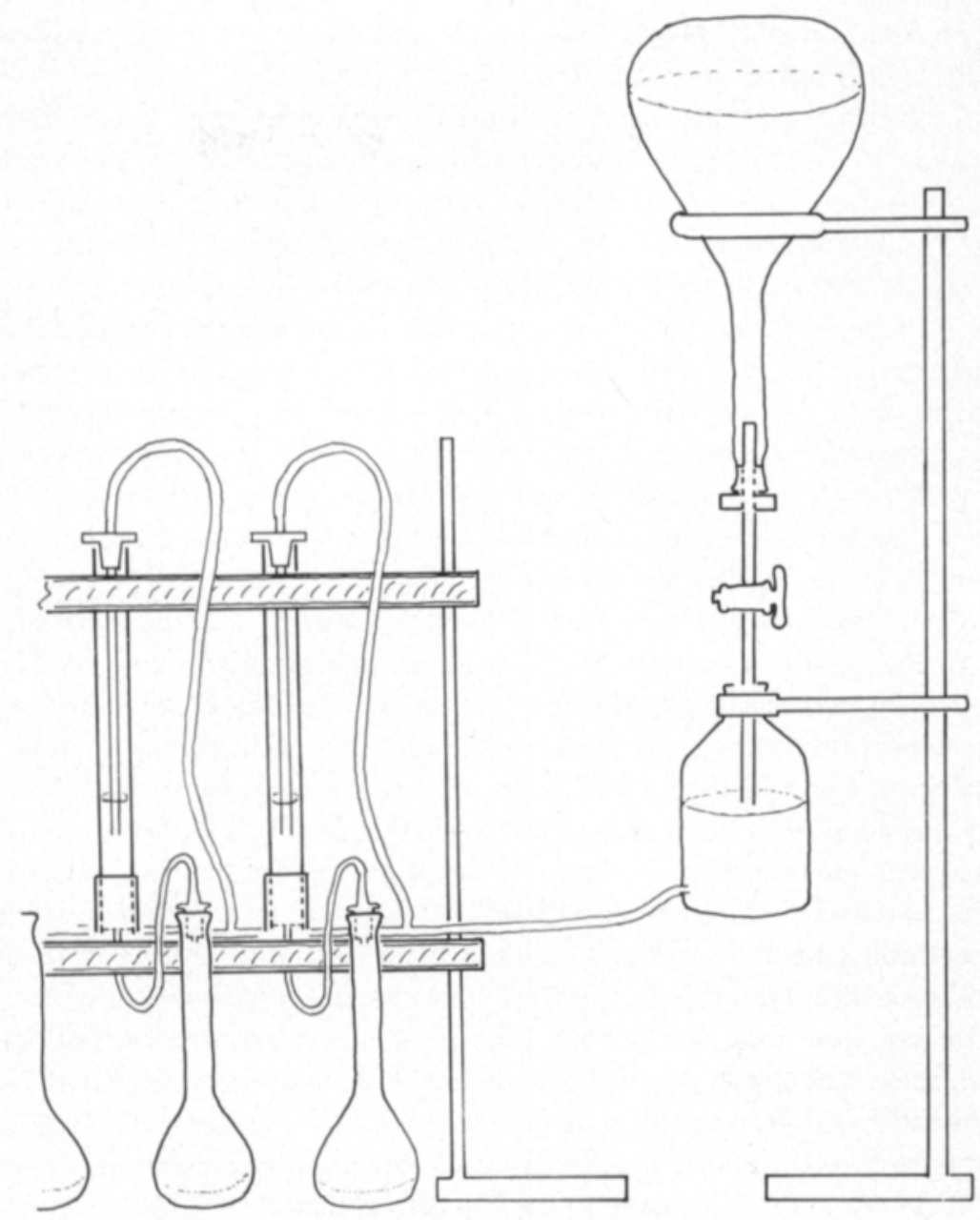

Fig. 2. Schematic diagramme of the elution apparatus.

$\mathrm{pH}$ of the suspension during extraction. Extraction was carried out as far as possible under $\mathrm{pH}$ conditions corresponding to those prevailing in the soil. KUNIN (1974) recommends that when Amberlite IR-120 is used it should be in either the $\mathrm{H}^{+}$or the $\mathrm{Na}^{+}$form. According to STEENBJERG (1933), SCHACHTSCHABEL $(1956,1957)$ and BEYME (1971), magnesium is a good exchanger of manganese. Thus the ion exchange resin was tested in the $\mathrm{H}^{+}, \mathrm{Na}^{+}$ and $\mathrm{Mg}^{2+}$ form. 5,0 g of air-dry soil was weighed out into a beaker, $200 \mathrm{ml}$ of deionized water added, the suspension mixed and the $\mathrm{pH}$ measured after 30 minutes. The resin cylinders were connected to the apparatus and shaking was carried out for one hour. The resin cylinders were then removed and the $\mathrm{pH}$ of the soil suspensions measured. A sample which was treated without any resin was used as the control (Table 1). The type of the cation in the resin had an effect on the $\mathrm{pH}$ of the suspension. Resin saturated with $\mathrm{H}^{+}$ions decreased the $\mathrm{pH}$ of the suspension by $1,61-1,66 \mathrm{pH}$ units after the results had been corrected using the value for the blank. The resin saturated with $\mathrm{Na}^{+}$ions increased the $\mathrm{pH}$ by $0,46-0,80 \mathrm{pH}$ 
units. Resin saturated with $\mathrm{Mg}^{2+}$ ions did not alter the $\mathrm{pH}$ of the suspension to any statistically significant degree $(\mathrm{P}=0,05)$.

The aim of the study was to extract exchangeable manganese at $\mathrm{pH}$ conditions corresponding to those of the soil samples. Ion exchange resins saturated with $\mathrm{H}^{+}$ or $\mathrm{Na}^{+}$ions did not satisfy this requirement. As the cation exchange resin saturated with $\mathrm{Mg}^{2+}$ did not change the $\mathrm{pH}$ of the suspension during extraction, it can be considered that extraction took place at the $\mathrm{pH}$ of the soil. Cation exchange resin saturated with magnesium was therefore chosen to be used in the extraction.

Uniform quality of the extraction apparatus. Before the extraction of soil manganese by the resin method was started, the uniform quality of the extraction apparatus was checked. The determination of extractable manganese was carried out as two replicates. On the average, manganese was extracted $32,0 \mathrm{mg} / \mathrm{kg}$ air-dry soil, the values ranging from $31,5 \mathrm{mg} / \mathrm{kg}$ to $32,7 \mathrm{mg} / \mathrm{kg}$ air-dry soil. The differences were not statistically significant $(P=0,05)$.

Volume and concentration of the eluant. The amount of eluant required to elute the $\mathrm{Mn}$ retained by the ion exchange resin was studied. A known amount of manganese $\left(\mathrm{MnSO}_{4} \cdot \mathrm{H}_{2} \mathrm{O}\right)$ was added to $200 \mathrm{ml}$ of deionized water in the beakers used for extraction. The samples were then shaken for one hour on the extraction apparatus and then eluted with four $50 \mathrm{ml}$ aliquots of the eluate over a period of one hour. The resin was eluted with $0,5 \mathrm{M} \mathrm{H}_{2} \mathrm{SO}_{4}$. Over $90 \%$ of the manganese was recovered in the first $50 \mathrm{ml}$ of eluate (Table 2). It was therefore decided to carry out elution with $100 \mathrm{ml}$ of eluant over a period of 1 hour.

The concentration of the eluant required for quantitative elution of manganese was investigated by adding manganese $500 \mu \mathrm{g}\left(\mathrm{MnSO}_{4} \cdot \mathrm{H}_{2} \mathrm{O}\right)$ to deionized water, shaking for one hour and eluting with $100 \mathrm{ml}$ of eluant over a period of one hour. Sulphuric acid was used when the manganese was to be determined spectrophotometrically and hydrochloric acid when $\mathrm{Mn}$ was determined on an atomic absorption spectrophotometer (Table 3). The results indicated that either $1,00 \mathrm{M}$ $\mathrm{HCl}$ or $0,50 \mathrm{M} \mathrm{H}_{2} \mathrm{SO}_{4}$ should be used as the eluant.

Table 1. Effect of the cation in the cation exchange resin on the $\mathrm{pH}$ of the extraction suspension of soils. ${ }^{1}$

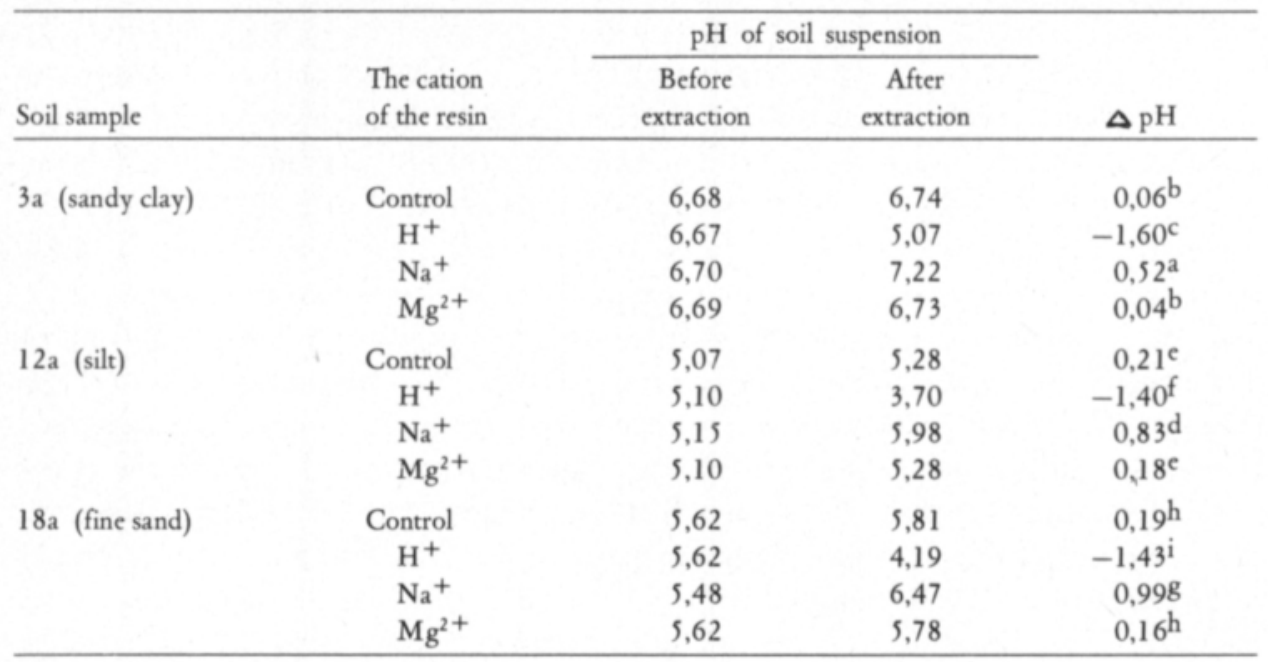

1 Each soil sample has been tested separately. 
Table 2. Recovery of manganese from the cation exchange resin with $0,5 \mathrm{M} \mathrm{H}_{2} \mathrm{SO}_{4}$ during a total elution period of one hour.

\begin{tabular}{|c|c|c|c|c|c|}
\hline \multirow{2}{*}{$\begin{array}{l}\text { Added } \\
\text { Mn } \mu \mathrm{g}\end{array}$} & \multicolumn{4}{|c|}{ Recovered in $50 \mathrm{ml}$ eluate fractions, $\%$} & \multirow[b]{2}{*}{ Sum $\%$} \\
\hline & 1 & II & III & IV & \\
\hline 10 & $98,6 \pm 2,2$ & $0,0 \pm 0,0$ & 0 & 0 & $98,6 \pm 2,2$ \\
\hline 20 & $99,7 \pm 0,8$ & $0,0 \pm 0,0$ & 0 & 0 & $99,7 \pm 0,8$ \\
\hline 40 & $98,0 \pm 1,9$ & $2,2 \pm 0,9$ & 0 & 0 & $100,2 \pm 0,9$ \\
\hline 80 & $97,3 \pm 2,0$ & $2,4 \pm 0,7$ & 0 & 0 & $99,7 \pm 2,3$ \\
\hline 160 & $96,0 \pm 0,6$ & $3,1 \pm 1,3$ & 0 & 0 & $99,1 \pm 1,3$ \\
\hline 320 & $94,1 \pm 2,0$ & $4,9 \pm 0,9$ & 0 & 0 & $99,0 \pm 2,0$ \\
\hline 640 & $94,0 \pm 0,8$ & $4,8 \pm 1,2$ & 0 & 0 & $98,8 \pm 1,1$ \\
\hline
\end{tabular}

Table 3. Effect of eluant and its concentration on the elution of manganese from the cation exchange resin within one hour.

\begin{tabular}{lcc}
\hline $\begin{array}{l}\text { Eluant and its } \\
\text { concentration }\end{array}$ & \multicolumn{2}{c}{ Recovered manganese } \\
$\mu \mathrm{g}$ & $\%$ \\
\hline $0,50 \mathrm{M} \mathrm{HCl}$ & 406,3 & $81,3^{\mathrm{b}}$ \\
$1,00 \mathrm{M} \mathrm{HCl}$ & 498,6 & $99,7^{\mathrm{a}}$ \\
$2,00 \mathrm{M} \mathrm{HCl}$ & 494,3 & $98,9^{\mathrm{a}}$ \\
$0,25 \mathrm{M} \mathrm{H}_{2} \mathrm{SO}_{4}$ & 399,4 & $79,9^{\mathrm{b}}$ \\
$0,50 \mathrm{M} \mathrm{H}_{2} \mathrm{SO}_{4}$ & 489,0 & $97,8^{\mathrm{a}}$ \\
$1,00 \mathrm{M} \mathrm{H}_{2} \mathrm{SO}_{4}$ & 488,6 & $97,7^{\mathrm{a}}$ \\
\hline
\end{tabular}

c. Reliability of cation exchange resin extraction in the determination of exchangeable manganese in the soil

The reliability of the resin method for extracting the exchangeable soil manganese was studied by determining the reproducability of the results obtained from two soil samples. According to the following results the reproducability of the exchangeable manganese could be considered to be satisfactory:

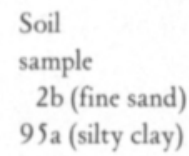

\begin{tabular}{ccccc}
\multicolumn{5}{c}{ Exchangeable Mn mg/kg air-dry soil } \\
$\mathrm{n}$ & $\overline{\mathrm{x}} \ddot{\mathrm{A}}$ & $\mathrm{Md}$ & $\mathrm{s}$ & $\mathrm{V} \%$ \\
16 & 31,9 & 32,1 & 0,78 & 2,44 \\
9 & 10,8 & 11,0 & 0,44 & 4,09
\end{tabular}

In addition, the method was checked by adding known amounts of manganese $\left(\mathrm{MnSO}_{4} \cdot \mathrm{H}_{2} \mathrm{O}\right)$ to the deionized water in order that none of manganese would be bound by the soil. Extraction and elution of the resin was then carried out. The amounts of manganese added corresponded to $\mathrm{Mn} 0-128 \mathrm{mg} / \mathrm{kg}$ air-dry soil. It was considered that this range would cover the content of exchangeable manganese in the soil samples (Table 4). About 3-5\% of the added manganese was not recovered. Only a very small amount of the largest manganese addition was recovered from the filtrate which was obtained after filtering the suspension. The manganese was probably lost during the washing and transfer of the resin to the elution tube. It was possible that during the extraction soluble manganese would 
Table 4. Recovery of added manganese from the resin and extraction suspension in the cation exchange resin method.

\begin{tabular}{ccc}
\hline $\begin{array}{c}\text { Added } \\
\text { Mn } \mu \mathrm{g}\end{array}$ & $\begin{array}{c}\text { Recovered } \\
\text { from resin, } \%\end{array}$ & $\begin{array}{c}\text { Recovered from } \\
\text { extraction suspension, } \%\end{array}$ \\
\hline 20 & $96,7 \pm 0,0$ & $0,0 \pm 0,0$ \\
40 & $96,3 \pm 0,6$ & $0,0 \pm 0,0$ \\
80 & $94,8 \pm 0,0$ & $0,0 \pm 0,0$ \\
160 & $94,8 \pm 0,0$ & $0,0 \pm 0,0$ \\
320 & $95,5 \pm 0,6$ & $0,0 \pm 0,0$ \\
640 & $94,9 \pm 1,0$ & $0,3 \pm 0,0$ \\
\hline
\end{tabular}

remain in the soil suspension, because the manganese could be present as neutral and/or negative complexes in the suspension, too. This manganese was studied on ten soil samples (2a, 3a, 4b, 10b, 15a, 16a, 17a, 18a, 101b, 106b) using the cation exchange resin method. Four replications were carried out. The extraction suspensions were filtered immediately after shaking and the manganese content of the filtrates determined. The contents of manganese in the filtrates were under the detection limit of the manganese.

\section{d. Sources of error in the resin method}

Temperature has an effect on the exchange of ions between the ion exchanger and the soil. As the temperature increases, the resin extraction process becomes more efficient. According to WADDY and VIMPAY (1970) the potassium content increases by $0,2-1,8 \%$ per ${ }^{\circ} \mathrm{C}$ when the temperature is $70-80{ }^{\circ} \mathrm{C}$. The content of some macronutrients increases by about $0,5 \%$ per ${ }^{\circ} \mathrm{C}$ in conventional extraction methods, when the temperature is $20^{\circ} \mathrm{C}$ (SILLANPÄÄ 1977). The extractions were carried out in this study at room temperature, which varied from $18-20^{\circ} \mathrm{C}$. According to references, the error due to the variation in the temperature during the extraction could be considered to be slight.

The amount of ion exchange resin has a direct effect on the extraction results (ACQUAYE et al. 1972). The handling of the resin is difficult, because the resin is wet. Thus the amount of the resin used in the extraction can vary and so the extraction ratio can change. To avoid this error the resin, which was stored in an extraction funnel, was poured into a filter funnel and after the excess water had drained off, the amount of the resin required was weighed out into the extraction cylinders.

Incomplete washing of the ion exchange resin after shaking represented a source of error if soil was carried into the elution tube along with the resin. Removal of inorganic soil material was usually rather successful. On the other hand, much water had to be used in the washing stage if the soil sample contained a lot of organic matter. During washing part of the bound nutrients may also have been leached out of the ion exchange resin. However, no measurable amounts of manganese were found in the rinsing water. If care was not taken during decantation, organic matter passed into the elution tube. This resulted in a coloured eluate.

The up-and-down movement of the resin during shaking may have resulted in 
the destruction of some of the resin particles. All the resin pellets used in the extraction would not then have been transferred to the elution tube.

\section{e. Method for determining the exchangeable manganese in the soil}

$5,0 \mathrm{~g}$ of air-dry soil was weighed out into a beaker. In the case of moist soil samples, amounts equivalent to $5,0 \mathrm{~g}$ of air-dry soil were as far as possible used. In this case, the exact amount of air-dry soil was determined by evaporating the suspension after extraction in a drying oven and then weighing the dried residue. Then $200 \mathrm{ml}$ of deionized water was added to a beaker. This amount of water was used on the basis of the study carried out by ACQUAYE et al. (1972). The soil and water suspension was mixed with a glass rod and left to stand for 30 minutes before shaking. The time which the samples were left to stand was determined by practical considerations since during this time the resin was being weighed out. Acidic cation exchange resin (Amberlite IR-120), saturated with $\mathrm{Mg}^{2+}$, was used as the ion exchanger. $5,0 \mathrm{~g}$ of wet ion exchange resin was weighed out into the shaking cylinders. This amount of resin had an exchange capacity of 7,5 me (KUNIN 1974), the capacity of the ion exchange resin thus exceeding the capacity of the soil by a factor of ten at least during the extraction. The results obtained by ACQUAYE et al. (1972) were partly used in determining the amount of resin to be added. Water was added to the resin cylinder immediately after the resin had been weighed out. A shaking time of one hour was chosen on the basis of the results obtained by ACQUAYE et al. (1972).

After shaking, the resin was initially washed while still in the extraction apparatus with $200 \mathrm{ml}$ of deionized water. The resin was then washed out into a beaker. After this, the organic matter was decanted off and the ion exchange resin transferred to the elution tube using a funnel. $0,5 \mathrm{M} \mathrm{H}_{2} \mathrm{SO}_{4}$ was used as the eluant when manganese was determined by spectrophotometry, and $1,0 \mathrm{M} \mathrm{HCl}$ when it was determined on an atomic absorption spectrophotometer. The elution of the resin was carried out over a period of one hour, $100 \mathrm{ml}$ of eluate being collected. The ion exchange resin was regenerated using a solution of $2 \mathrm{M} \mathrm{MgSO}_{4} \cdot 7 \mathrm{H}_{2} \mathrm{O}$. When the filtrate became neutral the resin was considered to be fully saturated with magnesium. The resin was then washed with deionized water until sulphate could no longer be detected as a precipitate of barium sulphate after adding barium chloride to the filtrate. The manganese and iron contents of the eluate were determined.

\section{Determination of reducible manganese}

It has been shown in a number of studies that plants are able to utilize the manganese in manganese oxides and manganese oxyhydroxides (LEEPER 1947, JONES and LEEPER 1951 a, 1951 b, HEINTZE 1956, JONES 1957 a, 1957 b, 1957 c, BROMFIELD 1958, 1959, GHANEM et al. 1971). It therefore appears to be advantageous to determine reducible manganese fractions in the soil. As most of the manganese taken up by plants is in the form of the divalent cation, the manganese in oxides and oxyhydroxides must first be reduced. 
It was initially planned to reduce the soil manganese by means of redox resins. However, it was not possible to obtain them. In any case, they would have been rather difficult to use because the reducing agent would have had to be eliminated from the eluate before the manganese could be determined. The reducing agent for manganese could be either masked or otherwise eliminated before carrying out the oxidizing stage in the determination of manganese. It was therefore decided to use hydroquinone, hydroxylammonium chloride and ascorbic acid. These can be deactivated by heating.

\section{a. Properties of the reducing agents}

Hydroquinone $\mathrm{C}_{6} \mathrm{H}_{4}(\mathrm{OH})_{2}$

Hydroquinone takes part reversibly in reduction-oxidation reactions. According to ADAMS (1965) and ROBERTS et al. (1971), it is oxidized to p-benzoquinone:<smiles>[Z20][PH2+][C+]=C1C=CC(=O)C=C1</smiles>

In fact hydroquinone is typically a very weak acid, $\mathrm{k}_{\mathrm{a} 1}=4,5 \cdot 10^{-11}$ and $\mathrm{k}_{\mathrm{a}}{ }^{2}=$ $1 \cdot 10^{-12}$ (BAXENDALE et al. 1951, HANDBOOK OF CHEMISTRY AND PHYSICS 1969, D90). Its protolysis does not appear to be very complete at the $\mathrm{pH}$ of the soil suspensions. According to VETTER (1952), the way in which hydroquinone acts as a reducing agent depends on $\mathrm{pH}$ as follows:

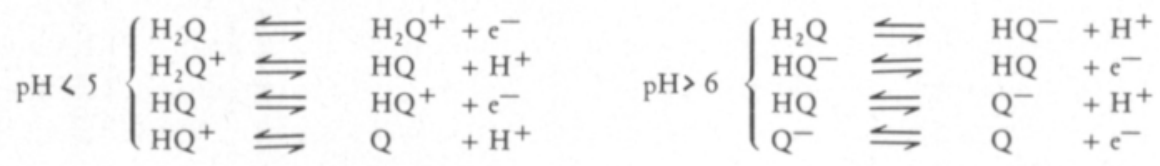

Obviously under $\mathrm{pH}$ conditions corresponding to those prevailing in the soil, reactions take place according to both equations.

The ability of hydroquinone to reduce manganese is based on the fact that its reduction potential is lower than that of manganese compounds, according to LATIMER (1952, p. 138), e ${ }^{\circ} \mathrm{C}_{6} \mathrm{H}_{4} \mathrm{O}_{2} / \mathrm{C}_{6} \mathrm{H}_{4}(\mathrm{OH})_{2}=0,699 \mathrm{~V}$. In studies on the reactions between hydroquinone and manganese, the trivalent manganese mostly has been examined (WELLS and KURITSYN 1970). In these reactions almost complete oxidation of hydroquinone occurs. When hydroquinone reacts with trivalent manganese, it forms a short-lived (6-8 ms) complex with hexaaquo or pentaaquomanganese ions before reducing the manganese. Reduced manganese does not form a complex with hydroquinone (DAVIES and KUSTIN 1969 b, WELLS and KURITSYN 1970). 
The ability of hydroxylammonium chloride to reduce manganese compounds is based on the reducing tendencies of the hydroxylammonium ion, $\mathrm{NH}_{3} \mathrm{OH}^{+}$. Depending on the conditions, the hydroxylammonium ion can be oxidized into nitrogen, nitric oxide or hyponitrous acid (MOELLER 1959, p. 580):

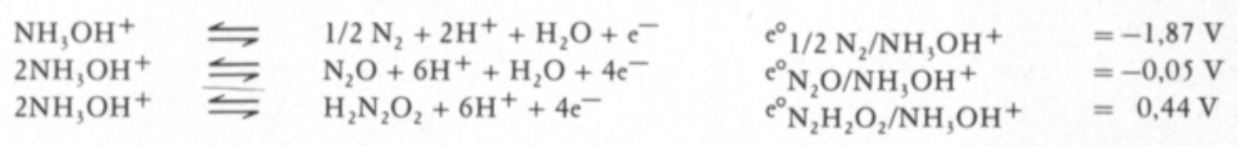

The reduction potential values indicate that the hydroxylammonium ion is a strong reducing agent. In addition, the reactions are also associated with the donation of protons. In the absence of the reducing agent, the hydroxylammonium ion acts as a weak acid (ROBINSON and BOWER 1961, IVASKA 1974):

$$
\mathrm{NH}_{3} \mathrm{OH}^{+} \leftrightharpoons \mathrm{NH}_{2} \mathrm{OH}+\mathrm{H}^{+} \quad \mathrm{k}_{\mathrm{a}}=1,1 \cdot 10^{-6}-8,9 \cdot 10^{-7}
$$

However, the oxidation process causes a larger change in the $\mathrm{pH}$ of the suspension than would be expected on the basis of the protolysis constant.

Studies on the reactions between hydroxylammonium ions and manganese have primarily been concerned with the reduction of trivalent manganese (DAVIES and KUSTIN 1969 a, JINDAL et al. 1970). If only small amounts of the reducing agent are used then the hydroxylammonium ions are oxidized to nitrates (DAVIES and KUSTIN 1969 a). In the opposite case the hydroxylammonium ions are oxidized into free nitrogen (JINDAL et al. 1970). Manganese is assumed to form a complex with the hydroxylammonium ion during the reduction reaction. In actual fact, the complex appears to be unstable and very short-lived, because it has not been possible to demonstrate it (DAVIES and KUSTIN 1969 a). According to CHAO (1972), manganese oxides in soils and sediments are found to be ready dissolved by a hydroxylammonium chloride solution leaving the major part of iron oxides in the residue.

\section{L-ascorbic acid $\mathrm{C}_{6} \mathrm{H}_{8} \mathrm{O}_{6}$}

The action of ascorbic acid as a reducing agent is based on oxidation in its dienol system. Protolysis is associated with the reversible oxidation of ascorbic acid ( HARRIS 1954, SMITH 1954):

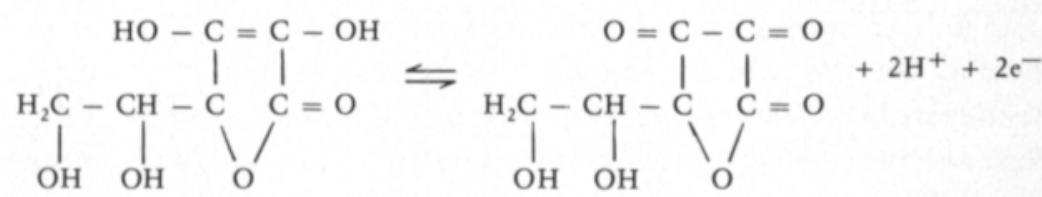

Ascorbic acid is a strong reducing agent, because its reduction potential is low, $e^{\circ} \mathrm{C}_{6} \mathrm{H}_{6} \mathrm{O}_{6} / \mathrm{C}_{6} \mathrm{H}_{8} \mathrm{O}=0,390 \mathrm{~V}$ (BALL 1937). The release of electrons takes place in two stages (NORD 1955, GRINSTEAD 1960, KHAN and MARTELL 1967). The $\mathrm{pH}$ of the solution is the main factor determining the forms which act as reducing and oxidizing agents (KHAN and MARTELL 1967, BIELSKI et al. 1971). Ascorbic 
acid belongs to the class of weak acids, $\mathrm{k}_{\mathrm{a} 1}=9,3 \cdot 10^{-9}$ (PELIZZETTI et al. 1976) and $\mathrm{k}_{\mathrm{a} 2}=4,6 \cdot 10^{-12}$ (WAHLBERG and ULMGREN 1967).

The reactions between ascorbic acid and metals are usually preceded by protolysis (MEHROTRA et al. 1969, 1970, MUSHRAN et al. 1974). The ampholyte of the ascorbic acid complexes with the metal (GRINSTEAD 1960, KHAN and MARTELL 1967), the complex breaks down and forms the ascorbate radical and the reduced metal ion. The radical reacts further with a new metal ion and reduces it (KUSTIN and TOPPEN 1973, MUSHRAN et al. 1974). According to KUSTIN and TOPPEN (1973), unprotolysed ascorbic acid can also form a complex with the metal. Ascorbate ion may form a complex $\mathrm{MnHA}^{+}$with reduced manganese. The value of the formation constant of this complex is 12,59 ( ULMGREN and WAHLBERG 1971).

\section{b. Development of the resin method}

Extraction of reducible manganese from soil samples was carried out by the ion exchange resin method. The reducing agents were added to the extraction suspension before shaking. Preliminary experiments showed that all three reducing agents were bound by the cation exchange resin saturated with magnesium ions. This indicates that the reducing agents were present in the extraction suspension as cations and therefore passed into the eluate during the elution stage. Possible cation forms of hydroquinone are $\mathrm{H}_{2} \mathrm{Q}^{+}$and $\mathrm{HQ}^{+}$(EGGINS and CHAMBERS 1969). However, only the former acts as a reducing agent. The presence of this radical in the eluate could be demonstrated indirectly, because oxidation of manganese in the eluate into permanganate did not occur until the reducing agent had been inactivated. The reducing moiety in hydroxylammonium chloride, the hydroxylammonium ion, is a cation, and hence its binding by the cation exchange resin and subsequent release into the eluate was expected. According to BIELSKI et al. (1971), the reducing form of ascorbic acid is $\mathrm{H}_{2} \mathrm{~A}^{+}$. This cation can be bound to the cation exchange resin and on release into the eluate during elution inhibits the oxidation of manganese. Owing to the $\mathrm{pH}$ of the extraction suspension, the other possible cation of ascorbic acid, $\mathrm{HA}^{+}$, was present in the eluate in considerably greater amounts than the radical $\mathrm{H}_{2} \mathrm{~A}^{+}$. However, $\mathrm{HA}^{+}$cannot prevent the oxidation of manganese because this ion had already been totally oxidized.

Inactivation of the reducing agents in the eluate. The reducing agents were inactivated in the eluate by heating. As regards reduction with ascorbic acid, no changes had to be made in the method used for oxidizing manganese because ascorbic acid decomposes already at a temperature of about $70^{\circ} \mathrm{C}$. Since the temperature of the samples was raised to $100^{\circ} \mathrm{C}$ on a sand bath, the use of ascorbic acid as the reducing agent did not cause any additional work during the oxidizing stage. Hydroquinone and hydroxylammonium chloride inihibited the oxidation of manganese to permanganate at a temperature of $100{ }^{\circ} \mathrm{C}$. In addition, hydroxylammonium chloride brought about the reduction of the metaperiodate into iodide instead of iodate. Hydroquinone and hydroxylammonium chloride were successfully inactivated by evaporating the solutions taken for analysis on a sand bath and continuing heating until all oxides of sulphur had evaporated. 
The reliability of the heating treatment used in the method was tested. A known amount of manganese $\left(\mathrm{MnSO}_{4} \mathrm{H}_{2} \mathrm{O}\right)$ was added to a porcelain crucible, the reducing agent added, the crucible heated until the solution had evaporated and the manganese then oxidized to permanganate. According to the following results, the method proved to be moderately reliable:

\begin{tabular}{llcc} 
Reducing & Added & \multicolumn{2}{c}{ Recovered $\mathrm{Mn}$} \\
agent & $\mathrm{Mn} \mu \mathrm{g}$ & $\mu \mathrm{g}$ & $\%$ \\
$\mathrm{C}_{6} \mathrm{H}_{4}(\mathrm{OH})_{2}$ & 20,0 & 19,4 & $97,0^{\mathrm{a}}$ \\
$\mathrm{HONH}_{3} \mathrm{Cl}$ & 20,0 & 19,6 & $98,0^{\mathrm{a}}$ \\
$\mathrm{C}_{6} \mathrm{H}_{8} \mathrm{O}_{6}$ & 20,0 & 19,9 & $99,5^{\mathrm{a}}$
\end{tabular}

Carefully evaporating the solution to dryness proved to be necessary, especially when treating with hydroquinone. When heating was carried out without due care, there was a black residue which could not easily be dissolved. The black residue effected a colour to the solution.

Amounts of reducing agents used. The concentration of reducing agent used in studies on the determination of reducible manganese in the soil has usually been $0,2 \%$ with respect to the extraction solution (SHERMAN et al. 1942, SHERMAN and HARMER 1942, LEEPER 1947, HEINTZE and MANN 1949, 1951, SCHACHTSCHABEL 1956, 1957, BROWMAN et al. 1969, SEMB and ØIEN 1970, SCHÜTZ $1978,1980)$. Reducing agent at a level of $0,02-0,04 \mathrm{~g} / \mathrm{g}$ soil has been used when the extracting ratio has varied from 1:10-1:20. The extracting solution used in the studies of JONES and LEEPER (1951 a, 1951 b) was $0,05 \%$ with respect to the reducing agent, and $0,0125 \%$ in the study of BOKEN (1956).

The amount of reducing agents to be used was determined as follows: $5,0 \mathrm{~g}$ airdry soil was added to $200 \mathrm{ml}$ deionized water and $0,25-4,00 \mathrm{mmol}$ of reducing agent added. Extraction, elution and determination of the manganese was then carried out according to the resin method. The amounts of hydroquinone used did not have any effect on the content of reduced manganese (Table 5). On the other

Table 5. Effect of amount of reducing agent on content of reducible soil manganese extracted. ${ }^{1}$

\begin{tabular}{llccc}
\multicolumn{2}{c}{ Reducing agent } & \multicolumn{3}{c}{ Reduced manganese mg/kg air-dry soil } \\
\cline { 2 - 5 } mmol/5,0 g soil & Soil 5b & Soil 11a & Soil 15 a \\
\hline $\mathrm{C}_{6} \mathrm{H}_{4}(\mathrm{OH})_{2}$ & 0,25 & $0,7^{\mathrm{k}}$ & $3,9^{\mathrm{h}}$ & $28,0^{\mathrm{c}}$ \\
& 0,50 & $0,6^{\mathrm{k}}$ & $3,9^{\mathrm{h}}$ & $27,8^{\mathrm{c}}$ \\
& 1,00 & $0,7^{\mathrm{k}}$ & $4,0^{\mathrm{h}}$ & $28,6^{\mathrm{c}}$ \\
& 2,00 & $0,7^{\mathrm{k}}$ & $3,9^{\mathrm{h}}$ & $27,7^{\mathrm{c}}$ \\
$\mathrm{HONH}_{3} \mathrm{Cl}$ & 0,50 & $1,1^{\mathrm{j}}$ & $11,0^{\mathrm{g}}$ & $85,0^{\mathrm{b}}$ \\
& 1,00 & $1,1^{\mathrm{j}}$ & $11,1^{\mathrm{g}}$ & $87,0^{\mathrm{b}}$ \\
& 2,00 & $1,2^{\mathrm{j}}$ & $11,1^{\mathrm{g}}$ & $82,6^{\mathrm{b}}$ \\
& 4,00 & $1,2^{\mathrm{j}}$ & $12,2^{\mathrm{f}}$ & $86,6^{\mathrm{b}}$ \\
$\mathrm{C}_{6} \mathrm{H}_{8} \mathrm{O}_{6}$ & 0,25 & $2,3^{\mathrm{i}}$ & $12,9^{\mathrm{e}}$ & $120,9^{\mathrm{a}}$ \\
& 0,50 & $2,2^{\mathrm{i}}$ & $12,8^{\mathrm{e}}$ & $117,2^{\mathrm{a}}$ \\
& 1,00 & $2,3^{\mathrm{i}}$ & $12,9^{\mathrm{e}}$ & $122,2^{\mathrm{a}}$ \\
& 2,00 & $2,3^{\mathrm{i}}$ & $15,7^{\mathrm{d}}$ & $128,3^{\mathrm{a}}$ \\
\hline
\end{tabular}

1 Each soil has been tested separately. 
hand, increasing the amounts of hydroxylammonium chloride and ascorbic acid resulted in a significant increase in the amount of manganese extracted from a heavy clay sample. This may have been due to the effect of the reducing agent on the $\mathrm{pH}$ of the extraction suspension. Depending on the amounts used, the $\mathrm{pH}$ values of the aqueous solutions of the reducing agents when calculated on the basis of the protolysis constants (HANDBOOK OF CHEMISTRY AND PHYSICS 1969, D-89, D90), were on the average:

\begin{tabular}{ccccc}
$\begin{array}{c}\text { Amount of reducing agent } \\
\mathrm{mmol}\end{array}$ & \multicolumn{4}{c}{$\mathrm{pH}^{\mathrm{H}}$ of aqueous solutions of the reducing agents } \\
& & $\mathrm{C}_{6} \mathrm{H}_{4}(\mathrm{OH})_{2}$ & $\mathrm{HONH}_{3} \mathrm{Cl}$ & $\mathrm{C}_{6} \mathrm{H}_{8} \mathrm{O}_{6}$ \\
0,25 & 1,25 & 6,59 & - & 3,50 \\
0,50 & 2,50 & 6,46 & 4,31 & 3,35 \\
1,00 & 5,00 & 6,31 & 4,16 & 3,20 \\
2,00 & 10,00 & 6,17 & 4,01 & 3,05 \\
4,00 & 20,00 & - & 3,86 & -
\end{tabular}

The $\mathrm{pH}$ of an aqueous solution of hydroquinone was higher than the average $\mathrm{pH}\left(\mathrm{H}_{2} \mathrm{O}\right)$ of Finnish mineral soils. On the other hand, hydroxylammonium chloride and ascorbic acid had a reducing effect on the $\mathrm{pH}$ when compared to the average $\mathrm{pH}\left(\mathrm{H}_{2} \mathrm{O}\right)$ value of Finnish mineral soils, i.e. 5,7 (SIPPOLA and TARES 1978). The amount of reducing agent to be used, $1 \mathrm{mmol} / 5 \mathrm{~g}$ air-dry soil, was chosen on the basis of the results in Table 5. This value is in good agreement with the amounts cited in the literature. The reducing capacity of the reducing agents was found to be sufficient to reduce manganese almost $11 \mathrm{~g} / \mathrm{kg}$ air-dry soil. This reducing capacity would not limit the reduction of manganese.

c. The reliability of resin extraction in determining reducible manganese in the soil

The reducing agents used to reduce manganese form complexes with metals. Formation of complexes depends on the oxidation state of the metal in question. Depending on the oxidation state of the complex formed, it is possible that the soil manganese mobilised in the reduction treatment cannot be completely recovered by means of cation exchange resin.

The suitability of the cation exchange resin method for determining the content of reducible manganese in soil was studied by determining the reproducability of the results. The extraction procedure was performed separately with each reducing agent. According to the following results, the reproducability of the determinations could be considered to be satisfactory:

Reducing agent and

Soil sample

Hydroquinone

$84 a$ (silt)

102a (finer fine sand)

Hydroxylammonium chloride

58 b (sandy clay)

76a (finer fine sand)

Ascorbic acid

25a (silty clay)

$69 \mathrm{~b}$ (silt) n

12

9

9

7

11

8
Extracted Mn mg/kg air-dry soil

$\begin{array}{llll}\overline{\mathbf{x}} & \text { Md } & s & \text { V \% }\end{array}$

16,0

8,4

16,3

0,65

4,06

$8,4 \quad 0,47$

5,56

6,93

$\begin{array}{llll}23,4 & 23,2 & 1,62 & 6,93 \\ 57,6 & 58,0 & 2,30 & 3,99\end{array}$

58,1

57,0

1,93

3,32

34,4

0,79

2,30 
Table 6. The effect of reducing agent on amounts of added manganese recovered from cation exchange resin and from the extraction solution.

\begin{tabular}{|c|c|c|c|c|c|c|}
\hline \multirow[b]{2}{*}{$\begin{array}{l}\text { Added } \\
\text { Mn } \mu_{\mathrm{g}}\end{array}$} & \multicolumn{2}{|c|}{$\mathrm{C}_{6} \mathrm{H}_{4}(\mathrm{OH})_{2}$} & \multicolumn{2}{|c|}{$\mathrm{HONH}_{3} \mathrm{Cl}$} & \multicolumn{2}{|c|}{$\mathrm{C}_{6} \mathrm{H}_{8} \mathrm{O}_{6}$} \\
\hline & $\begin{array}{c}\text { Recovered } \\
\text { from resin } \\
\% \\
\end{array}$ & $\begin{array}{l}\text { Recovered from } \\
\text { extraction } \\
\text { solution, \% }\end{array}$ & $\begin{array}{c}\text { Recovered } \\
\text { from resin } \\
\% \\
\end{array}$ & $\begin{array}{c}\text { Recovered from } \\
\text { extraction } \\
\text { solution, \% }\end{array}$ & $\begin{array}{c}\text { Recovered } \\
\text { from resin } \\
\% \\
\end{array}$ & $\begin{array}{c}\text { Recovered from } \\
\text { extraction } \\
\text { solution, } \%\end{array}$ \\
\hline 20 & $94,4 \pm 0,0$ & $0,0 \pm 0,0$ & $95,1 \pm 0,7$ & $0,0 \pm 0,0$ & $92,9 \pm 0,0$ & $0,0 \pm 0,0$ \\
\hline 40 & $93,7 \pm 0,0$ & $0,0 \pm 0,0$ & $91,5 \pm 9,7$ & $4,4 \pm 0,1$ & $98,6 \pm 3,0$ & $0,0 \pm 0,0$ \\
\hline 80 & $93,0 \pm 0,0$ & $0,0 \pm 0,0$ & $90,3 \pm 3,9$ & $5,0 \pm 0,2$ & $92,3 \pm 2,0$ & $0,0 \pm 0,0$ \\
\hline 160 & $89,9 \pm 1,1$ & $0,9 \pm 1,0$ & $90,6 \pm 2,8$ & $4,6 \pm 0,2$ & $91,9 \pm 2,6$ & $0,5 \pm 0,0$ \\
\hline 320 & $92,1 \pm 0,0$ & $0,6 \pm 1,0$ & $90,3 \pm 1,6$ & $4,3 \pm 0,2$ & $92,6 \pm 0,5$ & $0,7 \pm 0,2$ \\
\hline 640 & $92,4 \pm 0,0$ & $0,5 \pm 0,6$ & $94,4 \pm 2,3$ & $3,5 \pm 0,3$ & $91,4 \pm 0,0$ & $0,6 \pm 0,1$ \\
\hline
\end{tabular}

In addition, the method was studied by adding known amounts of manganese $\left(\mathrm{MnSO}_{4} \cdot \mathrm{H}_{2} \mathrm{O}\right)$ to the deionized water. Reducing agent $(1 \mathrm{mmol})$ was then added and extraction, rinsing and elution of the resin carried out according to the resin method. The extraction suspension was filtered. The manganese content of the eluate and the filtrate were determined (Table 6).

The amounts of manganese remaining in the extraction suspension after treatment with hydroquinone were small. This result partly confirms the observation that hydroquinone does not form complexes with divalent manganese (DAVIES and KUSTIN 1969 b, WELLS and KURITSYN 1970). On the other hand, 0-5 \% of the added manganese remained in the suspension after treatment with hydroxylammonium chloride. This would suggest that hydroxylammonium chloride forms neutral and/or negative complexes with divalent manganese. After the treatment with ascorbic acid $0-0,7 \%$ of the added manganese remained in the suspension. The results for ascorbic acid and hydroquinone were thus very similar and better than that for hydroxylammonium chloride. With divalent manganese the ascorbate ion may form the complex $\mathrm{MnHA}^{+}$(ULMGREN and WAHLBERG 1971). However, as a cation this complex can be bound by cation exchange resin. The small amounts of manganese remaining in the extraction suspension following the treatment with reducing agents may be partly due to the equilibrium between the ion exchange resin and the suspension.

Table 7. The effect of reducing agent on contents of manganese recovered from cation exchange resin and from soil suspension.

\begin{tabular}{|c|c|c|c|c|c|c|}
\hline \multirow[b]{3}{*}{$\begin{array}{l}\text { Soil } \\
\text { sample }\end{array}$} & \multicolumn{6}{|c|}{ Extracted manganese $\mathrm{mg} / \mathrm{kg}$ air-dry soil } \\
\hline & \multicolumn{2}{|c|}{$\mathrm{C}_{6} \mathrm{H}_{4}(\mathrm{OH})_{2}$} & \multicolumn{2}{|c|}{$\mathrm{HONH}_{3} \mathrm{Cl}$} & \multicolumn{2}{|c|}{$\mathrm{C}_{6} \mathrm{H}_{8} \mathrm{O}_{6}$} \\
\hline & $\begin{array}{l}\text { Recovered } \\
\text { from eluate }\end{array}$ & $\begin{array}{l}\text { Remaining in } \\
\text { extraction } \\
\text { suspension }\end{array}$ & $\begin{array}{l}\text { Recovered } \\
\text { from eluate }\end{array}$ & $\begin{array}{l}\text { Remaining in } \\
\text { extraction } \\
\text { suspension }\end{array}$ & $\begin{array}{l}\text { Recovered } \\
\text { from eluate }\end{array}$ & $\begin{array}{l}\text { Remaining in } \\
\text { extraction } \\
\text { suspension }\end{array}$ \\
\hline $4 \mathrm{~b}$ & $1,2 \pm 0,0$ & $0,2 \pm 0,0$ & $6,4 \pm 0,5$ & $0,2 \pm 0,0$ & $9,3 \pm 2,1$ & $1,0 \pm 0,5$ \\
\hline $10 \mathrm{~b}$ & $5,7 \pm 0,3$ & $0,3 \pm 0,2$ & $27,7 \pm 1,2$ & $1,8 \pm 0,4$ & $30,0 \pm 0,3$ & $2,3 \pm 0,6$ \\
\hline $18 \mathrm{a}$ & $5,6 \pm 0,3$ & $0,1 \pm 0,2$ & $7,9 \pm 1,0$ & $0,8 \pm 0,8$ & $13,5 \pm 1,7$ & $0,7 \pm 0,0$ \\
\hline $101 b$ & $34,2 \pm 2,3$ & $0,3 \pm 0,2$ & $64,0 \pm 1,8$ & $4,3 \pm 0,0$ & $86,0 \pm 4,2$ & $5,9 \pm 0,6$ \\
\hline $106 \mathrm{~b}$ & $45,1 \pm 2,8$ & $0,7 \pm 0,3$ & $218,0 \pm 6,7$ & $11,7 \pm 0,6$ & $232,5 \pm 20,6$ & $14,5 \pm 1,4$ \\
\hline
\end{tabular}


The effect of the reducing treatment on the amounts of manganese bound and umbound on the cation exchange resin was studied using the soil samples, too. The reducing agents were added to the soil suspensions and extraction and elution carried out in the normal way. The extraction suspensions were filtered immediately after shaking. The manganese content of the eluates and filtrates were determined (Table 7). Manganese not bound by the cation exchange resin remained in the suspension. In conjunction with the determination of exchangeable manganese, it was found that cation exchange resin treatment without a reducing agent does not result in any measurable amounts of manganese remaining in the extraction suspension. Apart from reduction with hydroxylammonium chloride, no divalent manganese at all was left in the extraction suspension. Therefore it can be concluded that the manganese remaining in suspensions of soil samples has been present as a neutral and/or negative complex and is therefore not retained by the cation exchange resin. The result shows indirectly, that the manganese remaining in the extraction suspension has not been divalent manganese. The soil manganese extracted with cation exchange resin and reducing agent is therefore divalent manganese.

\section{d. Method for determining reducible manganese in the soil}

$5,0 \mathrm{~g}$ of air-dry soil was weighed out into a beaker. In the case of moist samples, amounts as close as possible to the corresponding air-dry weight were used. The exact amount of soil was determined by drying the suspension after shaking and then weighing it. $200 \mathrm{ml}$ deionized water and $1 \mathrm{mmol}$ of reducing agent were added. The suspension was then carefully mixed using a glass rod and left to stand for 30 minutes. The resin was weighed during this time. Cation exchange resin saturated with $\mathrm{Mg}^{2+}$ ions was used to extract both exchangeable and reducible manganese. The same amounts of resin were used as for determining exchangeable manganese. The same shaking apparatus was also used. Shaking was started 30 minutes after adding the reducing agent. Hydroquinone and hydroxylammonium chloride in the eluate were inactivated for the spectrophotometric determinations by evaporating the eluate to dryness and heating the residue on a sand bath until the oxides of sulphur had evaporated. After cooling the residue was dissolved in $0,5 \mathrm{M}$ sulphuric acid. Ascorbic acid was inactivated in the heating stage required for the oxidation of manganese. The reducing agents were not inactivated when the manganese determinations were carried out on an atomic absorption spectrophotometer. In this method the effects of the reducing agents were taken into account in the preparation of the standard series. The exchangeable manganese values were subtracted from those for the manganese obtained using the reducing treatment on the same soil. The difference represented the content of reducible manganese. The ion exchange resin used to extract reducible manganese was regenerated in the same way as the resin used in determining the exchangeable manganese. 


\section{Determination of total manganese in the soil}

In order to find a suitable method for determining total manganese in the soil, the acid extraction method $\left(\mathrm{HNO}_{3}, \mathrm{H}_{2} \mathrm{SO}_{4}, \mathrm{HF}\right)$ of ADAMS (1965) and the sodium carbonate fusion method of KANEHIRO and SHERMAN (1965) were compared. The total manganese content of 17 plough layer soils and 16 deeper layers were determined using both methods. According to the following results, the difference between the methods did not deviate significantly from zero (plough layer $t_{0,05}=0,64$ deeper layer $t_{0,05}=0,22$ ):

\begin{tabular}{|c|c|c|c|}
\hline & & Manganese ext & g/g air-dry soil \\
\hline & $\mathrm{n}$ & $\begin{array}{l}\text { Sodium carbonate } \\
\text { fusion }\end{array}$ & $\begin{array}{l}\text { Acid extraction } \\
\text { method }\end{array}$ \\
\hline Plough layer & 17 & 511 & 468 \\
\hline Deeper layer & 16 & 421 & 430 \\
\hline
\end{tabular}

The sodium carbonate fusion method (KANEHIRO and SHERMAN 1965) was chosen for determining the total content of manganese in the soil:

$0,5 \mathrm{~g}$ air-dry soil ground in a mortar $(\varnothing<0,1 \mathrm{~mm})$ was weighed out into a platinum dish. The organic matter was removed by heating the sample over a low flame for half an hour. The dish was then left to cool. $5,0 \mathrm{~g} \mathrm{Na}_{2} \mathrm{CO}_{3}$ was added, mixed carefully with a glass rod and $1,0 \mathrm{~g} \mathrm{Na}_{2} \mathrm{CO}_{3}$ spread on the top of the mixture. The mixture was then fused over a bunsen burner. The dish was allowed to cool and then placed in a $100 \mathrm{ml}$ beaker, $10 \mathrm{ml}$ of deionized water, $1 \mathrm{ml} \mathrm{C} 2 \mathrm{H}, \mathrm{OH}$ and $20 \mathrm{ml}$ of conc. $\mathrm{HCl}$ were added. After the suspension had stopped effervescing it was transferred to a beaker using a glass rod. The platinum dish was rinsed with hot deionized water. The beaker was transferred to a boiling water bath and evaporated to dryness. After cooling, $5 \mathrm{ml}$ of conc. $\mathrm{HCl}$ was added and the beaker left to stand for 15 minutes. $20 \mathrm{ml}$ of hot deionized water was then added and the beaker placed on a boiling water bath for 15 minutes. The hot suspension was filtered through hard filter paper (Schleicher \& Schüll Selecta $\mathrm{Nr} 589 / 3$ ) into a $100 \mathrm{ml}$ volumetric flask. The beaker and the residue were washed with hot deionized water and the flask filled up to the mark. The manganese content of the filtrate was determined on an atomic absorption spectrophotometer.

The reliability of the method for determining total manganese was studied by determining the reproducability of the method. According to the following results the reproducability of the determinations was satisfactory:

\begin{tabular}{lrcccr} 
& & \multicolumn{4}{c}{ Manganese $\mathrm{mg} / \mathrm{kg}$ air-dry soil } \\
Soil sample & $\mathrm{n}$ & $\overline{\mathrm{x}}$ & $\mathrm{Md}$ & $\mathrm{s}$ & $\mathrm{V} \%$ \\
9b (sandy clay) & 11 & 439 & 443 & 10,9 & 2,48 \\
$12 \mathrm{~b}$ (silt) & 5 & 431 & 424 & 13,3 & 3,09
\end{tabular}

The method was also studied by adding known amounts of manganese, over the range $100-1000 \mathrm{mg} / \mathrm{kg}$ air-dry soil, to the soil samples. The samples were then analysed in accordance with the above method. As the following results indicate the sodium carbonate fusion method may be satisfactory:

\begin{tabular}{lccrrr} 
Added & \multicolumn{5}{c}{ Recovery $\%$} \\
Mn mg & $7 \mathrm{~b}$ & $10 \mathrm{~b}$ & $18 \mathrm{a}$ & $37 \mathrm{~b}$ & $102 \mathrm{a}$ \\
0,05 & $91,0 \pm 3,3$ & $95,1 \pm 2,9$ & $91,6 \pm 3,0$ & $100,2 \pm 4,0$ & $92,7 \pm 2,6$ \\
0,10 & $95,1 \pm 1,6$ & $97,0 \pm 2,0$ & $94,6 \pm 2,1$ & $96,8 \pm 0,8$ & $92,9 \pm 1,4$ \\
0,50 & $96,7 \pm 1,0$ & $90,3 \pm 3,0$ & $93,4 \pm 4,7$ & $97,3 \pm 0,6$ & $93,2 \pm 3,2$
\end{tabular}




\section{Determination of manganese in plant material}

The manganese content of the plant material was determined using the dry ashing method as follows:

$1,0 \mathrm{~g}$ of plant material was weighed out into a quartz crucible. The sample was burnt in a muffle furnace overnight at $450{ }^{\circ} \mathrm{C}$. After the crucible had cooled, a few drops of deionized water were added, the crucible covered with a watch glass and $10 \mathrm{ml}$ of $3 \mathrm{M} \mathrm{HCl}$ slowly added. The dish was transferred to a boiling water bath and kept on it until white fumes started to escape from the solution. The watch glass was then removed and the hot solution filtered (Schleicher \& Schüll Selecta $\mathrm{Nr} 589 / 2$ ) into a $50 \mathrm{ml}$ volumetric flask. The dish, filter paper and residue were washed with $10 \mathrm{ml}$ of deionized water. The filter paper and insoluble residue were placed in the original quartz dish and burnt at $600{ }^{\circ} \mathrm{C}$ for one hour. The cooled ash was dissolved in $0,5 \mathrm{ml}$ of $6 \mathrm{M} \mathrm{HCl}$ and placed on a boiling water bath. The dish was kept on the bath until the residue was almost dry. $10 \mathrm{ml}$ of deionized water was then added and the suspension filtered into the same volumetric flask used in the first stage of the treatment. The dish, filter paper and residue were washed with deionized water and the volumetric flask filled up to the mark.

The reliability of the dry ashing method was studied by determining the reproducability of the method. The following results indicate that the reproducability of the determinations was good:

\begin{tabular}{cccccc} 
& & \multicolumn{4}{c}{ Manganese $\mathrm{mg} / \mathrm{kg}$ dry-matter } \\
& $\mathrm{n}$ & $\overline{\mathrm{x}}$ & $\mathrm{Md}$ & $\mathrm{s}$ & $\mathrm{V} \%$ \\
Potato sample & 14 & 13,4 & 13,4 & 0,10 & 0,77
\end{tabular}

The method was also studied by adding known amounts of manganese to the plant sample. According to the following results, the method used for determining the manganese content of the plant material was considered to satisfy the requirements:

\begin{tabular}{ccc} 
Added & \multicolumn{2}{c}{ Recovered Mn } \\
Mn $\mu \mathrm{g}$ & $\mu \mathrm{g}$ & $\%$ \\
0 & $12,5 \pm 0,0$ & - \\
5 & $17,4 \pm 0,2$ & 98,0 \\
10 & $21,8 \pm 0,6$ & 93,0 \\
20 & $32,2 \pm 1,1$ & 98,5
\end{tabular}

\section{B. Other analytical methods}

The particle size composition of the inorganic matter in the soil samples was determined by the pipette method (ELONEN 1971). The bulk density of the soil was determined by means of weighing a $20 \mathrm{ml}$ sample of ground air-dry soil (ERVIÖ 1971). The $\mathrm{pH}$ of the soil was measured from the stirred soil - 0,01 M $\mathrm{CaCl}_{2}$ suspension $(1: 2,5)$ after standing for two hours (RYTI 1965). The organic carbon content of the soil samples was determined using a modification (GRAHAM 1948) of ALTEN's wet digestion method. The to tal ir on content of the soil was determined from the solution prepared by the sodium carbonate fusion method (KANEHIRO and SHERMAN 1965). Iron in the plant material was determined from the same solution, prepared by the dry ashing method, as was used for the determination of the plant manganese. 


\section{Statistical treatment of the results}

The t-test was used for carrying out comparisons between pairs of means. The 95 $\%$ confidence limits were calculated for means that were not compared with each other. DUNCAN's (1955) test and $95 \%$ confidence level was used for comparing more than two means. Correlation and regression analysis were used for studying the dependence between variables (EZEKIEL and FOX 1961). Partial correlation coefficients and the $95 \%$ confidence level were used for testing the significance of the independent variables. Statistically insignificant independent variables were excluded from the regression equation and the equation was recalculated and its parameters were tested again. The partial regression coefficients used for testing the independent variables were tabulated. Partial regression coefficients which were used for indicating the final significance of the independent variables, were presented for the statistically significant $(\mathrm{P}=0,05)$ variables. Values of the coefficients which indicated the insignificance of the variables, were presented for the statistically insignificant $(P=0,05)$ variables. Beta coefficients were used for depicting the relative importance of the variables. The beta coefficients were calculated for the significant variables only, and were presented in the same tables as the partial regression coefficients. The significance of the coefficient of multiple determination was studied using the F-test (SNEDECOR and COCHRAN 1978). Standard deviations were calculated for the mean of the dependent variable and for the net regression coefficients of the equation. The sekwness of the distribution in the material was studied using Pearson's coefficient (MATTILA 1967). The significance of differences between the coefficients of multiple determination was tested with the $\mathrm{z}$-transformation test (SNEDECOR and COCHRAN 1978).

\section{Research material}

Soil samples were collected from different parts of Finland during the period 1975-1979. The samples were taken from the plough layer $(a=0-20 \mathrm{~cm})$ and from the deeper layer $(b=20-40 \mathrm{~cm})$. Exceptions to this were samples 18, 19, 20, 21, 97 and 109, the samples being taken from the surface soil only. In addition, samples 22 and 23 were subsoil samples $(80-100 \mathrm{~cm})$ only. The sampling locations are shown in Fig. 3 and the general properties of the samples in Appendix 1.

The soil samples were dried at room temperature $\left(20-25^{\circ} \mathrm{C}\right)$ in order to keep the soil as unchanged as possible (WALKER and BARBER 1960, NELSON 1977, KHANNA and MISHRA 1978). The samples were then broken up by hand using a wooden disk and then passed through a $\varnothing 2 \mathrm{~mm}$ sieve. The samples were not ground because otherwise the structure of the primary particles would have been destroyed (SOLTANPOUR et al. 1976). The air-dry samples were stored in cardboard boxes.

The research material was classified into mineral soils and organogenic soils. In organogenic soils the content of organic matter $(1,9 \mathrm{x}$ org. C \%) was over $40 \%$. The mineral soils were classified into soil groups on the basis of their particle size distribution as follows: 


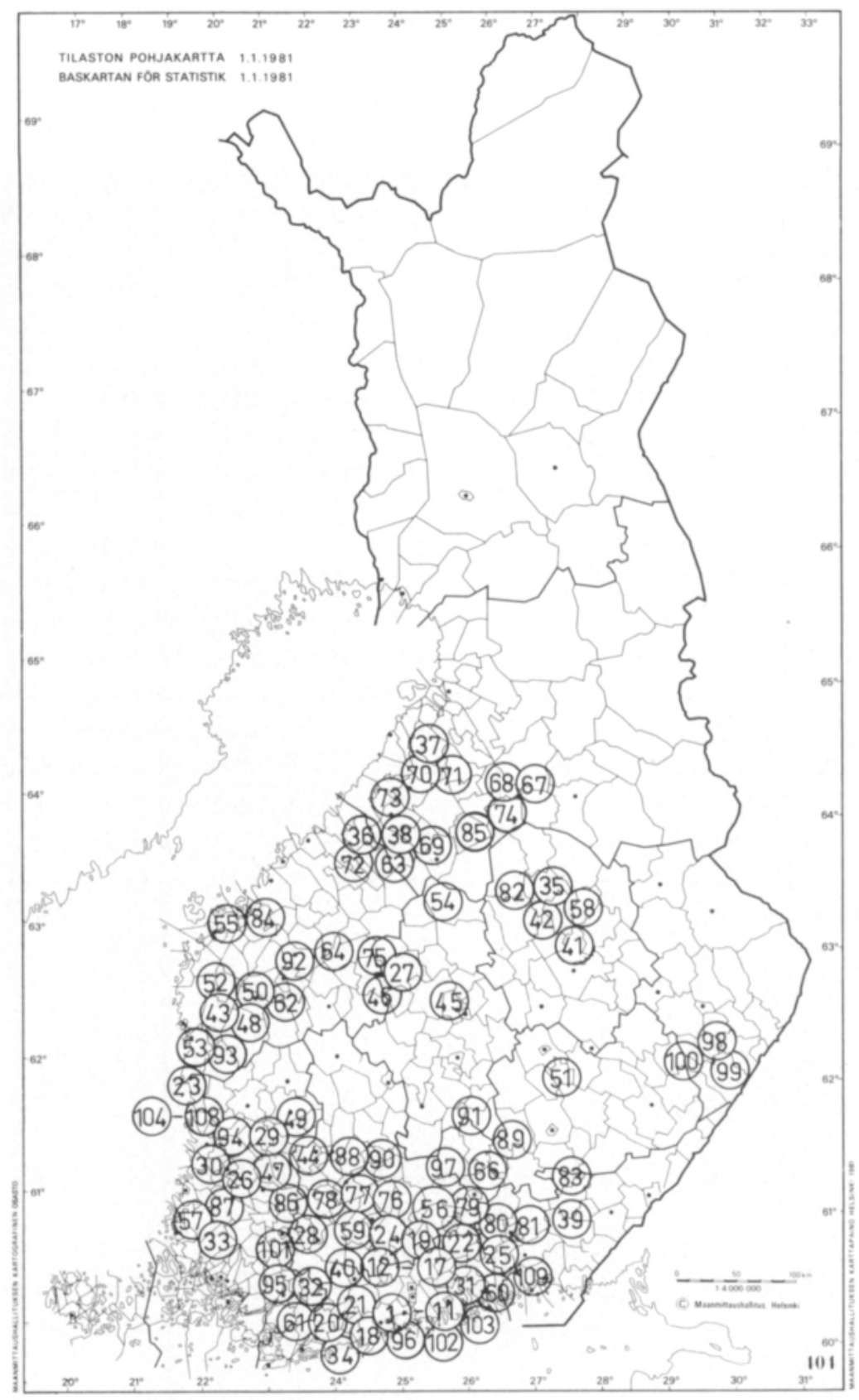

Fig. 3. Location of the sampling points. 


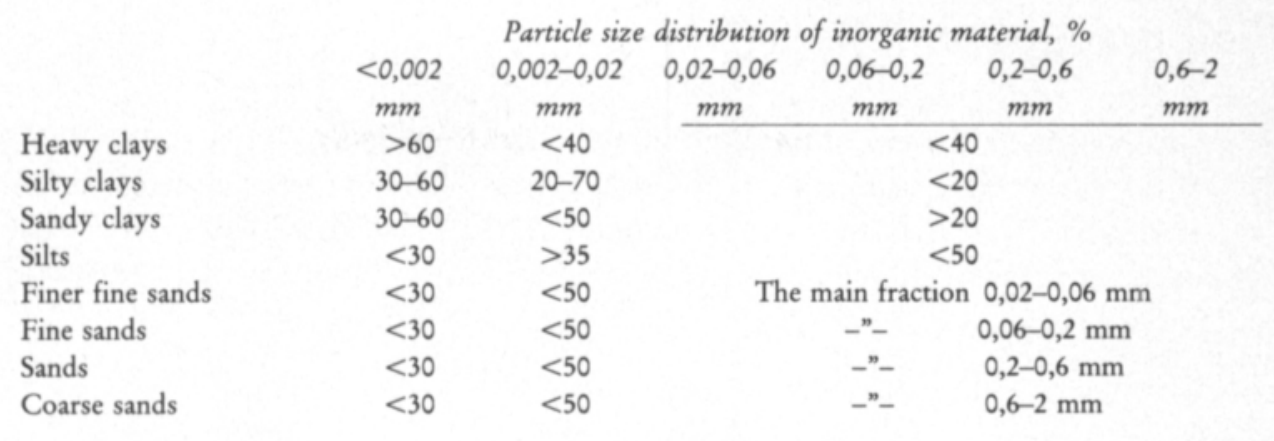

However, the heavy, silty and sandy clay soil groups were so small that they were combined to form a single group of clay soils. Similarly, fine sands, sands, coarse sands and 3 sand moraines were combined to form a single group of coarse soils. The bulk density, organic carbon content, content of extractable manganese, total iron content and total manganese content of the soil samples were calculated on the basis of air-dry soil.

The bulk density of the soil in the plough layer of the mineral soils increased slightly from the clay soils to the coarse soils (Table 8). The bulk density varied from 0,55 to $1,33 \mathrm{~kg} / \mathrm{dm}^{3}$, the $\mathrm{pH}$ from 3,9 to 7,2 , and the organic carbon content from 0,7 to $16,4 \%$. The properties of the deeper layers followed the same trend as for the topsoils. The bulk density of the plough layer of the organogenic soils varied from 0,16 to $0,71 \mathrm{~kg} / \mathrm{dm}^{3}$, the $\mathrm{pH}$ from 3,6 to 4,7 , and the organic carbon content from 21,9 to $49,6 \%$. The properties of the deeper layers were almost the same as those of the topsoils (Table 8). The average properties of the soil groups corresponded rather well to the mean properties of Finnish mineral soils (SIPPOLA and TARES 1978).

Table 8. Basic properties of the soil groups.

\begin{tabular}{|c|c|c|c|c|c|c|c|c|c|c|c|c|c|c|c|c|c|}
\hline \multirow{3}{*}{$\begin{array}{l}\text { Soil } \\
\text { group }\end{array}$} & \multirow[b]{3}{*}{$\mathrm{n}$} & \multirow{2}{*}{\multicolumn{2}{|c|}{$\begin{array}{c}\text { Bulk } \\
\text { density, } \\
\mathrm{kg} / \mathrm{dm}^{3}\end{array}$}} & \multirow{2}{*}{\multicolumn{2}{|c|}{$\begin{array}{c}\mathrm{pH} \\
\mathrm{CaCl}_{2}\end{array}$}} & \multirow{2}{*}{\multicolumn{2}{|c|}{$\begin{array}{c}\text { Org.C, } \\
\%\end{array}$}} & \multicolumn{10}{|c|}{ Particle-size distribution, \% } \\
\hline & & & & & & & & \multicolumn{2}{|c|}{$\begin{array}{c}<0,002 \\
\mathrm{~mm}\end{array}$} & \multicolumn{2}{|c|}{$\begin{array}{c}0,002-0,02 \\
\mathrm{~mm}\end{array}$} & \multicolumn{2}{|c|}{$\begin{array}{c}0,02-0,06 \\
\mathrm{~mm}\end{array}$} & \multicolumn{2}{|c|}{$\begin{array}{c}0,06-0,2 \\
\mathrm{~mm}\end{array}$} & \multicolumn{2}{|c|}{$\begin{array}{c}0,2-2 \\
\mathrm{~mm}\end{array}$} \\
\hline & & $\overline{\mathbf{x}}$ & s & $\overline{\mathbf{x}}$ & s & $\overline{\mathbf{x}}$ & s & $\overline{\mathbf{x}}$ & s & $\overline{\mathbf{x}}$ & $\mathbf{s}$ & $\overline{\mathbf{x}}$ & $s$ & $\overline{\mathbf{x}}$ & $\mathbf{s}$ & $\tilde{\mathbf{x}}$ & $\mathbf{s}$ \\
\hline \multicolumn{18}{|l|}{ Clays } \\
\hline - plough layer & 30 & 0,94 & 0,16 & 5,1 & 0,71 & 4,6 & 3,2 & 43 & 8 & 31 & 11 & 13 & 6 & 9 & 5 & 3 & 2 \\
\hline $\begin{array}{l}\text { - deeper layer } \\
\text { Silts }\end{array}$ & 34 & 0,95 & 0,15 & 5,1 & 0,77 & 2,6 & 2,2 & 44 & 11 & 31 & 12 & 11 & 6 & 9 & 7 & 3 & 2 \\
\hline - plough layer & 13 & 0,97 & 0,11 & 5,2 & 0,55 & 3,6 & 1,4 & 22 & 4 & 49 & 7 & 20 & 8 & 5 & 5 & 3 & 2 \\
\hline - deeper layer & 13 & 0,96 & 0,16 & 5,0 & 0,42 & 2,0 & 1,8 & 21 & 5 & 51 & 8 & 19 & 8 & 7 & 7 & 3 & 3 \\
\hline \multicolumn{18}{|c|}{ Finer fine sands } \\
\hline - plough layer & 26 & 0,98 & 0,19 & 5,0 & 0,63 & 4,1 & 3,7 & 13 & 7 & 27 & 10 & 36 & 10 & 19 & 10 & 3 & 2 \\
\hline - deeper layer & 24 & 1,00 & 0,16 & 4,9 & 0,65 & 2,8 & 4,1 & 11 & 7 & 25 & 12 & 41 & 9 & 20 & 12 & 2 & 2 \\
\hline \multicolumn{18}{|l|}{$\begin{array}{l}\text { Fine sands, sands } \\
\text { and moraines }\end{array}$} \\
\hline - plough layer & 29 & 1,10 & 0,16 & 5,0 & 0,44 & 3,4 & 2,5 & 9 & 6 & 13 & 8 & 16 & 9 & 40 & 16 & 21 & 16 \\
\hline - deeper layer & 24 & 1,16 & 0,19 & 4,8 & 0,39 & 1,6 & 1,2 & 9 & 6 & 13 & 9 & 16 & 9 & 40 & 18 & 23 & 17 \\
\hline \multicolumn{18}{|l|}{ All mineral soils } \\
\hline - plough layer & 98 & 1,00 & 0,16 & 5,1 & 0,59 & 4,0 & 3,0 & & & & & & & & & & \\
\hline - deeper layer & 95 & 1,02 & 0,16 & 4,9 & 0,62 & 2,3 & 2,6 & & & & & & & & & & \\
\hline \multicolumn{18}{|c|}{ Organogenic soils } \\
\hline - plough layer & 9 & 0,48 & 0,15 & 4,1 & 0,39 & 31,0 & 9,1 & & & & & & & & & & \\
\hline - deeper layer & 8 & 0,36 & 0,11 & 4,0 & 0,33 & 41,5 & 11,8 & & & & & & & & & & \\
\hline
\end{tabular}




\section{Soil manganese}

The manganese content of the earth's crust varies from 0,05 to 0,5 \% (BEAR 1964, p. 329), and therefore manganese is the second most common trace element of the magma rocks of the earth (RANKAMA and SAHAMA 1950, p. 640). The most important manganese-containing minerals are as follows (RANKAMA and SAHAMA 1950, pp. 641-642):

\begin{tabular}{|c|c|c|c|}
\hline $\begin{array}{l}\text { Mineral } \\
\text { galaxite } \\
\text { jacobsite } \\
\text { manganosite } \\
\text { hausmannite } \\
\text { braunite } \\
\text { pyrophanite } \\
\text { pyrolusite } \\
\text { manganomelane } \\
\text { pyrochroite } \\
\text { bäckströmite } \\
\text { manganite } \\
\text { rhodochrosite } \\
\text { alabandite }\end{array}$ & $\begin{array}{l}\text { Composition } \\
\mathrm{MnAl}_{2} \mathrm{O}_{4} \\
\mathrm{MnFe}_{2} \mathrm{O}_{4} \\
\mathrm{MnO} \\
\mathrm{Mn}_{3} \mathrm{O}_{4} \\
\left(\mathrm{Mn}_{3} \mathrm{Si}_{2} \mathrm{O}_{3}\right. \\
\mathrm{MnTiO}_{3} \\
\mathrm{MnO}_{2} \\
\mathrm{MnO}_{2} \\
\mathrm{Mn}_{2}(\mathrm{OH})_{2} \\
\mathrm{Mn}(\mathrm{OH})_{2} \\
\mathrm{MnOOH} \\
\mathrm{MnCO} \\
\alpha-\mathrm{MnS}_{3}\end{array}$ & $\begin{array}{l}\text { Mineral } \\
\text { knebelite } \\
\text { rhodonite } \\
\text { pyroxmangite } \\
\text { spessartite } \\
\text { manganepidote } \\
\text { manganphlogopite } \\
\text { manganchlorite } \\
\text { hübnerite } \\
\text { triphylite } \\
\text { lithiophilite } \\
\text { triplite }\end{array}$ & $\begin{array}{l}\text { Composition } \\
(\mathrm{Mn}, \mathrm{Fe})_{2} \mathrm{SiO}_{4} \\
(\mathrm{Mn}, \mathrm{Fe}, \mathrm{Ca}) \mathrm{SiO}_{3} \\
(\mathrm{Mn}, \mathrm{Fe}) \mathrm{SiO}_{3} \\
\mathrm{Mn}_{3} \mathrm{Al}_{2}\left(\mathrm{SiO}_{4}\right)_{3}\end{array}$ \\
\hline
\end{tabular}

The abundance of manganese minerals is well illustrated by the composition of the Eräjärvi pegmatite deposit near Tampere. Of the 29 phosphate minerals occurring in this deposit, iron, manganese or both, are the main components of 21 of them (LAHTI 1981). The main reason for the great number of different manganese minerals is the multiple oxidation states of manganese. It occurs in magma rocks in the oxidation state $\mathrm{Mn}^{2+}$, and in sediments and soils mainly as $\mathrm{Mn}^{3+}$ and $\mathrm{Mn}^{4+}$ (McKENZIE 1972). Compounds corresponding to the oxidation states $\mathrm{Mn}^{6+}$ and $\mathrm{Mn}^{7+}$ do not occur in nature (DAY 1963).

Another factor which contributes towards the large number of manganese minerals is substitution. The $\mathrm{Mn}^{4+}$ in oxide and hydroxide minerals can be substituted by $\mathrm{Mn}^{2+}$ and $\mathrm{Mn}^{3+}$ (McKENZIE 1977). The manganese ions may therefore be oxidized or reduced without changing position. When sufficient changes in the oxidation state have occurred, the stability of the crystalline structure is weakened and finally rearrangement occurs (FEITKNECHT et al. 1960). As a result of oxidation, the oxygen-manganese bond is lengthened and in order to maintain electroneutrality some of the $\mathrm{O}^{2-}$ ions are substituted by $\mathrm{OH}^{-}$ions (McKENZIE 1977). For this reason, manganese oxides form a continuos serie from $\mathrm{MnO}$ to $\mathrm{MnO}_{2}$. There is considerably variation in the stability of these oxides.

Oxides and oxyhydroxides of manganese are formed as a result of geochemical processes. According to RANKAMA and SAHAMA (1950, pp. 647-652), the manganese of primary minerals has initially been dissolved out as bicarbonate and sometimes as sulphate. However, manganous bicarbonate is only stable under reducing conditions, e.g., when organic compounds are present. On the other hand, organic compounds can form complexes with manganous ions and thus bring about manganous ions on migration and leaching. Decomposition of manganous bicarbonate results in the formation of a manganese compound with an oxidation state of $\mathrm{Mn}^{4+}$. 
The oxidized manganese may initially remain in solution as a colloidal hydroxide, which can still be stabilized by organic compounds. In favourable conditions, precipitation of pyrochroite, $\mathrm{Mn}(\mathrm{OH})_{2}$, may occur. However, in nature this is an unstable compound and its oxidation results in the formation of oxides corresponding to other oxidation states of manganese.

The most important oxides and oxyhydroxides of manganese are as follows (GATTOW and GLEMSER 1961 a, 1961 b, GLEMSER et al. 1961, GIOVANOLI et al. 1967, GIOVANOLI 1969, GIOVANOLI and LEUENBERGER 1969, GIOVANOLI and STÄHLI 1970, GIOVANOLI et al. 1970 a, 1970 b, 1971):

$\begin{array}{llll}\begin{array}{l}\text { Mineral } \\ \text { pyrolusite }\end{array} & \text { Composition } & \begin{array}{l}\text { Mineral } \\ \text { hollandite }\end{array} & \begin{array}{l}\text { Composition } \\ \text { ramsdellite }\end{array} \\ \mathrm{MnO}_{2} & \mathrm{BnO}_{2} \mathrm{Mn}_{8} \mathrm{O}_{16} \\ \text { nsutite } & \text { coronadite } & \mathrm{Pb}_{2} \mathrm{Mn}_{8} \mathrm{O}_{16} \\ \text { virnessite } & \text { variable } & \text { lithiophorite } & (\mathrm{Al}, \mathrm{Li}) \mathrm{MnO}_{2}(\mathrm{OH})_{2} \\ \text { buserite } & \text { variable } & \text { groutite } & \mathrm{MnOOH} \\ \text { todorokite } & \text { variable } & \text { manganite } & \mathrm{MnOOH} \\ \text { cryptomelane } & \mathrm{K}_{2} \mathrm{Mn}_{8} \mathrm{O}_{16} & \text { partridgeite } & \mathrm{Mn}_{2} \mathrm{O}_{3} \\ \text { hausmannite } & \mathrm{Mn}^{2+} \mathrm{Mn}_{2}{ }^{3+} \mathrm{O}_{4}\end{array}$

Despite the large number of different manganese oxides and oxyhydroxides, they have only rarely been identified in soils. The most commonly identified manganese oxides in the soil appear to be lithiophorite (TILLER 1963, TAYLOR et al. 1964), birnessite (TAYLOR et al. 1964, KOLJONEN et al. 1976, CARLSON et al. 1977), hollandite, pyrolusite and todorokite (TAYLOR et al. 1964) and manganite (ESWARAN and RAGHU MOHAN 1973). Birnessite has been identified in Finnish gravel deposits (KOLJONEN et al. 1976, CARLSON et al. 1977).

Birnessite is a group name for various manganous manganites. The ratio $\mathrm{O} / \mathrm{Mn}$ varies from 1,74 to 1,99 (BRICKER 1965). According to BUSER et al. (1954) and GIOVANOLI et al. (1970 b), these minerals have a double layer structure. The main layers consist of sheets of $\mathrm{Mn}^{4+} \mathrm{O}_{6}$ octahedra linked by sharing edges. The structure of the intermediate layers consist of $\mathrm{Mn}^{2+}$ and $\mathrm{Mn}^{3+}$ co-ordinated to $\mathrm{OH}^{-}$ions and water molecules. One out of every sixth octahedral sites of $\mathrm{Mn}^{4+}$ is unoccupied, and $\mathrm{Mn}^{3+}$ and $\mathrm{Mn}^{2+}$ ions are considered to lie above and below these vacant sites. The distance between the $\mathrm{MnO}_{6}$ octahedra layers is about $0,72 \mathrm{~nm}$ in the direction of the $\mathrm{c}$ axis. $\mathrm{Na}, \mathrm{K}, \mathrm{Ca}, \mathrm{Mg}$ and $\mathrm{Fe}$ may be present as foreign cations (GIOVANOLI and BÜRKI 1975). The prevailing redox potential controls the crystallization of birnessite. It crystallizes in slightly basic soils (TAYLOR et al. 1964) and in slightly acid soils (KOLJONEN et al. 1976, ROSS et al. 1976, CARLSON et al. 1977). The chemical composition of the birnessite found in Finland is $(\mathrm{Ca}, \mathrm{K}, \mathrm{Na})(\mathrm{Mn}, \mathrm{Fe}, \mathrm{Al}, \mathrm{Mg})_{7} \mathrm{O}_{14}$ $\cdot \mathrm{nH}_{2} \mathrm{O}$ (KOLJONEN et al. 1976). $\delta-\mathrm{MnO}_{2}$ oxides of manganese belonging to the birnessite group are considered to be the most active oxides of manganese (e.g. MORGAN and STUMM 1964, MURRAY et al. 1968, LOGANATHAN and BURAU 1973, LOGANATHAN et al. 1977).

Although it has been supposed that there may be oxides in the soil where manganese occurs in the oxidation state $\mathrm{Mn}^{3+}$ (DION and MANN 1946, MANN and QUASTEL 1946), they have, however, not yet been found (McKENZIE 1972). If, as it has been assumed, the oxides and oxyhydroxides of manganese in the soil are mainly only weakly crystallized (McKEAGUE et al. 1968), then this would partly explain why 
it is difficult to find oxide and oxyhydroxide minerals of manganese in the soil.

Only a small part of the soil manganese is to be found in the soil solution. It appears to be mainly manganous manganese. According to GEERING et al. (1969), the manganese content of the soil solution varies from 0,01 to $3,75 \mathrm{ppm}$, and 84 to $99 \%$ of it is present in complex form. According to OLOMU et al. (1973), the manganese content of the soil solution may vary from 0,0 to $17,1 \mathrm{ppm}$. Of this, about $70 \%$ would be in the oxidation state $\mathrm{Mn}^{2+}$ and the rest as neutral and/or negative complexes. According to SIMS and PATRICK (1978), about $75 \%$ of the soil manganese extractable with water is in the form of negative complexes.

The manganese in the soil solution is in equilibrium with exchangeable manganese. Apart from the manganese in the soil solution, exchangeable manganese is the most easily mobilised form of manganese (FINCK 1956). It, in turn, is in equilibrium with the manganese of organic complexes, and with manganese oxides and oxyhydroxides. The importance of sparingly-soluble compounds of manganese, such as carbonates, phosphates and silicates, appears to be very small from the point of view of exchangeable manganese and manganese in the soil solution, because the mobilization of manganese from primary minerals would presuppose weathering (RANKAMA and SAHAMA 1950, pp. 647-652). Weathering, in turn, results in the formation of manganese oxides and oxyhydroxides.

According to FINCK (1956), the more humus there is in the soil and the longer the time the soil has weathered, then the greater the amount of manganese bound to the organic matter in the soil. Manganese bound to organic matter is thus not only derived from plant material from which the humus has developed. Complexed manganese can be extracted with, for instance, aqueous solutions of copper and zinc salts (HEINTZE and MANN 1947, 1949, HEMSTOCK and LOW 1953, WALKER and BARBER 1960, ELLIS and KNEZEK 1972). According to PAGE (1962), the formation of manganese complexes results in a decrease in manganese availability to plants. However, manganese is the weakest complex former in the first serie of transition metals (MELLOR and MALEY 1948, IRVING and WILLIAMS 1953). Thus when the $\mathrm{pH}$ of the soil is below 6,1, manganese complexes are hardly likely to be present (SERDOBOLSKII and SINYAGINA 1953). However, the complexation of manganese appears to be one reason for the decrease in the content of extractable manganese in the soil when the $\mathrm{pH}$ of soil is increased (GROOT 1956, ZAHER 1979).

The availability of manganese to plants is regulated by redox properties of manganese oxides and oxyhydroxides. In addition, owing to the high sorption capacity, manganese oxides and hydroxides can also regulate the extractability of other micronutrients (McKENZIE 1977). Most of the manganese oxides and oxyhydroxides in the soil are assumed to be weakly crystallized (e.g. McKEAGUE et al. 1968). Owing to the high reactivity, they represent an important factor regulating the content of extractable manganese in the soil.

\section{A. Total manganese}

The total content of manganese in the research material varied from 177 to 2196 $\mathrm{mg} / \mathrm{kg}$ in the plough layer of mineral soils, and from 80 to $335 \mathrm{mg} / \mathrm{kg}$ in the plough layer of organogenic soils (Appendix 2). The content of manganese in the deeper 
layer varied from 161 to $2481 \mathrm{mg} / \mathrm{kg}$ in the mineral soils, and from 170 to $253 \mathrm{mg} / \mathrm{kg}$ in the organogenic soils (Appendix 2).

The mean contents of total manganese in the clay and silt soil groups were of almost the same order of magnitude (Table 9). The situation was the same in the fine sand and sand groups, although the mean contents of manganese were about $25 \%$ smaller than those for the clay and silt soils. Apart from the group of fine sand and sand soils, the mean total contents of manganese were smaller than the results of VUORINEN (1958), ERVIÖ and VIRRI (1965) and SILLANPÄÄ (1975). The differences between the materials may be due to differences in the analytical methods. In the studies of VUORINEN (1958), ERVIÖ and VIRRI (1965) and SILLANPÄÄ (1975), the manganese contents were determined spectrographically. On the other hand, the number of samples used in this study was rather limited in comparison to the research material of VUORINEN (1958). This fact may explain the differences between the results, because the variation in the content of soil total manganese is very large (LE RICHE 1973). The fact that the mean manganese content of the coarse mineral soils was in good agreement with VUORINEN's (1958) results supports this assumption. According to ANDERSSON (1977), the content of manganese extractable with nitric acid in Swedish soils is, on the average, $456 \mathrm{mg} / \mathrm{kg}$. More than $85 \%$ of the manganese extractable with hydrofluoric acid is solubilised with nitric acid (ANDERSSON 1975). The mean content of total manganese in the plough layer of all the soils studied, $520 \mathrm{mg} / \mathrm{kg}$ (Table 9), is thus of the same order of magnitude as that in Swedish mineral soils, $534 \mathrm{mg} / \mathrm{kg}$ (ANDERSSON 1977).

Table 9. Contents of extractable and total manganese and total iron of the soil groups.

\begin{tabular}{|c|c|c|c|c|c|c|c|c|c|c|c|c|c|}
\hline \multirow{3}{*}{$\begin{array}{l}\text { Soil } \\
\text { group }\end{array}$} & \multirow[b]{3}{*}{$\mathrm{n}$} & \multirow{2}{*}{\multicolumn{2}{|c|}{$\begin{array}{c}\text { Exchangeable } \\
\mathrm{Mn}, \mathrm{mg} / \mathrm{kg}\end{array}$}} & \multicolumn{6}{|c|}{ Reducible manganese, $\mathrm{mg} / \mathrm{kg}$} & \multirow{2}{*}{\multicolumn{2}{|c|}{$\begin{array}{c}\text { Total } \\
\mathrm{Mn}, \mathrm{mg} / \mathrm{kg}\end{array}$}} & \multirow{2}{*}{\multicolumn{2}{|c|}{$\begin{array}{c}\text { Total } \\
\mathrm{Fe}, \mathrm{g} / \mathrm{kg}\end{array}$}} \\
\hline & & & & \multicolumn{2}{|c|}{$\mathrm{C}_{6} \mathrm{H}_{4}(\mathrm{OH})_{2}$} & \multicolumn{2}{|c|}{$\mathrm{HONH}_{3} \mathrm{Cl}$} & \multicolumn{2}{|c|}{$\mathrm{C}_{6} \mathrm{H}_{8} \mathrm{O}_{6}$} & & & & \\
\hline & & $\overline{\mathbf{x}}$ & $s$ & $\overline{\mathbf{x}}$ & $s$ & $\overline{\mathbf{x}}$ & $\mathbf{s}$ & $\overline{\mathbf{x}}$ & $s$ & $\overline{\mathbf{x}}$ & s & $\tilde{\mathbf{x}}$ & $s$ \\
\hline \multicolumn{14}{|l|}{ Clays } \\
\hline - plough layer & 30 & 7,2 & 4,2 & 21,2 & 18,9 & 47,4 & 48,6 & 62,9 & 53,7 & 601 & 273 & 39,6 & 14,7 \\
\hline - deeper layer & 34 & 5,8 & 6,4 & 15,5 & 12,9 & 46,1 & 45,6 & 57,3 & 51,3 & 568 & 276 & 44,6 & 14,2 \\
\hline \multicolumn{14}{|l|}{ Silts } \\
\hline - plough layer & 13 & 8,1 & 3,5 & 27,8 & 15,9 & 56,4 & 35,9 & 78,1 & 57,7 & 634 & 302 & 32,0 & 5,4 \\
\hline - deeper layer & 13 & 5,5 & 3,3 & 18,8 & 12,4 & 40,7 & 35,2 & 63,6 & 65,5 & 529 & 199 & 30,3 & 10,0 \\
\hline \multicolumn{14}{|l|}{ Finer fine sands } \\
\hline - plough layer & 26 & 11,7 & 26,8 & 39,5 & 100,0 & 63,4 & 158,9 & 72,1 & 134,5 & 457 & 381 & 23,0 & 5,3 \\
\hline - deeper layer & 24 & 10,4 & 28,0 & 28,5 & 80,7 & 53,6 & 155,5 & 50,0 & 130,3 & 463 & 439 & 25,0 & 5,9 \\
\hline \multicolumn{14}{|c|}{$\begin{array}{l}\text { Fine sands, sands } \\
\text { and moraines }\end{array}$} \\
\hline - plough layer & 29 & 10,1 & 7,4 & 34,4 & 26,7 & 58,3 & 45,9 & 73,0 & 55,4 & 438 & 134 & 20,3 & 7,1 \\
\hline - deeper layer & 24 & 5,3 & 6,2 & 19,1 & 21,7 & 35,8 & 40,7 & 45,5 & 49,3 & 367 & 146 & 19,2 & 7,3 \\
\hline \multicolumn{14}{|l|}{ All mineral soil } \\
\hline - plough layer & 98 & 9,4 & 14,6 & 30,8 & 54,5 & 56,0 & 81,4 & 70,3 & 83,0 & 520 & 289 & 28,5 & 12,6 \\
\hline - deeper layer & 95 & 6,8 & 14,9 & 20,1 & 42,6 & 44,7 & 85,2 & 54,4 & 79,1 & 485 & 301 & 31,3 & 14,7 \\
\hline \multicolumn{14}{|c|}{ Organogenic soils } \\
\hline - plough layer & 9 & 37,0 & 22,5 & 10,8 & 17,7 & 23,5 & 31,2 & 25,9 & 35,3 & 212 & 85 & 16,0 & 7,7 \\
\hline - deeper layer & 8 & 46,3 & 19,6 & 14,0 & 16,8 & 29,7 & 26,7 & 30,4 & 26,1 & 203 & 27 & 16,1 & 5,9 \\
\hline
\end{tabular}


The dependence of the total manganese content of the soil samples on the iron content and overall properties of the samples was studied by means of regression analysis. The organogenic soils were treated separately. The results for soil sample 27 (Appendix 2) were omitted from the calculations because they deviated from the distribution of the rest of the material. The distribution of the total manganese content of the plough layer of the mineral soil samples was skewed, $\mathrm{S}=1,25(\mathrm{Md}=$ $405 \mathrm{mg} / \mathrm{kg}$ ). Logarithmic values of the total manganese contents $(\mathrm{S}=0,37, \mathrm{Md}=$ $6,074 \mathrm{mg} / \mathrm{kg}$ ) were thus used in the calculations. The proportion of clay fractions was calculated as weight percentages of air-dry soil. For this purpose, the organic carbon content was first transformed into organic matter content using the coefficient 1,9 (HEINONEN 1960). The variables were as follows:

\footnotetext{
$\mathrm{X}_{1} \ln$ content of total manganese, $\mathrm{mg} / \mathrm{kg}$ air-dry soil

$\mathrm{X}_{2}$ total iron content, $\mathrm{g} / \mathrm{kg}$ air-dry soil

$\mathrm{X}$, organic carbon content, \% of air-dry soil

$\mathrm{X}_{4}$ clay fraction content, \% of air-dry soil

$\mathrm{X}_{5}$ soil $\mathrm{pH}$
}

The total iron content, organic carbon content, clay fraction content and $\mathrm{pH}$ of the soil explained, to a statistically significant degree $(P=0,001), 45,7 \%$ of the variation in the total manganese content of the plough layer of the mineral soils:

$$
\begin{array}{ll}
\mathrm{X}_{1}=4,759+0,023 & \mathrm{X}_{2}-0,029 \mathrm{X}_{3}-0,0056 \mathrm{X}_{4}+0,185 \mathrm{X}_{5}\left(\mathrm{~F}=19,12^{\mathrm{xx}}\right) \\
\mathrm{R}_{1.2345}^{2}=0,457 & \mathrm{~s}_{\mathrm{b}(12.345)}=0,004 \\
\mathrm{~S}_{1.2345}=0,321 & \mathrm{~s}_{\mathrm{b}(13.245)}=0,013 \\
\mathrm{n}=96 & \mathrm{~s}_{\mathrm{b}(14.235)}=0,0048 \\
& \mathrm{~s}_{\mathrm{b}(15.234)}=0,056
\end{array}
$$

In the deeper layer of the mineral soil samples, the iron content and clay fraction content explained $50,0 \%$ of the variation in the manganese content of the soil:

$$
\begin{array}{ll}
\mathrm{X}_{1}=5,444+0,027 & \mathrm{X}_{2}-0,0092 \mathrm{X}_{4}\left(\mathrm{~F}=45,58^{\mathrm{xxx}}\right) \\
\mathrm{R}_{1.24}^{2}=0,500 & \mathrm{~s}_{\mathrm{b}(12.4)}=0,003 \\
\mathrm{~S}_{1.24}=0,287 & s_{\mathrm{b}(14.2)}=0,0027 \\
\mathrm{n}=94 &
\end{array}
$$

The total iron content, clay fraction content and $\mathrm{pH}$ of the soil explained $42,4 \%$ of the variation in the manganese content of all the mineral soil samples:

$$
\begin{array}{ll}
X_{1}=5,217+0,025 & X_{2}-0,0084 X_{4}+0,061 X_{5}\left(F=45,62^{x x}\right) \\
R_{1.245}^{2}=0,424 & s_{b(12.45)}=0,003 \\
S_{1.245}=0,317 & s_{b(14.25)}=0,0021 \\
n=190 & s_{b(15.24)}=0,030
\end{array}
$$

In the case of the organogenic soils, none of the independent variables studied explained the variation in the total manganese content, to a statistically significant degree $(P=0,05)$, Table 10 .

The total manganese content of the soil increased along with an increase in the iron content of the soil. The iron content explained $30,1 \%$ of the variation in the manganese content of the plough layer of the mineral soils and $43,0 \%$ in the deeper layer samples, and $66,3 \%$ of the variation in the manganese content of all the mineral 
soils, when the other statistically significant $(P=0,05)$ variables were kept constant (Table 10). The correlation between manganese and iron is presumably due to the fact that they react in similar ways during geochemical processes. Manganous manganese can diadochically replace ferrous iron in magma rocks (RANKAMA and SAHAMA 1950 , p. 645). $\mathrm{Mn}^{2+}$ and $\mathrm{Fe}^{2+}$ ions, which are released during weathering, may come into contact with acid ground water containing a lot of organic matter. When iron and manganese end up in the surface layers of the soil, i.e. in oxidizing conditions, they are oxidized and form precipitates in eskers, peatlands, ditches, rivers, lakes and clay soils (VASARI et al. 1972, ALHONEN et al. 1975, KOLJONEN et. al. 1976). In podzolic soils, iron is mainly precipitated in the B horizon (AALTONEN 1941, JAUHIAINEN 1973) and if the redox potential of the B horizon is high enough, manganese will accumulate in the lower part of the horizon (MATTSON and NILSSON 1935, McKEAGUE et al. 1968). Manganese minerals often contain appreciable amounts of iron (e.g. TAYLOR and McKENZIE 1966, KOLJONEN et al. 1976) and the iron content of the soil usually also increases if the manganese content does (SCHLICHTING and ELGALA 1975). According to SIPPOLA (1974), the manganese content of the soil increases along with an increase in the content of iron extractable with dithionite.

The content of total manganese of the soil decreased as the organic carbon content of the soil increased. It explained $18,5 \%$ of the variation in the manganese content of the plough layer of the mineral soil samples, when the other statistically significant $(P=0,05)$ independent variables were kept constant (Table 10). Organic carbon was not a statistically significant variable in the deeper layer and in all the mineral soil samples. The fact that the organic matter content had an effect on the total manganese content of the soil may be interpreted as indicating that the organic matter in the soil contains, on the average, less manganese than the mineral fraction. This is despite the fact that the organic matter would have sorbed manganese from sources other than plant residues (FINCK 1956). According to ANDERSSON (1977), the content of manganese extractable with nitric acid decreases as the humus content increases.

The content of total manganese of the soil decreased along with an increase in the proportion of the clay fraction. The content of the clay fraction in the plough layer of the mineral soils explained $5,2 \%$ of the variation in the total manganese content, $11,7 \%$ in the deeper layer samples and $7,6 \%$ in all the mineral soil samples when the other statistically significant $(\mathrm{P}=0,05)$ variables were kept constant (Table 10$)$. The total manganese content of the soil did not appear to be very closely connected with the particle size distribution of the soil. According to ROBINSON (1929), the highest manganese contents are to be found in the silt and fine sand fractions, and according to YAALON et al. (1972) in the clay fraction. The manganese content is higher in coarse clay fractions than in fine clay ones (LE RICHE 1973). According to SIPPOLA (1974), the manganese content increases along with an increase in the clay content, although the dependence is rather weak. It is likely that manganese, either alone or together with iron, forms oxide and hydroxide precipitates (ANDERSSON 1975) and therefore is not likely to be correlated with the particle size distribution properties of the soil.

The content of total manganese of the soil increased along with an increase in the $\mathrm{pH}$ value of the soil. The $\mathrm{pH}$ explained $7,1 \%$ of the variation in the total manganese content of the plough layer of the mineral soil samples and 2,6 \% in all the mineral 
Table 10. Coefficients of partial $\left(\mathrm{r}_{1 \mathrm{x} .}\right)$ correlation between $\ln$ total manganese content $(\mathrm{mg} / \mathrm{kg})$ of the soil and other soil variables, and the beta coefficients $(\beta)$ between the variables.

\begin{tabular}{|c|c|c|c|c|c|c|c|c|c|}
\hline & \multirow[b]{2}{*}{$\mathrm{n}$} & \multicolumn{2}{|c|}{ Total $\mathrm{Fe}, \mathrm{g} / \mathrm{kg}$} & \multicolumn{2}{|c|}{ Organic C, \% } & \multicolumn{2}{|c|}{ Clay fraction, $\%$} & \multicolumn{2}{|c|}{$\mathrm{pH}\left(\mathrm{CaCl}_{2}\right)$} \\
\hline & & $r_{12 \ldots}$ & $\beta$ & $r_{13 \ldots}$ & $\beta$ & $\mathbf{r}_{14 \ldots}$ & $\beta$ & $r_{15} \ldots$ & $\beta$ \\
\hline \multicolumn{10}{|l|}{ Mineral soils } \\
\hline - plough layer & 96 & $0,549^{\mathrm{xxx}}$ & 0,696 & $-0,430^{x x x}$ & $-0,186$ & $-0,229^{x}$ & $-0,206$ & $0,266^{x x}$ & 0,259 \\
\hline - deeper layer & 94 & $0,656^{\mathrm{xx}}$ & 0,977 & $-0,063^{n s}$ & - & $-0,341^{x x x}$ & $-0,409$ & $0,143^{\text {ns }}$ & - \\
\hline - total & 190 & $0,814^{x x}$ & 0,846 & $-0,113^{\text {ns }}$ & - & $-0,275^{\mathrm{xx}}$ & $-0,339$ & $0,162^{x}$ & 0,090 \\
\hline \multicolumn{10}{|l|}{ Organogenic soils } \\
\hline - total & 17 & $0,468^{\text {ns }}$ & - & $-0,277^{\mathrm{ns}}$ & - & - & - & $0,286^{\mathrm{ns}}$ & - \\
\hline
\end{tabular}

soils, when the other statistically significant $(P=0,05)$ variables were kept constant (Table 10). The $\mathrm{pH}$ was not a significant variable in the case of the group of deeper layer samples because it explained only $2,0 \%$ of the variation. According to the stability diagrammes presented for manganese oxides (PONNAMPERUMA et al. 1969), the manganese in manganic oxides and oxyhydroxides is reduced in acid soils to manganous manganese. Since manganous manganese is relatively weakly adsorbed in the soil (ZAHER 1979), it is susceptible to leaching. It is therefore to be expected that the total manganese content of soils where the $\mathrm{pH}$ is low will be smaller than in soils where the $\mathrm{pH}$ is high.

The total iron content of the soil was the most important independent variable explaining the variation in the total manganese content of the soil (Table 10). The second most important variable in all the mineral soils was the clay content, although in the group of plough layer samples $\mathrm{pH}$ was a more important variable than the clay content. Soil $\mathrm{pH}$ was of only slight importance in all the mineral soils in comparison to the other variables. Similarly, the organic carbon content was of little significance in the plough layer samples (Table 10).

\section{B. Extractable manganese}

In this study, manganese extractable from the soil was divided into two groups: exchangeable and reducible manganese. Exchangeable manganese refers to the manganese in cationic form, present in the soil solution or adsorbed on soil particles, which can be displaced by magnesium ions. Reducible manganese refers to the manganese fraction which is obtained by subtracting the content of exchangeable manganese from the content of extractable manganese obtained following the reduction treatment.

\section{Exchangeable manganese}

The content of exchangeable manganese of the mineral soils varied in the plough layer samples from 1,2 to $34,4 \mathrm{mg} / \mathrm{kg}$ and in the deeper layer samples from 0,1 to 33,2 $\mathrm{mg} / \mathrm{kg}$. In the organogenic soils, the exchangeable manganese varied in the plough 
layer from 9,8 to $75,0 \mathrm{mg} / \mathrm{kg}$ and in the deeper layer from 13,3 to $64,1 \mathrm{mg} / \mathrm{kg}$ (Appendix 2).

The mean contents of exchangeable manganese of the samples in the different mineral soil groups were of almost the same order of magnitude. The values for the deeper layer samples were on the average slightly lower than for the plough layer ones (Table 9). According to KURKI (1972), on the average, in Finnish soils manganese is extracted with $0,1 \mathrm{M} \mathrm{MgSO}_{4}$ from clay soils $5,2 \mathrm{mg} / \mathrm{l}$, from silt soils 7,6 $\mathrm{mg} / \mathrm{l}$, from finer fine sand soils $6,8 \mathrm{mg} / \mathrm{l}$ and from fine sand soils and sand soils 6,9 $\mathrm{mg} / \mathrm{l}$. In addition, the contents of manganese extractable in Finnish mineral soils with acid ammonium acetate - EDTA $\left(0,5 \mathrm{M} \mathrm{CH}_{3} \mathrm{COONH}_{4}, 0,5 \mathrm{M} \mathrm{CH}_{3} \mathrm{COOH}, 0,02 \mathrm{M}\right.$ $\mathrm{Na}_{2}$ EDTA, $\left.\mathrm{pH} 4,65\right)$ are of the same order of magnitude for the different soil groups (SIPPOLA and TARES 1978), although about ten times higher than the values obtained in this study.

The dependence between the content of exchangeable manganese of the soil and different soil factors was studied by means of regression analysis. The independent variables were: $\mathrm{pH}$, organic carbon content, the content of reducible manganese and the content of residual total manganese (=Res. tot. Mn), which was obtained by subtracting the contents of exchangeable and reducible manganese from the content of total manganese in the soil. The fractions of reducible manganese were each used separately as independent variables when calculating the regression equations. The results for soil No. 27 (Appendix 2) were omitted from the calculation because they deviated from the distribution of the material. The distribution of the content of exchangeable manganese was skewed, $\mathrm{S}=1,09$ and $\mathrm{Md}=6,0 \mathrm{mg} / \mathrm{kg}$. The skewness was corrected by transforming the values into logarithms, the coefficient of skewness being $\mathrm{S}=0,39$ and $\mathrm{Md}=1,775 \mathrm{mg} / \mathrm{kg}$.

\section{Hydroquinone-reducible manganese as an independent variable}

The variation in the content of exchangeable manganese in the soil was studied using the following variables:

$\mathrm{X}_{1}$ ln content of exchangeable manganese, $\mathrm{mg} / \mathrm{kg}$ air-dry soil

$\mathrm{X}_{2}$ soil $\mathrm{pH}$

$\mathrm{X}_{3}$ organic carbon content, $\%$ of air-dry soil

$\mathrm{X}_{4}$ content of hydroquinone-reducible manganese, $\mathrm{mg} / \mathrm{kg}$ air-dry soil

$\mathrm{X}_{5}$ "total" manganese content, $\mathrm{mg} / \mathrm{kg}$ air- $\mathrm{dry}$ soil (= total manganese - exchangeable manganese hydroquinone-reducible manganese)

The $\mathrm{pH}$, organic carbon content and the content of hydroquinone-reducible manganese of the soil explained, to a statistically significant degree $(P=0,001)$, the variation in the manganese content of the mineral soils:

Plough layer soils:

$X_{1}=4,533-0,654 X_{2}+0,048 X_{3}+0,018 X_{4}\left(F=62,32^{x x}\right)$

$R_{1.234}^{2}=0,670 \quad s_{b(12.34)}=0,069$

$\mathrm{S}_{1.234}=0,395 \quad \mathrm{~s}_{\mathrm{b}(13.24)}=0,015$

$\mathrm{n}=96 \quad \mathrm{~s}_{\mathrm{b}(14.23)}=0,002$ 
Deeper layer soils:

$\mathrm{X}_{1}=3,922-0,681 \mathrm{X}_{2}+0,089 \mathrm{X}_{3}+0,033 \mathrm{X}_{4}\left(\mathrm{~F}=34,13^{\mathrm{xx}}\right)$

$R_{1.234}^{2}=0,532 \quad s_{b(12.34)}=0,122$

$\mathrm{S}_{1.234}=0,676 \quad \mathrm{~s}_{\mathrm{b}(13.24)}=0,037$

$\mathrm{n}=94 \quad \mathrm{~s}_{\mathrm{b}(14.23)}=0,004$

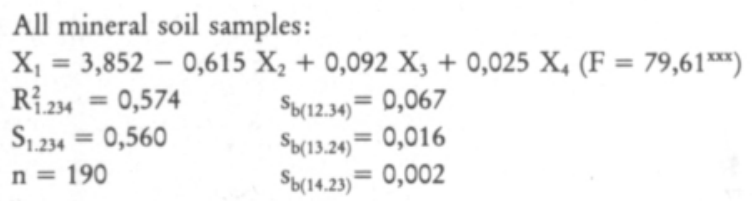

It was found in the first stage of testing the independent variables describing the variation in the content of exchangeable manganese in organogenic soils, that the "total" manganese content was a statistically significant $(P=0,05)$ variable when the effects of the other variables were kept constant. The "total" manganese content explained in this case $26,5 \%$ of the variation in the content of exchangeable manganese. When the statistically insignificant variables were removed from the equation and the $\mathrm{pH}$, organic carbon content and the content of hydroquinonereducible manganese thus able to vary according to the material, it was found that "total" manganese content was no longer a significant explainer of the variation (Table 11).

The content of exchangeable manganese of the soil decreased along with an increase in the soil $\mathrm{pH}$. The $\mathrm{pH}$ explained $49,5 \%$ of the variation in the content of exchangeable manganese of the plough layer samples in the mineral soils, $28,2 \%$ of the variation in the content of exchangeable manganese in the deeper layer soils and $30,3 \%$ of the variation in the content of exchangeable manganese of all the mineral soils when the effects of the other statistically significant $(P=0,05)$ independent variables were kept constant (Table 11). For instance, according to CHRISTENSEN et al. (1950), KURKI (1972, 1979), BROWMAN et al. (1969) and RANDALL et al. (1976), the content of exchangeable manganese of the soil decreases as the soil $\mathrm{pH}$ increases. According to STÅHLBERG and SOMBATPANIT (1974), pH explains $17,1 \%$ of the variation in the content of exchangeable manganese of the soil and the content of exchangeable manganese decreases as the $\mathrm{pH}$ increases. According to SIPPOLA and TARES (1978), the content of manganese extractable with acid ammonium acetate EDTA increases as the $\mathrm{pH}$ of the soil increases, while according to BROWMAN et al. (1969), the content of ammonium acetate - EDTA -extractable manganese decreases as the $\mathrm{pH}$ increases.

The organic carbon content of the plough layer in the mineral soils explained 9,3 $\%$ of the variation in the content of exchangeable manganese in the soil when the effects of the other statistically significant $(P=0,05)$ variables were kept constant. It explained $14,4 \%$ of the variation in the content of exchangeable manganese of all the mineral soils (Table 11). The content of exchangeable manganese of the soil increased along with an increase in the organic carbon content. STÅHLBERG and SOMBATPANIT (1974) propose that the content of exchangeable manganese in the soil is affected by the organic matter content of the soil, although they were not able to demonstrate this hypothesis. According to SILLANPÄÄ (1962), the content of soluble manganese in the soil increases along with the carbon content when the values are expressed in w/w units. The content of EDTA-extractable manganese also increases as the organic 
matter content increases (GHANEM et al. 1971), and the relative proportion of manganese bound in the organic matter increases as the degree of humification increases (FINCK 1956). Despite the low values of the constants govering the complex formation between manganese and organic matter (SCHNITZER and SKINNER 1967, SCHNITZER 1969), formation of organometallic manganese complexes appears, however, to be one reason for the decrease in the content of exchangeable manganese as the $\mathrm{pH}$ increases (GROOT 1956, SIMS and PATRICK 1978, ZAHER 1979). The proportion of complexed manganese also increases as the organic carbon content increases (CHEAM 1973). The stability of organometallic complexes of manganese is, however, so low that manganese may be relatively easily exchanged with magnesium ions, for instance, because the formation constants of organometallic complexes of magnesium are not much smaller than that for manganese (SCHNITZER and HANSEN 1970, DIJK 1971, BLOOMFIELD and SANDERS 1977). In the case of other micronutrients, such as copper and nickel, the amount of complexed metal ions also increases as the organic carbon content increases (PRATT et al. 1964).

The content of exchangeable manganese of the soil increased along with an increase in the content of hydroquinone-reducible manganese. It explained $49,8 \%$ of the variation in the content of exchangeable manganese in the plough layer of the mineral soils when the effects of other statistically significant $(P=0,05)$ independent variables were kept constant. In the deeper layer samples it explained $39,7 \%$, and in all the mineral soil samples $44,7 \%$ of the variation in the content of exchangeable manganese (Table 11). According to e.g. SCHACHTSCHABEL (1957) and STÅHLBERG and SOMBATPANIT (1974), the content of exchangeable manganese of the soil increases along with an increase in the content of reducible manganese.

The $\mathrm{pH}$, organic carbon content and the content of hydroquinone-reducible manganese of the soil explained $67,0 \%$ of the variation in the content of exchangeable manganese in the plough layer of the mineral soils, 53,2 \% in the deeper layer samples and $57,4 \%$ in all the mineral soils. The content of hydroquinone-reducible manganese was the most important independent variable, although the $\mathrm{pH}$ was almost as important in the plough layer samples. The organic carbon content was of only slight significance in comparison to the other variables (Table 11).

Table 11. Coefficients of partial $\left(\mathrm{r}_{1 \mathrm{x} .}\right)$ correlation between $\mathrm{ln}$ content of exchangeable manganese $(\mathrm{mg} / \mathrm{kg})$ of soil and other soil variables, and the beta coefficients $(\beta)$ between the variables.

\begin{tabular}{|c|c|c|c|c|c|c|c|c|c|}
\hline & \multirow[b]{2}{*}{$\mathrm{n}$} & \multicolumn{2}{|c|}{$\mathrm{pH}\left(\mathrm{CaCl}_{2}\right)$} & \multicolumn{2}{|c|}{ Organic C, \% } & \multicolumn{2}{|c|}{$\begin{array}{c}\mathrm{C}_{6} \mathrm{H}_{4}(\mathrm{OH})_{2}-\mathrm{Mn}, \\
\mathrm{mg} / \mathrm{kg} \\
\end{array}$} & \multicolumn{2}{|c|}{$\begin{array}{c}\text { Res. tot. Mn, } \\
\mathrm{mg} / \mathrm{kg}\end{array}$} \\
\hline & & $r_{12 \ldots}$ & $\beta$ & $\mathbf{r}_{13 \ldots}$ & $\beta$ & $r_{14 \ldots}$ & $\beta$ & $\mathbf{r}_{15} \ldots$ & $\beta$ \\
\hline \multicolumn{10}{|l|}{ Mineral soils } \\
\hline - plough layer & 96 & $-0,704^{x x}$ & $-0,576$ & $0,306^{\mathrm{xx}}$ & 0,193 & $0,706^{\mathrm{xx}}$ & 0,587 & $0,172^{\mathrm{ns}}$ & - \\
\hline - deeper layer & 94 & $-0,531^{\mathrm{xx}}$ & $-0,465$ & $0,262^{x}$ & 0,198 & $0,643^{\mathrm{xx}}$ & 0,587 & $0,046^{\mathrm{ns}}$ & - \\
\hline - total & 190 & $-0,550^{\operatorname{xxx}}$ & $-0,441$ & $0,380^{\times x x}$ & 0,273 & $0,669^{\mathrm{xxx}}$ & 0,593 & $0,069^{\mathrm{ns}}$ & - \\
\hline \multicolumn{10}{|c|}{ Organogenic soils } \\
\hline - total & 17 & $-0,461^{\mathrm{ns}}$ & - & $0,172^{\text {ns }}$ & - & $0,219^{\text {ns }}$ & - & $0,515^{\mathrm{ns}}$ & - \\
\hline
\end{tabular}




\section{Hydroxylammonium chloride-reducible manganese as an independent variable}

The variation in the content of exchangeable manganese in the soil was studied using the following variables:

$\mathrm{X}_{1}$ ln content of exchangeable manganese, $\mathrm{mg} / \mathrm{kg}$ air-dry soil

$\mathrm{X}_{2}$ soil $\mathrm{pH}$

$\mathrm{X}_{3}$ organic carbon content, \% of air-dry soil

$\mathrm{X}_{4}$ content of hydroxylammonium chloride-reducible manganese, $\mathrm{mg} / \mathrm{kg}$ air-dry soil

$\mathrm{X}_{5}$ "total" manganese content, $\mathrm{mg} / \mathrm{kg}$ air-dry soil (= total manganese - exchangeable manganese hydroxylammonium chloride-reducible manganese)

The $\mathrm{pH}$, organic carbon content and the content of hydroxylammonium chloride-reducible manganese of the soil explained, to a statistically significant degree $(\mathrm{P}$ $=0,001)$, the variation in the content of exchangeable manganese of the mineral soil samples:

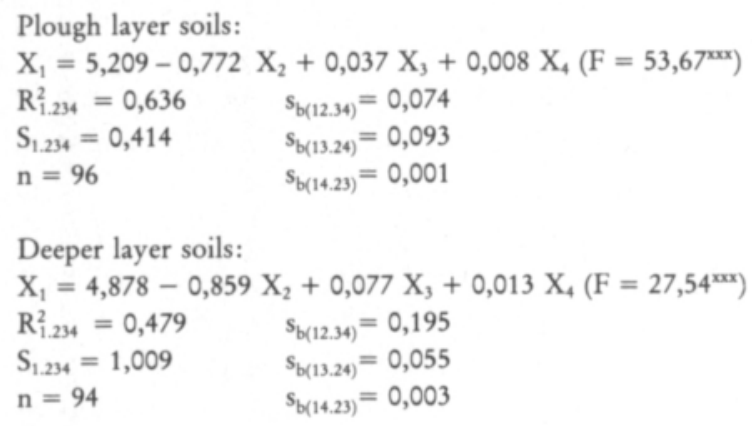

All mineral soil samples:

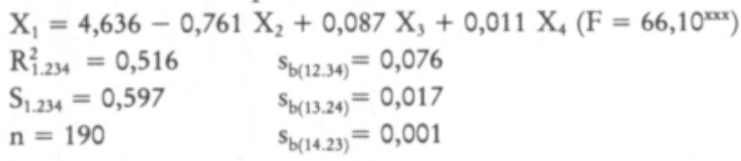

The $\mathrm{pH}$, organic carbon content and the content of hydroxylammonium chloride-reducible manganese of the soil explained $63,6 \%$ of the variation in the content of exchangeable manganese in the plough layer of the mineral soils, $47,9 \%$ in the deeper layer samples and $51,6 \%$ in all the mineral soil samples. The content of hydroxylammonium chloride-reducible manganese alone explained $44,7 \%$ of the variation in the plough layer, $34,7 \%$ in the deeper layer samples and $37,2 \%$ in all the mineral soil samples when the effects of the other statistically significant $(P=0,05)$ idependent variables were kept constant (Table 12). The $\mathrm{pH}$ of the soil in the plough layer samples was a slightly more important variable than the content of hydroxylammonium chloride-reducible manganese. However, they were of almost the same order of importance in the case of the deeper layer samples and the whole of the mineral soil material. The importance of the organic carbon content as an explainer of the variation in the content of exchangeable manganese was only slight in comparison to the other independent variables (Table 12). The content of "total" manganese was of no importance as an explainer of the content of exchangeable manganese in the soil. 
Table 12. Coefficients of partial $\left(\mathrm{r}_{1 \mathrm{x} .}\right)$ correlation between $\mathrm{ln}$ content of exchangeable manganese $(\mathrm{mg} / \mathrm{kg})$ of the soil and other soil variables, and the beta coefficients $(\beta)$ between the variables.

\begin{tabular}{|c|c|c|c|c|c|c|c|c|c|}
\hline & \multirow[b]{2}{*}{$\mathrm{n}$} & \multicolumn{2}{|c|}{$\mathrm{pH}\left(\mathrm{CaCl}_{2}\right)$} & \multicolumn{2}{|c|}{ Organic C, \% } & \multicolumn{2}{|c|}{$\begin{array}{c}\mathrm{HONH}_{3} \mathrm{Cl}-\mathrm{Mn}, \\
\mathrm{mg} / \mathrm{kg}\end{array}$} & \multicolumn{2}{|c|}{$\begin{array}{l}\text { Res. tot. } \mathrm{Mn} \text {, } \\
\mathrm{mg} / \mathrm{kg}\end{array}$} \\
\hline & & $r_{12 \ldots}$ & $\beta$ & $r_{13 \ldots}$ & $\beta$ & $r_{14} \ldots$ & $\beta$ & $r_{15} \ldots$ & $\beta$ \\
\hline \multicolumn{10}{|l|}{ Mineral soils } \\
\hline - plough layer & 96 & $-0,694^{x x}$ & $-0,680$ & $0,232^{x}$ & 0,147 & $0,669^{\operatorname{cxx}}$ & 0,562 & $0,052^{\mathrm{ns}}$ & - \\
\hline - deeper layer & 94 & $-0,574^{x x}$ & $-0,586$ & $0,216^{x}$ & 0,170 & $0,589^{x x x}$ & 0,577 & $-0,024^{\mathrm{ns}}$ & - \\
\hline - total & 190 & $-0,591^{x x}$ & $-0,545$ & $0,343^{\operatorname{cxx}}$ & 0,259 & $0,610^{x x x}$ & 0,565 & $0,025^{\text {ns }}$ & - \\
\hline \multicolumn{10}{|c|}{ Organogenic soils } \\
\hline - total & 17 & $-0,441^{\mathrm{ns}}$ & - & $-0,040^{\mathrm{ns}}$ & - & $0,435^{\mathrm{ns}}$ & - & $0,474^{\mathrm{ns}}$ & - \\
\hline
\end{tabular}

After the first stage of testing the independent variables for the organogenic soil samples, the content of hydroxylammonium chloride-reducible manganese was found to explain $18,9 \%$ of the variation in the exchangeable manganese when the effects of the other independent variables tested were kept constant (Table 12). When the statistically insignificant $(P=0,05)$ independent variables were removed from the equation, the content of hydroxylammonium chloride-reducible manganese was no longer a significant independent variable (Table 12).

\section{Ascorbic acid-reducible manganese as an independent variable}

The variation in the content of exchangeable manganese in the soil was studied using the following variables:

$\mathrm{X}_{1}$ ln content of exchangeable manganese, $\mathrm{mg} / \mathrm{kg}$ air-dry soil

$\mathrm{X}_{2}$ soil $\mathrm{pH}$

$\mathrm{X}_{3}$ organic carbon content, \% of air-dry soil

$\mathrm{X}_{4}$ content of ascorbic acid-reducible manganese, $\mathrm{mg} / \mathrm{kg}$ air-dry soil

$\mathrm{X}_{\mathrm{s}}$ "total" manganese content, $\mathrm{mg} / \mathrm{kg}$ air-dry soil (= total manganese - exchangeable manganese ascorbic acid-reducible manganese)

The $\mathrm{pH}$, organic carbon content and the content of ascorbic acid-reducible manganese explained, to a statistically significant degree $(P=0,001)$, the variation in the content of exchangeable manganese of the mineral soil samples as follows:

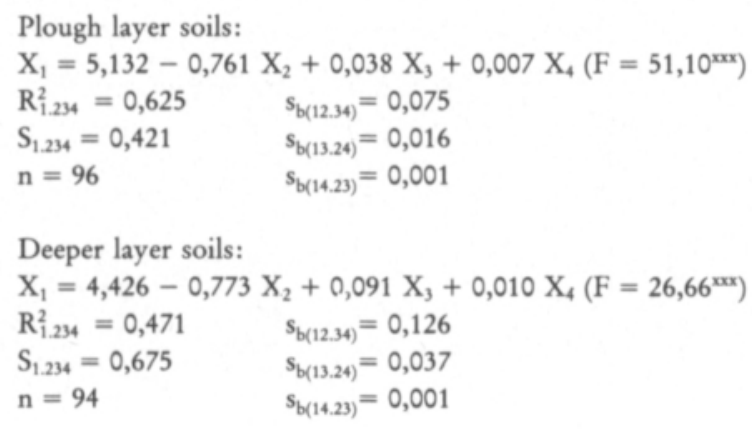


All mineral soil samples:

$\begin{array}{ll}\mathrm{X}_{1}=4,448-0,732 & \mathrm{X}_{2}+0,090 \mathrm{X}_{3}+0,009 \mathrm{X}_{4}\left(\mathrm{~F}=67,29^{\mathrm{mxx}}\right) \\ \mathrm{R}_{1.234}^{2}=0,521 & \mathrm{~s}_{\mathrm{b}(12.34)}=0,075 \\ \mathrm{~S}_{1.234}=0,594 & \mathrm{~s}_{\mathrm{b}(13.24)}=0,017 \\ \mathrm{n}=190 & \mathrm{~s}_{\mathrm{b}(14.23)}=0,001\end{array}$

The $\mathrm{pH}$, organic carbon content and the content of ascorbic acid-reducible manganese of the soil explained $62,5 \%$ of the variation in the content of exchangeable manganese of the plough layer in the mineral soil samples, $47,1 \%$ in the deeper layer samples and $52,1 \%$ in all the mineral soil samples. The content of ascorbic acidreducible manganese alone explained $43,0 \%$ of the variation in the plough layer samples, $33,6 \%$ in the deeper layer and $37,8 \%$ in all the mineral soil samples when the effects of the other statistically significant $(P=0,05)$ independent variables were kept constant (Table 13). However, the $\mathrm{pH}$ of the soil in the plough layer samples was a relatively more important independent variable than the content of ascorbic acid-reducible manganese. In the deeper layer samples and in all the mineral soil samples they were of almost the same order of importance. The organic carbon content was of only slight importance as an independent variable in comparison to the other independent variables (Table 13). The "total" manganese content was of no importance as an explainer of the variation in the content of exchangeable manganese.

The content of ascorbic acid-reducible manganese explained 32,6\% of the variation in the content of exchangeable manganese in the organogenic soil samples when the effects of the other independent variables were kept constant. However, when the other independent variables which were not statistically significant $(\mathrm{P}=$ 0,05 ) were removed from the equation, the content of ascorbic acid-reducible manganese no longer explained to a significant degree the content of exchangeable manganese (Table 13).

The activity of reducible manganese compounds in the soil is assumed to be unity (e.g. GEERING et al. 1969, BOHN 1970, OLOMU et al. 1973, BRÜMMER 1974, STÅHLBERG et al. 1976). The activity of the manganese oxides thus does not affect the magnitude of the activity quotient describing the equilibrium of the reduction reaction. According to empirical results, however, the content of reducible manganese in the soil explains, to a significant degree, the variation in the content of exchangeable manganese of the soil. On the other hand, the "total" manganese content is an insignificant variable as far as the content of exchangeable manganese is concerned. The extraction time is obviously an important factor in estimating the cases where the activity of the reducible oxide represents a factor regulating the activity quotient. According to the empirical results, for instance, the $\mathrm{pH}$ and the content of hydroquinone-reducible manganese explained, to a statistically significant degree $(P=0,001)$, the variation in the content of exchangeable manganese in the plough layer of the mineral soil samples:

$\ln ($ exchangeable $\mathrm{Mn})=4,912-0,686 \mathrm{pH}+0,016$ (hydroquinone-reducible $\mathrm{Mn}$ )

The equation, written in the general form of the activity quotient, can be presented as follows:

$$
K=\frac{a_{\text {(exchangeable } M n)}}{a_{(\text {hydroquinone-reducible } \mathrm{Mn}) \cdot \mathrm{a}_{\left(\mathrm{H}^{+}\right) \cdot b}}}
$$


Table 13. Coefficients of partial $\left(\mathrm{r}_{1 \mathrm{x} .}\right)$ correlation between $\ln$ content of exchangeable manganese $(\mathrm{mg} / \mathrm{kg})$ of the soil and other soil variables, and the beta coefficients $(\beta)$ between the variables.

\begin{tabular}{|c|c|c|c|c|c|c|c|c|c|}
\hline & \multirow[b]{2}{*}{$\mathrm{n}$} & \multicolumn{2}{|c|}{$\mathrm{pH}\left(\mathrm{CaCl}_{2}\right)$} & \multicolumn{2}{|c|}{ Organic C, \% } & \multicolumn{2}{|c|}{$\begin{array}{c}\mathrm{C}_{6} \mathrm{H}_{8} \mathrm{O}_{6}-\mathrm{Mn} \\
\mathrm{mg} / \mathrm{kg}\end{array}$} & \multicolumn{2}{|c|}{$\begin{array}{c}\begin{array}{c}\text { Res. tot. Mn, } \\
\mathrm{mg} / \mathrm{kg}\end{array} \\
\end{array}$} \\
\hline & & $r_{12 \ldots}$ & $\beta$ & $r_{13 \ldots}$ & $\beta$ & $r_{14 \ldots}$ & $\beta$ & $r_{15} \ldots$ & $\beta$ \\
\hline \multicolumn{10}{|l|}{ Mineral soils } \\
\hline - plough layer & 96 & $-0,729^{\mathrm{xxx}}$ & $-0,671$ & $0,235^{x}$ & 0,151 & $0,656^{\operatorname{xx}}$ & 0,551 & $-0,049^{\mathrm{ns}}$ & - \\
\hline - deeper layer & 94 & $-0,543^{x x x}$ & $-0,528$ & $0,377^{x x}$ & 0,201 & $0,580^{x x x}$ & 0,551 & $-0,080^{\mathrm{ns}}$ & - \\
\hline - total & 190 & $-0,583^{\mathrm{xx}}$ & $-0,525$ & $0,356^{\mathrm{xx}}$ & 0,269 & $0,615^{\operatorname{xx}}$ & 0,569 & $-0,065^{\mathrm{ns}}$ & - \\
\hline \multicolumn{10}{|c|}{ Organogenic soils } \\
\hline- total & 17 & $-0,440^{n s}$ & - & $0,176^{\text {ns }}$ & - & $0,429^{\mathrm{ns}}$ & - & $0,444^{\mathrm{ns}}$ & - \\
\hline
\end{tabular}

This regression model explains $63,6 \%$ of the variation $\left(\mathrm{F}=162,32^{\mathrm{xxx}}\right)$ in the content of exchangeable manganese. Since, for this reason, the content of reducible manganese cannot be ignored in the equation, it can be considered to represent a reactive manganese compound whose activity is not unity. In addition to the $\mathrm{pH}$ of the soil, it regulates to a considerable extent the variation in the content of exchangeable manganese.

\section{Reducible manganese}

The reducible manganese in the soil was determined using hydroquinone, hydroxylammonium chloride and ascorbic acid as the reducing agent.

\section{Hydroquinone-reducible manganese $\mathrm{C}_{6} \mathrm{H}_{4}(\mathrm{OH})_{2}-\mathrm{Mn}$}

The content of hydroquinone-reducible manganese in the material varied from 0,3 to $517,6 \mathrm{mg} / \mathrm{kg}$ in the plough layer and from 0,1 to $400,3 \mathrm{mg} / \mathrm{kg}$ in the deeper layer of the mineral soil samples. The corresponding values for the organogenic soil samples were from 0,2 to $54,5 \mathrm{mg} / \mathrm{kg}$ and from 0,1 to $45,0 \mathrm{mg} / \mathrm{kg}$ (Appendix 2).

The mean values for the content of hydroquinone-reducible manganese in the different mineral soil groups were of the same order of magnitude (Table 9). Slightly smaller contents of extractable manganese were obtained from the deeper layer than from the plough layer samples. However, the differences were not statistically significant $(t=1,52)$. The content of hydroquinone-reducible manganese of the organogenic soil samples was, on the average, slightly lower than that for the mineral soil samples $\left(t=3,44^{x x}\right)$.

There is no information available about the content of hydroquinone-reducible manganese in Finnish soils. According to studies carried out abroad, it can vary from at least 1 to $775 \mathrm{mg} / \mathrm{kg}$ depending on the samples and conditions (CHRISTENSEN et al. 1950, ADAMS and WEAR 1957, BROWMAN et al. 1969, RANDALL et al. 1976).

The dependence of the variation in the content of hydroquinone-reducible manganese of the soil on different properties of the soil was studied by means of regression analysis. The variables were as follows: 
$\mathrm{X}_{1}$ content of hydroquinone-reducible manganese, $\mathrm{mg} / \mathrm{kg}$ air-dry soil

$\mathrm{X}_{2}$ soil $\mathrm{pH}$

$\mathrm{X}_{3}$ organic carbon content, $\%$ of air-dry soil

$\mathrm{X}_{4}$ "total" manganese content, $\mathrm{mg} / \mathrm{kg}$ air-dry soil (= total manganese - hydroquinone-reducible manganese)

The "total" manganese content of the mineral soils explained, to a statistically significant degree $(P=0,001)$, the variation in the content of hydroquinonereducible manganese of the soil as follows:

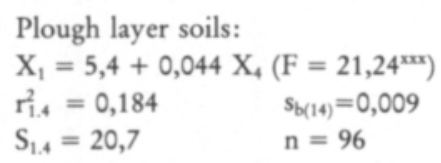

Deeper layer soils:

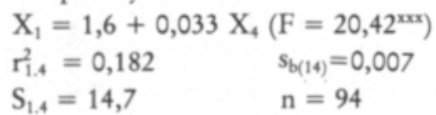

All mineral soil samples:

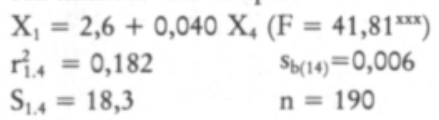

In the case of the organogenic soil samples, none of the independent variables studied explained the variation in the content of hydroquinone-reducible manganese in the soil to a statistically significant $(\mathrm{P}=0,05)$ degree (Table 14$)$.

The "total" manganese content of the soil explained $18,4 \%$ of the variation in the content of hydroquinone-reducible manganese of the plough layer in the mineral soil samples, $18,2 \%$ in the deeper layer samples and $18,2 \%$ of the variation in the content of hydroquinone-reducible manganese of all the mineral soil samples. In addition, it was the only statistically significant $(P=0,05)$ independent variable. According to BROWMAN et al. (1969) and HOYT and NYBORG (1971), the total manganese content of the soil explains, to a statistically significant degree $(P=0,05)$, the variation in the content of hydroquinone-reducible manganese. On the other hand, the $\mathrm{pH}$ and the organic matter content are not significant independent variables (BROWMAN et al. 1969, HOYT and NYBORG 1971, RANDALL et al. 1976).

Table 14. Coefficients of partial ( $\mathrm{r}_{1 \mathrm{x} .}$ ) correlation between content of hydroquinone-reducible manganese $(\mathrm{mg} / \mathrm{kg})$ of the soil and other soil variables, and the beta coefficients $(\beta)$ between the variables.

\begin{tabular}{|c|c|c|c|c|c|c|c|}
\hline & \multirow[b]{2}{*}{$\mathrm{n}$} & \multicolumn{2}{|c|}{$\mathrm{pH}\left(\mathrm{CaCl}_{2}\right)$} & \multicolumn{2}{|c|}{ Organic C, \% } & \multicolumn{2}{|c|}{ Res. tot. $\mathrm{Mn}, \mathrm{mg} / \mathrm{kg}$} \\
\hline & & $r_{12 \ldots}$ & $\beta$ & $\mathbf{r}_{13 \ldots}$ & $\beta$ & $r_{14 \ldots}$ & $\beta$ \\
\hline \multicolumn{8}{|l|}{ Mineral soils } \\
\hline - plough layer & 96 & $-0,098^{\mathrm{ns}}$ & - & $-0,138^{\mathrm{ns}}$ & - & $0,429^{\mathrm{xx}}$ & 0,429 \\
\hline - deeper layer & 94 & $0,104^{\mathrm{ns}}$ & - & $-0,012^{\mathrm{ns}}$ & - & $0,426^{\mathrm{xx}}$ & 0,426 \\
\hline- total & 190 & $0,038^{\text {ns }}$ & - & $-0,038^{\mathrm{ns}}$ & - & $0,427^{x \times x}$ & 0,427 \\
\hline \multicolumn{8}{|l|}{ Organogenic soils } \\
\hline - total & 17 & $0,325^{\mathrm{ns}}$ & - & $-0,017^{\mathrm{ns}}$ & - & $0,377^{\mathrm{ns}}$ & - \\
\hline
\end{tabular}


The content of hydroxylammonium chloride-reducible manganese varied from 0,8 to $718,4 \mathrm{mg} / \mathrm{kg}$ in the plough layer of the mineral soil samples and from 0,1 to $770,3 \mathrm{mg} / \mathrm{kg}$ in the deeper layer samples. The corresponding values for the organogenic soil samples were from 1,3 to $98,7 \mathrm{mg} / \mathrm{kg}$ and 1,4 to $71,8 \mathrm{mg} / \mathrm{kg}$ (Appendix 2). The content of hydroxylammonium chloride-reducible manganese in the soil can vary from 0 to $805 \mathrm{mg} / \mathrm{kg}$ (RANDALL et al. 1976, ROORDA van EYSINGA et al. 1978). According to RANDALL et al. (1976), the mean content of hydroxylammonium chloride-reducible manganese of the soils containing large amounts of organic matter is smaller than that of soils containing small amounts of organic matter.

The dependence of the content of hydroxylammonium chloride-reducible manganese in the soil on different soil properties was studied using the following variables:

$\mathrm{X}_{1}$ content of hydroxylammonium chloride-reducible manganese, $\mathrm{mg} / \mathrm{kg}$ air-dry soil

$\mathrm{X}_{2}$ soil $\mathrm{pH}$

$\mathrm{X}_{3}$ organic carbon content, \% of air-dry soil

$\mathrm{X}_{4}$ "total" manganese content, $\mathrm{mg} / \mathrm{kg}$ air-dry soil (= total manganese - hydroxylammonium chloride-reducible manganese)

Either the "total" manganese content of the soil alone, or together with $\mathrm{pH}$, explained, to a statistically significant degree $(P=0,001)$, the variation in the content of hydroxylammonium chloride-reducible manganese in the mineral soil samples as follows:

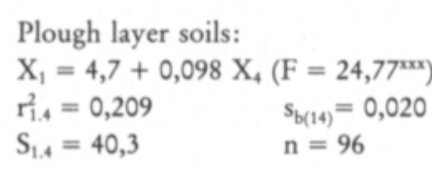

Deeper layer soils:

$\mathrm{X}_{1}=104,8+21,3 \mathrm{X}_{2}+0,085 \mathrm{X}_{4}\left(\mathrm{~F}=46,05^{\mathrm{xx}}\right)$

$R_{1.24}^{2}=0,336 \quad s_{b(12.4)}=5,6$

$\mathrm{S}_{1.24}=33,1 \quad \mathrm{~s}_{\mathrm{b}(14.2)}=0,018$

$\mathrm{n}=94$

All mineral soil samples:

$\mathrm{X}_{1}=78,2+16,4 \mathrm{X}_{2}+0,090 \mathrm{X}_{4}\left(\mathrm{~F}=70,43^{\mathrm{xx}}\right)$

$\mathrm{R}_{1.24}^{2}=0,274 \quad \mathrm{~s}_{\mathrm{b}(12.4)}=4,5$

$\mathrm{S}_{1.24}=36,9 \quad \mathrm{~s}_{\mathrm{b}(14.2)}=0,013$

$\mathrm{n}=190$

In the case of the organogenic soil samples, none of the independent variables studied explained, to a statitically significant degree $(P=0,05)$, the variation in the content of hydroxylammonium chloride-reducible manganese (Table 15).

"Total" manganese content and $\mathrm{pH}$ explained $27,4 \%$ of the variation in the content of hydroxylammonium chloride-reducible manganese of the whole mineral soil material. These two variables explained $33,6 \%$ of the corresponding variation in 
Table 15. Coefficients of partial $\left(\mathrm{r}_{1 \mathrm{x} .}\right)$ correlation between content of hydroxylammonium chloridereducible manganese $(\mathrm{mg} / \mathrm{kg})$ of the soil and other soil variables, and the beta coefficients $(\beta)$ between the variables.

\begin{tabular}{|c|c|c|c|c|c|c|c|}
\hline & \multirow[b]{2}{*}{$\mathrm{n}$} & \multicolumn{2}{|c|}{$\mathrm{pH}\left(\mathrm{CaCl}_{2}\right)$} & \multicolumn{2}{|c|}{ Organic C, \% } & \multicolumn{2}{|c|}{ Res. tot. $\mathrm{Mn}, \mathrm{mg} / \mathrm{kg}$} \\
\hline & & $r_{12 \ldots}$ & $\beta$ & $r_{13 \ldots}$ & $\beta$ & $\mathbf{r}_{14 \ldots}$ & $\beta$ \\
\hline \multicolumn{8}{|l|}{ Mineral soils } \\
\hline - plough layer & 96 & $0,136^{\mathrm{ns}}$ & - & $-0,076^{\mathrm{ns}}$ & - & $0,457^{x \times x}$ & 0,457 \\
\hline - deeper layer & 94 & $0,370^{\operatorname{xx}}$ & 0,330 & $0,058^{\mathrm{ns}}$ & - & $0,451^{\operatorname{xxx}}$ & 0,419 \\
\hline - total & 190 & $0,259^{x x}$ & 0,232 & $0,007^{n s}$ & - & $0,440^{\operatorname{mxx}}$ & 0,425 \\
\hline \multicolumn{8}{|c|}{ Organogenic soils } \\
\hline - total & 17 & $0,507^{n s}$ & - & $0,342^{\mathrm{ns}}$ & - & $0,239^{\mathrm{ns}}$ & - \\
\hline
\end{tabular}

the deeper layer samples. The "total" manganese content was the only statistically significant $(P=0,05)$ independent variable as far as the plough layer samples were concerned, and explained $20,9 \%$ of the variation in the content of hydroxylammonium chloride-reducible manganese. This variable explained $20,3 \%$ of the variation in the deeper layer samples and $19,4 \%$ of the variation in all the mineral soil samples when the effect of $\mathrm{pH}$ was kept constant (Table 15). The $\mathrm{pH}$ of the soil explained $13,7 \%$ of the variation in the deeper layer samples and $6,7 \%$ in all the mineral soil samples when the variation in the "total" manganese content was kept constant. The "total" manganese content was a relatively more important independent variable than the soil $\mathrm{pH}$ (Table 15).

The content of hydroxylammonium chloride-reducible manganese in the different soil groups was almost twice the content of hydroquinone-reducible manganese (Table 9). The difference between the mean contents in the plough layer of the mineral soil samples was significant $\left(t=2,52^{x}\right)$. According to DION et al. (1947) however, these two reducing agents are almost as effective in extracting reducible manganese. The content of hydroxylammonium chloride-reducible manganese increases along with an increase in the $\mathrm{pH}$ of the soil (RANDALL et al. 1976, ROORDA van EYSINGA et al. 1978, VORM and DIEST 1979). According to VORM and DIEST (1979), the content of reducible manganese increases as the $\mathrm{pH}$ increases because the reducible manganese fraction is leached away in acid soils. The organic matter content is not an important variable explaining the variation in the content of hydroxylammonium chloride-reducible manganese in the soil (RANDALL et al. 1976, ROORDA van EYSINGA et al. 1978).

\section{Ascorbic acid-reducible manganese $\mathrm{C}_{6} \mathrm{H}_{8} \mathrm{O}_{6}-\mathrm{Mn}$}

The content of ascorbic acid-reducible manganese varied in the plough layer of the mineral soil samples from 1,4 to $680,7 \mathrm{mg} / \mathrm{kg}$ and in the deeper layer samples from 0,1 to $647,0 \mathrm{mg} / \mathrm{kg}$. The corresponding values for the organogenic soil samples were from 2,2 to $112,7 \mathrm{mg} / \mathrm{kg}$ and from 4,2 to $68,3 \mathrm{mg} / \mathrm{kg}$ (Appendix 2). The mean content of ascorbic acid-reducible manganese of the mineral soil samples was higher 
than that of the organogenic soil samples (plough layer $t=4,56^{\mathrm{xxx}}$, deeper layer $\left.t=6,20^{x \times x}\right)$. The content of ascorbic acid-reducible manganese was, on the average, higher than the contents of hydroxylammonium chloride-reducible and hydroquinone-reducible manganese (Table 9). However, only the difference between the contents of hydroquinone-reducible and ascorbic acid-reducible manganese was statistically significant $\left(t=3,90^{x x x}\right)$.

The dependence of the variation in the content of ascorbic acid-reducible manganese in the soil on different soil properties was studied using the following variables:

$\mathrm{X}_{1}$ content of ascorbic acid-reducible manganese, $\mathrm{mg} / \mathrm{kg}$ air-dry soil

$\mathrm{X}_{2}$ soil $\mathrm{pH}$

$\mathrm{X}_{3}$ organic carbon content, \% of air dry soil

$\mathrm{X}_{4}$ "total" manganese content, $\mathrm{mg} / \mathrm{kg}$ air-dry soil (= total manganese - ascorbic acid-reducible manganese)

The "total" manganese content of the soil either alone, or together with $\mathrm{pH}$, explained, to a statistically significant degree $(P=0,001)$, the variation in the content of ascorbic acid-reducible manganese in the mineral soil samples as follows:

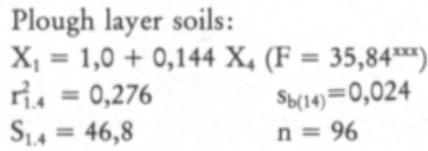

Deeper layer soils:

$\mathrm{X}_{1}=-103,4+20,3 \mathrm{X}_{2}+0,122 \mathrm{X}_{4}\left(\mathrm{~F}=43,23^{\mathrm{xx}}\right)$

$R_{1.24}^{2}=0,322 \quad s_{b(12.4)}=7,1$

$\mathrm{S}_{1.24}=41,7 \quad \mathrm{~s}_{\mathrm{b}(14.2)}=0,023$

$\mathrm{n}=94$

All mineral soil samples:

$\mathrm{X}_{1}=-80,0+15,9 \mathrm{X}_{2}+0,132 \mathrm{X}_{4}\left(\mathrm{~F}=84,42^{\mathrm{xxx}}\right)$

$\mathrm{R}_{1.24}^{2}=0,311 \quad s_{\mathrm{b}(12.4)}=5,3$

$\mathrm{S}_{1.24}=43,7 \quad s_{\mathrm{b}(14.2)}=0,017$

$\mathrm{n}=190$

The $\mathrm{pH}$ of the organogenic soil samples was a statistically significant $(\mathrm{P}=0,05)$ explainer of the variation in the content of ascorbic acid-reducible manganese when the other independent variables were kept constant (Table 16). This variable explained $28,2 \%$ of the variation. As the other variables were not statistically significant, they were removed from the equation. However, when this was done the $\mathrm{pH}$ was no longer a significant independent variable as it explained only $21,3 \%$ of the variation (Table 16).

The $\mathrm{pH}$ and the "total" manganese content explained $31,1 \%$ of the variation in the content of ascorbic acid-reducible manganese of the mineral soil samples. The corresponding value for the deeper layer samples was $32,2 \%$. The "total" manganese content was the only statistically significant $(P=0,05)$ independent variable in the case of the plough layer samples and explained $27,6 \%$ of the variation in the content of ascorbic acid-reducible manganese. When the effect of $\mathrm{pH}$ was kept constant, it explained $23,3 \%$ of the variation in the deeper layer samples and $25,1 \%$ in all the 
Table 16. Coefficients of partial $\left(r_{1 \times .}\right)$ correlation between content of ascorbic acid-reducible manganese $(\mathrm{mg} / \mathrm{kg})$ of the soil and other soil variables, and the beta coefficients $(\beta)$ between the variables.

\begin{tabular}{|c|c|c|c|c|c|c|c|}
\hline & \multirow[b]{2}{*}{$\mathrm{n}$} & \multicolumn{2}{|c|}{$\mathrm{pH}\left(\mathrm{CaCl}_{2}\right)$} & \multicolumn{2}{|c|}{ Organic C, \% } & \multicolumn{2}{|c|}{ Res.tot. $\mathrm{Mn}, \mathrm{mg} / \mathrm{kg}$} \\
\hline & & $r_{12 \ldots}$ & $\beta$ & $r_{13 \ldots}$ & $\beta$ & $r_{14 \ldots}$ & $\beta$ \\
\hline \multicolumn{8}{|l|}{ Mineral soils } \\
\hline - plough layer & 96 & $0,112^{\text {ns }}$ & - & $-0,076^{\mathrm{ns}}$ & - & $0,525^{x x}$ & 0,525 \\
\hline - deeper layer & 94 & $0,289^{\mathrm{gx}}$ & 0,253 & $-0,009^{\text {ns }}$ & - & $0,483^{\mathrm{mx}}$ & 0,463 \\
\hline- total & 190 & $0,214^{x x}$ & 0,184 & $-0,007^{\mathrm{ns}}$ & - & $0,501^{x x x}$ & 0,486 \\
\hline \multicolumn{8}{|c|}{ Organogenic soils } \\
\hline - total & 17 & $0,461^{\mathrm{ns}}$ & - & $0,325^{\mathrm{ns}}$ & - & $0,180^{\mathrm{ms}}$ & - \\
\hline
\end{tabular}

mineral soil samples (Table 16). When the effect of the "total" manganese content was kept constant, the $\mathrm{pH}$ explained $8,4 \%$ of the variation in the deeper layer samples and 4,6 \% in all the mineral soil samples. The "total" manganese content was a considerably more important independent variable than $\mathrm{pH}$ (Table 16).

The "total" manganese content of the soil explained the variation in the content of reducible manganese the better, the more effective the reducing agent in question. This could be interpreted to mean that as the effectiveness of the reducing agent increases, then the content of reducible manganese will approach the total manganese content. In this study, the hydroquinone treatment reduced, on the average, 5,9\% of the total manganese in the plough layer of the mineral soil samples, the hydroxylammonium chloride treatment $10,8 \%$ and the ascorbic acid treatment 13,5 \% (Table 9).

\section{Availability of manganese}

In the soil manganese is present in the soil solution, in an exchangeable form, in organic complexes, as oxides and oxyhydroxides and as primary minerals. Part of the soil manganese is easily extractable, part in an active form (the sum of exchangeable and reducible manganese), and the rest in a form which is not easily extractable. Available manganese can be in a form that the plants can use as such, or it first has to be converted into a utilizable form. A considerable proportion of the soil manganese appears to be unavailable for plants. Although an absolute deficiency of manganese is rare, plant stands have frequently been shown to be suffering from a deficiency of manganese (e.g. SCHACHTSCHABEL 1957, SEMB and ØIEN 1970, SCHÜTZ 1978).

The availability of soil manganese can be altered. The factors most frequently mentioned as having an effect on availability include moisture, redox potential, organic matter content and $\mathrm{pH}$ of the soil. Availability can be measured, for instance, by determining the content of manganese extracted by different extraction methods. However, the actual utilizer of manganese - the plant stand - is the only true depictor of availability. In point of fact, information which is obtained in this manner about the availability of manganese already present in the soil or added to the soil comes to light at too late a stage from the point of view of the yield. Means therefore have to be found which can be used to predict, in advancê, the availibility of the soil manganese and the fate of that added to the soil. 


\section{A. Factors affecting the availability of manganese}

The effects of soil moisture, the plant stand, the redox potential, the organic matter content and liming on the extractability of soil manganese were studied. Also the dependence of the manganese content and manganese uptake of the yield on different soil properties were investigated. The effect of liming on the content of extractable manganese in the soil and on the manganese in the yield is examined in the section dealing with the availability of added manganese.

\section{Effect of soil moisture and the plant stand}

The aerobic status of the soil decreases as the moisture increases. As a result of this, the redox potential of the soil decreases and the content of extractable manganese can change. According to JACKSON and SHERMAN (1953), the oxidation and reduction of manganese varies according to the time of year. During wet periods the manganese is reduced and during dry ones it is oxidized. In actual fact the moisture of the soil obviously has to exceed field capacity before the moisture can bring about the conversion of soil manganese into an exchangeable form (HARTER and McLEAN 1965). Such changes are also affected by temperature if the moisture of the soil is sufficiently high (CHENG et al. 1971). On the other hand, the oxidation or reduction of manganese is always associated with the reduction or oxidation of another element. The transfer of electrons from one element to another always means that two or more elements are involved in the process. The reducing agent may usually be organic matter since the addition of organic matter brings about an increase in the content of exchangeable manganese (CHRISTENSEN et al. 1950, MISRA and DWIVEDI 1979, PAL et al. 1979, ASGHAR and KANEHIRO 1980). The plant stand has a similar effect since it produces easily oxidizing organic matter and thus alters the content of extractable manganese (GODO and REISENAUER 1981).

The effects of soil moisture and the plant stand on the content of exchangeable and reducible manganese of the soil were studied by means of pot experiments. The variables used in the experiments were incubation and plant stand at different soil moisture conditions as follows:

Moisture
Saturated with water
pF 1,0
pF 2,0
pF $2,7-3,0$

Incubation and plant stand

Incubation -

Incubation and oats

Incubation and oats

Incubation and oats

In the experiments the moisture conditions - saturated with water and $\mathrm{pF} 1$ were selected on the basis of the results of HARTER and McLEAN (1965), since they claim that the moisture condition of the soil should be above field capacity if it is to bring about changes in the content of extractable manganese. The moisture values $\mathrm{pF}$ 2,0 and $\mathrm{pF} 2,7-3,0$ were considered to represent aerobic conditions and also the type of moisture conditions prevailing in the soil.

The first experiment was set up with three replicates (apart from incubation saturated with water) on fine sand soil (18a, Appendix 1). One liter polythene pots, 
each containing $1400 \mathrm{~g}$ air-dry soil, were used in the experiment. All the pots were fertilized at the beginning of the experiment as follows:

$\begin{array}{crl}\text { Nutrient } & \text { mg/kg soil } & \text { Compound } \\ \text { N } & 300 & \mathrm{Ca}\left(\mathrm{NO}_{3}\right)_{2} \cdot 4 \mathrm{H}_{2} \mathrm{O} \\ \mathrm{P} & 85 & \mathrm{Ca}\left(\mathrm{H}_{2} \mathrm{PO}_{4}\right)_{2} \cdot \mathrm{H}_{2} \mathrm{O} \\ \mathrm{K} & 160 & \mathrm{KCl} \\ \mathrm{Mg} & 50 & \mathrm{MgCl} \cdot 6 \mathrm{H}_{2} \mathrm{O} \\ \mathrm{Ca} & 340 & \mathrm{Ca}\left(\mathrm{NO}_{3}\right)_{2} \cdot 4 \mathrm{H}_{2} \mathrm{O}, \mathrm{Ca}\left(\mathrm{H}_{2} \mathrm{PO}_{4}\right)_{2} \cdot \mathrm{H}_{2} \mathrm{O} \\ \mathrm{S} & 50 & \mathrm{Na}_{2} \mathrm{SO}_{4}, \mathrm{FeSO}_{4} \cdot 7 \mathrm{H}_{2} \mathrm{O} \\ \mathrm{Fe} & 2 & \mathrm{FeSO}_{4} \cdot 7 \mathrm{H}_{2} \mathrm{O} \\ \mathrm{Cu} & 2 & \mathrm{CuCl} \cdot 2 \mathrm{H}_{2} \mathrm{O} \\ \mathrm{Zn} & 0,7 & \mathrm{Zn}_{2}-\mathrm{EDTA}^{2} \\ \text { B } & 0,5 & \mathrm{H}_{3} \mathrm{BO}_{3} \\ \text { Mo } & 0,3 & \mathrm{Na}_{2} \mathrm{MoO}_{4} \cdot 2 \mathrm{H}_{2} \mathrm{O}\end{array}$

In each pot 33 oats seeds (Hordeum vulgare L.) were sown. A 0,5 cm thick layer of quartz sand, which had been washed with $3 \mathrm{M} \mathrm{HCl}$ and rinsed with deionized water, was spread over the surface of the soil in the pots to prevent crusting of the soil surface during watering. The nutrients were added as an aqueous solution after the seeds had been sown. The experiment was terminated when the oats had reached the boot stage.

After the first experiment the effects of soil moisture and plant stand on the content of extractable manganese were studied in the second experiment using soil samples 1a, 3a, 6a and 15a (Appendix 1). $150 \mathrm{~g}$ air-dry soil was weighed out into 0,51 polythene pots. In each pot 11 oats seeds per pot were sown and the experiment was carried out with four replicates. Fertilization and harvesting were the same as for the first experiment.

Maintenance of constant soil moisture. The maintenance of constant moisture condition in pot experiments is usually brought about by weighing the pots at intervals and then adding water equivalent to the amount which has been lost (BIGSBY 1963, KROGMAN 1963, STEVENSON and MUNN 1970, DYCK 1977, McLAUGHLIN 1977). Using this method, however, it is not possible to take into account the changes caused by the increase in the mass of the plants, nor the changes which take place in the water-holding properties of the soil during the course of the experiment. As soil moisture was one of the treatments in the experiment, it had to be kept as constant as possible. The use of a sintered glass funnel regulating soil moisture, as proposed by MOSS (1964), was initially tested. However, the evapotranspiration was so great that air bubbles were formed under the funnel soon after the start of the experiment and the water contact was broken. The air bubbles could not be removed during the course of the experiment. On the basis of preliminary experiments a set-up in which a tensiometer was inserted in the experimental pot was found to be most practiable. The tensiometer was constructed from a sintered glass (pore size 3-16 $\mu \mathrm{m}$ ) plate, cut to $40 \times 10 \times 6 \mathrm{~mm}$ in size, a $70 \mathrm{~cm}$ long plastic tube ( $\varnothing 2 \mathrm{~mm}$ ) being fastened to one end. The tensiometer and plastic tube were filled with water and connected to a mercury valve constructed from T- and L-shaped polythene connectors. The tensiometer mediated tension into the mercury valve. An increase in tension caused the valve to open, with the result that water flowed into the experimental pot. When the tension caused by the evapotranspiration and 
conducted by the tensiometer started to decrease, the valve closed (Fig. 4). The moisture values $(\mathrm{pF} 1$ and $\mathrm{pF} 2)$ required in the pots were obtained by regulating the difference between the mercury levels in the U-shaped tube.

The tensiometers were placed vertically in the center of the pots, below the watering point, at a depth of about $0,5 \mathrm{~cm}$ below the surface of the soil. As the end of the watering tube consisted of a capillary tube and the free surface of the water in the water reservoir was at a height of only $2 \mathrm{~cm}$ above the end of the watering tube, water was added at a rate of between 1 to 5 drops each time it operated. The action of the tensiometer and the watering device were investigated by weighing two experimental pots each day for ten successive days. The accuracy was considered to be good:

$\begin{array}{lcc} & \mathrm{n} & \text { Weight of pot } \mathrm{g} \\ \text { pot } 1 & 10 & 622,6 \pm 0,4 \\ \text { pot } 2 & 10 & 453,7 \pm 0,5\end{array}$

However, the weakness of the device became apparent when it was used for longterm experiments. The functioning of the tensiometers was retarded as the experiment proceeded. The fine soil particles gradually blocked the pores of the tensiometers with the result that the pots became over-watered. The tensiometers were cleaned by removing the blocked layer of the tensiometer surface with fine sandpaper.

The tensiometers were made from a sintered glass plate with a pore size of 3-16 $\mu \mathrm{m}$. According to CZERATZKI (1958), moisture condition equivalent to $\mathrm{pF} 2,27$ cannot be exceeded with this pore size. It was therefore decided that the watering of the pots with the driest moisture regime $(\mathrm{pF} 2,7-3,0)$ would be regulated by weighing the pots. The pots were given sufficient water to give a $\mathrm{pF}$ value of 2,7 and then allowed to dry out to $\mathrm{pF} 3,0$ before being rewatered. However, in the final stage of the experiment when transpiration was high, on some days the soil in the pots became drier than $\mathrm{pF} 3,0$ before being rewatered.

The content of extractable manganese was determined on moist soil samples immediately after the termination of the experiments. In the incubated soils, the content of exchangeable manganese of the soil samples saturated with water was



Fig 4. Schematic diagramme of the watering apparatus. 
significantly $(P=0,05)$ higher than in the other incubated soil samples which had a different moisture condition (Table 17). However, not even this treatment brought about an increase in the content of exchangeable manganese of soil sample No. 15a (silt). A moisture of $\mathrm{pF} 1$ brought about a slight increase in the content of exchangeable manganese in the soil sample No. 18a (fine sand) in comparison to drier soil samples. An increase in the moisture resulted in a decrease in the reducible manganese fraction in incubated soils saturated with water (Table 17). The increase in the content of exchangeable manganese obviously took place at the expense of the reducible fractions.

In the experiments in which oats were grown there was a statistically significant $(P=0,05)$ increase in the content of exchangeable manganese in four out of five soil samples when the moisture of the soil was raised to $\mathrm{pF} 1$ (Table 17). When the $\mathrm{pF}$ value was 2 or between 2,7 to 3,0 the contents of exchangeable manganese in the soil were, apart from the finer fine sand samples (1a), not dependent on the moisture. When the moisture was $\mathrm{pF} 1$ there was a decrease in the content of reducible manganese as the content of exchangeable manganese increased in three soil samples (Table 17).

In the incubation experiments, saturating the soil with water did not even increase the content of extractable manganese in all soil samples. The moisture condition did not have any effect on the content of extractable manganese when the moisture was near to field capacity or drier. According to SHUMAN (1980), the moisture of the soil does not affect the content of exchangeable manganese of fine sand. In addition, according to CHRISTENSEN et al. (1950), HARTER and McLEAN (1965) and SHUMAN (1980), the moisture of the soil does not affect the content of extractable manganese if the moisture is below field capacity. On the other hand, saturating the soil with water increases the content of exchangeable manganese (HARTER and McLEAN 1965, GRASMANIS and LEEPER 1966, TURNER and PATRICK 1968, SHUMAN 1980).

In the oats experiments, the content of exchangeable manganese in the soil increased, to a statistically significant degree $(P=0,05)$, in four soils out of five when the moisture of the soil was increased from $\mathrm{pF} 2$ to $\mathrm{pF} 1$ (Table 17). It was considered that the plant stand promoted manganese reduction in the oats experiments as compared with incubation experiments (Table 17). It may be that there was not enough easily oxidizing organic matter in the incubated soils because increasing the moisture did not unambiguously increase the content of exchangeable manganese. On the other hand, the organic compounds produced by the roots in the oats experiments may have been easily oxidizing and the manganese therefore been reduced. According to HARTER and McLEAN (1965), the reduction of manganese is purely a chemical reaction. According to CHRISTENSEN et al. (1950), the moisture of the soil indirectly affects the content of extractable manganese by regulating the rate of decomposition of the organic matter. Substances excreted by the roots increase the solubility of manganese by reducing manganese oxides and complexing the divalent manganese released (GODO and REISENAUER 1980).

Determination of soil redox potential. Changes in soil redox conditions were studied in the pot experiment of soil sample No. 18a. For measuring of soil redox potential an inert electrode was made from platinum wire for each of the pots. Pieces of platinum wire, $4 \mathrm{~mm}$ long and about $1,5 \mathrm{~mm}$ thick, were fixed onto the end of 


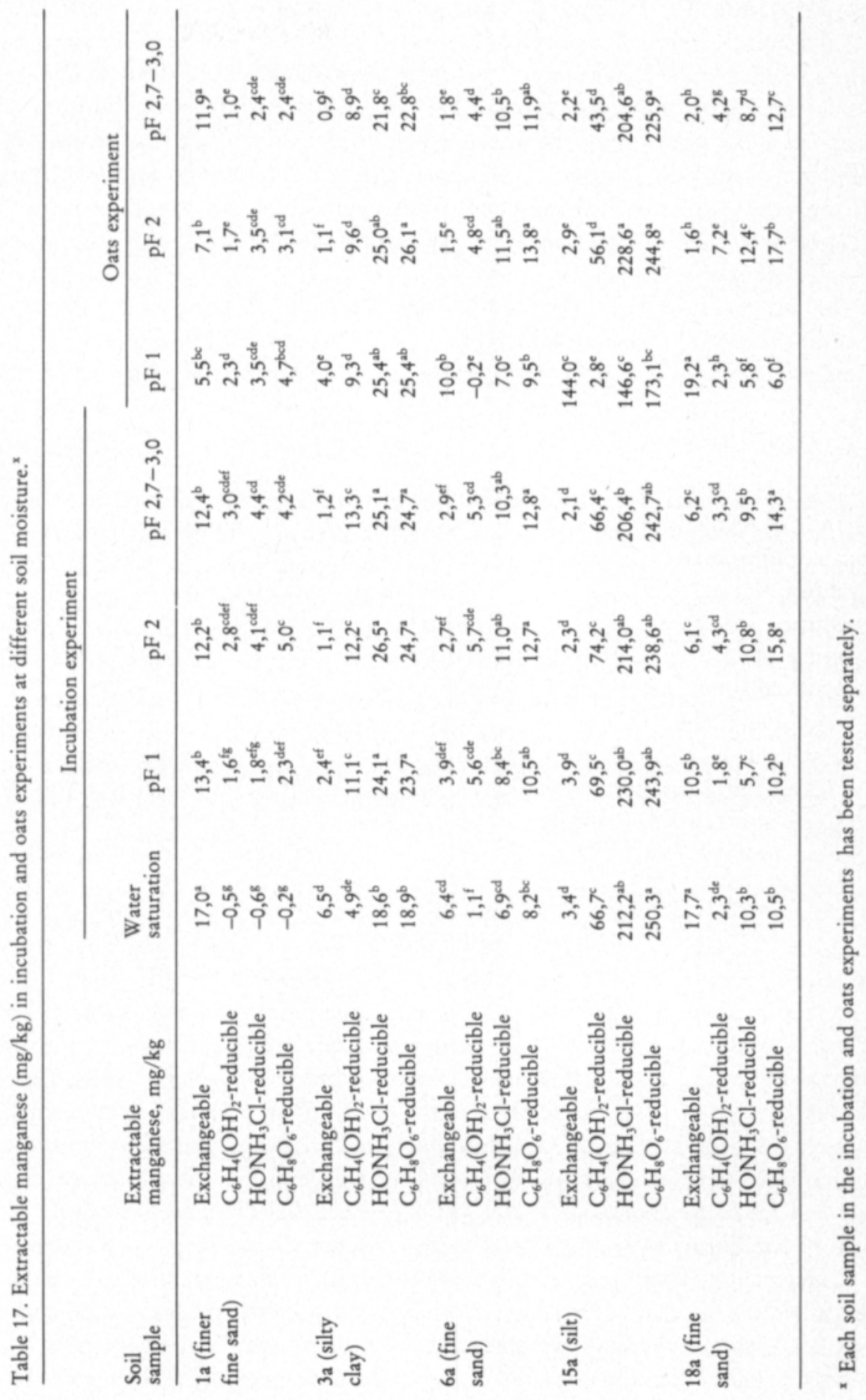


copper wires. The electrodes were protected by glass tubes according to the direction of WARTIOVAARA (1943). According to JACOB (1970), the size of the electrode does not affect the results. The electrodes were cleaned with dilute nitric acid (1:3) and rinsed with deionized water. The electrodes were tested using the ferro-ferric cyanide buffer of ZoBELL (1946). The largest variation between the electrodes was $2 \mathrm{mV}$. The electrodes were placed in the center of the pots, about $2 \mathrm{~cm}$ from the bottom, at the same time as the pot experiment was being set up. A calomel electrode, consisting of calomel in a saturated solution of $\mathrm{KCl}$, was used as the reference electrode. Soil $\mathrm{pH}$ and the redox potential measurements were carried out at the same time. The measurements were carried out every day during the first week of the experiment, and then every second day.

The potential of the calomel reference electrode is temperature-dependent. According to GARRELS and CHRIST (1965, p. 127), the potential of a calomel electrode can be calculated with respect to a hydrogen electrode using the following formula:

$$
E_{h}=244,4-0,66\left(t-25^{\circ} \mathrm{C}\right)
$$

Using this formula, the potential of the electrode can be corrected to a level corresponding to a temperature of $25^{\circ} \mathrm{C}$ and the reading converted into millivolts. The value of the redox potential of the soil is also dependent on the $\mathrm{pH}$ if, in addition to electrons, protons also take part in the reaction. According to PATRICK (1960), the effect of changes in $\mathrm{pH}$ may vary from $-60 \mathrm{mV}$ to $-232 \mathrm{mV}$ per $\mathrm{pH}$ unit. Despite this, a value of $-59 \mathrm{mV}$ at a temperature of $25^{\circ} \mathrm{C}$ is usually used for $\mathrm{dE} / \mathrm{dpH}$ (PONNAMPERUMA 1972), and it has been found to correspond rather well to changes in potential taking place in the soil per $\mathrm{pH}$ unit (JACKSON 1956). In this study the potential values were calculated with respect to a hydrogen electrode and corrected to correspond to values at $\mathrm{pH} 7$ and a temperature of $25^{\circ} \mathrm{C}$ using the following formula:

$$
\mathrm{E}_{7}=\underset{\text { result }}{\mathrm{EMF}_{\text {measured }}}+244,4-0,66\left(\mathrm{t}-25^{\circ} \mathrm{C}\right)-59(\mathrm{pH}-7)
$$

The redox potential of the soil was obtained in millivolts.

In the incubation experiment, the redox potential of the soils saturated with water fell rapidly to about $0,6 \mathrm{~V}$. The potential in one pot then fell during the period of one week to 0,3 V, where it remained almost unchanged for three weeks. This was followed by a gradual decline right up to the end of the experiment. The potential in the other pot decreased rather regularly throughout the course of the experiment. In the incubated samples saturated with water, the potential at the end of the experiment had fallen to about $0,2 \mathrm{~V}$ (Fig. 5). The potential of one of the soils where moisture conditions were maintained at $\mathrm{pF} 1$ did not change very much throughout the course of the experiment, and in two other pots it fell to about the 0,4 to $0,3 \mathrm{~V}$ level. When the moisture of the soil was $\mathrm{pF} 2$, there was a sharp fall in the potential to about $0,3 \mathrm{~V}$ during the first two weeks of the experiment in one of the pots. There was only a slight fall in the potential in one of the pots when the moisture was below field capacity (Fig. 5).

When the moisture in the oats experiment was $\mathrm{pF} 1$, the potential fell sharply, to some extent stepwise, throughout the course of the experiment. There was a slight 

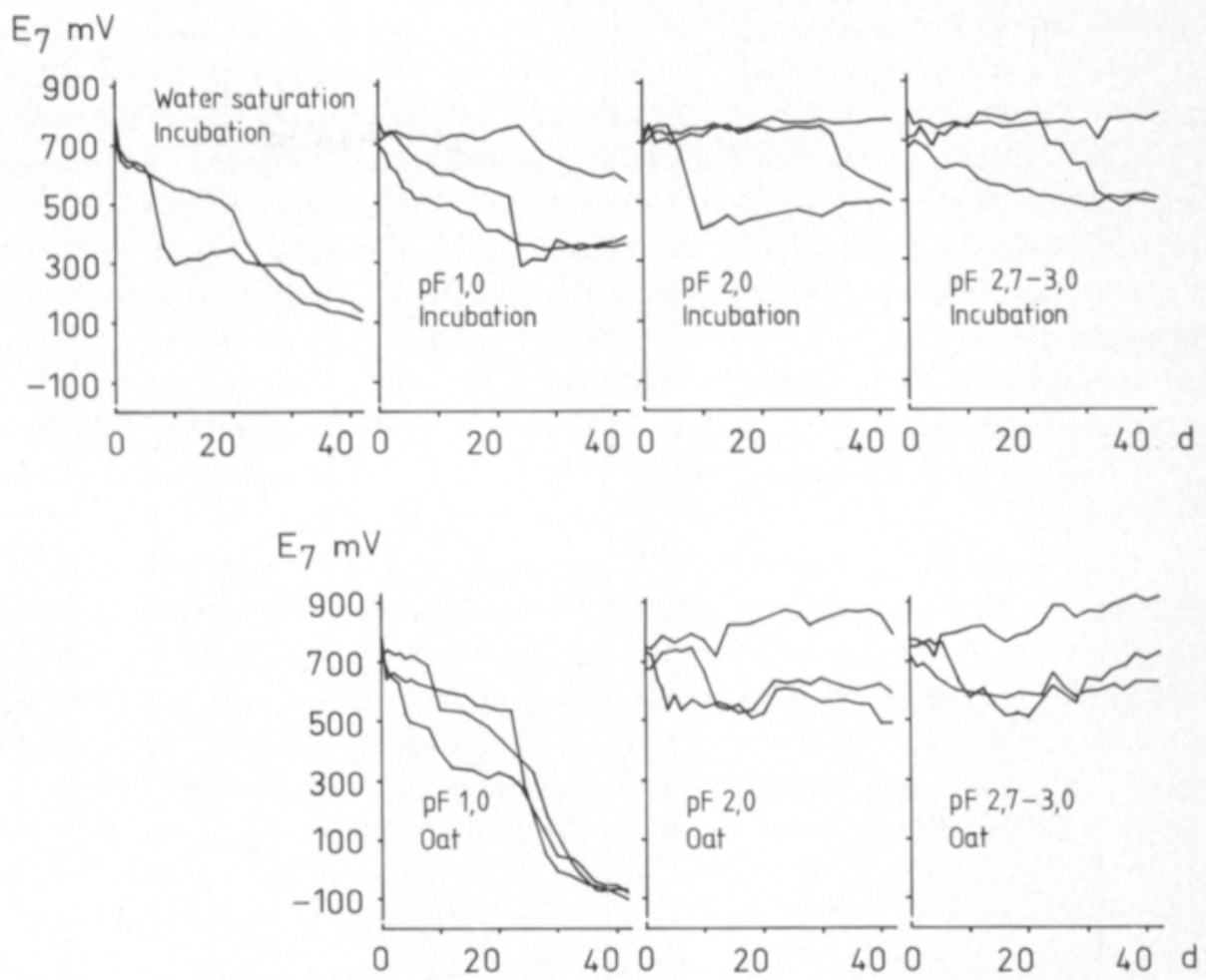

Fig. 5. Soil redox potential in the incubation and oats experiments at different soil moisture (replicates plotted).

levelling-off in the potential to about $-0,1 \mathrm{~V}$ in the final stage of the experiment (Fig. 5 ). When the moisture of the soil was pF 2, the potential in two of the pots fell slightly at the beginning of the experiment. Similar changes occurred in the pots where the moisture was below field capacity. There was a slight increase in the potential in the other pots during the course of the experiment (Fig. 5).

Mean values of the redox potentials in the replicates were not calculated because the differences between the replicates were large. The results were considered to describe, as such, the heterogenity of the soil with regard to the redox potential. According to PONNAMPERUMA and CASTRO (1964), the redox potential of the soil describes the local potential which develops as a result of microbial activity. It is thus only representative of a smallish area around the measuring point. The redox potentials were characterised by sharp local drops which were then followed by a levelling off. The potential remains stable while the reduction of certain compounds is taking place. As long as the compound is present the potential is maintained at a stable level. When the compound has been completely reduced, the potential rapidly falls to a new level where the reduction of another compound, which stabilizes the potential, starts. A relatively stable stage was observed at a potential of $0,6 \mathrm{~V}$ in the incubated pot saturated with water and in the oats experiment when the moisture was $\mathrm{pF} 1$ (Fig. 5). This may be caused by the reduction of oxygen because the conditions above the $0,6 \mathrm{~V}$ porential appear to be still very oxidizing (PONNAMPERUMA and CASTRO 1964). Oxygen starts to be reduced at a potential of about $0,6 \mathrm{~V}$ and it stabilizes the potential between 0,6 and 0,5 V (TAKAI and KAMURA 1966). The 
presence of oxygen can no longer be demonstrated if the potential has fallen to $0,3 \mathrm{~V}$ (TURNER and PATRICK 1968). The reduction of nitrate appears to stabilize the potential at about 0,4 to $0,3 \mathrm{~V}$ (PONNAMPERUMA and CASTRO 1964), although the reduction of manganese compounds also starts at this potential (PATRICK and HENDERSON 1981 a). According to TAKAI and KAMURA (1966), manganates are reduced when the potential is between 0,6 and $0,4 \mathrm{~V}$ and, according to TURNER and PATRICK (1968), not until the potential falls to between 0,2 to $0,1 \mathrm{~V}$. The reduction of manganese in manganese compounds starts when $\mathrm{E}_{7}$ is 0,3 to $0,2 \mathrm{~V}$ (PATRICK and HENDERSON 1981 b). When the moisture in the oats experiment was $\mathrm{pF} \mathrm{1,} \mathrm{the}$ potential in the final stage of the experiment appeared to be stabilized by the reduction of iron compounds at about 0,1 V (PATRICK 1964, PATRICK and HENDERSON 1981 b).

The content of exchangeable manganese of the soil in the incubated soils and in the oats experiment were determined after the experiments had been terminated. The content of exchangeable manganese was calculated per unit weight of the total content of manganese in the soil and then compared to the corresponding redox potential value. The results were divided into two groups after they had been examined graphically: contents of exchangeable manganese dependent on or independent of the redox potential (Fig. 6). When the potential was above 0,59 $\mathrm{V}$ the content of exchangeable manganese was $4,8 \pm 0,8 \mathrm{mg} / \mathrm{kg}$ soil manganese. When the potential fell below $0,57 \mathrm{~V}$, the content of exchangeable manganese increased the more, the lower was the redox potential (Fig. 6).

The increase in the content of exchangeable manganese in the soil started rather close to the $0,5-0,4 \mathrm{~V}$ potential, at which point most of the manganese compounds are considered to have strated to be reduced (TAKAI and KAMURA 1966, BRUMMMER 1974, SIMS and PATRICK 1978, PAL et al. 1979, PATRICK and HENDERSON 1981 a). In fact, according to TAKAI and KAMURA (1966), manganates may start to be reduced already at the 0,5 V potential. However, according to TURNER and PATRICK (1968), this does not happen until the potential is closer to $0,2 \mathrm{~V}$. The differences may due to the properties of the reducible compounds in question.

The reduction curves of a number of standard minerals have been drawn in

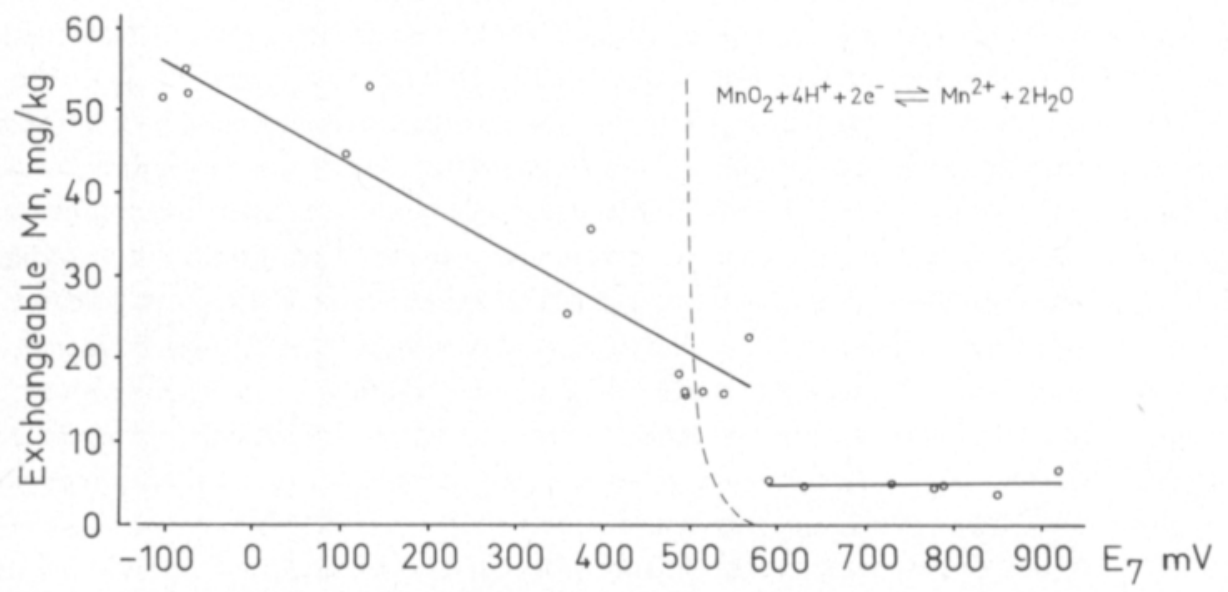

Fig. 6. Content of exchangeable manganese $(\mathrm{mg} / \mathrm{kg})$ of soil as a function of soil redox potential. 
Figure 6 as a function of the potential, based on the values presented by LATIMER (1952, p. 7) and PONNAMPERUMA et al. (1969). Reduction of manganese in the soil started within approximately the same potential region as for the standard minerals. However, the content of reduced manganese in the soil increased at a considerably slower rate than was to be expected on the basis of the theoretical model. Furthermore, according to BRÜMMER (1974), the content of exchangeable manganese in the soil increases more slowly than would be assumed on the basis of values derived from potential measurements.

The slow solubility of manganese compounds in water may be the reason why they are not reduced as fast as the redox potential would indicate (PONNAMPERUMA 1972). On the other hand, it is not clear whether the redox potential is at all the right parameter to depict variations in the content of exchangeable manganese. The soil redox potential may rather be the result of oxidation and reduction reactions taking place in the soil and hence, being a qualitative parameter, not very suitable for quantitative calculations. This is supported by the results of PATRICK and HENDERSON (1981 b), who found that changes in the redox potential alone do not bring about changes in the content of extractable manganese.

\section{Effect of organic matter and microbial activity}

The results of the incubation and oats experiments showed that a plant stand has a considerable effect on the content of extractable manganese in the soil. However, regulation of the soil moisture alone was not sufficient to bring about a change in the content of exchangeable manganese. The easily oxidizing compounds produced and excreted by the plants may act as electron donors and correspondingly, the manganese compounds as electron acceptors. Addition of organic matter to the soil results in the reduction of manganese (CHRISTENSEN et al. 1950, GROOT 1956, GHANEM et al. 1971, MISRA and DWIVEDI 1979, PAL et al. 1979, ASGHAR and KANEHIRO 1980). According to HARTER and McLEAN (1965), the reduction of manganese is solely a non-biological process, while PAL et al. (1979) consider it to be both a non-biological and biological process. PATRICK and HENDERSON (1981 b) demonstrated that the reduction of manganese in the soil is, by nature at least, non-biological. In any case root exudates increase the solubility of manganese oxides because the solubility of the oxides is greater in the rhizosphere than outside it (GODO and REISENAUER 1980).

The importance of organic matter as a factor affecting the content of extractable manganese in the soil and the role played by biological factors in the reduction of manganese were studied through incubation experiments. Two sandy clay soils ( $5 \mathrm{a}$ and 10a), one silt (17a) and two fine sand (7a and 13a) soils (Appendix 1) were used in the experiment. The soil samples were treated in three different ways in order to regulate the biological activity of the soil. The beat treatment $\left(60^{\circ} \mathrm{C}\right)$ was carried out by placing the soil samples in 1 liter beakers in a drying oven, the bulb of a thermometer being positioned in the centre of the samples. The oven temperature was raised to $60^{\circ} \mathrm{C}$ and the samples kept at this temperature for two hours, after the internal temperature of the samples had reached $60^{\circ} \mathrm{C}$. The samples were removed from the oven and allowed to cool to room temperature. The heat treatment was used to partially denature enzymes in the soil. Germicidal irradiation treatment was 
carried out using an AIRAM LU $30 \mathrm{~W}$ disinfection lamp, of which most of the radiation, 90-95\% of the total, is emitted at a wavelength of $253,7 \mathrm{~nm}$. The soil samples were spread in a layer about $1 \mathrm{~cm}$ thick on watchglasses $(\varnothing 35 \mathrm{~cm})$. The radiation source, which was fitted with a reflective cylindrical parabolic aluminium shield, was placed at a height of about $40 \mathrm{~cm}$ above the soil samples. The samples were mixed daily so as to expose as large a sample area as possible to the germicidal radiation during the 7 days treatment period. The aim of the radiation treatment was to inactivate the micro-organisms in the surface layer of the soil. Germicidal radiation given as low-energy electromagnetic radiation $(5 \mathrm{eV}, 253,7 \mathrm{~nm})$ affects only the exposed surface of the soil sample. Gamma irradiation treatment of the soil samples was carried out with ${ }^{60} \mathrm{Co}$ (cobalt source of the Dept. Radiochemistry, Univ. of Helsinki). The samples were exposed to $4 \mathrm{Mrad}\left(10^{4} \mathrm{~J} / \mathrm{kg}\right)$ of energy during a period of 2,5 days. The aim of the treatment was to inactivate the biological activity of the soil. However, even this dosage of energy is not enough to inactivate all the enzymes (ROBERGE and KNOWLES 1968, SKUJINS and McLAREN 1969). Glucose was used as the organic substrate, and was added to the soil samples at the rate of 0 or 5,0 $\mathrm{g} / 100 \mathrm{~g}$ air-dry soil. $100 \mathrm{~g}$ of soil was weighed out into $250 \mathrm{ml}$ beakers, glucose added, the samples mixed with a glass rod and deionized water added to give a moisture of $\mathrm{pF} 2$. The moisture of the soil samples was checked every second day by weighing the pots and the amount of water lost through evaporation was replaced. Soil sample No. 5a was incubated for two weeks, No. 7a for three weeks, No. 10a for four weeks, No. 13a for five weeks and No. 17a for six weeks. The content of extractable manganese of the moist soils was determined after the experiment had been terminated.

The content of extractable manganese in the soil may change as a result of measures which inactivate soil micro-organisms (MÄNTYLAHTI and YLÄRANTA 1981). The difference $\left(C_{1}-C_{0}\right)$ between the contents of extractable manganese with $\left(\mathrm{C}_{1}\right)$ and without $\left(\mathrm{C}_{0}\right)$ glucose addition had to be calculated when determining the effect of organic matter on the content of extractable manganese in the soil. The effect of the heat treatment resulted in an increase in the content of exchangeable manganese in the sandy clay soil sample (10a) compared to the untreated soil sample (Table 18). Germicidal irradiation increased the content of exchangeable manganese of two of the soil samples (7a and 10a) and decreased that of one sample (5a). Gamma irradiation reduced the content of exchangeable manganese of three of the soil samples (7a, 10a and 17a) in comparison to the untreated soil samples (Table 18). Addition of glucose increased the proportion of exchangeable manganese out of the total manganese content of the soil as the incubation period was lengthened. Almost $60 \%$ of the total manganese content of the soil sample incubated for the longest time (17a) had been transformed into an exchangeable form as a result of the addition of glucose.

The content of exchangeable manganese in the soil increased at the expense of the reducible manganese in the soil. In general, the content of hydroquinone-reducible manganese was low in soils with glucose addition. As the effectiveness of the reducing agent used increased, the change in the content of reducible manganese approached that of the content of exchangeable manganese (Table 18). The increase in the content of exchangeable manganese brought about by the addition of glucose took place mostly at the expense of the content of ascorbic acid-reducible manganese. 


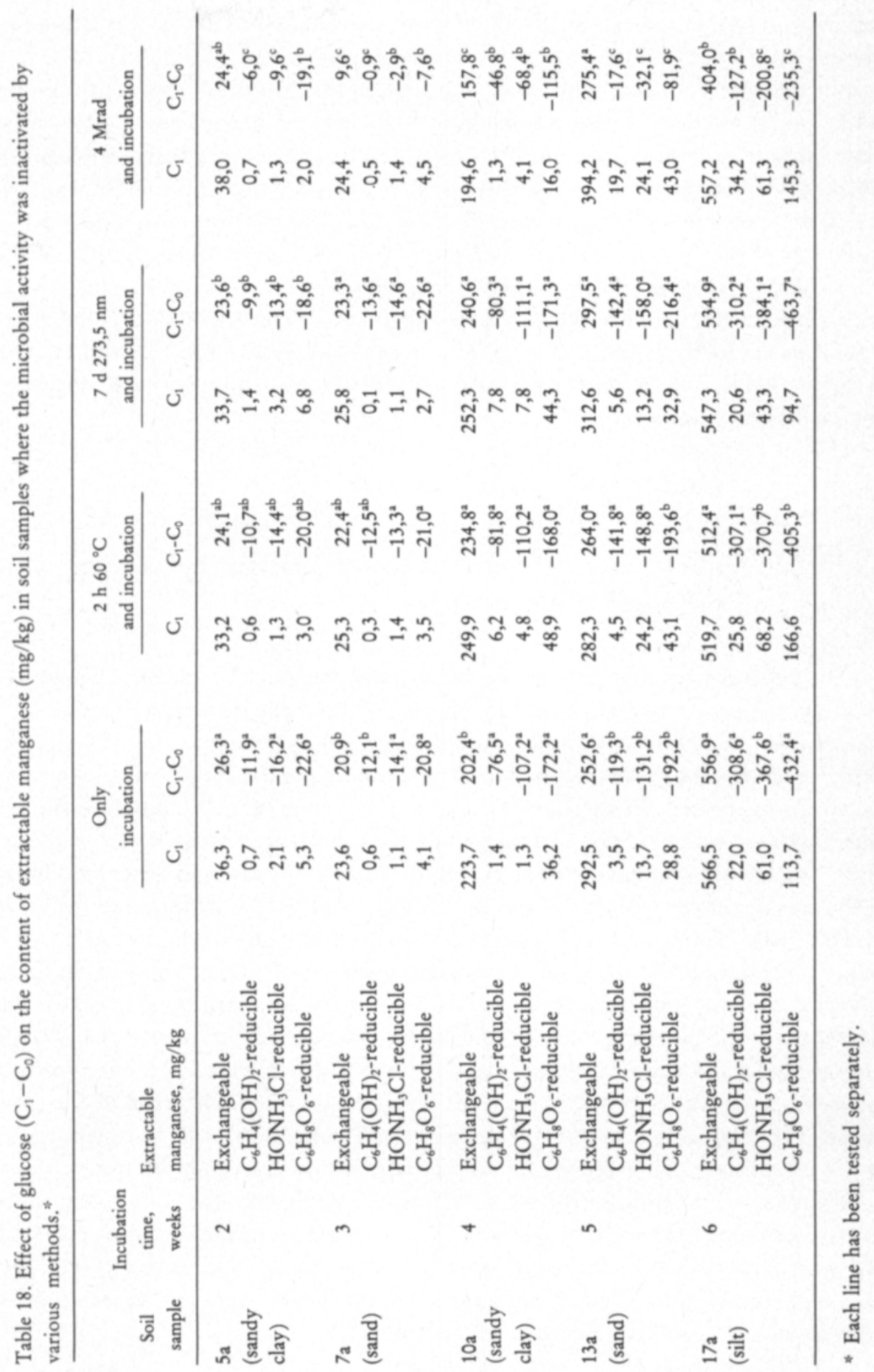


Glucose addition increased the content of exchangeable manganese in the soil. However, effective inactivation of the micro-organisms brought about a smaller increase in the content of exchangeable manganese than no inactivation. This observation would indicate that reduction of manganese in the soil was a biological process. However, the content of exchangeable manganese did increase also in the inactivated soil samples. This was interpreted as indicating that non-biological reduction of manganese had taken place. Reduction of manganese in the soil was thus, both a biological and non-biological process, the progression of which was dependent on the availability of easily oxidizing organic matter. Glucose was found to be an effective reducing agent. Results which show that the oxidation and reduction of manganese is either biological (LEEPER and SWABY 1940, BROMFIELD and SKERMAN 1950, INGOLS and ENGINUN 1968, MULDER and VEEN 1968, MEEK et al. 1973, BROMFIELD 1978, BROMFIELD and DAVID 1978, UREN and LEEPER 1978, WEBER et al. 1979, GOMAH et al. 1980) or non-biological (HARTER and MacLEAN 1965, PATRICK and HENDERSON 1981 b), do not thus disagree with the results obtained in this study.

\section{B. Dependence of manganese uptake and manganese content of the yield on different soil properties}

The dependence of the manganese uptake and manganese content of the yield on different soil properties was studied by means of a pot experiment. $100 \mathrm{ml}$ of air-dry surface soil (Appendix 1) was measured out into 0,3 1 polythene pots. $100 \mathrm{ml}$ quartz sand, which had been washed with $3 \mathrm{M} \mathrm{HCl}$ and rinsed with deoinized water, was mixed into the soils. In each pot 37 seeds of Italian ryegrass (Lolium multiflorum Lam.) were sown. Ryegrass was chosen as the test plant because it can be cropped several yields without having to be reseeded. Most of the manganese already present in the seeds appears to be removed in the first yield. After seeding, the seeds were covered with $100 \mathrm{ml}$ of quarz sand to prevent soil crusting during watering. It has earlier been shown that the soil moisture has no effect on the content of exchangeable manganese in the soil if the moisture is less than field capacity. Deionized water equivalent to $20 \%$ of the total volume of the soils was added to each pot. The pots were weighed and watered one to two times a day. After the ryegrass had sprouted, the number of seedlings was reduced to 35 and the pots transferred to the greenhouse. The temperature in the greenhouse varied from 18 to $29^{\circ} \mathrm{C}$ during the course of the experiment. The experiment was carried out with three replicates.

The soils were fertilized for the first time one week after the grass had sprouted, and for the second time two weeks later. The soils were fertilized again after the yield had been harvested and once more two weeks after cutting. The nutrients were given as an aqueous solution per unit volume of the soil. The amounts of nutrients and the form in which they were applied were as follows: 


$\begin{array}{ccl}\text { Nutrient } & \mathrm{mg} / 1 \text { soil yield } & \text { Compound } \\ \mathrm{N} & 300 & \mathrm{NH}_{4} \mathrm{NO}_{3}, \mathrm{Ca}\left(\mathrm{NO}_{3}\right)_{2} \cdot 4 \mathrm{H}_{2} \mathrm{O} \\ \mathrm{P} & 63 & \mathrm{~K}_{2} \mathrm{HPO}_{4} \\ \mathrm{~K} & 160 & \mathrm{~K}_{2} \mathrm{HPO}_{4} \\ \mathrm{Ca} & 46 & \mathrm{Ca}\left(\mathrm{NO}_{3}\right)_{2} \cdot 4 \mathrm{H}_{2} \mathrm{O} \\ \mathrm{Mg} & 50 & \mathrm{MgSO}_{4} \cdot 7 \mathrm{H}_{2} \mathrm{O} \\ \mathrm{S} & 68 & \mathrm{MgSO}_{4} \cdot 7 \mathrm{H}_{2} \mathrm{O}, \mathrm{CuSO}_{4} \cdot 5 \mathrm{H}_{2} \mathrm{O}, \mathrm{ZnSO}_{4} \cdot 7 \mathrm{H}_{2} \mathrm{O} \\ \mathrm{Cu} & 2 & \mathrm{CuSO}_{4} \cdot 5 \mathrm{H}_{2} \mathrm{O} \\ \mathrm{Zn} & 0,7 & \mathrm{ZnSO}_{4} \cdot 7 \mathrm{H}_{2} \mathrm{O} \\ \text { B } & 0,5 & \mathrm{H}_{3} \mathrm{BO}_{3} \\ \mathrm{Mo} & 0,3 & \mathrm{Na}_{2} \mathrm{MoO}_{4} \cdot 2 \mathrm{H}_{2} \mathrm{O}\end{array}$

Iron was applied only when the experiment was set up (Fe $2 \mathrm{mg} / \mathrm{l}$ soil) in order to prevent the plants from suffering from iron deficiency. Additional iron was not given because it acts as an antagonist of manganese (LÖHNIS 1951, GUPTA 1972). In fact, iron may also promote the uptake of manganese by the plants by reducing manganese oxides (BOKEN 1955, 1956, 1957).

Four yields were harvested from the pot experiment. The yield was dried at $75^{\circ} \mathrm{C}$ and then weighed. The iron and manganese contents of the plant material were determined. The roots of the ryegrass plants were carefully separated from the soil after the final yield had been cut, and then washed and dried. The manganese content of the roots was determined.

The material was divided into two groups on the basis of the organic carbon content of the soil. The group of the mineral soils $(<21 \%$ organic carbon) consisted of 89 soil samples, and the group of organogenic soils of 9 soil samples. The dry matter yields $\mathrm{g} / \mathrm{pot}$ were as follows:

\begin{tabular}{|c|c|c|c|c|c|c|c|c|c|}
\hline & & & & & & & & Yie & \\
\hline & $\mathrm{n}$ & $\overline{\mathbf{x}}$ & $s$ & $\overline{\mathbf{x}}$ & $s$ & $\overline{\mathbf{x}}$ & $s$ & $\overline{\mathbf{x}}$ & $s$ \\
\hline samol & 89 & 1,65 & 0,34 & 1,87 & 0,25 & 1,64 & 0,19 & 1,41 & 0,16 \\
\hline ganogenic soil samples & 9 & 1,63 & 0,36 & 1,53 & 0,18 & 1,38 & 0,26 & 1,19 & 0,27 \\
\hline
\end{tabular}

On the mineral soils the mean yield was $6,57 \mathrm{~g} / 100 \mathrm{ml}$ soil and on the organogenic soils $5,72 \mathrm{~g} / 100 \mathrm{ml}$ soil. When these yields are converted into yields per hectare, assuming that the amount of surface soil per hectare is $2 \cdot 10^{6}$ liters, then the mean total yields harvested in the pot experiment were $130 \mathrm{t} / \mathrm{ha} \cdot 20 \mathrm{~cm}$ for the mineral soil samples, and $110 \mathrm{t} / \mathrm{ha} \cdot 20 \mathrm{~cm}$ for the organogenic soil samples.

\section{Manganese uptake of the yield}

The amount of manganese $(\mu \mathrm{g} / \mathrm{pot})$ in the ryegrass yields in the pot experiment were as follows:

Mineral soil samples Mineral soil samples Organogenic soil samples

\begin{tabular}{|c|c|c|c|c|c|c|c|c|}
\hline \multirow[b]{2}{*}{$\mathrm{n}$} & \multicolumn{2}{|c|}{ Yield I } & \multicolumn{2}{|c|}{ Yield II } & \multicolumn{2}{|c|}{ Yield III } & \multicolumn{2}{|c|}{ Yield IV } \\
\hline & $\overline{\mathbf{x}}$ & $s$ & $\overline{\mathbf{x}}$ & $\mathbf{s}$ & $\tilde{\mathbf{x}}$ & $s$ & $\tilde{\mathbf{x}}$ & $s$ \\
\hline 89 & 142 & 124 & 276 & 161 & 262 & 158 & 260 & 158 \\
\hline 86 & 124 & 61 & 261 & 132 & 250 & 137 & 250 & 141 \\
\hline 9 & 341 & 212 & 349 & 205 & 236 & 154 & 216 & 143 \\
\hline
\end{tabular}


The amount of manganese removed in four ryegrass yields from the mineral soil samples was $940 \mu \mathrm{g} /$ pot and from the organogenic soil samples $1142 \mu \mathrm{g} / \mathrm{pot}$. If it is assumed that the plants remove nutrients from a layer of soil $20 \mathrm{~cm}$ thick, then the amount of manganese removed in the yields in the pot experiment would be equivalent to about $18,8 \mathrm{~kg} / \mathrm{ha} \cdot 20 \mathrm{~cm}$ in the case of mineral soils, and about $22,8 \mathrm{~kg} /$ ha. $20 \mathrm{~cm}$ in the case of organogenic soils. The amount of manganese removed in the four yields already exceeded, by a factor of 20 , the amount of manganese removed in the total yield of cocksfoot reported by SILLANPÄÄ and RINNE (1975).

If the amount of manganese removed in the yield is calculated per unit surface area only, then the amount of manganese removed in the ryegrass yield in the pot experiment still exceeds that removed in the cocksfoot yield. This comparison well illustrates the capacity of pot experiments to indicate, over a short period of time, whether the variables being studied explain the variation in the amount of manganese removed in the yield.

The distribution of the manganese uptake of the ryegrass yields was studied using coefficient of skewness. The distribution in the first yield was skewed positively ( $\mathrm{S}=$ $0,61, \mathrm{Md}=117,0 \mu \mathrm{g} / \mathrm{pot}$ ). The skewness in the distribution was reduced when the results for soil samples No. $27 \mathrm{a}, 67 \mathrm{a}$ and $89 \mathrm{a}$ were removed from the material $(\mathrm{S}=$ $0,44, \mathrm{Md}=115,5 \mu \mathrm{g} / \mathrm{pot})$. The regression calculations for the variation in the manganese uptake of the yields were carried out on a material consisting of 86 soil samples. In addition to the soil analyses, it was apparent from the results for the manganese uptake of the first yield that the results for organogenic soil samples should be considered as a separate group. If these results would have been combined with the mineral soil material, then the distribution would have become even more skewed $(\mathrm{S}=0,88, \mathrm{Md}=120,0 \mu \mathrm{g} /$ pot $)$.

The variation in the manganese uptake of the ryegrass yields from the mineral soil samples was studied by means of regression analysis. The soil $\mathrm{pH}$, organic carbon content and the contents of exchangeable and reducible manganese were used as the independent variables. The reducible manganese fractions were used as separate independent variables when the regression equations were being calculated. Statistically insignificant variables which exceeded the $5 \%$ risk level were removed.

\section{Hydroquinone-reducible manganese as an independent variable}

The variation in the manganese uptake of the ryegrass yields was initially studied using the following variables:

\footnotetext{
$\mathrm{X}_{1}$ manganese uptake of the yield, $\mu \mathrm{g} / \mathrm{pot}$

$\mathrm{X}_{2}$ soil $\mathrm{pH}$

$\mathrm{X}_{3}$ organic carbon content, \% of air-dry soil

$\mathrm{X}_{4}$ ln content of exchangeable manganese, $\mathrm{mg} / \mathrm{kg}$ air-dry soil

$\mathrm{X}_{\mathrm{s}}$ content of hydroquinone-reducible manganese, $\mathrm{mg} / \mathrm{kg}$ air-dry soil
}

Of the independent variables studied, only the content of exchangeable manganese in the soil explained, to a statistically significant degree $(P=0,001)$, the variation in the manganese uptake of the 1st ryegrass yield as follows: 


$$
\begin{array}{ll}
\mathrm{X}_{1}=44,7+43,50 \mathrm{X}_{4}\left(\mathrm{~F}=24,87^{\times x}\right) \\
\overrightarrow{\mathrm{r}}_{1.4}=0,228 & \mathrm{~s}_{\mathrm{b}(14)}=8,72 \\
\mathrm{~S}_{1,4}=53,5 & \mathrm{n}=86
\end{array}
$$

The content of exchangeable manganese explained only $22,8 \%$ of the variation in the manganese uptake of the yield. Thus over $75 \%$ of the variation is due to variables not included in the regression equation. When the effects of other independent variables were kept constant, the soil $\mathrm{pH}$ explained only $1,9 \%$ of the variation, the organic carbon content $0,0 \%$ and the content of hydroquinone-reducible manganese $1,4 \%$ (Table 19).

The soil $\mathrm{pH}$ and the content of exchangeable manganese explained, to a statistically significant degree $(\mathrm{P}=0,001)$, the variation in the manganese uptake of the 2 nd ryegrass yield as follows:

$$
\begin{array}{ll}
\mathrm{X}_{1}=-561,0+113,3 & \mathrm{X}_{2}+133,35 \mathrm{X}_{4}\left(\mathrm{~F}=18,67^{\mathrm{xxx}}\right) \\
\mathrm{R}_{1.24}^{2}=0,308 & \mathrm{~s}_{\mathrm{b}(12.4)}=25,3 \\
\mathrm{~S}_{1.24}=111,5 & \mathrm{~s}_{\mathrm{b}(14.2)}=22,41 \\
\mathrm{n}=86 &
\end{array}
$$

The statistically significant variables together explained $30,8 \%$ of the variation in the manganese uptake of the second yield. The soil $\mathrm{pH}$ explained $19,4 \%$ of the variation when the effect of the content of exchangeable manganese of the soil was kept constant, and the content of exchangeable manganese explained $29,9 \%$ of the variation when the effect of $\mathrm{pH}$ was kept constant. The content of exchangeable manganese of the soil was a slightly more important variable in explaining the variation than the $\mathrm{pH}$ of the soil (Table 19). The carbon content and the content of hydroquinone-reducible manganese of the soil explained only 1 to $2 \%$ of the variation.

The soil $\mathrm{pH}$, and the contents of exchangeable and hydroquinone-reducible manganese explained, to a statistically significant degree $(P=0,001)$, the variation in the manganese uptake of the 3rd ryegrass yield as follows:

$$
\begin{array}{ll}
\mathrm{X}_{1}=-509,7+104,2 & \mathrm{X}_{2}+94,46 \mathrm{X}_{4}+2,18 \mathrm{X}_{5}\left(\mathrm{~F}=23,95^{\mathrm{xxx}}\right) \\
\mathrm{R}_{1.245}^{2}=0,467 & \mathrm{~s}_{\mathrm{b}(12.45)}=25,9 \\
\mathrm{~S}_{1.245}=101,9 & \mathrm{~s}_{\mathrm{b}(14.25)}=27,41 \\
\mathrm{n}=86 & \mathrm{~s}_{\mathrm{b}(15.24)}=0,64
\end{array}
$$

The independent variables in the regression equation explained $46,7 \%$ of the variation in the manganese uptake of the yield. When the effects of the other variables were kept constant, the individual variables explained the variation as follows: $\mathrm{pH} 16,5 \%$, content of exchangeable manganese $12,7 \%$, and content of hydroquinone-reducible manganese $11,4 \%$. The content of exchangeable manganese was the most important of the variables, although the importance of soil $\mathrm{pH}$ was not much smaller. The importance of the content of hydroquinone-reducible manganese was clearly less than that of the soil $\mathrm{pH}$ or the content of exchangeable manganese (Table 19). The organic carbon content, which was not statistically significant $(\mathrm{P}=$ 0,05 ), explained $3,5 \%$ of the variation when the effects of the other variables were kept constant.

The independent variables explained, to a statistically significant degree $(\mathrm{P}=$ $0,001)$, the variation in the manganese uptake of the 4th ryegrass yield as follows: 


$$
\begin{array}{ll}
\mathrm{X}_{1}=-565,2+121,2 & \mathrm{X}_{2}-9,8 \mathrm{X}_{3}+92,43 \mathrm{X}_{4}+2,53 \mathrm{X}_{5}\left(\mathrm{~F}=28,27^{x \times x}\right) \\
\mathrm{R}_{1.2345}^{2}=0,583 & \mathrm{~s}_{\mathrm{b}(12.345)}=24,2 \\
\mathrm{~S}_{1.2345}=93,1 & \mathrm{~s}_{\mathrm{b}(13.245)}=4,7 \\
\mathrm{n}=86 & \mathrm{~s}_{\mathrm{b}(14.235)}=26,84 \\
& \mathrm{~s}_{\mathrm{b}(15.234)}=0,66
\end{array}
$$

The independent variables in the regression equation explained $58,3 \%$ of the variation in the manganese uptake of the fourth yield. When the effects of the other variables were kept constant, the individual variables explained the variation as follows: pH 23,7 \%, organic carbon content 5,1\%, content of exchangeable manganese $12,8 \%$ and content of hydroquinone-reducible manganese $14,9 \%$ (Table 19). The most important of the variables was $\mathrm{pH}$, followed by the content of exchangeable manganese, the content of hydroquinone-reducible manganese and the organic carbon content (Table 19).

The content of exchangeable manganese of the soil was the only one of the independent variables studied which explained, to a statistically significant degree $(\mathrm{P}$ $=0,05)$, the variation in the manganese uptake of the first ryegrass yield. The importance of this variable became even more apparent in the case of the second yield. However, the importance of the content of exchangeable manganese as an independent variable gradually decreased, in successive yields, in comparison to the other variables. The soil $\mathrm{pH}$ did not explain to a statistically significant degree $(\mathrm{P}=$ $0,05)$, the variation in the manganese uptake of the first yield. However, it was an important independent variable in later yields, in the case of the fourth yield being the most important variable. The content of hydroquinone-reducible manganese of the soil did not explain, to a statistically significant degree $(P=0,05)$, the variation in the manganese uptake of the first and second yield, but its importance then increased with every successive yield. The importance of the organic carbon content of the soil as an independent variable also increased with each successive yield. By the fourth yield it was already a statistically significant $(P=0,05)$ variable explaining the variation in the manganese uptake of the yield.

\section{Hydroxylammonium chloride-reducible manganese as an independent variable}

The variation in the manganese uptake of the ryegrass yield was studied using the following variables:

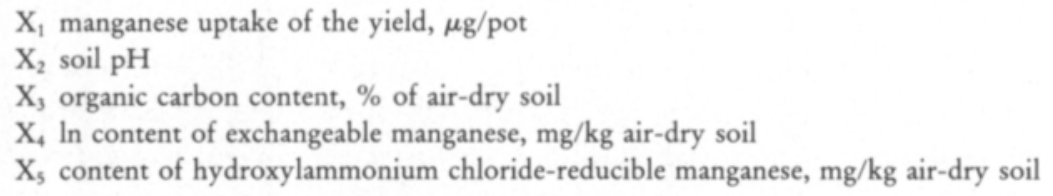

The content of hydroxylammonium chloride-reducible manganese of the soil was as poor an explainer of the manganese uptake of the 1st ryegrass yield as the content of hydroquinone-reducible manganese. When the $5 \%$ risk level was used as the criterion in testing the independent variables, the content of hydroxylammonium chloride-reducible manganese, as well as the soil $\mathrm{pH}$ and the carbon content, were found to be insignificant independent variables (Table 20). The regression equation 
Table 19. Coefficients of partial $\left(\mathrm{r}_{1 \mathrm{x} .}\right)$ correlation between uptake of manganese ( $\left.\mu \mathrm{g} / \mathrm{pot}\right)$ of Italian ryegrass (Lolium multiflorum Lam.) yields I-IV and soil variables, and the beta coefficients ( $\beta$ ) between the variables.

\begin{tabular}{|c|c|c|c|c|c|c|c|c|c|}
\hline \multirow[b]{2}{*}{ Yield } & \multirow[b]{2}{*}{$\mathrm{n}$} & \multicolumn{2}{|c|}{$\mathrm{pH}\left(\mathrm{CaCl}_{2}\right)$} & \multicolumn{2}{|c|}{ Organic C, \% } & \multicolumn{2}{|c|}{$\begin{array}{c}\text { Exchangeable } \\
\mathrm{Mn}, \mathrm{mg} / \mathrm{kg}\end{array}$} & \multicolumn{2}{|c|}{$\begin{array}{l}\text { Hydroquinone- } \\
\text { reducible } \mathrm{Mn}, \mathrm{mg} / \mathrm{kg}\end{array}$} \\
\hline & & $r_{12 \ldots}$ & $\beta$ & $\mathbf{r}_{13 \ldots}$ & $\beta$ & $r_{14 \ldots}$ & $\beta$ & $r_{15} \ldots$ & $\beta$ \\
\hline 1 st yield & 86 & $0,139^{\mathrm{ns}}$ & - & $0,012^{\text {ns }}$ & - & $0,478^{\operatorname{mx}}$ & 0,478 & $0,117^{\mathrm{ns}}$ & - \\
\hline 2nd yield & 86 & $0,441^{\operatorname{mx}}$ & 0,504 & $-0,152^{\mathrm{ns}}$ & - & $0,547^{2 x x}$ & 0,670 & $0,106^{\mathrm{ns}}$ & - \\
\hline 3rd yield & 86 & $0,406^{\operatorname{mxx}}$ & 0,448 & $-0,188^{\mathrm{ns}}$ & - & $0,356^{\operatorname{xx}}$ & 0,459 & $0,338^{\mathrm{xx}}$ & 0,351 \\
\hline 4 th yield & 86 & $0,486^{\mathrm{mx}}$ & 0,507 & $-0,227^{x}$ & $-0,166$ & $0,357^{x x}$ & 0,437 & $0,387^{2 \times x}$ & 0,396 \\
\hline
\end{tabular}

was thus reduced to the same form as when the hydroquinone-reducible manganese fraction was used as the independent variable.

The content of hydroxylammonium chloride-reducible manganese of the soil explained, to a statistically significant degree $(P=0,001)$, the variation in the manganese uptake of the 2 nd ryegrass yield as follows:

$$
\begin{array}{ll}
\mathrm{X}_{1}=155,7+2,23 & \mathrm{X}_{\mathrm{s}}\left(\mathrm{F}=62,70^{\mathrm{xxx}}\right) \\
\mathrm{r}_{1.5}^{2}=0,427 & \mathrm{~s}_{\mathrm{b}(15)}=0,28 \\
\mathrm{~S}_{1.5}=100,9 & \mathrm{n}=86
\end{array}
$$

The content of hydroxylammonium chloride-reducible manganese of the soil explained $42,7 \%$ of the variation in the manganese uptake of the yield. Of the statistically insignificant $(\mathrm{P}=0,05)$ variables, soil $\mathrm{pH}$ explained $2,7 \%$ of the variation, the organic carbon content $0,2 \%$ and the content of exchangeable manganese $4,4 \%$, when the effects of the other independent variables were kept constant (Table 20).

The soil $\mathrm{pH}$ and the contents of exchangeable and hydroxylammonium chloridereducible manganese explained, to a statistically significant degree $(P=0,001)$, the variation in the manganese uptake of the 3rd ryegrass yield as follows:

$$
\begin{array}{ll}
\mathrm{X}_{1}=-222,2+53,5 & \mathrm{X}_{2}+54,18 \mathrm{X}_{4}+2,13 \mathrm{X}_{5}\left(\mathrm{~F}=40,73^{\mathrm{xx}}\right) \\
\mathrm{R}_{1.245}^{2}=0,598 & \mathrm{~s}_{\mathrm{b}(12.45)}=24,4 \\
\mathrm{~S}_{1.245}=88,3 & \mathrm{~s}_{\mathrm{b}(14.25)}=23,62 \\
\mathrm{n}=86 & \mathrm{~s}_{\mathrm{b}(15.24)}=0,33
\end{array}
$$

The statistically significant variables explained $59,8 \%$ of the variation in the manganese uptake of the yield. When the effects of the other variables were kept constant, the individual independent variables explained the variation as follows: $\mathrm{pH}$ $6,4 \%$, content of exchangeable manganese $7,0 \%$ and content of hydroxylammonium chloride-reducible manganese $27,4 \%$. The content of hydroxylammonium chloride-reducible manganese was the most important variable explaining the variation in the manganese uptake of the third yield. The second most important variable was the content of exchangeable manganese, although the $\mathrm{pH}$ was not very much less important (Table 20). The only insignificant variable $(\mathrm{P}=0,05)$, the organic carbon content, explained only $1,0 \%$ of the variation in the manganese uptake of the yield when the effects of the other independent variables were kept constant (Table 20). 
The soil $\mathrm{pH}$ and the contents of exchangeable and hydroxylammonium chloridereducible manganese initially explained, to a statistically significant degree $(\mathrm{P}=$ 0,001 ), the variation in the manganese uptake of the 4 th ryegrass yield. As the organic carbon content was statistically insignificant $(P=0,05)$, it was omitted from the regression equation and the variables were retested. The result was that only the soil $\mathrm{pH}$ and the content of hydroxylammonium chloride-reducible manganese explained, to a statistically significant degree $(P=0,001)$, the variation in the manganese uptake of the fourth ryegrass yield. The regression equation was as follows:

$$
\begin{array}{ll}
\mathrm{X}_{1}=-41,6+30,6 & \mathrm{X}_{2}+2,87 \mathrm{X}_{5}\left(\mathrm{~F}=86,91^{\mathrm{xx}}\right) \\
\mathrm{R}_{1.25}^{2}=0,677 & \mathrm{~s}_{\mathrm{b}(12.5)}=27,1 \\
\mathrm{~S}_{1.25}=80,9 & \mathrm{~s}_{\mathrm{b}(15.2)}=0,41 \\
\mathrm{n}=86 &
\end{array}
$$

The statistically significant $(P=0,05)$ variables explained $67,7 \%$ of the variation in the manganese uptake of the yield. When the effects of the other independent variables were kept constant, the $\mathrm{pH}$ explained $4,8 \%$ of the variation and the content of hydroxylammonium chloride-reducible manganese $65,4 \%$. The content of reducible manganese was a considerably more important explainer of the variation than the soil $\mathrm{pH}$ (Table 20). As far as the independent variables removed from the regression equation were concidered, the organic carbon content explained 2,9 $\%$ of the variation in the manganese uptake of the yield and the content of exchangeable manganese $4,1 \%$, when the effects of the other independent variables being studied were kept constant (Table 20).

The content of hydroxylammonium chloride-reducible manganese was no better an explainer of the variation in the manganese uptake of the first yield of ryegrass than the content of hydroquinone-reducible manganese. Thus the only variable which explained, to a statistically significant degree $(P=0,05)$, the variation in the manganese uptake of the first yield was the content of exchangeable manganese of the soil. However, in later yields the content of exchangeable manganese was of only slight importance as an independent variable. The importance of the content of hydroxylammonium chloride-reducible manganese increased with each successive yield. The importance of the soil $\mathrm{pH}$ showed a similar trend. The organic carbon content of the soil was of no statistical significance $(P=0,05)$ as an explainer of the variation in the manganese uptake of the yield, although there was a slight trend indicating that its importance may increase with each successive yield.

\begin{tabular}{|c|c|c|c|c|c|c|c|c|c|}
\hline \multirow[b]{2}{*}{ Yield } & \multirow[b]{2}{*}{$\mathrm{n}$} & \multicolumn{2}{|c|}{$\mathrm{pH}\left(\mathrm{CaCl}_{2}\right)$} & \multicolumn{2}{|c|}{ Organic C, \% } & \multicolumn{2}{|c|}{$\begin{array}{c}\text { Exchangeable } \\
\mathrm{Mn}, \mathrm{mg} / \mathrm{kg}\end{array}$} & \multicolumn{2}{|c|}{$\begin{array}{c}\text { Hydroxylammonium } \\
\text { chloride-reducible } \\
\mathrm{Mn}, \mathrm{mg} / \mathrm{kg}\end{array}$} \\
\hline & & $r_{12 \ldots}$ & $\beta$ & $r_{13 \ldots}$ & $\beta$ & $r_{14 \ldots}$ & $\beta$ & $\mathbf{r}_{15 \ldots}$ & $\beta$ \\
\hline 1 st yield & 86 & $0,122^{\mathrm{ns}}$ & - & $0,026^{\mathrm{ns}}$ & - & $0,478^{\mathrm{xx}}$ & 0,478 & $-0,078^{\mathrm{ns}}$ & - \\
\hline 2nd yield & 86 & $0,164^{\text {ns }}$ & - & $-0,041^{\mathrm{ns}}$ & - & $0,210^{\mathrm{ns}}$ & - & $0,654^{\operatorname{xx}}$ & 0,654 \\
\hline 3rd yield & 86 & $0,236^{x}$ & 0,230 & $-0,101^{\mathrm{ns}}$ & - & $0,245^{x}$ & 0,263 & $0,577^{x \times x}$ & 0,603 \\
\hline 4th yield & 86 & $0,219^{x}$ & 0,129 & $-0,170^{\text {ns }}$ & - & $0,201^{\mathrm{ns}}$ & - & $0,809^{x \times x}$ & 0,792 \\
\hline
\end{tabular}

Table 20. Coefficients of partial $\left(\mathrm{r}_{1 \mathrm{x} .}\right)$ correlation between uptake of manganese ( $\left.\mu \mathrm{g} / \mathrm{pot}\right)$ of Italian ryegrass (Lolium multiflorum Lam.) yields I-IV and soil variables, and the beta coefficients ( $\beta$ ) between the variables. 
The variation in the manganese uptake of the ryegrass yields was studied using the following variables:

$\mathrm{X}_{1}$ manganese uptake of the yield, $\mu \mathrm{g} /$ pot

$\mathrm{X}_{2}$ soil $\mathrm{pH}$

$\mathrm{X}_{3}$ organic carbon content, \% of air-dry soil

$\mathrm{X}_{4}$ ln content of exchangeable manganese, $\mathrm{mg} / \mathrm{kg}$ air-dry soil

$\mathrm{X}_{5}$ content of ascorbic acid-reducible manganese, $\mathrm{mg} / \mathrm{kg}$ air-dry soil

No improvement was obtained in explaining the variation in the manganese uptake of the 1st ryegrass yield even though the content of ascorbic acid-reducible manganese was used as the variable for the reducible manganese fraction. The content of ascorbic acid-reducible manganese explained only $0,2 \%$ of the variation in the manganese uptake of the yield when the other independent variables were kept constant (Table 21). The regression equation describing the variation in the manganese uptake of the yield was thus reduced to the same form as when the content of hydroquinone-reducible or hydroxylammonium chloride-reducible manganese was used as the independent variable.

It was found in the first stage of testing the independent variables describing the variation in the manganese uptake of the 2nd ryegrass yield, that the contents of exchangeable manganese and ascorbic acid-reducible manganese of the soil explained, to a statistically significant degree $(P=0,001)$, the variation in the manganese uptake of the yield. These variables explained $44,1 \%$ of the variation. Because soil $\mathrm{pH}$ and organic carbon content were insignificant variables they were omitted from the equation and the remaining independent variables were tested again. It was found that the content of exchangeable manganese of the soil was no longer included in the regression equation. This was the case because it explained only $2,3 \%$ of the variation in the manganese uptake of the yield when the content of ascorbic acid-reducible manganese was kept constant (Table 21). The content of ascorbic acid-reducible manganese of the soil thus explained, to a statistically significant degree $(P=0,001)$, the variation in the manganese uptake of the ryegrass yield as follows:

$$
\begin{array}{ll}
\mathrm{X}_{1}=152,5+1,73 \quad \mathrm{X}_{\mathrm{S}}\left(\mathrm{F}=62,74^{\mathrm{xx}}\right) \\
\mathrm{r}_{1.5}^{2}=0,428 & \mathrm{~s}_{\mathrm{b}(15)}=0,22 \\
\mathrm{~S}_{1.5}=100,8 & \mathrm{n}=86
\end{array}
$$

The content of ascorbic acid-reducible manganese of the soil explained $42,8 \%$ of the variation in the manganese uptake of the yield. When the effects of the other independent variables were kept constant, the soil $\mathrm{pH}$ explained 3,9\% of the variation and the organic carbon content $0,2 \%$ (Table 21).

The soil $\mathrm{pH}$ and the contents of exchangeable and ascorbic acid-reducible manganese explained, to a statistically significant degree $(P=0,001)$, the variation in the manganese uptake in the 3 rd ryegrass yield as follows:

$$
\begin{array}{ll}
\mathrm{X}_{1}=-301,6+65,7 & \mathrm{X}_{2}+66,13 \mathrm{X}_{4}+1,54 \mathrm{X}_{\mathrm{s}}\left(\mathrm{F}=38,95^{\mathrm{mx}}\right) \\
\mathrm{R}_{1.245}^{2}=0,588 & \mathrm{~s}_{\mathrm{b}(12.45)}=23,9 \\
\mathrm{~S}_{1.245}=89,5 & \mathrm{~s}_{\mathrm{b}(14.25)}=22,97 \\
\mathrm{n}=86 & \mathrm{~s}_{\mathrm{b}(15.24)}=0,25
\end{array}
$$


The statistically significant $(\mathrm{P}=0,05)$ variables explained $58,8 \%$ of the variation in the manganese uptake of the yield. When the effects of the other independent variables were kept constant, the $\mathrm{pH}$ explained $8,5 \%$ of the variation, the content of exchangeable manganese $9,2 \%$ and the content of ascorbic acid-reducible manganese $31,5 \%$. The content of ascorbic acid-reducible manganese was the most important variable, the content of exchangeable manganese the second, and the soil $\mathrm{pH}$ the third (Table 21). The organic carbon content of the soil explained only $1,6 \%$ of the variation in the manganese uptake of the yield when the effects of the other variables were kept constant.

The soil $\mathrm{pH}$ and the contents of exchangeable and ascorbic acid-reducible manganese explained, to a statistically significant degree $(P=0,001)$, the variation in the manganese uptake of the 4th ryegrass yield as follows:

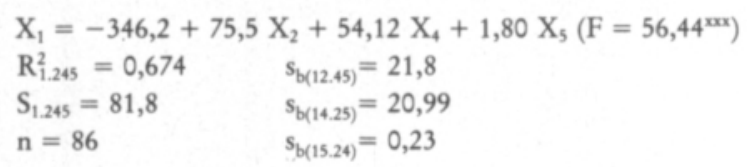

The soil $\mathrm{pH}$, the content of exchangeable manganese and the content of ascorbic acid-reducible manganese explained $67,4 \%$ of the variation in the manganese uptake of the ryegrass yield. When the effects of the other independent variables were kept constant, the soil $\mathrm{pH}$ explained $12,8 \%$ of the variation, the content of exchangeable manganese $7,5 \%$ and the content of ascorbic acid-reducible manganese $43,0 \%$. The most important variable was the content of ascorbic acid-reducible manganese and the content of exchangeable manganese of the soil the least important (Table 21). The organic carbon content, which was a statistically insignificant $(P=0,05)$ variable, explained $4,0 \%$ of the variation in the manganese uptake of the yield when the effects of the other variables were kept constant.

The content of ascorbic acid-reducible manganese of the soil was no better an explainer of the variation in the manganese uptake of the first yield than were any of the other reducible manganese fractions. The content of exchangeable manganese of the soil was thus the only suitable independent variable when the variation in the manganese uptake of the 1st yield was examined. However, the content of exchangeable manganese was of only slight importance in the case of the other yields. In

Table 21. Coefficients of partial ( $r_{1 x}$.) correlation between uptake of manganese ( $\left.\mu \mathrm{g} / \mathrm{pot}\right)$ of Italian ryegrass (Lolium multiflorum Lam.) yields I-IV and soil variables, and the beta coefficients $(\beta)$ between the variables.

\begin{tabular}{|c|c|c|c|c|c|c|c|c|c|}
\hline \multirow[b]{2}{*}{ Yield } & \multirow[b]{2}{*}{$\mathrm{n}$} & \multicolumn{2}{|c|}{$\mathrm{pH}\left(\mathrm{CaCl}_{2}\right)$} & \multicolumn{2}{|c|}{ Organic C, \% } & \multicolumn{2}{|c|}{$\begin{array}{l}\text { Exchangeable } \\
\mathrm{Mn}, \mathrm{mg} / \mathrm{kg}\end{array}$} & \multicolumn{2}{|c|}{$\begin{array}{l}\text { Ascorbic acid- } \\
\text { reducible } \\
\mathrm{Mn}, \mathrm{mg} / \mathrm{kg}\end{array}$} \\
\hline & & $r_{12 \ldots}$ & $\beta$ & $r_{13 \ldots}$ & $\beta$ & $r_{14 \ldots}$ & $\beta$ & $r_{15 \ldots}$ & $\beta$ \\
\hline 1st yield & 86 & $0,055^{\mathrm{ns}}$ & - & $0,073^{\text {ns }}$ & - & $0,478^{x x x}$ & 0,478 & $0,044^{\mathrm{ns}}$ & - \\
\hline 2 nd yield & 86 & $0,197^{\mathrm{ns}}$ & - & $-0,049^{\mathrm{ns}}$ & - & $0,150^{\mathrm{ns}}$ & - & $0,654^{\operatorname{xx}}$ & 0,654 \\
\hline 3rd yield & 86 & $0,291^{x x}$ & 0,282 & $-0,127^{\mathrm{ns}}$ & - & $0,303^{\mathrm{xx}}$ & 0,321 & $0,561^{\mathrm{mx}}$ & 0,561 \\
\hline 4th yield & 86 & $0,357^{x x x}$ & 0,316 & $-0,201^{\mathrm{ns}}$ & - & $0,274^{x}$ & 0,256 & $0,655^{x x x}$ & 0,639 \\
\hline
\end{tabular}


successive yields beginning with the 2 nd ryegrass yield, the content of ascorbic acidreducible manganese proved to be the most important variable explaining the variation in the manganese uptake of the yield. The $\mathrm{pH}$, too, became more important with each successive yield.

The content of exchangeable manganese of the soil has been used with varying degrees of success to explain the variation in the manganese uptake in yields (BROWMAN et al. 1969, HOYT and NYBORG 1971, RANDALL et al. 1976, DUANGPATRA et al. 1979). The water-extractable, exchangeable, acid-extractable and EDTA- and DTPA-extractable manganese have, in many cases, proved to be of equal value as explainers of the variation in the manganese uptake in yields (e.g. RANDALL et al. 1976, DUANGPATRA et al. 1979). However, the content of reducible manganese has rarely been found to be a suitable independent variable (HAMMES and BERGER 1960 b, RANDALL et al. 1976), and in most cases it is an inferior independent variable compared to the contents of manganese extractable by the other methods (BROWMAN et al. 1969, DUANGPATRA et al. 1979). According to BROWMAN et al. (1969), the soil $\mathrm{pH}$ and the content of manganese extractable with neutral ammonium acetate are better able to explain the variation in the manganese uptake of the yield than, in addition to the $\mathrm{pH}$, the sum of the contents of hydroquinonereducible and exchangeable manganese. This indicates that there may be reason to use the contents of exchangeable manganese and reducible manganese as separate variables when studying the variation in the manganese uptake of the yields.

The regression models explaining the variation in the manganese uptake of the ryegrass yields were studied by comparing the coefficients of multiple determination for all the four independent variables using the $\mathrm{z}$-transformation test. The differences between the different regression models were not statistically significant at the $5 \%$ risk level:

\section{Yield}

lst yield

2nd yield

3rd yield

4 th yield

$\mathrm{C}_{6} \mathrm{H}_{4}(\mathrm{OH})_{2} / \mathrm{HONH}_{3} \mathrm{Cl}$
$\delta z_{1}-z_{2}$
$0,08^{\mathrm{ns}}$
$-0,86^{\mathrm{ns}}$
$-1,15^{\mathrm{ns}}$
$-1,45^{\mathrm{ns}}$

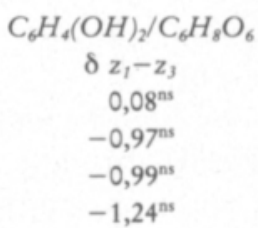

The regression models were also compared by determining how many statistically significant independent variables were required to form the final equation. The equation in which soil $\mathrm{pH}$, organic carbon content and the contents of exchangeable manganese and hydroxylammonium chloride-reducible manganese were the independent variables, was found to be the best one in this respect.

When the different manganese fractions were compared, the content of hydroxylammonium chloride-reducible manganese was found to be the best variable describing the variation in the manganese uptake of the yield. The extraction conditions used in determining the content of hydroxylammonium chloride-reducible manganese may have better corresponded to the natural conditions prevailing in the soil than the methods used to determine the contents of hydroquinone or ascorbic acid-reducible manganese. The relative unimportance of soil $\mathrm{pH}$ in the regression model in which the content of hydroquinone-reducible manganese was used as the variable for the reducible manganese fraction, supports this assumption. 
The mean content of exchangeable manganese of the soil in the pots, $625 \mu \mathrm{g} / \mathrm{pot}$, appears to have satisfied the manganese requirements of the yields for a fairly long time. The content of exchangeable manganese of the soil was therefore the factor regulating the variation in the manganese uptake of the first yields. The soil $\mathrm{pH}$ and the content of reducible manganese better explained the variation in the manganese uptake in successive yields. Obviously the content of reducible manganese, which was used as the variable describing the capacity factor of soil manganese and which is regulated by $\mathrm{pH}$, became the most important variable at the stage when the importance of the content of exchangeable manganese of the soil, which was the variable describing the intensity factor of soil manganese, started to decrease. The increase in the importance of the organic carbon content with successive yields can be interpreted to indicate that it is a variable reducing the total manganese content of the soil, and thus also the variable reducing the fractions of extractable manganese.

Regression analysis was not carried out on the variation in the manganese uptake of the ryegrass yields grown on organogenic soil samples owing to the small number of such samples.

\section{Manganese content of the yield}

The manganese content (mg/kg D.M.) of the different ryegrass yields harvested in the pot experiment were as follows:

\begin{tabular}{lrrrrrrrrr} 
& & \multicolumn{2}{c}{ Yield I } & \multicolumn{2}{c}{ Yield II } & \multicolumn{2}{c}{ Yield III } & \multicolumn{2}{c}{ Yield IV } \\
& $\mathrm{n}$ & \multicolumn{1}{c}{$\overline{\mathrm{x}}$} & \multicolumn{1}{c}{$\mathrm{s}$} & \multicolumn{1}{c}{} & $\mathrm{s}$ & $\mathrm{x}$ & $\mathrm{s}$ & \multicolumn{1}{c}{} & \multicolumn{1}{c}{$\mathrm{s}$} \\
Mineral soils. & 89 & 90,1 & 80,9 & 148,3 & 93,4 & 159,8 & 97,1 & 183,9 & 109,5 \\
Mineral soils & 86 & 76,8 & 35,1 & 137,8 & 65,1 & 152,2 & 80,1 & 176,5 & 97,5 \\
Organogenic soils & 9 & 204,6 & 126,6 & 224,6 & 130,7 & 170,7 & 109,4 & 173,9 & 106,0
\end{tabular}

The manganese content of the first yield in the experiment with the mineral soil samples was considerably smaller than that obtained in later yields. There were no such differences in the case of the organogenic soil samples. The lowest manganese content in the first yield, $19,1 \mathrm{mg} / \mathrm{kg}$ D.M., occurred in sample No. $30 \mathrm{a}$ and the highest, 582,5 mg/kg D.M., in sample No. 27a.

The distribution of the manganese content in the first yield was initially studied using the whole mineral soil material. The distribution was skewed positively, the coefficient of skewness being $\mathrm{S}=0,62$ ( $\mathrm{Md}=73,4 \mathrm{mg} / \mathrm{kg}$ D.M.). The coefficient of skewness fell to $\mathrm{S}=0,38$ ( $\mathrm{Md}=72,3 \mathrm{mg} / \mathrm{kg}$ D.M.) when the results for samples No. $27 \mathrm{a}, 67 \mathrm{a}$ and $89 \mathrm{a}$ were omitted. The manganese contents of the ryegrass yields for these three samples were therefore removed and the samples used in calculating the regression equations were the same as those used in studying the manganese uptake of the yields.

The variation in the manganese content of the ryegrass yields obtained with the mineral soil samples were studied using regression analysis. The soil $\mathrm{pH}$, organic carbon content and the contents of exchangeable manganese and reducible manganese were used as the independent variables. The reducible manganese fractions, hydroquinone-, hydroxylammonium chloride- or ascorbic acid-reducible manga- 
nese, were used as separate independent variables when the equations were being constructed.

\section{Hydroquinone-reducible manganese as an independent variable}

The variation in the manganese content of the ryegrass yields was studied using the following variables:

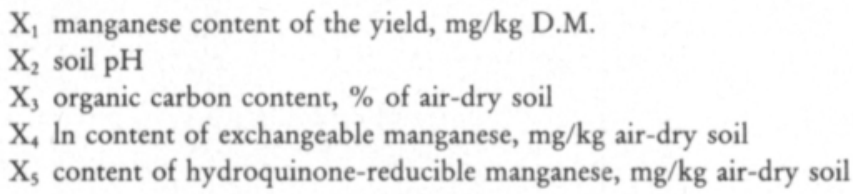

The content of exchangeable manganese of the soil explained, to a statistically significant degree $(\mathrm{P}=0,001)$, the variation in the manganese content of the 1st ryegrass yield as follows:

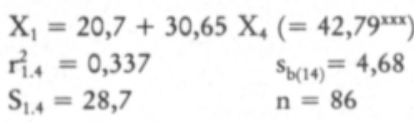

The content of exchangeable manganese of the soil explained $33,7 \%$ of the variation in the manganese content of the yield. Of the statistically insignificant $(P=0,05)$ independent variables, the soil $\mathrm{pH}$ explained $2,7 \%$ of the variation in the manganese content of the yield, the organic carbon content $1,1 \%$ and the content of hydroquinone-reducible manganese $0,7 \%$ when the effects of the other independent variables were kept constant (Table 22).

The soil $\mathrm{pH}$ and the content of exchangeable manganese explained, to a statistically significant degree $(\mathrm{P}=0,001)$, the variation in the manganese content of the 2 nd ryegrass yield as follows:

$$
\begin{array}{ll}
\mathrm{X}_{1}=-190,3+39,4 & \mathrm{X}_{2}+69,41 \mathrm{X}_{4}\left(\mathrm{~F}=20,89^{\mathrm{xx}}\right) \\
\mathrm{R}_{1.24}^{2}=0,335 & \mathrm{~s}_{\mathrm{b}(12.4)}=12,2 \\
\mathrm{~S}_{1.24}=53,7 & \mathrm{~s}_{\mathrm{b}(14.2)}=10,79 \\
\mathrm{n}=86 &
\end{array}
$$

The soil $\mathrm{pH}$ and the content of exchangeable manganese explained 33,5 \% of the variation in the manganese content of the yield. The soil $\mathrm{pH}$ alone explained $11,2 \%$ of the variation and the content of exchangeable manganese $33,3 \%$ when the effect of the other independent variable was kept constant. The content of exchangeable manganese of the soil was a considerably more important independent variable than the soil $\mathrm{pH}$ (Table 22). As far as the statistically insignificant $(\mathrm{P}=0,05)$ variables were concerned, the organic carbon content of the soil explained $0,5 \%$ of the variation in the manganese content of the yield and the content of hydroquinone-reducible manganese $3,3 \%$ when the effects of the other independent variables were kept constant (Table 22).

The soil $\mathrm{pH}$ and the contents of exchangeable manganese and hydroquinonereducible manganese explained, to a statistically significant degree $(P=0,001)$, the variation in the manganese content of the $3 r d$ ryegrass yield as follows: 


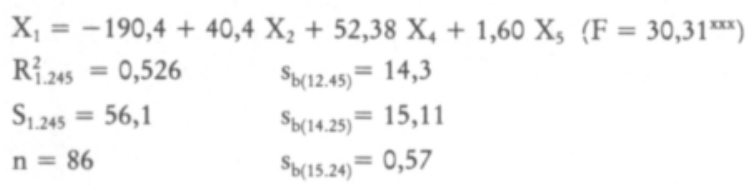

The soil $\mathrm{pH}$ and the contents of exchangeable manganese and hydroquinonereducible manganese explained $52,6 \%$ of the variation in the manganese content of the yield. As far as the statistically significant $(P=0,05)$ independent variables were concerned, the soil $\mathrm{pH}$ explained $8,9 \%$ of the variation, the content of exchangeable manganese $12,8 \%$ and the content of hydroquinone-reducible manganese $18,5 \%$ when the effects of the other independent variables were kept constant. The contents of exchangeable manganese and hydroquinone-reducible manganese were almost as important variables as each other. The importance of $\mathrm{pH}$ as an explainer of the variation in the manganese content of the yield was less than that of the manganese fractions (Table 22). The organic carbon content of the soil, which was statistically insignificant $(P=0,05)$, explained $2,8 \%$ of the variation when the effects of the other independent variables were kept constant (Table 22).

The soil $\mathrm{pH}$, the organic carbon content and the contents of exchangeable manganese and hydroquinone-reducible manganese explained, to a statistically significant degree $(P=0,001)$, the variation in the manganese content of the 4 th ryegrass yield as follows:

$$
\begin{array}{ll}
\mathrm{X}_{1}=-234,2+53,8 \mathrm{X}_{2}-6,6 \mathrm{X}_{3}+56,87 \mathrm{X}_{4}+2,21 \mathrm{X}_{5}\left(\mathrm{~F}=33,01^{x x}\right) \\
\mathrm{R}_{1.2345}^{2}=0,620 & \mathrm{~s}_{\mathrm{b}(12.345)}=16,0 \\
\mathrm{~S}_{1.2345}=61,6 & \mathrm{~s}_{\mathrm{b}(13.245)}=3,1 \\
\mathrm{n}=86 & \mathrm{~s}_{\mathrm{b}(14.235)}=17,76 \\
& \mathrm{~s}_{\mathrm{b}(15.234)}=0,45
\end{array}
$$

The soil $\mathrm{pH}$, the organic carbon content and the contents of exchangeable manganese and hydroquinone-reducible manganese explained $62,0 \%$ of the variation in the manganese content of the yield. The individual variables explained the variation in the manganese content of the yield, when the effects of the other independent variables were kept constant, as follows: the soil $\mathrm{pH} 12,3 \%$, the organic carbon content $5,3 \%$, the content of exchangeable manganese $11,2 \%$ and the content of hydroquinone-reducible manganese $23,3 \%$. The most important variable was the content of hydroquinone-reducible manganese, and the second most important one the content of exchangeable manganese, although the soil $\mathrm{pH}$ was almost as important. The importance of the organic carbon content was only slight compared to the other variables (Table 22).

The content of exchangeable manganese of the soil was the only independent variable which explained, to a statistically significant degree $(P=0,05)$, the variation in the manganese content of the 1st yield. Its importance in successive yields gradually decreased in comparison to the other variables. The soil $\mathrm{pH}$ became a statistically significant variable $(P=0,05)$ after the second yield had been harvested and its importance increased, compared to the content of exchangeable manganese, with each successive yield starting from the second one. The content of hydroquinone-reducible manganese became an important variable regulating the variation in the manganese content of the yield starting from the third yield. The importance 
Table 22. Coefficients of partial $\left(\mathrm{r}_{1 \times .}\right)$ correlation between manganese content $(\mathrm{mg} / \mathrm{kg})$ of Italian ryegrass (Lolium multiflorum Lam.) yields I-IV and soil variables, and the beta coefficients $(\beta)$ between the variables.

\begin{tabular}{|c|c|c|c|c|c|c|c|c|c|}
\hline \multirow[b]{2}{*}{ Yield } & \multirow[b]{2}{*}{$\mathrm{n}$} & \multicolumn{2}{|c|}{$\mathrm{pH}\left(\mathrm{CaCl}_{2}\right)$} & \multicolumn{2}{|c|}{ Organic C, \% } & \multicolumn{2}{|c|}{$\begin{array}{c}\text { Exchangeable } \\
\mathrm{Mn}, \mathrm{mg} / \mathrm{kg}\end{array}$} & \multicolumn{2}{|c|}{$\begin{array}{c}\text { Hydroquinone- } \\
\text { reducible } \mathrm{Mn}, \mathrm{mg} / \mathrm{kg}\end{array}$} \\
\hline & & $r_{12 .}$ & $\beta$ & $r_{13 \ldots}$ & $\beta$ & $r_{14 \ldots}$ & $\beta$ & $r_{15 \ldots}$ & $\beta$ \\
\hline 1 st yield & 86 & $-0,165^{\mathrm{ns}}$ & - & $0,103^{\mathrm{ns}}$ & - & $0,581^{x x}$ & 0,581 & $-0,082^{\mathrm{ns}}$ & - \\
\hline 2nd yield & 86 & $0,334^{\mathrm{xx}}$ & 0,357 & $-0,073^{\mathrm{ns}}$ & - & $0,577^{\mathrm{xx}}$ & 0,710 & $0,181^{\mathrm{ns}}$ & - \\
\hline 3rd yield & 86 & $0,298^{\mathrm{xx}}$ & 0,297 & $-0,168^{\mathrm{ns}}$ & - & $0,357^{x x x}$ & 0,435 & $0,430^{x x x}$ & 0,439 \\
\hline 4th yield & 86 & $0,350^{\mathrm{xx}}$ & 0,325 & $-0,229^{x}$ & $-0,160$ & $0,335^{\mathrm{xx}}$ & 0,388 & $0,483^{\operatorname{mxx}}$ & 0,499 \\
\hline
\end{tabular}

of the organic carbon content of the soil also increased with each successive yield. By the time that the fourth yield had been harvested, it had become a statistically significant $(P=0,05)$ variable regulating the variation in the manganese content of the yield.

\title{
Hydroxylammonium chloride-reducible manganese as an independent variable
}

The variation in the manganese content of the ryegrass yields was studied using the following variables:

\author{
$\mathrm{X}_{1}$ manganese content of the yield, $\mathrm{mg} / \mathrm{kg}$ D.M. \\ $\mathrm{X}_{2}$ soil $\mathrm{pH}$ \\ $\mathrm{X}_{3}$ organic carbon content, \% of air-dry soil \\ $\mathrm{X}_{4}$ ln content of exchangeable manganese, $\mathrm{mg} / \mathrm{kg}$ air-dry soil \\ $\mathrm{X}_{\mathrm{s}}$ content of hydroxylammonium chloride-reducible manganese, $\mathrm{mg} / \mathrm{kg}$ air-dry soil
}

During the first stage of testing the independent variables describing the variation in the manganese content of the 1st ryegrass yield, it was found that the soil $\mathrm{pH}$ and the content of exchangeable manganese explained, to a statistically significant degree $(\mathrm{P}=0,05), 36,2 \%$ of the variation in the manganese content of the yield. The organic carbon content and the content of hydroxylammonium chloride-reducible manganese were then removed from the regression model and the significance of the remaining independent variables retested. The soil $\mathrm{pH}$ was then found to be an insignificant variable because it explained only $3,8 \%$ of the variation in the manganese content of the yield when the effect of the content of exchangeable manganese was kept constant (Table 23). The regression equation describing the variation in the manganese content of the yield was thus reduced to the same form as when the content of hydroquinone-reducible manganese was used as the independent variable. Of the variables removed from the regression model in the initial stage, the organic carbon content of the soil explained $2,2 \%$ of the variation in the manganese content of the yield and the content of hydroxylammonium chloridereducible manganese $1,6 \%$, the effects of the other independent variables being kept constant (Table 23).

The contents of exchangeable manganese and hydroxylammonium chloridereducible manganese explained, to a statistically significant degree $(P=0,001)$, the variation in the manganese content of the 2 nd ryegrass yield as follows: 


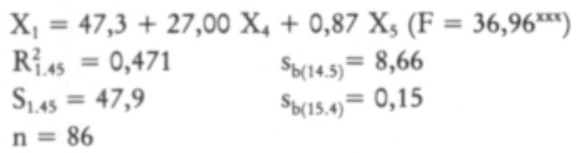

The contents of exchangeable manganese and hydroxylammonium chloride-reducible manganese of the soil explained $47,1 \%$ of the variation in the manganese content of the yield. When the effect of the other statistically significant $(P=0,05)$ independent variable was kept constant, the content of exchangeable manganese explained $10,5 \%$ of the variation and the content of hydroxylammonium chloridereducible manganese $29,4 \%$. The content of reducible manganese was a considerably more important independent variable than the content of exchangeable manganese (Table 23). As regards the statistically insignificant $(\mathrm{P}=0,05)$ variables, the $\mathrm{pH}$ explained $0,1 \%$ of the variation in the manganese content of the yield and the organic carbon content $0,1 \%$ when the effects of the other variables were kept constant (Table 23).

The contents of exchangeable manganese and hydroxylammonium chloridereducible manganese explained, to a statistically significant degree $(P=0,001)$, the variation in the manganese content of the 3rd ryegrass yield as follows:

$$
\begin{array}{ll}
X_{1}=58,7+24,76 & X_{4}+1,42 X_{5}\left(F=72,41^{x x}\right) \\
R_{1.45}^{2 x}=0,636 & s_{b(14.5)}=8,84 \\
S_{1.45}=48,9 & s_{b(15.4)}=0,15 \\
n=86 &
\end{array}
$$

The contents of exchangeable manganese and hydroxylammonium chloride-reducible manganese explained $63,6 \%$ of the variation in the manganese content of the yield. When the effect of the other independent variable was kept constant, the content of exchangeable manganese explained $8,6 \%$ of the variation and the content of hydroxylammonium chloride-reducible manganese $48,8 \%$. The content of reducible manganese was a considerably more important explainer of the variation in the manganese content of the yield than the content of exchangeable manganese (Table 23). As regards the statistically insignificant $(\mathrm{P}=0,05)$ variables, the $\mathrm{pH}$ explained $1,7 \%$ of the variation in the manganese content of the yield and the organic carbon content of the soil $1,1 \%$ when the effects of the other variables were kept constant (Table 23).

It was initially found when testing the variables explaining the variation in the manganese content of the 4 th ryegrass yield, that the soil $\mathrm{pH}$ and the organic carbon content were not statistically significant $(\mathrm{P}=0,05)$ independent variables since $\mathrm{pH}$ explained only $2,6 \%$ of the variation and the organic carbon content $4,0 \%$, the effects of the other variables being kept constant (Table 23). A new regression equation was formed in which the contents of exchangeable manganese and hydroxylammonium chloride-reducible manganese were the independent variables. The equation explained $69,7 \%$ of the variation in the manganese content of the yield. However, after the variables had been tested, it was found that when the $\mathrm{pH}$ and the organic carbon content were allowed to vary according to the material, then the content of exchangeable manganese had become a statistically insignificant $(\mathrm{P}=$ 0,05 ) independent variable even though it explained 3,4 \% of the variation (Table 23). Thus the content of hydroxylammonium chloricie-reducible manganese in the soil 
Table 23. Coefficiènts of partial $\left(\mathbf{r}_{\mid \mathbf{x} .}\right)$ correlation between manganese content $(\mathrm{mg} / \mathrm{kg})$ of Italian ryegrass (Lolium multiflorum Lam.) yields I-IV and soil variables, and the beta coefficients ( $\beta$ ) between the variables.

\begin{tabular}{|c|c|c|c|c|c|c|c|c|c|}
\hline \multirow[b]{2}{*}{ Yield } & \multirow[b]{2}{*}{$\mathrm{n}$} & \multicolumn{2}{|c|}{$\mathrm{pH}\left(\mathrm{CaCl}_{2}\right)$} & \multicolumn{2}{|c|}{ Organic C, \% } & \multicolumn{2}{|c|}{$\begin{array}{c}\text { Exchangeable } \\
\mathrm{Mn}, \mathrm{mg} / \mathrm{kg}\end{array}$} & \multicolumn{2}{|c|}{$\begin{array}{l}\text { Hydroxylammonium } \\
\text { chloride-reducible } \\
\mathrm{Mn}, \mathrm{mg} / \mathrm{kg}\end{array}$} \\
\hline & & $r_{12 \ldots}$ & $\beta$ & $r_{13 \ldots}$ & $\beta$ & $r_{14 \ldots}$ & $\beta$ & $r_{15} \ldots$ & $\beta$ \\
\hline 1st yield & 86 & $-0,194^{\mathrm{ns}}$ & - & $0,148^{\mathrm{ns}}$ & - & $0,581^{\mathrm{xx}}$ & 0,581 & $0,128^{\mathrm{ns}}$ & - \\
\hline 2nd yield & 86 & $0,034^{\mathrm{ns}}$ & - & $0,024^{\mathrm{ns}}$ & - & $0,324^{\mathrm{x}}$ & 0,276 & $0,542^{\mathrm{xx}}$ & 0,520 \\
\hline 3rd yield & 86 & $0,131^{\mathrm{ns}}$ & - & $0,103^{\text {ns }}$ & - & $0,294^{\mathrm{x}}$ & 0,206 & $0,698^{\mathrm{xx}}$ & 0,686 \\
\hline 4th yield & 86 & $0,161^{\mathrm{ns}}$ & - & $-0,200^{\mathrm{ns}}$ & - & $0,185^{\mathrm{ns}}$ & - & $0,828^{\mathrm{xx}}$ & 0,828 \\
\hline
\end{tabular}

alone explained, to a statistically significant degree $(P=0,001)$, the variation in the manganese content of the yield as follows:

$$
\begin{array}{ll}
\mathrm{X}_{1}=78,4+2,08 \mathrm{X}_{5}\left(\mathrm{~F}=183,72^{\mathrm{xxx}}\right) \\
\mathrm{r}_{1.5}^{2}=0,686 & \mathrm{~s}_{\mathrm{b}(15)}=0,15 \\
\mathrm{~S}_{1.5}=54,9 & \mathrm{n}=86
\end{array}
$$

The content of hydroxylammonium chloride-reducible manganese of the soil explained $68,6 \%$ of the variation in the manganese content of the yield.

The content of exchangeable manganese of the soil was the only independent variable which explained, to a statistically significant degree $(P=0,05)$, the variation in the manganese content of the first ryegrass yield. Its importance in the two next yields decreased, and by the time the fourth yield was harvested it was no longer a significant independent variable. The importance of the content of hydroxylammonium chloride-reducible manganese as an independent variable increased with each successive yield. By the time the fourth yield had been harvested, it was the only variable which explained, to a statistically significant degree, the variation in the manganese content of the yield. The importance of the soil $\mathrm{pH}$ and the organic carbon content as independent variables gradually increased with each successive yield. Despite this, however, they were not statistically significant $(P=0,05)$ variables in any of the regression models.

\section{Ascorbic acid-reducible manganese as an independent variable}

The variation in the manganese content of the ryegrass yields was studied using the following variables:

$\mathrm{X}_{1}$ manganese content of the yield, $\mathrm{mg} / \mathrm{kg}$ D.M.

$\mathrm{X}_{2}$ soil $\mathrm{pH}$

$\mathrm{X}_{3}$ organic carbon content, \% of air-dry soil

$\mathrm{X}_{4}$ ln content of exchangeable manganese, $\mathrm{mg} / \mathrm{kg}$ air-dry soil

$\mathrm{X}_{\mathrm{s}}$ content of ascorbic acid-reducible manganese, $\mathrm{mg} / \mathrm{kg}$ air-dry soil

Of the different independent variables, only the content of exchangeable manganese of the soil explained, to a statistically significant degree $(\mathrm{P}=0,05)$, the variation in the manganese content of the 1st ryegrass yield. In actual fact, the soil $\mathrm{pH}$ was also found to be a significant variable in the first test when the effects of the 
other independent variables were kept constant. However, when the organic carbon content and the content of ascorbic acid-reducible manganese, which were insignificant variables, were removed from the model, the proportion of the variation explained by the soil $\mathrm{pH}$ decreased so much that it was no longer a statistically significant variable. The statistically insignificant variables explained the variation, when the effects of the other independent variables were kept constant, as follows: $\mathrm{pH} \mathrm{3,8} \%$, the organic carbon content $2,3 \%$ and the content of ascorbic acidreducible manganese $1,2 \%$ (Table 24 ).

The contents of exchangeable manganese and ascorbic acid-reducible manganese explained, to a statistically significant degree $(\mathrm{P}=0,001)$, the variation in the manganese content of the 2 nd ryegrass yield as follows:

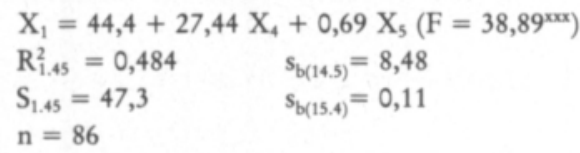

The contents of exchangeable manganese and ascorbic acid-reducible manganese explained $48,4 \%$ of the variation in the manganese content of the yield. The content of exchangeable manganese explained $11,2 \%$ of the variation and the content of ascorbic acid-reducible manganese $31,1 \%$ when the effect of the other variable was kept constant. The content of reducible manganese was a more important explainer of the variation in the manganese content of the yield than the content of exchangeable manganese (Table 24). As regards the statistically insignificant $(\mathrm{P}=0,05)$ variables, the $\mathrm{pH}$ explained $0,3 \%$ of the variation and the organic carbon content $0,0 \%$ when the effects of the other independent variables were kept constant (Table 24).

The contents of exchangeable manganese and ascorbic acid-reducible manganese of the soil explained, to a statistically significant degree $(P=0,001)$, the variation in the manganese content of the 3 rd ryegrass yield as follows:

$$
\begin{array}{ll}
\mathrm{X}_{1}=35,7+27,41 & \mathrm{X}_{4}+1,06 \mathrm{X}_{5}\left(\mathrm{~F}=66,17^{\mathrm{xx}}\right) \\
\mathrm{R}_{1,45}^{2}=0,614 & \mathrm{~s}_{\mathrm{b}(14.5)}=9,02 \\
\mathrm{~S}_{1,45}=50,3 & s_{\mathrm{b}(15.4)}=0,12 \\
\mathrm{n}=86 &
\end{array}
$$

The contents of exchangeable manganese and ascorbic acid-reducible manganese explained $61,4 \%$ of the variation in the manganese content of the yield. The content of exchangeable manganese explained $10,0 \%$ of the variation and the content of ascorbic acid-reducible manganese $48,4 \%$ when the effect of the other independent variable was kept constant. The content of ascorbic acid-reducible manganese was a considerably more important independent variable than the content of exchangeable manganese (Table 24). As regards the statistically insignificant $(\mathrm{P}=0,05)$ variables which were removed from the regression model, the $\mathrm{pH}$ explained $3,9 \%$ of the variation in the manganese content of the yield and the organic carbon content of the soil $1,7 \%$ when the effects of the other independent variables were kept constant (Table 24).

The soil $\mathrm{pH}$, organic carbon content and the contents of exchangeable manganese and ascorbic acid-reducible manganese explained, to a statistically significant degree $(\mathrm{P}=0,001)$, the variation in the manganese content of the 4th ryegrass yield as follows: 


$$
\begin{array}{ll}
\mathrm{X}_{1}=-144,3+34,8 & \mathrm{X}_{2}-6,0 \mathrm{X}_{3}+50,92 \mathrm{X}_{4}+1,15 \mathrm{X}_{5}\left(\mathrm{~F}=44,41^{\mathrm{xx}}\right) \\
\mathrm{R}_{1.2345}^{2}=0,687 & \mathrm{~s}_{\mathrm{b}(12.345)}=15,2 \\
\mathrm{~S}_{1.2345}=55,9 & \mathrm{~s}_{\mathrm{b}(13.245)}=2,6 \\
\mathrm{n}=86 & \mathrm{~s}_{\mathrm{b}(14.235)}=15,10 \\
& \mathrm{~s}_{\mathrm{b}(15.234)}=0,17
\end{array}
$$

The independent variables explained $68,7 \%$ of the variation in the manganese content of the yield. When the effects. of the other variables were kept constant, the soil $\mathrm{pH}$ explained $6,1 \%$ of the variation in the manganese content of the yield, the organic carbon content $5,6 \%$, the content of exchangeable manganese $12,3 \%$ and the content of ascorbic acid-reducible manganese $36,8 \%$. The content of ascorbic acid-reducible manganese was the most important variable of these independent variables. The content of exchangeable manganese and the soil $\mathrm{pH}$ were almost as important as each other. The organic carbon content of the soil was the least important explainer of the variation in the manganese content of the yield (Table 24).

In the first ryegrass yield, the content of exchangeable manganese of the soil was the only variable which explained, to a statistically significant degree, the variation in the manganese content of the yield. However, its importance compared to other variables decreased in successive yields. The importance of the content of ascorbic acid-reducible manganese increased with each successive yield. It was the most important variable starting from the second yield. The soil $\mathrm{pH}$ and the organic carbon content became statistically significant variables by the time that the fourth yield had been harvested.

The regression models explaining the variation in the manganese content of the ryegrass yields were studied by comparing the coefficients of multiple determination of the models, containing all the independent variables, by means of the z-transformation. The regression equations in which the content of reducible manganese of the soil had been determined by different methods were thus compared with each other. The differences between the coefficients of multiple determination of the different

\begin{tabular}{|c|c|c|c|c|c|c|c|c|c|}
\hline \multirow[b]{2}{*}{ Yield } & \multirow[b]{2}{*}{$\mathrm{n}$} & \multicolumn{2}{|c|}{$\mathrm{pH}\left(\mathrm{CaCl}_{2}\right)$} & \multicolumn{2}{|c|}{ Organic C, \% } & \multicolumn{2}{|c|}{$\begin{array}{c}\text { Exchangeable } \\
\mathrm{Mn}, \mathrm{mg} / \mathrm{kg}\end{array}$} & \multicolumn{2}{|c|}{$\begin{array}{l}\text { Ascorbic acid- } \\
\text { reducible } \\
\mathrm{Mn}, \mathrm{mg} / \mathrm{kg}\end{array}$} \\
\hline & & $r_{12 \ldots}$ & $\beta$ & $r_{13 \ldots}$ & $\beta$ & $r_{14 \ldots}$ & $\beta$ & $r_{15} \ldots$ & $\beta$ \\
\hline 1st yield & 86 & $-0,194^{\mathrm{ns}}$ & - & $0,150^{\mathrm{ns}}$ & - & $0,581^{x x}$ & 0,581 & $0,109^{\mathrm{ns}}$ & - \\
\hline 2nd yield & 86 & $0,057^{n s}$ & - & $0,020^{\mathrm{ns}}$ & - & $0,335^{x}$ & 0,281 & $0,557^{x \times x}$ & 0,530 \\
\hline 3rd yield & 86 & $0,197^{\mathrm{ns}}$ & - & $-0,132^{\mathrm{ns}}$ & - & $0,316^{x x}$ & 0,228 & $0,696^{\mathrm{xx}}$ & 0,661 \\
\hline 4th yield & 86 & $0,247^{x}$ & 0,174 & $-0,236^{x}$ & $-0,119$ & $0,351^{x x}$ & 0,179 & $0,607^{x \times x}$ & 0,714 \\
\hline
\end{tabular}
models were not statistically significant at the $5 \%$ risk level:

$\begin{array}{lccc} & \mathrm{C}_{6} \mathrm{H}_{4}(\mathrm{OH})_{2} / \mathrm{HONH}_{3} \mathrm{Cl} & \mathrm{C}_{6} \mathrm{H}_{4}(\mathrm{OH})_{2} / \mathrm{C}_{6} \mathrm{H}_{8} \mathrm{O}_{6} & \mathrm{HONH}_{3} \mathrm{Cl}_{2} \mathrm{C}_{6} \mathrm{H}_{8} \mathrm{O}_{6} \\ \text { Yield } & \delta \mathrm{z}_{1}-\mathrm{z}_{2} & \delta z_{7}-\mathrm{z}_{3} & \delta \mathrm{z}_{2}-\mathrm{z}_{3} \\ \text { 1st yield } & -0,10^{\mathrm{ns}} & -0,10^{\mathrm{ns}} & -0,10^{\mathrm{ns}} \\ \text { 2nd yield } & -0,90^{\mathrm{ns}} & -1,02^{\mathrm{ns}} & -0,12^{\mathrm{ss}} \\ \text { 3rd yield } & -1,10^{\mathrm{ns}} & -1,10^{\mathrm{ns}} & 0,00^{\mathrm{ms}} \\ \text { 4th yield } & -1,11^{\mathrm{ns}} & -0,79^{\mathrm{ns}} & 0,32^{\mathrm{ms}}\end{array}$

Table 24. Coefficients of partial $\left(\mathrm{r}_{1 \mathrm{x} .}\right)$ correlation between manganese content $(\mathrm{mg} / \mathrm{kg})$ of Italian ryegrass (Lolium multiflorum Lam.) yields I-IV and soil variables, and the beta coefficients $(\beta)$ between the variables. 
Regression models were also compared by determining how many statistically significant variables were needed to form each final equation. It was then found that when the soil $\mathrm{pH}$, organic carbon content and the contents of exchangeable and hydroxylammonium chloride-reducible manganese were used as the independent variables, that in most cases the equation was reduced to the form containing fewer variables than when some other reducible manganese fraction was used instead of the content of hydroxylammonium chloride-reducible manganese. In this respect the content of hydroquinone-reducible manganese proved to be a weaker variable in the regression equations, and the content of ascorbic acid-reducible manganese to be almost as good a variable as the content of hydroxylammonium chloride-reducible manganese.

The content of exchangeable manganese of the soil was an important explainer of the variation in the manganese content of the first yield in particular. The soil $\mathrm{pH}$ had no statistically significant effect on the variation. Determination of the content of exchangeable manganese of the soil by means of a non-buffered extractant obviously also includes the effect of the $\mathrm{pH}$ of the soil sample. When buffered extractants are used to extract manganese, then the soil $\mathrm{pH}$ has to be used as an independent variable, as well as the manganese content, if the variation in the manganese content of the yield is to be studied (SIPPOLA and KURKI 1981). Similarly, when the importance of the content of exchangeable manganese, which describes the intensity factor of soil manganese, decreased, the importance of the content of reducible manganese, which describes the capacity factor of soil manganese, became more important with each successive yield. The content of hydroxylammonium chloridereducible manganese was the best variable describing the capacity factor of soil manganese. The $\mathrm{pH}$ of the extractant used in determining the content of hydroxylammonium chloride-reducible manganese of the soil may have been close to the $\mathrm{pH}$ value of the soil samples. Thus the soil $\mathrm{pH}$ had no significant effect in describing the variation in the manganese content of the yield in those cases where the content of hydroxylammonium chloride-reducible manganese was used as the reducible manganese fraction. The use of the content of hydroquinone-reducible manganese, in particular, as a describer of the variation in the manganese content of the yield also presupposed that the $\mathrm{pH}$ of the soil was taken into account. When the analytical methods were tested, it was found that the hydroquinone treatment increased the $\mathrm{pH}$ of the extractant. The importance of the organic carbon content as an explainer of the variation in the manganese content of the fourth yield may be due to the fact that the total manganese content decreases as the organic carbon content increases. Initially the organic carbon content had an opposite effect which may be caused by the fact that the organic matter in the soil regulates the soil $\mathrm{pH}$ and thus, in turn, the content of exchangeable manganese.

The variation in the manganese content of the yield has been explained, with varying degrees of success, by means of the water-soluble, exchangeable and EDTAand DTPA-extractable manganese of the soil (TISDALE and BERTRAMSON 1950, HAMMES and BERGER 1960 a, PAGE et al. 1962, BEYME 1971, HOYT and NYBORG 1971, GUPTA 1972, KÄHÄRI and NISSINEN 1978, ROORDA van EYSINGA et al. 1978, SCHÜTZ 1978, 1980). The content of reducible manganese of the soil is usually less successful at explaining the variation in the manganese content of the yield than the content of exchangeable manganese (HAMMES and BERGER 1960 a, SEMB and ØIEN 
1970, BEYME 1971, HOYT and NYBORG 1971, ROORDA van EYSINGA et al. 1978, DUANGPATRA et al. 1979). According to BEYME (1971) and SCHÜTZ $(1978,1980)$, for instance, the content of reducible manganese of the soil is not a statistically significant independent variable at all.

The iron content of the soil may have an effect on the manganese content of the yield. However, the content of extractable iron of the soil was not used as an explainer of the variation in the manganese content of the yield because the reliability of the method for determining the content of extractable iron would have first had to be studied. On the other hand, the iron content of the yield was used as an explainer of the variation in the manganese content of the yield. However, the iron content of the yield explained only $0,5 \%$ of the variation in the manganese content of the first ryegrass yield. The results of the iron determinations were not subsequently used in the regression calculations.

\section{Manganese content of the roots}

After the 4th Italian ryegrass yield had been harvested, the pots were emptied. The roots of the ryegrass plants were carefully separated from the soil, washed and dried at $75{ }^{\circ} \mathrm{C}$. The manganese content of the roots was determined and was, on the average, as follows (mg/kg D.M.):

\begin{tabular}{lrrrc} 
& $\mathrm{n}$ & $\overline{\mathrm{x}}$ & \multicolumn{1}{c}{$s$} & Range \\
Mineral soil samples & 89 & 109,4 & 120,3 & $11,8-1075,5$ \\
Mineral soil samples & 86 & 99,0 & 74,2 & $11,8-289,2$ \\
Organogenic soil samples & 9 & 55,1 & 42,9 & $12,1-148,9$
\end{tabular}

The distribution of the manganese content in the roots was studied using the coefficient of skewness. The distribution of the whole mineral soil material was positively skewed, $\mathrm{S}=0,83$ ( $\mathrm{Md}=76,2 \mathrm{mg} / \mathrm{kg}$ D.M.). When three root samples (27a, $67 \mathrm{a}$ and $89 \mathrm{a}$ ) were omitted the standard deviation decreased but the skewness of the distribution increased, $\mathrm{S}=1,12$ ( $\mathrm{Md}=71,3 \mathrm{mg} / \mathrm{kg}$ D.M.). However, because the calculations concerning the manganese uptake and the manganese content of the yield were carried out using a material consisting of 86 samples, the results for the manganese content of the roots were also calculated using 86 samples.

The variation in the manganese content of the roots was studied using soil $\mathrm{pH}$, organic carbon content and the contents of exchangeable and reducible manganese of the soil as the independent variables. The contents of hydroquinone-, hydroxylammonium chloride- and ascorbic acid-reducible manganese were each used separately as the reducible manganese fraction together with the other independent variables. The variation in the manganese content of the roots was studied using the following variables:

$\mathrm{X}_{1}$ manganese content of the roots, $\mathrm{mg} / \mathrm{kg}$ D.M.

$\mathrm{X}_{2}$ soil $\mathrm{pH}$

$\mathrm{X}_{3}$ organic carbon content, \% of air-dry soil

$\mathrm{X}_{4} \mathrm{ln}$ content of exchangeable manganese, $\mathrm{mg} / \mathrm{kg}$ air-dry soil

$\mathrm{X}_{\mathrm{s}}$ content of reducible manganese, $\mathrm{mg} / \mathrm{kg}$ air-dry soil 
Soil $\mathrm{pH}$ and the contents of exchangeable and hydroguinone-reducible manganese of the soil explained, to a statistically significant degree $(P=0,001)$, the variation in the manganese content of the roots:

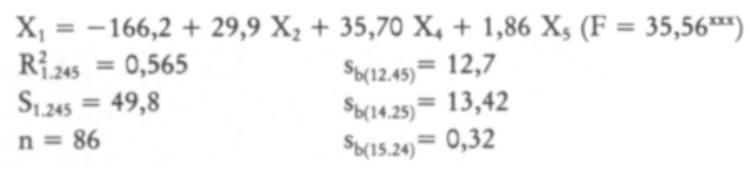

The soil $\mathrm{pH}$ and the contents of exchangeable and hydroquinone-reducible manganese of the soil explained $56,5 \%$ of the variation in the manganese content of the roots. Soil $\mathrm{pH}$ explained $6,3 \%$ of the variation, the content of exchangeable manganese $7,9 \%$ and the content of hydroquinone-reducible manganese $28,1 \%$ when the effects of the other statistically significant $(P=0,05)$ variables were kept constant. The most important variable was the content of hydroquinone-reducible manganese and the least important variable soil $\mathrm{pH}$ (Table 25). The soil organic carbon content was not a statistically significant independent variable as it explained only $2,9 \%$ of the variation when the effects of the other variables were kept constant (Table 25).

When the content of hydroxylammonium chloride-reducible manganese was used as the reducible manganese fraction, the contents of exchangeable and hydroxylammonium chloride-reducible manganese explained, to a statistically significant degree $(P=0,001)$, the variation in the manganese content of the roots as follows:

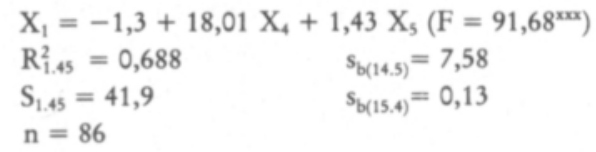

The contents of exchangeable and hydroxylammonium chloride-reducible manganese of the soil explained $68,8 \%$ of the variation in the manganese content of the roots. The content of exchangeable manganese alone explained $6,4 \%$ of the variation when the effect of the content of the reducible manganese was kept constant, and correspondingly, the content of hydroxylammonium chloride-reducible manganese explained $59,3 \%$ of the variation when the effect of exchangeable manganese was kept constant. The content of hydroxylammonium chloride-reducible manganese was a much more important variable than the content of exchangeable manganese (Table 25). As regards the statistically insignificant $(\mathrm{P}=0,05)$ variables, the soil $\mathrm{pH}$ explained $0,4 \%$ of the variation and the organic carbon content $1,4 \%$ when the effects of the other independent variables were kept constant (Table 25).

When the content of ascorbic acid-reducible manganese was used as the reducible manganese fraction, the contents of exchangeable and ascorbic acid-reducible manganese explained, to a statistically significant degree $(P=0,001)$, the variation in the manganese content of the roots as follows:

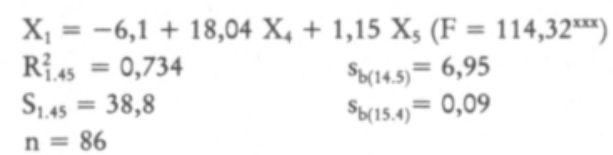


Table 25. Coefficients of partial $\left(\mathrm{r}_{1 \mathrm{x} .}\right)$ correlation between manganese content $(\mathrm{mg} / \mathrm{kg})$ of roots of Italian ryegrass (Lolium multiflorum Lam.) and soil variables, and the beta coefficients ( $\beta$ ) between the variables.

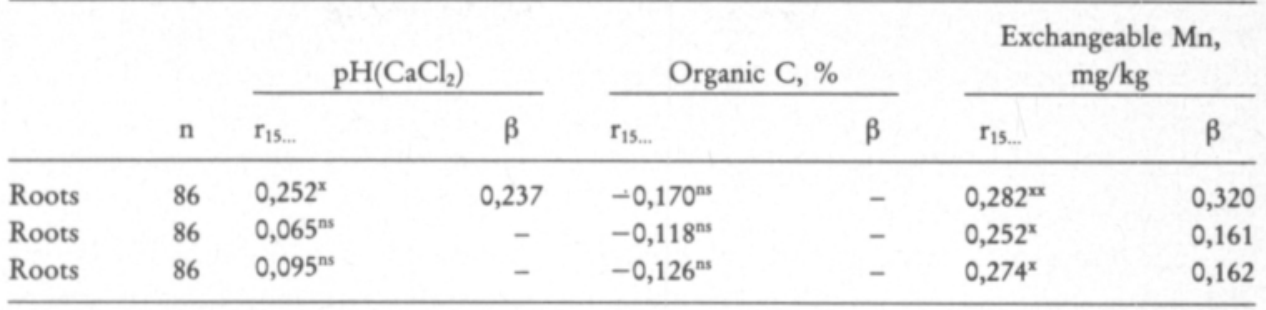

\begin{tabular}{|c|c|c|c|c|c|}
\hline \multicolumn{6}{|c|}{ Reducible manganese, $\mathrm{mg} / \mathrm{kg}$} \\
\hline \multicolumn{2}{|c|}{$\mathrm{C}_{6} \mathrm{H}_{4}(\mathrm{OH})_{2}$} & \multicolumn{2}{|c|}{$\mathrm{HONH}_{3} \mathrm{Cl}$} & \multicolumn{2}{|c|}{$\mathrm{C}_{6} \mathrm{H}_{8} \mathrm{O}_{6}$} \\
\hline$r_{15} \ldots$ & $\beta$ & $r_{15} \ldots$ & $\beta$ & $r_{15 \ldots}$ & $\beta$ \\
\hline $0,530^{\mathrm{xx}}$ & 0,552 & - & - & - & - \\
\hline - & - & $0,770^{\operatorname{mxx}}$ & 0,747 & - & - \\
\hline - & - & - & - & $0,807^{m x}$ & 0,777 \\
\hline
\end{tabular}

The contents of exchangeable and ascorbic acid-reducible manganese of the soil explained $73,4 \%$ of the variation in the manganese content of the roots. The content of exchangeable manganese explained $7,5 \%$ of the variation and the content of ascorbic acid-reducible manganese $65,2 \%$ when the effect of the other statistically significant $(\mathrm{P}=0,05)$ variable was kept constant. The importance of the content of exchangeable manganese was minor compared with the content of ascorbic acidreducible manganese (Table 25). As regards the statistically insignificant variables, the soil $\mathrm{pH}$ explained $0,9 \%$ of the variation and the organic carbon content $1,6 \%$ when the effects of the other variables were kept constant (Table 25).

The different regression equations were compared with each other. The soil $\mathrm{pH}$, organic carbon content and the content of exchangeable manganese were used as the independent variables in all the equations. The contents of hydroquinone-, hydroxylammonium chloride- and ascorbic acid-reducible manganese were used alternatively as the reducible manganese fraction. According to the following results, the differences between the coefficients of multiple determination, calculated using all the variables, were not statistically significant $(P=0,05)$ :

$$
\begin{gathered}
\mathrm{C}_{6} \mathrm{H}_{4}(\mathrm{OH})_{2} / \mathrm{HONH} \mathrm{HCl}_{3} \\
\delta \mathrm{z}_{1}-\mathrm{z}_{2} \\
-1,36^{\mathrm{ns}}
\end{gathered}
$$

$$
\begin{gathered}
\mathrm{C}_{6} \mathrm{H}_{4}(\mathrm{OH})_{2} / \mathrm{C}_{6} \mathrm{H}_{8} \mathrm{O}_{6} \\
\delta \mathrm{z}_{1}-\mathrm{z}_{3} \\
-1,96^{\mathrm{ns}}
\end{gathered}
$$$$
\begin{gathered}
\mathrm{HONH} \mathrm{H}_{3} \mathrm{Cl} / \mathrm{C}_{6} \mathrm{H}_{8} \mathrm{O}_{6} \\
\delta \mathrm{z}_{2}-\mathrm{z}_{3} \\
-0,60^{\mathrm{ns}}
\end{gathered}
$$

When the content of hydroquinone-reducible manganese was used as an independent variable in the regression equation, the soil $\mathrm{pH}$ and the content of exchangeable manganese were also included as independent variables. When either the content of hydroxylammonium chloride-reducible or ascorbic acid-reducible manganese was used as the reducible manganese fraction, the soil $\mathrm{pH}$ and the organic carbon content were eliminated from the regression equation. The hydroxylammonium chloride- 
and ascorbic acid-reducible manganese fractions were considered to be better independent variables than the content of hydroquinone-reducible manganese.

The variation in the manganese content of the roots was well explained by the variables describing capacity factors of soil manganese. The variable describing the intensity factor of the soil manganese explained only a small proportion of the variation in the manganese content. However, its significance became pronounced when the content of hydroquinone-reducible manganese was used as the capacity factor of soil manganese.

The manganese content of the roots growing in the mineral soil samples was, on the average, $56 \pm 7 \%$ of the manganese content of the 4 th yield. The variation ranged from 18 to $236 \%$. According to ERKAMA (1947), plant roots are more sensitive to high manganese contents than shoots. However, depending on the plant species, the roots may tolerate quite high manganese contents without any decrease in the drymatter yield of the roots. According to REHAB and WALLACE (1978), for instance, the manganese content of cotton roots may increase as much as many hundreds and even to thousands of $\mathrm{mg} / \mathrm{kg}$ without any decrease in the dry-matter yield of the roots.

\section{Effect of liming on manganese availability}

Liming is used to decrease excessive soil acidity. However, liming also decreases the content of exchangeable manganese of the soil (CHRISTENSEN et al. 1950, JONES 1957 b, SANCHEZ and KAMPRATH 1959, WHITE 1970, GUPTA 1972, ANDERSSON and NILSSON 1976, OSMAN et al. 1978, KOWALENKO et al. 1980). If the content of exchangeable manganese of the soil decreases too much, the plant stand starts to suffer from manganese deficiency (e.g. GISIGER and HASLER 1948, KOWALENKO et al. 1980). However, liming can also be used to decrease contents of exchangeable manganese which are toxic to the plants (GUPTA et al. 1973). The decrease in the content of exchangeable manganese of the soil brought about by liming is not based exclusively on the increase in the soil $\mathrm{pH}$. The divalent manganese ions may be bound through chemisorption onto the surface of the calcite, and the sorption of added manganese is also proportional to the particle-size of the calcite (McBRIDE 1979).

The effects of liming material and manganese fertilizer on the content of extractable manganese of the soil, on the amount of manganese removed in the yields and on the manganese content of the yield were studied by means of pot experiments. The treatments were liming and manganese fertilization as follows:

\begin{tabular}{ccc} 
Liming & \multicolumn{2}{c}{ Calcite } \\
$\mathrm{L}_{0}$ & $\mathrm{~g} / \mathrm{kg}$ air-dry soil & $\mathrm{t} / \mathrm{ha} \cdot 20 \mathrm{~cm}$ \\
$\mathrm{~L}_{1}$ & 0 & 0 \\
$\mathrm{~L}_{2}$ & 1,7 & 3,5 \\
$\mathrm{~L}_{4}$ & 3,4 & 7,0 \\
& 6,9 & 14,0
\end{tabular}




$\begin{array}{ccc}\begin{array}{c}\text { Manganese } \\ \text { application }\end{array} & \begin{array}{c}\text { Manganese as } \\ \mathrm{mg} / \mathrm{kg} \text { air-dry soil }\end{array} & \begin{array}{c}\mathrm{MnSO}_{4} \cdot 4 \mathrm{H}_{2} \mathrm{O} \\ \mathrm{kg} / \mathrm{ha} \cdot 20 \mathrm{~cm}\end{array} \\ \mathrm{Mn}_{0} & 0 & 0 \\ \mathrm{Mn}_{1} & 2,86 & 5,7 \\ \mathrm{Mn}_{3} & 8,57 & 17,2 \\ \mathrm{Mn} & 25,71 & 51,5\end{array}$

The experiments were carried out with four replicates. In the incubation experiment 0,5 liter polythene pots were used and in the experiment with turnip rape 5 liter Mitscherlich-pots. The soil used in the experiments was fine sand (109a, Appendix 1). The soil in the pots was fertilized at the start of the experiments as follows:

$\begin{array}{ccl}\text { Nutrient } & \mathrm{mg} / \mathrm{kg} \text { soil } & \text { Compound } \\ \text { N } & 292 & \mathrm{NH}_{4} \mathrm{NO}_{3} \\ P & 117 & \mathrm{~K}_{2} \mathrm{HPO}_{4} \\ \mathrm{~K} & 292 & \mathrm{~K}_{2} \mathrm{HPO}_{4} \\ \mathrm{Mg} & 58 & \mathrm{MgSO}_{4} \cdot 7 \mathrm{H}_{2} \mathrm{O} \\ \mathrm{S} & 81 & \mathrm{MgSO}_{4} \cdot 7 \mathrm{H}_{2} \mathrm{O}, \mathrm{CuSO}_{4} \cdot 5 \mathrm{H}_{2} \mathrm{O}, \mathrm{ZnSO}_{4} \cdot 7 \mathrm{H}_{2} \mathrm{O} \\ \text { B } & 1,5 & \mathrm{H}_{3} \mathrm{BO}_{3} \\ \mathrm{Cu} & 4,4 & \mathrm{CuSO}_{4} \cdot 5 \mathrm{H}_{2} \mathrm{O} \\ \mathrm{Zn} & 2,9 & \mathrm{ZnSO}_{4} \cdot 7 \mathrm{H}_{2} \mathrm{O} \\ \mathrm{Mo} & 1,5 & \mathrm{Na}_{2} \mathrm{MoO}_{4} \cdot 2 \mathrm{H}_{2} \mathrm{O}\end{array}$

The nutrients were added to the soil samples as aqueous solutions, the soil samples then being mixed in a plastic dish and transferred to the pots.

In the incubation experiment $343 \mathrm{~g}$ of air-dry soil was weighed out per pot. Calcite was mixed to the soil at the start of the experiment. Manganese was added to the soils as an aqueous solution. The soil in the pots was watered to a moisture condition equivalent to $20 \%$ of the soil weight. After watering the pots were covered with polythene film in order to decrease evaporation. However, the film was perforated with small holes in order to prevent the development of anaerobic conditions in the pots. The pots were placed in a greenhouse consisting of a roof of glass and walls of wire netting. The pots were weighed twice during the growing season and the water which had evaporated was replaced. After four months incubation, the pots were transferred to a store maintained at constant temperature $\left(5{ }^{\circ} \mathrm{C}\right)$ for the winter. The following spring the pots were again transferred to the greenhouse and incubation continued till the autumn. The experiment was terminated, the soils were left to dry to the air-dry state and the content of extractable manganese then determined. The incubation time totalled 16 months.

In the experiment with turnip rape $3430 \mathrm{~g}$ of air-dry soil was weighed out into 5 liter Mitscherlich-pots. The liming and manganese fertilization treatments were carried out in the same way as in the incubation experiment. 10 turnip rape (B̈rassica campestris oleifera $\mathrm{L}$.) seeds were sown in each pot at a depth of about $1 \mathrm{~cm}$. The soil was carefully watered and the pots kept covered with polythene film untill the turnip rape sprouted. Two weeks after sowing the number of plants was thinned to seven per pot. However, owing to poor sprouting and damping-off, there were only five or six seedlings in some of the pots. The number of seedlings was increased to 7 by transferring seedlings from the replicates, and by reseeding. Manganese fertilizer was added as an aqueous solution after thinning the seedlings. The experiment was carried out in a greenhouse comprising a roof of glass and walls of wire netting. The 
pots were watered every day. Any water which collected in the dishes under the pots was poured back into the pots and enough deionized water added until water began to drip into the dish under the pot. The yield was harvested when the turnip rape plants were covered with about $80 \%$ blossom. The yield was dried at $60{ }^{\circ} \mathrm{C}$, weighed, milled and the manganese content determined. Soil samples were taken for analysis. The rest of the soil was stored in pots during the following winter. The next spring the soil from the pots was homogenized and fertilized with nitrogen and potassium in the same way as the previous spring. Liming and manganese fertilization were not repeated. Seeding with turnip rape, care of the experiment, harvesting and the taking of soil samples were carried out in the same way as the previous autumn.

\section{Effects of liming material and applied manganese on the content of extractable manganese of the soil}

The effects of liming material and added manganese on the content of extractable manganese of the soil were studied by determining the contents of exchangeable and hydroquinone-reducible manganese of the soil used in the incubation and turnip rape experiments.

In the incubation experiment, added manganese increased the contents of exchangeable and hydroquinone-reducible manganese of the unlimed soils (Table 26). However, the changes were small since after incubation for 16 months only 4 to $8 \%$ of the added manganese was recovered from the exchangeable and 2 to $4 \%$ from the hydroquinone-reducible soil manganese fractions. A total of 6 to $10 \%$ of the added manganese was recovered from the fractions which were determined (Table 26).

Depending on the amount used, calcite decreased the content of exchangeable manganese by 45 to $83 \%$. However, the content of hydroquinone-reducible manganese increased at the same time by 93 to $124 \%$. The summed content of exchangeable and hydroquinone-reducible manganese thus decreased by only 11 to $38 \%$ (Table 26).

Depending on the amount of calcite added, 0 to $6 \%$ of the added manganese was present in the form of exchangeable manganese in the limed soil samples (Table 26). Thus the decrease in the content of exchangeable manganese brought about by calcite application could not have been prevented by adding large amounts of manganese. The smallest amount of calcite added $\left(\mathrm{L}_{1}=3,5 \mathrm{t} / \mathrm{ha} \cdot 20 \mathrm{~cm}\right)$ brought about an increase in the content of hydroquinone-reducible manganese but the highest amount of calcite added $\left(\mathrm{L}_{4}=14 \mathrm{t} / \mathrm{ha} \cdot 20 \mathrm{~cm}\right)$ appeared to have induced the conversion of exchangeable as well as added manganese into some form other than hydroquinone-reducible manganese (Table 26). In the limed soil samples, 0 to $19 \%$ of the added manganese was recovered from the fractions of exchangeable and hydroquinone-reducible manganese.

The soil $\mathrm{pH}$, organic carbon content and the content of hydroquinone-reducible manganese explained $67 \%$ of the variation in the content of exchangeable manganese of the plough layer of the mineral soil samples (p.429). The content of exchangeable 
Table 26. Effect of liming and manganese fertilization on contents of exchangeable and hydroquinonereducible manganese in the incubation experiment."

\begin{tabular}{|c|c|c|c|c|c|c|c|}
\hline Treatment & $\begin{array}{l}\text { Soil } \\
\mathrm{pH}\end{array}$ & \multicolumn{2}{|c|}{$\begin{array}{c}\text { Exchangeable manganese, } \\
\mathrm{mg} / \mathrm{kg} \% \text { of added }\end{array}$} & \multicolumn{2}{|c|}{$\begin{array}{l}\text { Hydroquinone-reducible } \mathrm{Mn} \\
\mathrm{mg} / \mathrm{kg} \quad \% \text { of added }\end{array}$} & \multicolumn{2}{|c|}{ Sum of the fractions, } \\
\hline $\mathrm{L}_{0} \mathrm{Mn}_{0}$ & 4,6 & $8,9^{c}$ & - & $2,9^{\mathrm{h}}$ & - & $11,8^{\mathrm{c}}$ & - \\
\hline $\mathrm{Mn}_{1}$ & & $9,0^{\mathrm{bc}}$ & 3,5 & $3,0^{\text {eh }}$ & 3,5 & $12,0^{\mathrm{bc}}$ & 7,0 \\
\hline $\mathrm{Mn}_{3}$ & & $9,2^{b}$ & 3,5 & $3,1^{\text {gh }}$ & 2,3 & $12,3^{b c}$ & 5,8 \\
\hline $\mathrm{Mn}$ & & $11,0^{a}$ & 8,2 & $3,3^{8}$ & 1,6 & $14,3^{2}$ & 9,7 \\
\hline $\mathrm{L}_{1} \mathrm{Mn}_{0}$ & 5,0 & $4,9^{f}$ & - & $5,6^{f}$ & - & $10,5^{e}$ & - \\
\hline $\mathrm{Mn}_{1}$ & & $5,0^{f}$ & 3,5 & $5,8^{f}$ & 7,0 & $10,8^{\text {de }}$ & 10,5 \\
\hline $\mathrm{Mn}_{3}$ & & $5,4^{e}$ & 5,8 & $6,5^{\mathrm{de}}$ & 10,5 & $12,1^{b c}$ & 18,7 \\
\hline $\mathrm{Mn}$ & & $5,9^{d}$ & 3,9 & $6,7^{\mathrm{cd}}$ & 4,3 & $12,6^{b}$ & 8,2 \\
\hline $\mathrm{L}_{2} \mathrm{Mn}_{0}$ & 5,4 & $2,7^{\mathrm{h}}$ & - & $6,5^{\mathrm{de}}$ & - & $9,2^{\mathrm{B}}$ & - \\
\hline $\mathrm{Mn}_{1}$ & & $2,7^{h}$ & 0,0 & $6,5^{\mathrm{de}}$ & 0,0 & $9,2^{8}$ & 0,0 \\
\hline $\mathrm{Mn}_{3}$ & & $2,8^{\mathrm{gh}}$ & 1,2 & $7,0^{c}$ & 5,8 & $9,8^{f}$ & 7,0 \\
\hline $\mathrm{Mn}$, & & $3,0^{8}$ & 1,2 & $8,2^{2}$ & 6,6 & $11,2^{\mathrm{d}}$ & 7,8 \\
\hline $\mathrm{L}_{4} \mathrm{Mn}_{0}$ & 6,0 & $1,5^{i}$ & - & $5,8^{f}$ & - & $7,3^{i}$ & - \\
\hline $\mathrm{Mn}_{1}$ & & $1,5^{i}$ & 0,0 & $5,8^{f}$ & 0,0 & $7,3^{i}$ & 0,0 \\
\hline $\mathrm{Mn}_{3}$ & & $1,6^{i}$ & 1,2 & $6,3^{\mathrm{e}}$ & 5,8 & $7,9^{h}$ & 7,0 \\
\hline $\mathrm{Mn}$, & & $1,7^{i}$ & 0,8 & $7,4^{b}$ & 6,2 & $9,1^{8}$ & 7,0 \\
\hline
\end{tabular}

* Data in each column has been tested separately.

manganese of the incubated soils was calculated using the regression equation. Soil properties which were affected by the calcite treatments were used as independent variables in the regression equation and the results were compared with those of soil analysis:

$\begin{array}{ccc}\text { Liming } & \begin{array}{c}\text { Exchangeable Mn, mg/kg air-dry soil } \\ \text { According to } \\ \text { regression equation }\end{array} & \begin{array}{c}\text { According to } \\ \text { soil analysis }\end{array} \\ \mathrm{L}_{0} & 7,5 \pm 0,0 & 8,9 \pm 0,3 \\ \mathrm{~L}_{1} & 5,3 \pm 0,1 & 4,9 \pm 0,4 \\ \mathrm{~L}_{2} & 4,1 \pm 0,0 & 2,7 \pm 0,2 \\ \mathrm{~L}_{4} & 2,8 \pm 0,0 & 1,5 \pm 0,0\end{array}$

The content of exchangeable manganese of the unlimed soil samples was about 19 $\%$ higher than that derived from the regression equation. However, the calcite treatment decreased the content of exchangeable manganese faster than would have been presupposed from the changes in the independent variables. Calcite may have chemisorbed exchangeable manganese and the content of exchangeable manganese thus decreased more than would have been supposed on the basis of the changes in the soil $\mathrm{pH}$ and in the content of hydroquinone-reducible manganese.

In the unlimed soil samples in the turnip rape experiment, manganese addition increased the content of exchangeable manganese. 11 to $57 \%$ of the added manganese was recovered from the exchangeable manganese fraction, and 18 to $63 \%$ when the manganese uptake of the yield was calculated as part of the exchangeable manganese fraction (Table 27). However, the results may perhaps not to be this good because the maintenance of added manganese in exchangeable form was obviously affected to a great extent by the plant stand (Tables 26 and 27). 
Table 27. Effect of liming and manganese fertilization on contents of exchangeable and hydroquinonereducible manganese in the pot experiment with turnip rape (Brassica campestris oleifera $\mathrm{L}$.).*

\begin{tabular}{|c|c|c|c|c|c|c|c|}
\hline \multirow{2}{*}{$\frac{\text { Treatment }}{\mathrm{L}_{0} \mathrm{Mn}_{0}}$} & \multirow{2}{*}{$\begin{array}{c}\begin{array}{c}\text { Soil } \\
\mathrm{pH}\end{array} \\
4,6\end{array}$} & \multicolumn{2}{|c|}{$\begin{array}{l}\text { Exchangeable } \mathrm{Mn} \text {, } \\
\mathrm{mg} / \mathrm{kg} \% \text { of added }\end{array}$} & \multicolumn{2}{|c|}{$\begin{array}{c}\text { Hydroquinone-reducible } \mathrm{Mn} \\
\mathrm{mg} / \mathrm{kg} \% \text { of added }\end{array}$} & \multicolumn{2}{|c|}{$\begin{array}{l}\text { Sum of the fractions, } \\
\mathrm{mg} / \mathrm{kg} \% \text { of added }\end{array}$} \\
\hline & & $6,9^{c}$ & - & $3,1^{i}$ & - & $10,0^{\text {eff }}$ & - \\
\hline $\mathrm{Mn}_{1}$ & & $7,2^{c}$ & 17,5 & $4,3^{i j}$ & 42,0 & $11,5^{\mathrm{de}}$ & 59,4 \\
\hline $\mathrm{Mn}_{3}$ & & $11,0^{b}$ & 55,8 & $5,2^{\mathrm{hij}}$ & 24,5 & $16,2^{c}$ & 80,3 \\
\hline $\mathrm{Mn}$ & & $21,5^{2}$ & 63,3 & $6,0^{\text {eff }}$ & 14,8 & $28,4^{2}$ & 78,1 \\
\hline $\mathrm{L}_{1} \mathrm{Mn}_{0}$ & 5,0 & $3,7^{\text {ef }}$ & - & $5,3^{\mathrm{ghi}}$ & - & $9,0^{\text {eff }}$ & - \\
\hline $\mathrm{Mn}_{1}$ & & $4,1^{\text {de }}$ & 19,6 & $6,6^{\mathrm{efg}}$ & 45,5 & $10,7^{\text {ef }}$ & 65,0 \\
\hline $\mathrm{Mn}_{3}$ & & $5,6^{\mathrm{cd}}$ & 25,6 & $9,5^{\mathrm{d}}$ & 49,0 & $15,1^{\mathrm{c}}$ & 74,8 \\
\hline $\mathrm{Mn}_{9}$ & & $11,1^{b}$ & 32,8 & $17,2^{\mathrm{b}}$ & 46,3 & $28,3^{2}$ & 79,0 \\
\hline $\mathrm{L}_{2} \mathrm{Mn}_{0}$ & 5,4 & $2,5^{\text {ef }}$ & - & $5,7^{\text {tgh }}$ & - & $8,2^{f_{8}}$ & - \\
\hline $\mathrm{Mn}_{1}$ & & $2,8^{\text {ef }}$ & 12,9 & $7,5^{\text {ef }}$ & 62,9 & $10,3^{\text {ef }}$ & 75,9 \\
\hline $\mathrm{Mn}_{3}$ & & $3,7^{\text {ef }}$ & 15,8 & $10,2^{\text {cd }}$ & 52,5 & $13.9^{\mathrm{cd}}$ & 68,3 \\
\hline $\mathrm{Mn}_{9}$ & & $6,5^{c}$ & 17,7 & $20,1^{2}$ & 56,0 & $26,6^{\mathrm{ab}}$ & 73,7 \\
\hline $\mathrm{L}_{4} \mathrm{Mn}_{0}$ & 6,0 & $1,5^{8}$ & - & $6,2^{\mathrm{efg}}$ & - & 7,78 & - \\
\hline $\mathrm{Mn}_{1}$ & & $1,3^{8}$ & 0,0 & $7,6^{\text {de }}$ & 49,0 & $8,9^{\text {eff }}$ & 45,8 \\
\hline $\mathrm{Mn}_{3}$ & & $1,9^{\mathrm{g}}$ & 6,4 & $11,6^{c}$ & 63,0 & $13,5^{\text {cd }}$ & 69,4 \\
\hline $\mathrm{Mn}_{9}$ & & $2,7^{18}$ & 5,8 & $21,5^{2}$ & 59,5 & $24,2^{b}$ & 65,3 \\
\hline
\end{tabular}

* Data in each column has been tested separately.

Depending on the amount of calcite added the content of exchangeable manganese decreased by 46 to $78 \%$ in the soil samples used in the turnip rape experiment. When the amount of manganese uptake of the yield was included in the exchangeable manganese fraction, then the addition of calcite decreased the content of exchangeable manganese by 45 to $75 \%$ (Tables 27 and 29). Although liming brought about an increase in the content of hydroquinone-reducible manganese, the sum of the contents of exchangeable and reducible manganese decreased (Table 27). A part of the exchangeable manganese present in the soil and a part of the added manganese had also been converted into a form other than hydroquinone-reducible manganese.

The contents of exchangeable manganese of the soil samples of the turnip rape experiment were also compared with the contents of exchangeable manganese calculated using the regression equation (p. 429). The soil properties $\mathrm{pH}$, organic carbon content and the content of hydroquinone-reducible manganese, which were affected by liming were used as the independent variables. The results were as follows:

$\begin{array}{ccc}\text { Liming } & \begin{array}{c}\text { Exchangeable Mn, mg/kg air-dry soil } \\ \text { According to } \\ \text { According to } \\ \text { regression equation }\end{array} & \begin{array}{c}\text { soil analysis } \\ \mathrm{L}_{0}\end{array} \\ \mathrm{~L}_{1} & 6,4 \pm 0,2 & 3,7 \pm 1,7 \\ \mathrm{~L}_{2} & 5,2 \pm 0,1 & 3,7 \pm 0,3 \\ \mathrm{~L}_{4} & 4,0 \pm 0,1 & 2,5 \pm 0,5 \\ & 2,7 \pm 0,1 & 1,5 \pm 0,3\end{array}$

The content of exchangeable manganese of the unlimed soil samples was about 8 $\%$ higher than that calculated by means of the regression equation. If the calcite treatment had reduced the content of exchangeable manganese only according to the 
changes in the soil $\mathrm{pH}$ and in the content of hydroquinone-reducible manganese, then the content of exchangeable manganese of the limed soil samples would have had to be $8 \%$ higher than the contents calculated by means of the regression equation.

When the soils were incubated for 16 months, only a small percentage of the added manganese remained in exchangeable form. The added manganese remained as exchangeable manganese in both unlimed and limed soils, in greater amounts in the pots with a plant stand than in incubated soils. This may be caused by the easily oxidizing organic compounds produced by the plant stand. Organic compounds act as reducing agents of manganese compounds during oxidation. According to GODO and REISENAUER (1980), the availability of soil manganese is controlled by the combined effects of soil properties, plant characteristics, and the interaction of plant roots and the surrounding soil.

\section{Effects of liming and manganese fertilization on the manganese uptake and manganese content of the yield}

The effects of liming and manganese fertilization on the manganese uptake and manganese content of the yield were studied by means of a two-year turnip rape experiment. The residual effects of the treatments were studied during the second year.

\section{Yield}

In the first year a small amount of added manganese $\left(\mathrm{Mn}_{1}=5,7 \mathrm{~kg} / \mathrm{ha} \cdot 20 \mathrm{~cm}\right)$ had no statistically significant $(P=0,05)$ effect on the yield. The largest amount of manganese added $\left(\mathrm{Mn}_{9}=51,5 \mathrm{~kg} / \mathrm{ha} \cdot 20 \mathrm{~cm}\right)$ decreased the yield in the unlimed soil samples but in the limed ones added manganese appeared to have no injurious effects (Table 28). In the second year, calcite increased the yield but added manganese had no effect on the yield (Table 28).

Table 28. Effect of liming and manganese fertilization on the yield $(\mathrm{g} / \mathrm{pot})$ of turnip rape (Brassica campestris oleifera L.) in the first year and the residual effect in the second year."

\begin{tabular}{|c|c|c|c|c|c|}
\hline \multirow[b]{2}{*}{ Year } & \multirow{2}{*}{$\begin{array}{l}\text { Manganese } \\
\text { application }\end{array}$} & \multicolumn{4}{|c|}{ Liming } \\
\hline & & $\mathrm{L}_{0}$ & $\mathrm{~L}_{1}$ & $\mathrm{~L}_{2}$ & $\mathrm{~L}_{4}$ \\
\hline \multirow[t]{4}{*}{1980} & $\mathrm{Mn}_{0}$ & $28,1^{\text {cd }}$ & $33,9^{\mathrm{abc}}$ & $35,1^{\mathrm{abc}}$ & $37,1^{\text {sbc }}$ \\
\hline & $\mathrm{Mn}_{1}$ & $37,7^{\mathrm{bcc}}$ & $40,1^{\mathrm{ab}}$ & $35,0^{\text {abc }}$ & $39,7^{\mathrm{ab}}$ \\
\hline & $\mathrm{Mn}_{3}$ & $32,3^{3 b c}$ & $31,6^{\text {bed }}$ & $33,3^{\text {abed }}$ & $37,0^{\text {abc }}$ \\
\hline & $\mathrm{Mn}$, & $23,8^{\mathrm{d}}$ & $35,7^{\mathrm{abc}}$ & $29,6^{\text {bed }}$ & $43,6^{2}$ \\
\hline \multirow[t]{4}{*}{1981} & $\mathrm{Mn}_{0}$ & $23,3^{\text {cd }}$ & $29,8^{\mathrm{ab}}$ & $31,7^{2}$ & $28,9^{\mathrm{abc}}$ \\
\hline & $\mathrm{Mn}_{1}$ & $27,4^{4^{\text {bed }}}$ & $30,3^{2}$ & $29,0^{\text {abc }}$ & $31,0^{a}$ \\
\hline & $\mathrm{Mn}_{3}$ & $21,7^{\mathrm{d}}$ & $28,1^{\text {abc }}$ & $28,9^{\mathrm{abc}}$ & $29,4^{\text {abc }}$ \\
\hline & $\mathrm{Mn}$, & $23,6^{\text {bed }}$ & $30,1^{\mathrm{ab}}$ & $30,3^{2}$ & $28,9^{\text {abc }}$ \\
\hline
\end{tabular}

* The results for each year have been tested separately. 


\section{Manganese uptake of the yield}

In the first year calcite decreased, to a statistically significant degree $(P=0,05)$, the manganese uptake of the yield. On the other hand, added manganese increased the manganese uptake of the yield and hence the decrease in manganese which was brought about by the medium amount of calcite $\left(\mathrm{L}_{2}=7 \mathrm{t} / \mathrm{ha} \cdot 20 \mathrm{~cm}\right)$ could be prevented by means of manganese fertilization (Table 29). In the unlimed soil samples, the manganese uptake of the yield was about 36 to $39 \%$ of the amount of manganese added. Liming decreased the manganese uptake of the yield when it was calculated in per cent of added manganese:

$\begin{array}{ccccc}\begin{array}{c}\text { Manganese } \\ \text { application }\end{array} & \mathrm{L}_{0} & \mathrm{~L}_{1} & \mathrm{~L}_{2} & \mathrm{~L}_{4} \\ \mathrm{Mn}_{1} & 36 & 56 & 31 & 25 \\ \mathrm{Mn}_{3} & 39 & 35 & 17 & 14 \\ \mathrm{Mn}_{9} & 39 & 26 & 15 & 10\end{array}$

In the second year the residual effect of added manganese was statistically significant $(P=0,05)$ in the unlimed soil samples although the effect of added manganese had decreased compared with that in the first year (Table 29). In the limed soil samples, added manganese had no effect on the manganese uptake of the yield in those cases where the amount of manganese added the previous year had been less than the $\mathrm{Mn}_{3}$ level, i.e. 17,2 kg/ha $20 \mathrm{~cm}$ (Table 29). On the other hand, the residual effect of the largest amount of added manganese $\left(\mathrm{Mn}_{9}=51,5 \mathrm{~kg} / \mathrm{ha} \cdot 20\right.$ $\mathrm{cm})$ was statistically significant $(\mathrm{P}=0,05)$ when the amount of calcite added was not higher than the $\mathrm{L}_{2}$ level $(7 \mathrm{t} / \mathrm{ha} \cdot 20 \mathrm{~cm})$. The yield harvested in the second year took up 0 to $39 \%$ of the manganese added in the first year:

$\begin{array}{ccccc}\begin{array}{c}\text { Manganese } \\ \text { application }\end{array} & \mathrm{L}_{0} & \begin{array}{c}\text { Mn uptake of the yield, \% of added Mn } \\ \mathrm{Mn}_{1}\end{array} \mathrm{~L}_{1} & \mathrm{~L}_{2} & \mathrm{~L}_{4} \\ \mathrm{Mn}_{3} & 31 & 0 & 0 & 11 \\ \mathrm{Mn}_{9} & 39 & 0 & 0 & 3 \\ & 25 & 14 & 6 & 1\end{array}$

Table 29. Effect of liming and manganese fertilization on manganese uptake (mg/pot) by turnip rape (Brassica campestris oleifera L.) in the first year and the residual effect in the second year."

\begin{tabular}{|c|c|c|c|c|c|}
\hline \multirow[b]{2}{*}{ Year } & \multirow{2}{*}{$\begin{array}{l}\text { Manganese } \\
\text { application }\end{array}$} & \multicolumn{4}{|c|}{ Liming } \\
\hline & & $\mathrm{L}_{0}$ & $\mathrm{~L}_{1}$ & $\mathrm{~L}_{2}$ & $\mathrm{~L}_{4}$ \\
\hline \multirow[t]{4}{*}{1980} & $\mathrm{Mn}_{0}$ & $1,70^{\text {cd }}$ & $0,84^{8}$ & $0,60^{8}$ & $0,76^{8}$ \\
\hline & $\mathrm{Mn}_{1}$ & $2,06^{\mathrm{c}}$ & $1,40^{\text {def }}$ & $0,91^{8}$ & $1,01^{18}$ \\
\hline & $\mathrm{Mn}_{3}$ & $2,86^{\mathrm{b}}$ & $1,90^{\text {cd }}$ & $1,12^{\text {efg }}$ & $1,18^{\mathrm{efg}_{\mathrm{g}}}$ \\
\hline & $\mathrm{Mn}_{9}$ & $5,18^{2}$ & $3,17^{b}$ & $1,94^{\mathrm{c}}$ & $1,63^{\text {cde }}$ \\
\hline \multirow[t]{4}{*}{1981} & $\mathrm{Mn}_{0}$ & $1,29^{\mathrm{d}}$ & $1,26^{\mathrm{d}}$ & $0,83^{e}$ & $0,59^{e}$ \\
\hline & $\mathrm{Mn}_{1}$ & $1,62^{c}$ & $1,24^{\mathrm{d}}$ & $0,77^{e}$ & $0,70^{\circ}$. \\
\hline & $\mathrm{Mn}_{3}$ & $2,46^{b}$ & $1,20^{d}$ & $0,82^{e}$ & $0,67^{e}$ \\
\hline & $\mathrm{Mn}_{9}$ & $3,52^{2}$ & $2,49^{b}$ & $1,40^{\text {cd }}$ & $0,71^{e}$ \\
\hline
\end{tabular}

* The results for each year have been tested separately. 
In the unlimed soil samples, the yields took up 64 to $78 \%$ of the added manganese. The good result obtained with the unlimed soil samples may partly have been caused by the fact that 18 to $63 \%$ of the added manganese remained as exchangeable manganese throughout the experiment (Table 27). However, the result may be partly apparent and it might have been brought about by the indirect effect of the plant stand since, according to the corresponding results obtained with the incubated soil samples, only 4 to $8 \%$ of the added manganese was retained as exchangeable manganese (Table 26).

According to HOYT and NYBORG (1971), the manganese content of turnip rape harvested soon after blossom development is, on the average, $244 \mathrm{mg} / \mathrm{kg}$ D.M. (47-588 mg/kg D.M.). As the manganese content of turnip rape does not essentially deviate from the manganese content of Italian ryegrass, the regression equation calculated on the basis of the results of the Italian ryegrass experiment (p.455) was applied to the results of the turnip rape experiment. The results were calculated as relative values with respect to the manganese uptake of turnip rape grown on the unlimed soil samples. The regression equation describing the variation in the manganese uptake of the first Italian ryegrass yield was applied to the turnip rape results for the first year. Correspondingly, the turnip rape results for the second year were used in the regression equation describing the variation in the manganese uptake of the second Italian ryegrass yield (p. 455). The soil properties affected by the liming treatment were used as the independent variables. The results were as follows:

\begin{tabular}{ccccc} 
& \multicolumn{4}{c}{ Relative Mn uptake of the yield } \\
& $\mathrm{L}_{0}$ & $\mathrm{~L}_{1}$ & $\mathrm{~L}_{2}$ & $\mathrm{~L}_{4}$ \\
1980 Measured uptake & 100 & 49 & 35 & 45 \\
Calculated uptake & 100 & 52 & 38 & 28 \\
1981 Measured uptake & 100 & 98 & 64 & 46 \\
Calculated uptake & 100 & 74 & 66 & 62
\end{tabular}

The manganese uptake of turnip rape followed rather closely in the first year but only fairly in the second year the manganese uptake derived from the regression equation describing the variation in the manganese uptake of Italian ryegrass.

\section{Manganese content of the yield}

The smallest amount of manganese added $\left(\mathrm{Mn}_{1}=5,7 \mathrm{~kg} / \mathrm{ha} \cdot 20 \mathrm{~cm}\right)$ had no effect on the manganese content of turnip rape. On the other hand, the largest amount of manganese added $\left(\mathrm{Mn}_{9}=51,5 \mathrm{~kg} / \mathrm{ha} \cdot 20 \mathrm{~cm}\right)$ increased the manganese content of the yield by about four times compared to the manganese content of the yield obtained without the addition of manganese to the soil (Table 30). In the first year liming decreased the manganese content of the yield by about one third compared to the content of the yield without the addition of calcite to the soil. The decrease in the manganese content of the yield which was brought about by liming could be only partly prevented by means of manganese application (Table 30). In the second year, the effect of manganese fertilizer was considerably reduced compared with the effect in the first year. Only the largest amount of manganese added $\left(\mathrm{Mn}_{9}=51,5 \mathrm{~kg} / \mathrm{ha} \cdot 20\right.$ $\mathrm{cm}$ ) was now sufficient to compensate for and only slightly to increase the manga- 
Table 30. Effect of liming and manganese fertilization on manganese content ( $\mathrm{mg} / \mathrm{kg}$ D.M.) of turnip rape (Brassica campestris oleifera $\mathrm{L}$.) in the first year and the residual effect in the second year."

\begin{tabular}{|c|c|c|c|c|c|}
\hline \multirow[b]{2}{*}{ Year } & \multirow{2}{*}{$\begin{array}{l}\text { Manganese } \\
\text { application }\end{array}$} & \multicolumn{4}{|c|}{ Liming } \\
\hline & & $\mathrm{L}_{0}$ & $\mathrm{~L}_{1}$ & $\mathrm{~L}_{2}$ & $\mathrm{~L}_{4}$ \\
\hline \multirow[t]{4}{*}{1980} & $\mathrm{Mn}_{0}$ & $61,2^{c}$ & $25,9^{\text {ef }}$ & $17,2^{f}$ & $20,6^{f}$ \\
\hline & $\mathrm{Mn}_{1}$ & $56,0^{\text {cd }}$ & $34,9^{\text {ef }}$ & $25,8^{\text {ef }}$ & $24,9^{\text {ef }}$ \\
\hline & $\mathrm{Mn}_{3}$ & $91,2^{b}$ & $60,6^{\mathrm{c}}$ & $35,2^{\text {ef }}$ & $32,6^{\text {ef }}$ \\
\hline & $\mathrm{Mn}_{9}$ & $256,1^{2}$ & $89,7^{b}$ & $66,3^{\mathrm{c}}$ & $39,7^{\text {de }}$ \\
\hline \multirow[t]{4}{*}{1981} & $\mathrm{Mn}_{0}$ & $61,8^{\mathrm{d}}$ & $37,6^{\text {fgh }}$ & $27,7^{\mathrm{fgh}}$ & $23,7^{\mathrm{h}}$ \\
\hline & $\mathrm{Mn}_{1}$ & $59,4^{\text {de }}$ & $40,8^{\text {efgh }^{2}}$ & $26,7^{\text {gh }}$ & $22,5^{\mathrm{h}}$ \\
\hline & $\mathrm{Mn}_{3}$ & $112,5^{b}$ & $42,5^{\text {efg }}$ & $28,4^{\text {fgh }}$ & $22,9^{\mathrm{h}}$ \\
\hline & $\mathrm{Mn}_{9}$ & $146,9^{2}$ & $82,4^{a}$ & $46,2^{\text {ef }}$ & $24,2^{\mathrm{h}}$ \\
\hline
\end{tabular}

* The results for each year have been tested separately.

nese content of the yield when calcite was applied at the $\mathrm{L}_{2}$ level $(3,5 \mathrm{t} / \mathrm{ha} \cdot 20 \mathrm{~cm})$ only (Table 30).

The decrease in the manganese content of turnip rape brought about by liming was studied using the regression equation calculated for the variation in the manganese content of Italian ryegrass (p. 463). The results were calculated as relative values of the results obtained in the turnip rape experiment for the liming treatment only. The manganese content of the turnip rape in the first year was compared with the results obtained from the regression equation describing the variation in the manganese content of Italian ryegrass in the first yield. Correspondingly, the manganese content of the turnip rape in the second year was compared with the results obtained from the regression equation describing the variation in the manganese content of Italian ryegrass in the second yield (p. 463). Liming decreased the manganese content of the turnip rape in the first year by a slightly faster rate than was estimated on the basis of the content of exchangeable manganese of the soil. On the other hand, in the second year of the experiment the decrease in the manganese content was much higher than was estimated on the basis of the soil $\mathrm{pH}$ and the content of exchangeable manganese:

\begin{tabular}{ccccc} 
& \multicolumn{4}{c}{ Relative Mn content of the yield } \\
& $\mathrm{L}_{0}$ & $\mathrm{~L}_{1}$ & $\mathrm{~L}_{2}$ & $\mathrm{~L}_{4}$ \\
1980 Measured content & 100 & 42 & 28 & 34 \\
Calculated content & 100 & 52 & 38 & 28 \\
1981 Measured content & 100 & 61 & 45 & 38 \\
Calculated content & 100 & 69 & 59 & 52
\end{tabular}

The added manganese was converted, by liming, into the form of reducible manganese. In the experiments with Italian ryegrass, it was found that the reducible manganese in the soil is a potential source of manganese for the plants. However, the variations in the manganese uptake and content of the first yield were primarily regulated by the content of exchangeable manganese of the soil. Thus the conversion of added manganese, brouglit about by liming, into the reducible form of manganese 
was an unfavourable process. However, the manganese content of turnip rape increased when manganese was added, but the medium amount of calcite added $\left(\mathrm{L}_{2}\right.$ $=7 \mathrm{t} / \mathrm{ha} \cdot 20 \mathrm{~cm}$ ) was enough to prevent the increase in the manganese content of the yield which otherwise would have been produced by manganese application, or was enough to decrease the manganese. content of the yield in spite of manganese application.

The decrease in the content of extractable manganese of the soil and the decrease in the manganese content of the yield brought about by liming cannot very easily be compensated by manganese application. According to GUPTA (1972), for instance, if the soil $\mathrm{pH}$ increases from 4,2 to 6,2 then the manganese content of the yield decreases to about one fifth part of the original level. At the same time, heavy manganese fertilization is not even enough to compensate for the decrease in the manganese content of the yield brought about by liming.

\section{Discussion}

The only correct method of determining plant-available manganese would be to cultivate the plant in the soil under study. The growth factors would then regulate the manganese uptake and manganese content of the yield. It is possible, by determining the manganese uptake and manganese content of the yield, to describe the availability of soil manganese. However, this method gives information about the availability of soil manganese too late when considering the availability of soil manganese from the point of view of the produced yield. Means and methods for determining in advance the availability of soil manganese are therefore required. However, soil analyses give information about certain growth factors only. It is hardly possible using these analytical methods to describe accurately the plantavailability of soil manganese.

The variation in the manganese uptake and manganese content of the yield can be described by determining the content of extractable manganese of the soil, soil $\mathrm{pH}$ and organic carbon content of the soil. At the start of the yield development the intensity factor of soil manganese, i.e. the content of exchangeable manganese, is an important variable. The greater the number of yields harvested, the less important is the significance of the intensity factor of soil manganese. However, at the same time, the capacity factor of soil manganese, i.e. the content of reducible manganese, gradually becomes an important variable. The content of hydroxylammonium chloride-reducible manganese of the soil appears to depict rather well the capacity factor of soil manganese.

Explaining the variation in the manganese uptake and in the manganese content using soil characteristics is much more difficult in the case of the first yield than of the following yields. A low value for the coefficient of multiple determination in the case of the manganese uptake and the manganese content of the first yield could be attributed to many factors. The amount of nutrients in the seeds, low nutrient requirements compared to the amounts available at the beginning of growth of the yield and the growth stage of the plant roots are contributing factors. Some results of the amounts of manganese available to plants from the seeds are as follows: 
Avena sativa L. (cv. Nasta)

Triticum aestivum L. (cv. Ruso)

Lolium multiflorum Lam. (cv. Leda)

Brassica campestris oleifera L. (cv. Candle)

Trifolium pratense L. (cv. Venla)
Mn $\mu \mathrm{g} / 1000$ seeds

2080

2380

149

73

38

The amount of manganese present in the seeds of plants which produce small seeds is not high but might affect to some extent the rather weak coefficient of multiple determination. In the pot experiment with Italian ryegrass, the amount of manganese in the seeds corresponds to $4,4 \%$ of the manganese uptake of the first yield. The amount of exchangeable manganese in the soil was, on the average, more than seven times higher than the manganese uptake of the first yield. This indicates that the intensity factor of soil manganese should perhaps be determined using less effective extraction solutions than were used in this study. During the growth of the first yield the plant roots might not have developed enough, and therefore the manganese uptake and manganese content of the first yield were smaller than in the following yields. The manganese uptake is also extremely slow compared to that of, for instance, potassium (KANNAN and KEPPEL 1976). During the initial phase of growth, the plant roots might not be able to produce enough oxidizing organic compounds. It is therefore not to be expected that the content of reducible manganese of the soil, which describes the capacity factor of soil manganese, would explain the variation in the manganese uptake and in the manganese content of the first yield.

Variables describing intensity and capacity factors of soil manganese are regulated by various factors. For instance, liming decreases the content of exchangeable manganese of the soil but increases at the same time the content of reducible manganese. However, the manganese uptake and manganese content of the yield decreases at the same time, and the change is larger than that estimated on the basis of changes in the soil $\mathrm{pH}$. The manganese uptake of the yield can be affected by means of manganese fertilization. If liming and manganese fertilization are carried out in the same year, the effect of manganese fertilization is rather weak and of short duration. As the decrease in the manganese uptake and manganese content of the yield caused by liming cannot be fully compensated for by means of manganese fertilization, liming should be carried out with careful consideration.

Manganese is often linked with the factors regulated by the soil redox potential. However, soil manganese is not reduced as rapidly as the changes in the soil redox potential would indicate. Manganese reduction, however, starts at that redox potential where theoretically the reduction of synthetic manganese oxides also starts. According to the results of this study, the importance of the soil redox potential as a factor regulating the content of exchangeable manganese of the soil might be less important than has hereto been supposed. The soil redox potential is more likely to be the result of oxidation and reduction reactions in the soil as the cause of them. The results of, for instance, COLLINS and BUOL (1970), PATRICK and HENDERSON (1981 b) and OTTOW (1982) support this view. In addition, the results concerning the effect of easily oxidizing organic matter on the content of exchangeable manganese illustrate the importance of electron donors. Although there is organic matter present in the soil, it appears to be mainly organic matter which has already been oxidized and hence can no longer act as an electron donor. The organic compounds excreted 
by plant roots appear to be important in this respect as reducing agents of manganese compounds (GODO and REISENAUER 1980).

Soil micro-organisms are able to oxidize and reduce manganese and thus affect the amount of available manganese in the soil (BARBER and LEE 1974). According to the results of the incubation experimentș, the significance of easily oxidizing organic matter as a factor increasing the content of exchangeable manganese seems to be more important than the microbial activity. In intensive cultivation, the content of reducible manganese of the soil describes rather well the variation in the manganese uptake and the manganese content of the yield. As reducible manganese can presumably be reduced through the action of plant roots exudates, the importance of microbial activity in the reduction of soil manganese would thus appear to be less than expected.

According to GODO and REISENAUER (1980), the effect and importance of microbial activity are secondary in the reduction of soil manganese because the plant is able to grow as well in a sterile as in a non-sterile medium. Microbial activity may be more important as a factor regulating the soil manganese intensity than the capacity because the content of exchangeable manganese of the soil is less able to explain the variation in the manganese uptake and the manganese content of the first yield than the content of reducible manganese in the following yields.

The intensity and capacity factors of soil manganese are important variables describing the variation in the manganese uptake and the manganese content of the yield. The intensity factor is described by means of the content of exchangeable manganese and the capacity factor by means of the content of reducible manganese. The factor describing capacity appears to be based on manganese compounds in the soil which have manganese in the oxidation states, $\mathrm{Mn}^{3+}$ and $\mathrm{Mn}^{4+}$. The manganese corresponding to these oxidation states may be principally the manganese in secondary minerals, such as manganese oxides and oxyhydroxides. The manganese in the oxidation state $\mathrm{Mn}^{3+}$ has, however, not yet been identified in the soil (McKENZIE 1972). $\mathrm{Mn}^{3+}$ hardly exists in the soil solution because it is subject to disproportionation in aqueous solution, forming $\mathrm{Mn}^{2+}$ and $\mathrm{MnO}_{2}$ (STUMM and MORGAN 1970, p. 525). The factor describing the soil manganese intensity is based on manganese in the oxidation state $\mathrm{Mn}^{2+}$, including the manganese which occurs in soil solution and as exchangeable manganese in the soil.

The $\mathrm{pH}$ corresponding to the zero point of charge of manganese oxides and oxyhydroxides is usually lower than 4,5 (PARKS 1965). As a result of ligand exchange of anions, the $\mathrm{pH}$ of the ZPC of oxides and oxyhydroxides can be diminished. It is apparent when the soil is extracted that there are small-sized oxide- and oxyhydroxidepolymers of manganese in the extraction suspension, and in these polymers the manganese occurs in the oxidation states $\mathrm{Mn}^{4+}$ and $\mathrm{Mn}^{3+}$. If the soil extraction is carried out at a higher $\mathrm{pH}$ than the $\mathrm{pH}$ of $\mathrm{ZPC}$ of the manganese oxides and oxyhydroxides, then the polymers are charged negatively. Owing to the size of the polymers and the way extraction is carried out, variable amounts of polymers pass into the extraction filtrate. As the plants primarily take up manganese as $\mathrm{Mn}^{2+}$, soil extractable manganese in the oxidation state $\mathrm{Mn}^{2+}$, at least, should be determined. The cation exhange resin extraction procedure modified in this study seems to be suited for this purpose. It is possible using this method to extract the manganese in the soil solution in cationic form and the exchangeable soil manganese in cationic 
form. Furthermore, it is possible to prevent negatively charged manganese polymers with oxidation state of manganese $\mathrm{Mn}^{4+}$ and $\mathrm{Mn}^{3+}$ passing into the filtrate. On the other hand, manganese oxides and oxyhydroxides are a potential source of manganese for plants. However, the manganese in oxides and oxyhydroxides must first be reduced to the oxidation state $\mathrm{Mn}^{2+}$ before it becomens available for plants. A modified cation exchange resin method including treatments with reducing agents seems to be well suited for the determination of soil reducible manganese because it is possible using this method to determine the manganese reduced to the oxidation state $\mathrm{Mn}^{2+}$ during the extraction, in particular.

\section{Summary}

The aim of this study was to determine the plant-available manganese in the soil. Exchangeable and reducible manganese in the soil were determined and then used, together with the results of other soil analyses, as independent variables in studying the variation in the manganese uptake and manganese content of the yield. In addition, the factors affecting the variation in the content of extractable manganese of the soil, and whether it is possible to affect this variation were studied. The research material consisted of 193 mineral soil samples and 17 organogenic soil samples. In the mineral soil samples there was 98 plough layer soils and in the organogenic soil samples 9 plough layer soils. Oats (Avena sativa L.), Italian ryegrass (Lolium multiflorum Lam.) and turnip rape (Brassica campestris oleifera L.) were used as the test plants in the pot experiments.

A cation exchange resin method was developed for extracting soil manganese. The method enabled both exchangeable and reducible manganese to be determined with adequate reproducability. Exchangeable manganese comprised the manganese which was freely present in the soil solution in the cationic form as well as the manganese in the cationic form which could be exchanged from the soil. Reducible manganese was the manganese reduced to the oxidation state $\mathrm{Mn}^{2+}$, by the action of hydroquinone, hydroxylammonium chloride or ascorbic acid.

The total iron content of the soil explained 30 to $66 \%$ of the variation in the total manganese content of the soil. The variation was explained to a minor extent by the clay content, by the $\mathrm{pH}$ in plough layer samples of mineral soils and in all the mineral soil samples, and by the organic carbon content in plough layer samples of mineral soils. The content of reducible manganese, the $\mathrm{pH}$ and the organic carbon content explained 53 to $67 \%$ of the variation in the content of exchangeable manganese of the soil. The content of reducible manganese was a slightly more important independent variable than soil $\mathrm{pH}$. The importance of the organic carbon content as an independent variable was minor compared with the other variables studied. The contents of hydroquinone-, hydroxylammonium chloride- and ascorbic acid-reducible manganese were of almost equal importance as independent variables when explaining the variation in the content of exchangeable manganese. The soil "total" manganese content explained, to a minor extent, 18 to $34 \%$ of the variation in the content of reducible manganese of the soil.

The content of exchangeable manganese of the soil did not depend on soil 
moisture when the moisture was lower than the field capacity. On the other hand, the content of exchangeable manganese of the soil was increased by the presence of the plant stand, when compared with the incubated soil samples. According to the soil redox potential measurements, soil moisture depressed the redox potential only when the soil moisture was higher than the field capacity. The roots of the plant stand had an appreciable, soil redox potential-depressing effect. The content of exchangeable manganese of the soil began to increase when the soil redox potential dropped below 0,59 V. However, the content of exhangeable manganese did not increase by nearly as much as the theoretical reduction of synthetic manganese oxides would have presupposed. The content of exchangeable manganese increased following the inactivation of microbial activity and the addition of glucose. However, this did not depend very much on the degree of inactivation. It was concluded that the reduction of soil manganese in nature is both biological and non-biological. Easily oxidizing organic compound rapidly reduced soil manganese.

The content of exchangeable manganese of the soil explained $23 \%$ of the variation in the manganese uptake and $34 \%$ in the manganese content of the first yield. The more yields that were harvested, the smaller the significance of the content of exchangeable manganese appeared to be as an explainer of the variation in the manganese uptake and in the manganese content of the yield. On the other hand, the importance of the content of reducible manganese increased according to the number of yields harvested. The content of hydroxylammonium chloride-reducible manganese explained $68 \%$ of the variation in the manganese uptake and $69 \%$ of that in the manganese content of the fourth yield. The content of hydroxylammonium chloridereducible manganese was a better independent variable than the content of hydroquinone- or ascorbic acid-reducible manganese. The contents of exchangeable and ascorbic acid-reducible manganese of the soil explained $73 \%$ of the variation in the manganese content of the plant roots.

The content of exchangeable manganese of the soil was considered to describe the intensity factor of soil manganese. Correspondingly, the content of reducible manganese of the soil was considered to describe the capacity factor of soil manganese.

Manganese fertilization increased the manganese content of the yield and the content of extractable manganese of the soil. On the other hand, liming decreased the manganese uptake and also the manganese content of the yield. When liming and manganese fertilization were carried out in the same spring, the effect of manganese fertilization remained adequate when the amount of liming material used had been small. In the next growing period, applied manganese had hardly any residual effect when the amount of calcite used the previous year had been at least $7 \mathrm{t} / \mathrm{ha} \cdot 20 \mathrm{~cm}$. A large amount of manganese $(51,5 \mathrm{~kg} / \mathrm{ha} \cdot 20 \mathrm{~cm})$ was hardly sufficient to prevent the decrease in the manganese uptake and the manganese content of the yield affected by liming. The decrease in the content of exchangeable manganese of the soil affected by liming material was greater than that estimated on the basis of $\mathrm{pH}$ changes. Similarly, the decrease in the content of exchangeable manganese was associated with an increase in the content of reducible manganese of the soil.

If the aim is to determine the plant-available manganese in the soil so as to predict the manganese uptake and manganese content of the yield, then the determination of the factors describing the intensity and capacity of soil manganese would appear to 
be worthwhile. The exchangeable manganese in cationic form determined from unbuffered soil suspension might be the factor describing the intensity factor of soil manganese. The capacity factor of soil manganese might be described by the reducible manganese which is reduced to the oxidation state $\mathrm{Mn}^{2+}$ by means of hydroxylammonium chloride.

\section{References}

AALTONEN, V. T. 1941. Zur Stratigraphie des Podsolprofils. III. Comm. Inst. Forest. Fenn. 29: 1-47. ACQUAYE, D. K., ANKOMAH, A. B. \& KANABO, I. 1972. Estimation of available copper, iron, manganese and zinc in soils using cation-exchange resin. J. Sci. Food Agric. 23: 1035-1044.

ADAMS, F. 1965. Manganese. Agronomy 9, 2: 1011-1018.

— \& WEAR, J. I. 1957. Manganese toxicity and soil acidity in relation to crinkle leaf of cotton. Soil Sci. Soc. Amer. Proc. 21: 305-308.

ALHONEN, P., KOLJONEN, T., LAHERMO, P. \& UUSINOKA, R. 1975. Ferruginous concretions around root channels in clay and fine sand deposits. Bull. Geol. Soc. Finl. 47: 175-181.

ALLAN, J. E. 1971. The preparation of agricultural samples for analysis by atomic absorption spectroscopy. 15 p. Springvale.

ANDERSSON, A. 1975. Relative efficiency of nine different soil extractants. Swedish J. Agric. Res. 5: 125-135.

- 1977. Heavy metals in Swedish soils: On their retention, distribution and amounts. Swedish J. Agric. Res. 7: 7-20.

- \& NILSSON, K. A. 1976. Influence on the levels of heavy metals in soil and plant from sewage sludge used as fertilizer. Swedish J. Agric. Res. 6: 151-159.

ASGHAR, M. \& KANEHIRO, Y. 1980. Effects of sugarcane trash and pineapple residue on soil pH, redox potential, extractable $\mathrm{Al}, \mathrm{Fe}$ and $\mathrm{Mn}$. Tropical Agric. 57: 245-258.

AURA, E. 1978. Determination of available soil phosphorus by chemical methods. J. Scient. Agric. Soc. Finl. 50: 305-316.

BALL, E. G. 1937. Studies on oxidation-reduction. XXIII. Ascorbic acid. J. Biol. Chem. 118: 219-239.

BARBER, D. A. \& LEE, R. B. 1974. The effect of micro-organisms on the absorption of manganese by plants. New Phytol. 73: 97-106.

BAXENDALE, J. H., HARDY, H. R. \& SUTCLIFFE, L. H. 1951. Kinetics and equilibria in the system ferrous ion + ferric ion + hydroquinone + quinone. Trans. Faraday Soc. 47: 963-973.

BEAR, F. E. 1964. Chemistry of the soil. 515 p. New York.

BECKWITH, R. S. 1955. Metal complexes in soils. Aust. J. Agric. Res. 6: 685-698.

BEYME, B. 1971. Beziehungen zwischen Mangan-Gehalten in Haferpflanzen und Böden. Z. Pflanzenernähr. Bodenk. 130: 271-281.

BIELSKI, B. H. J., COMSTOCK, D. A. \& BOWEN, R. A. 1971. Ascorbic acid free radicals. I. Pulse radiolysis study of optical absorption and kinetic properties. J. Amer. Chem. Soc. 93: 5624-5629.

BIGSBY, F. W. 1963. Note on a constant moisture balance for maintaining the moisture content of individual soil containers. Can. J. Plant Sci. 43: 432-435.

BLOOMFIELD, C. \& SANDERS, J. R. 1977. The complexing of copper by humified organic matter from laboratory preparations, soil and peat. J. Soil Sci. 28: 435-444.

BOHN, H. L. 1970. Comparison of measured and theoretical $\mathrm{Mn}^{2+}$ concentrations in soil suspensions. Soil Sci. Soc. Amer. Proc. 34: 195-197.

BOKEN, E. 1955. On the effect of ferrous sulphate on the available manganese in the soil and the uptake of manganese by the plant. Plant and Soil 6: 97-112.

- 1956. On the effect of ferrous sulphate on the available manganese in the soil and the uptake of manganese by the plant. II. Plant and Soil 7: 237-252.

- 1957. The effect of ferrous sulphate on the yield and manganese uptake of oats on sandy soil fertilized with pyrolusite. Plant and Soil 8: 160-169. 
BORATYNSKI, K., KAMINSKA, W., ROSZYK, E., ROSZYKOWA, S., STRAHL, A. \& ZIETECKA, M. 1973. Comparison of the AAS method with colorimetric methods of determining some macroand microelements in plants. Part II. Copper, manganese, zinc. Polish J. Soil Sci. 6: 101-106.

BRANDENBURG, E., KLOKE, A., KORONOWSKI, P., LEH, H.-O. \& SCHROPP, W. 1969. Ernährungsstörungen. Handbuch der Pflanzenkrankheiten 1,2:1-478. 7. Aufl. Berlin.

BRICKER, O. 1965. Some stability relations in the system $\mathrm{Mn}-\mathrm{O}_{2}-\mathrm{H}_{2} \mathrm{O}$ at $25^{\circ}$ and one atmosphere total pressure. Amer. Mineral. 50: 1296-1354.

BROMFIELD, S. M. 1958. The properties of a biologically formed manganese oxide, its availability to oats and its solution by root washings. Plant and Soil 9: 325-337.

- 1959. The solution of $\gamma-\mathrm{MnO}_{2}$ by substances released from soil and from the roots of oats and vetch in relation to manganese availability. Plant and Soil 10: 147-160.

- 1978. The oxidation of manganous ions under acid conditions by an acidophilous actinomycete from acid soil. Aust. J. Soil Res. 16: 91-100.

- DAVID, D. J. 1978. Properties of biologically formed manganese oxide in relation to soil manganese. Aust. J. Soil Res. 16: 79-89.

- \& SKERMAN, B. D. 1950. Biological oxidation of manganese in soils. Soil Sci. 69: 337-348.

BROWMAN, M. G., CHESTERS, G. \& PIONKE, H. B. 1969. Evaluation of tests for predicting the availability of soil manganese to plants. J. Agric. Sci., Camb. 72: 335-340.

BRÜMMER, G. 1974. Redoxpotentiale und Redoxprozesse von Mangan-, Eisen- und Schwefelverbindungen in hydromorphen Böden und Sedimenten. Geoderma 12: 207-222.

BUSER, W., GRAF, P. \& FEITKNECHT, W. 1954. Beitrag zur Kenntnis der Mangan(II)-manganite und der $\delta-\mathrm{MnO}_{2}$. Helv. Chim. Acta 37: 2322-2333.

CARLSON, L., KOLJONEN, T., LAHERMO, P. \& ROSENBERG, R. J. 1977. Case study of a manganese and iron precipitate in a ground-water discharge in Somero, southwestern Finland. Bull. Geol. Soc. Finl. 49: 159-173.

CHAO, T. T. 1972. Selective dissolution of manganese oxides from soils and sediments with acidified hydroxylamine hydrochloride. Soil Sci. Soc. Amer. Proc. 36: 764-768.

CHEAM, V. 1973. Chelation study of copper(II): fulvic acid system. Can. J. Soil Sci. 53: 377-382.

CHENG, B. T., BOURGET, S. J. \& OUELLETTE, G. J. 1971. Effect of some physical properties on growth and $\mathrm{Mn}, \mathrm{Fe}, \mathrm{Al}$ and $\mathrm{Mo}$ content of oats. Can. J. Soil Sci. 51: 125-126.

— \& OUELLETTE, G. J. 1971. Manganese availability in soil. Soils and Fertilizers 34: 589-595.

CHRISTENSEN, P. D., TOTH, S. J. \& BEAR, F. E. 1950. The status of soil manganese as influenced by moisture, organic matter and pH. Soil Sci. Soc. Amer. Proc. 15: 279-282.

COLLINS, J. F. \& BUOL, S. W. 1970. Patterns of iron and manganese precipitation under specified Eh-pH conditions. Soil Sci. 110: 157-162.

CZERATZKI, W. 1958. Eine keramische Platte zur serienmässigen Untersuchung von Porengrössen im Boden im Spannungsbereich bis ca-1 Atm. Z. Pflanzenernähr. Bodenk. 81: 50-56.

DAVIES, G. \& KUSTIN, K. 1969 a. The stoichiometry and kinetics of manganese(III) reactions with hydroxylamine, o-methylhydroxylamine, and nitrous acid in acid perchlorate solution. Inorg. Chem. 8: 484-490.

- \& KUSTIN, K. 1969 b. Stoichiometry and kinetics of the reaction between manganese(III) and hydroquinone in acid perchlorate solution. Trans. Faraday Soc. 65: 1630-1637.

DAY, F. H. 1963. The chemical elements in nature. (Ref. McKenzie, R. M. 1972).

DIJK, H. van 1971. Cation binding of humic acids. Geoderma 5: 53-67.

DION, H. G. \& MANN, P. J. G. 1946. Trivalent manganese in soils. J. Agric. Sci., Camb. 36: 239-245.

— , MANN, P. J. G. \& HEINTZE, S. G. 1947. The "easily reducible" manganese of soils. J. Agric. Sci., Camb. 37: 17-22.

DOLAR, S. G. \& KEENEY, D. R. 1971. Availability of $\mathrm{Cu}, \mathrm{Zn}$ and $\mathrm{Mn}$ in soils. I. Influence of soil pH, organic matter and extractable phosphorus. J. Sci. Food Agric. 22: 273-278.

DUANGPATRA, P., SIMS, J. L. \& ELLIS, J. H. 1979. Estimating plant-available manganese in selected Kentucky soils. Soil Sci. 127: 35-40.

DUNCAN, D. B. 1955. Multiple range and multiple F tests. Biometrics 11: 1-42.

DYCK, F. B. 1977. A precise automatic water dispenser for greenhouse pots. Can. J. Plant Sci. 57: 617-618.

EGGINS, B. R. \& CHAMBERS, J. Q. 1969. Electrochemical oxidation of hydroquinone in acetonitrile. J. Chem. Soc. Chem. Comm: 232-233. 
ELLIS, B. G. \& KNEZEK, B. D. 1972. Adsorption reactions of micronutrients in soils. Micronutrients in agriculture. p. 59-78. Madison.

ELONEN, P. 1971. Particle-size analysis of soil. Acta Agr. Fenn. 122: 1-122.

ERKAMA, J. 1947. Über die Rolle von Kupfer und Mangan im Leben der höheren Pflanzen. 105 p. Helsinki.

ERVIÖ, R. 1971. Volymviktens inverkan på markkarteringsvärden. Nord. Jordbr. Forskn. 53: 216-218.

— \& VIRRI, K. 1965. Hivenaineista eteläisen Keski-Uudenmaan maaperässä. Ann. Agric. Fenn. 4: 178-184.

ESWARAN, H. \& RAGHU MOHAN, N. G. 1973. The microfabric of petroplinthite. Soil Sci. Soc. Amer. Proc. 37: 79-82.

EZEKIEL, M. \& FOX, K. A. 1961. Methods of correlation and regression analysis. 3rd Ed. 548 p. New York.

FEITKNECHT, W., OSWALD, H. R. \& FEITKNECHT-STEIMANN, V. 1960. Über die topochemische einphasige Reduktion von $\gamma-\mathrm{MnO}_{2}$. Helv. Chim. Acta 48: 147-1950.

FINCK, A. 1956. Die Bindungsformen des Mangans im Boden. Z. Pflanzenernähr. Bodenk. 73: 59-73.

GARCIA, C. G. \& SANCHEZ DE LA PUENTE, L. 1977. The absorption of manganese (III) in oat plants. Plant and Soil 47: 229-237.

GARRELS, R. M. \& CHRIST, C. L. 1965. Solutions, minerals and equilibria. 450 p. New York.

GATTOW, G. \& GLEMSER, O. 1961 a. Über Manganoxyde VIII. Darstellung und Eigenschaften von Braunsteinen. II. Z. anorg. allgem. Chem. 309: 20-36.

— \& GLEMSER, O. 1961 b. Über Manganoxyde. IX. Darstellung und Eigenschaften von Braunsteinen. III. Z. anorg. allgem. Chem. 309: 121-150.

GEERING, H. R., HODGSON, J., F. \& SDANO, C. 1969. Micronutrient cation complexes in soil solution: IV. The chemical state of manganese in soil solution. Soil Sci. Soc. Amer. Proc. 33: 81-85.

GHANEM, I., ELGABALY, M. M. \& TADROS, V. T. 1971. Studies on manganese in soils: III. Effect of adding organic materials on the transformation of added manganese dioxide. U.A.R. J. Soil Sci. 11: 159-169.

GIOVANOLI, R. 1969. A simplified scheme for polymorphism in the manganese dioxides. Chimia 23: $470-472$.

— \& BÜRKI, P. 1975. Comparison of X-ray evidence of marine manganese nodules and non-marine manganese ore deposits. Chimia 29: 266-269.

— , FEITKNECHT, W. \& FISCHER, F. 1971: Über Oxidhydroxide des vierwertigen Mangans mit Schichtengitter. 3. Mitteilung: Reduktion von mangan(III)-manganat(IV) mit Zimtalkohol. Helv. Chim. Acta 54: 1112-1124.

— \& LEUENBERGER, U. 1969. Über die Oxydation von Manganoxidhydroxid. Helv. Chim. Acta 52: $2333-2347$.

- , MAURER, R. \& FEITKNECHT, W. 1967. Zur Struktur des $\gamma-\mathrm{MnO}_{2}$. Helv. Chim. Acta 50: 1072-1080.

— \& STÄHLI, E. 1970. Oxide und Oxidhydroxide des drei- und vierwertigen Mangans. Chimia 24: 49-61.

— , STÄHLI, E. \& FEITKNECHT, W. 1970 a. Über Oxidhydroxide des vierwertigen Mangans mit Schichtengitter. 1. Mitteilung: Natriummangan(II, III)manganat(IV). Helv. Chim. Acta 53: 209-220.

— , STÄHLI, E. \& FEITKNECHT, W. 1970 b. Über Oxidhydroxide des vierwertigen Mangans mit Schichtengitter. 2. Mitteilung: Mangan(III) - manganat(IV). Helv. Chim. Acta 53: 453-464.

GISIGER, L. \& HASLER, A. 1948. Neuere Beobachtungen über die Ursachen der Dörrfleckenkrankheit beim Hafer. Plant and Soil 1: 19-50.

GLEMSER, O., GATTOW, G. \& MEISIEK, H. 1961. Über Manganoxyde. VII. Darstellung und Eigenschaften von Braunsteinen. I. Z. anorg. allgem. Chem. 309: 1-19.

GODO, G. H. \& REISENAUER, H. M. 1980. Plant effects on soil manganese availability. Soil Sci. Soc. Amer. J. 44: 993-995.

GOMAH, A. M., AWAD SOLIMAN, M. S. \& ABDEL-GHAFFAR, A. S. 1980. Manganese mobility in Egyptian soils as affected by inoculation with manganese reducing organisms. Z. Pflanzenernähr. Bodenk. 143: 274-281.

GRAHAM, E. R. 1948. Determination of soil organic matter by means of a photoelectric colorimeter. Soil Sci. 65: 181-183. 
GRASMANIS, V. O. \& LEEPER,. G. W. 1966. Toxic manganese in near-neutral soil. Plant and Soil 25: 41-48.

GRINSTEAD, R. R. 1960. The oxidation of ascorbic acid by hydrogen peroxide. Catalysis by etylenediaminetetraacetato-iron(III). J. Amer. Chem. Soc. 82: 3464-3471.

GROOT, A. J. de 1956. Influence of age and organic matter on the availability of manganese in marine and estuary soils. Proc. 6th Int. Congr. Soil Sci. 2: 531-539.

GUPTA, U. C. 1972. Effects of manganese and lime on yield and on the concentrations of manganese, molybdenium, boron, copper and iron in the boot stage tissue of barley. Soil Sci. 114: 131-136.

— , MACLEOD, J. A. \& MACLEOD, L. B. 1973. Effects of aluminum, manganese and lime on toxicity symptoms, nutrient composition, and yield of barley grown on a podsol soil. Plant and Soil 39: 413-421.

HAMMES, J. K. \& BERGER, K. C. 1960 a. Manganese deficiency in oats and correlation of plant manganese with various soil tests. Soil Scil. 90: 239-244.

- \& BERGER, K. C. 1960 b. Chemical extraction and crop removal of manganese from air-dried and moist soils. Soil Sci. Soc. Amer. Proc. 24: 361-364.

HANDBOOK OF CHEMISTRY AND PHYSICS 1969. 49th Ed. Cleveland.

HARRIS, R. S. 1954. Ascorbic acid. I. Nomenclature and formulas. The vitamins. Chemistry, physiology, pathology I: 179-180. New York.

HARTER, R. D. \& McLEAN, E. D. 1965. The effect of moisture level and incubation time on chemical equilibria of a Toledo clay loam soil. Agron. J. 57: 583-588.

HEALY, T. W., HERRING, A. P. \& FUERSTENAU, D. W. 1966. The effect of crystal structure on the surface properties of a series of manganese dioxides. J. Colloid Interface Sci. 21: 435-444.

HEINONEN, R. 1960. Density, amount and carbon content of organic matter in soils - some methodical reflections. J. Scient. Agric. Soc. Finl. 32: 125-127.

HEINTZE, S. G. 1956. The effects of various soil treatments on the occurrence of marsh spot in peas and on manganese uptake and yield of oats and timothy. Plant and Soil 7: 218-236.

— \& MANN, P. J. G. 1947. Soluble complexes of manganic manganese. J. Agric. Sci., Camb. 37: 23-26.

— \& MANN, P. J. G. 1949. Studies on soil manganese. J. Agric. Sci., Camb. 39: 80-95.

— \& MANN, P. J. G. 1951. A study of various fractions of the manganese of neutral and alkaline organic soils. J. Soil Sci. 2: 234-242.

HEMSTOCK, G. A. \& LOW, P. F. 1953. Mechanisms responsible for retention of manganese in colloidal fraction of soil. Soil Sci. 76: 331-343.

HOYT, P. B. \& NYBORG, M. 1971. Toxic metals in acid soil: II. Estimation of plant-available manganese. Soil Sci. Soc. Amer. Proc. 35: 241-244.

INGOLS, R. S. \& ENGINUN, M. E. 1968. Biological studies of manganese solution from its dioxide. Adv. Chem. Ser. 73: 143-148.

IRVING, H. \& WILLIAMS, R. J. P. 1948. Order of stability of metal complexes. Nature 162: 746-747.

IVASKA, A. 1974. Rapid determination of the equivalence volume in potentiometric acid-base titrations to a present $\mathrm{pH}-$ II. Talanta $21: 387-392$.

JACKSON, M. L. 1956. Soil chemical analysis - Advanced course. 991 p. Madison.

— \& SHERMAN, G. D. 1953. Chemical weathering of minerals in soils. Adv. Agron. 5: 219-318.

JACOB, H.-E. 1970. Redox potential. Methods in Microbiology 2: 91-123.

JAUHIAINEN, E. 1973. Effect of climate on podzolization in southwest and eastern Finland. Soc. Sci. Fenn. Commentat. Phys.-Math. 43: 213-242.

JINDAL, V. K., AGRAWAL, M. C. \& MUSHRAN, S. P. 1970. Mechanism of the oxidation of hydroxylamine by ferricyanide. J. Chem. Soc. A: 2060-2062.

JONES, L. H. P. 1957 a. The effect of liming a neutral soil on the uptake of manganese by plants. Plant and Soil 8: 301-314.

- $1957 \mathrm{~b}$. The effect of liming a neutral soil on the cycle of manganese. Plant and Soil 8: 315-327.

- 1957 c. The relative content of manganese in plants. Plant and Soil 8: 328-336.

- \& LEEPER, G. W. 1951 a. The availability of various manganese oxides to plants. Plant and Soil 3: $141-153$.

- \& LEEPER, G. W. 1951 b. Available manganese oxides in neutral and alkaline soils. Plant and Soil 3: 154-159.

KALOVOULOS, J. M. \& PAXINOS, S. A. 1963. Potassium uptake by cation-exchange resin Amberlite IR-120 from Fithian illite. Soil Sci. Soc. Amer. Proc. 27: 519-521. 
KANEHIRO, Y. \& SHERMAN, G. D. 1965. Fusion with sodium carbonate for total elemental analysis. Agronomy 9, 2: 952-958.

KANNAN, S. \& KEPPEL, H. 1976. A study on the cytoplasmic and vacuolar accumulation of Fe and $\mathrm{Mn}$ in excised wheat roots. Comm. Soil Sci. Plant Anal. 7: 763-775.

KHAN, M. M. T. \& MARTELL, A. E. 1967. Metal ion and metal chelate catalyzed oxidation of ascorbic acid by molecular oxygen. I. Cupric and ferric ion catalyzed oxidation. J. Amer. Chem. Soc. 89: 4176-4185.

KHANNA, P. K. \& MISHRA, B. 1978. Behavior of manganese in some acid soils in Western Germany in relation to $\mathrm{pH}$ and air-drying. Geoderma 20: 289-297.

KOLJONEN, T., LAHERMO, P. \& CARLSON, L. 1976. Origin, mineralogy, and chemistry of manganiferous and ferruginous precipitates found in sand and gravel deposits in Finland. Bull. Geol. Soc. Finl. 48: 111-135.

KOWALENKO, C. G., MAAS, E. F. \& VANLAERHOVEN, C. I. 1980. Residual effects of high rates of limestone, $\mathrm{P}, \mathrm{K}$ and $\mathrm{Mg}$ applications: Evidence of induced $\mathrm{Mn}$ and $\mathrm{Zn}$ deficiency in oats. Can. J. Soil Sci. 60: 757-761.

KROGMAN, K. K. 1963. Note on a method for soil-moisture control in greenhouse pots. Can. J. Plant Sci. 43: 410-411.

KUNIN, R. 1974. Amberlite ion exchange resins and other fluid process chemicals. Summary chart of properties and applications. Amber-hi-lites 141.8 p. Philadelphia.

KURKI, M. 1972. Suomen peltojen viljavuudesta. II. Viljavuuspalvelu Oy:ssä vuosina 1955-1970 tehtyjen viljavuustutkimusten tuloksia. Referat: Über die Fruchtbarkeit des finnischen Ackerbodens auf Grund der in den Jahren 1955-1970 durchgeführten Bodenfruchtbarkeitsuntersuchungen. $182 \mathrm{p}$. Helsinki.

-1979 . Suomen peltojen viljavuuden kehityksestä. 41 p. Helsinki.

KUSTIN, K. \& TOPPEN, D. L. 1973. Reduction of vanadium(V) by L-ascorbic acid. Inorg. Chem. 12: $1404-1407$.

KÄHÄRI, J. \& NISSINEN, H. 1978. The mineral element contents of timothy (Phleum pratense L.) in Finland. I. The elements calcium, magnesium, phosphorus, potassium, chromium, cobalt, copper, iron, manganese, sodium and zinc. Acta Agric. Scand. Suppl. 20: 26-39.

LAHTI, S. I. 1981. On the granitic pegmatites of the Eräjärvi area in Orivesi, southern Finland. Geol. Surv. Finl. Bull. 314: 1-82.

LAMM, C. G. 1964. Mangans kemi i jordbunden. 248 p. Kopenhavn.

LATIMER, W. M. 1952. Oxidation potentials. 2nd Ed. 392 p. New York.

LEEPER, G. W. 1935. Manganese deficiency of cereals: Plot experiments and a new hypothesis. Proc. Roy. Soc. Victoria 47: 225-261.

- 1947. The forms and reactions of manganese in the soil. Soil Sci. 63: 79-94.

- \& SWABY, R. J. 1940. The oxidation of manganous compounds by microorganisms in the soil. Soil Sci. 49: 163-169.

LE RICHE, H. H. 1973. The distribution of minor elements among the components of a soil developed in loess. Geoderma 9: 43-57.

LOGANATHAN, P. \& BURAU, R. G. 1973. Sorption of heavy metal ions by a hydrous manganese oxide. Geochim. Cosmochim. Acta 37: 1277-1293.

- , BURAU, R. G. \& FUERSTENAU, D. W. 1977. Influence of $\mathrm{pH}$ on the sorption of $\mathrm{Co}^{2+}, \mathrm{Zn}^{2+}$ and $\mathrm{Ca}^{2+}$ by a hydrous manganese oxide. Soil Sci. Soc. Amer. J. 41: 57-62.

LÖHNIS, M. P. 1951. Manganese toxicity in field and market garden crops. Plant and Soil 3:193-222.

MacLEAN, A. J. 1961. Potassium-supplying power of some Canadian soils. Can. J. Soil Sci. 41: 196-206.

MacLEAN, K. S. \& LANGILLE, W. M. 1976. The extractable trace element content of acid soils and the influence of $\mathrm{pH}$, organic matter and clay content. Comm. Soil Sci. Plant Anal. 7: 777-785.

MANN, P. J. G. \& QUASTEL, J. H. 1946. Manganese metabolism in soils. Nature 158: 154-156.

MATTILA, S. 1967. Tilastotiede II. 174 p. Helsinki.

MATTSON, S. \& NILSSON, I. 1935. The chemical characteristics of soil properties: III. The podsol complex. Ann. Agric. Coll. Sweden 2: 115-134.

McBRIDE, M. B. 1979. Chemisorption and precipitation of $\mathrm{Mn}^{2+}$ at $\mathrm{CaCO}_{3}$ surfaces. Soil Sci. Soc. Amer. J. 43: 693-698.

McHARGUE, J. S. 1922. The role of manganese in plants. J. Amer. Chem. Soc. 44: 1592-1598.

McKEAGUE, J. A., DAMMAN, A. W. H. \& HERINGA, P. K. 1968. Iron-manganese and other pans in some soils of Newfoundland. Can. J. Soil Sci. 48: 243-253. 
McKENZIE, R. M. 1972. The manganese oxides in soils - A review. Z. Pflanzenernähr. Bodenk. 131: 221-242.

- 1977. Manganese oxides and hydroxides. Minerals in soil environments. p. 181-193. Madison.

McLAUGHLIN, N. B. 1977. A semiautomatic pot watering device. Can. J. Soil Sci. 57: 77-79.

MEEK, B. D., PAGE, A. L. \& MARTIN, J. P. 1973. The oxidation of divalent manganese under conditions present in tile lines as related to temperature, soil surfaces, micro-organisms, and solution chemical composition. Soil Sci. Soc. Amer. Proc. 37: 542-548.

MEHROTRA, U. S., AGRAWAL, M. C. \& MUSHRAN, S. P. 1969. Kinetics of the reduction of hexacyanoferrate (III) by ascorbic acid. J. Phys. Chem. 73: 1996-1999.

- , AGRAWAL, M. C. \& MUSHRAN, S. P. 1970. Reduction of hexachloroplatinate by ascorbic acid. J. Inorg. Nucl. Chem. 32: 2325-2329.

MELLOR, D. P. \& MALLEY, L. 1948. Order of stability of metal complexes. Nature 161: 436-437.

MILLER, M. H. \& OHLROGGE, A. J. 1958 a. Water-soluble chelating agents in organic materials: I. Characterization of chelating agents and their reactions with trace metals in soils. Soil Sci. Soc. Amer. Proc. 22: 225-228.

— \& OHLROGGE, A. J. 1958 b. Water-soluble chelating agents in organic materials: II. Influence of chelate-containing materials on the availability of trace metals to plants. Soil Sci. Soc. Amer. Proc. 22: $228-231$.

MISRA, S. G. \& DWIVEDI, R. S. 1979. Effect of iron-nickel interactions on the availability of copper and manganese. An. Edaf. Agrobiol. 38: 167-171.

MOELLER, T. 1959. Inorganic chemistry. 996 p. New York.

MORGAN, J. J. \& STUMM, W. 1964. Colloid-chemical properties of manganese dioxide. J. Colloid Sci. 19: 347-359.

MOSS, P. 1964. Some aspects of the cation status of soil moisture. Part V: The effect of soil moisture tension on growth and cation uptake by plants. Plant and Soil 20: 271-286.

MULDER, E. G. \& VEEN, L. W. van 1968. Effect of microorganisms on the transformation of mineral fractions in soil. Trans. 9th Int. Congr. Soil Sci. 4: 651-661.

MURRAY, D. J., HEALY, T. W. \& FUERSTENAU, D. W. 1968. The adsorption of aqueous metal on colloidal hydrous manganese oxide. Adv. Chem. Ser. 79: 74-81.

MUSHRAN, S. P., AGRAWAL, M. C., MEHROTRA, R. M. \& SANEHI, R. 1974. Kinetics and mechanism of reduction of silver(I) by ascorbic acid. J. Chem. Soc., Dalton Trans: 1460-1462.

MÄNTYLAHTI, V. \& YLÄRANTA, T. 1981. The effect of heat treatment and ionizing irradiation on the extractability of some macro- and micronutrients in soils. Ann. Agric. Fenn. 20: 253-260.

NELSON, L. E. 1977. Changes in water-soluble Mn due to soil sample preparation and storage. Comm. Soil Sci. Plant Anal. 8: 479-487.

NORD, H. 1955. Kinetics and mechanism of the copper catalysed autoxidation of ascorbic acid. Acta Chem. Scand. 9: 442-454.

OLOMU, M. O., RACZ, G. J. \& CHO, C. M. 1973. Effect of flooding on the Eh, pH and concentrations of $\mathrm{Fe}$ and $\mathrm{Mn}$ in several Manitoba soils. Soil Sci. Soc. Amer. Proc. 37: 220-224.

OSMAN, A. Z., EL-SHERIF, A. F. \& BASSIONY, H. 1978. Manganese availability as affected by calcium carbonate levels. Z. Pflanzenernähr. Bodenk. 141: 77-82.

OTTOW, J. C. G. 1982. Bedeutung des Redoxpotentials für die Reduktion von Nitrat und $\mathrm{Fe}$ (III)Oxiden in Böden. Z. Pflanzenernähr. Bodenk. 145: 91-93.

PAGE, E. R. 1962. Studies in soil and plant manganese. II. The relationship of soil $\mathrm{pH}$ to manganese availability. Plant and Soil 16:247-257.

— , SCHOFIELD-PALMER, E. K. \& McGREGOR, A. J. 1962. Studies in soil and plant manganese. I. Manganese in soil and its uptake by oats. Plant and Soil 16: 238-246.

PAL, S. S., SUDHAKAR-BARIK \& SETHUNATHAN, N. 1979. Effects of benomyl on iron and manganese reduction and redox potential in flooded soil. J. Soil Sci. 30: 155-159.

PARKS, G. A. 1965. The isoelectric points of solid oxides, solid hydroxides, and aqueous hydroxo complex systems. Chem. Rev. 65: 177-198.

PATRICK, W. H., Jr. 1960. Nitrate reduction rates in a submerged soil as affected by redox potential. Trans. 7th Int. Congr. Soil Sci. 2: 494-500.

- 1964. Extractable iron and phosphorus in a submerged soil at controlled redox potentials. Trans. 8th Int. Congr. Soil Sci. 4: 605-609.

- \& HENDERSON, R. E. 1981 a. A method for controlling redox potential in packed soil cores. Soil Sci. Soc. Amer. J. 45: 35-38. 
— \& HENDERSON, R. E. 1981 b. Reduction and reoxidation cycles of manganese and iron in flooded soil and in water solution. Soil Sci. Soc. Amer. J. 45: 855-859.

PELIZZETTI, E., MENTASTI, E. \& PRAMAURO, E. 1976. Kinetics and mechanism of the oxidation of ascorbic acid by tris(1,10-phenantroline)iron(III) and its derivates in aqueous acidic perchlorate media. Inorg. Chem. 15: 2898-2900.

PONNAMPERUMA, F. N. 1972. The chemistry of submerged soils. Adv. Agron. 24: 29-96.

— \& CASTRO, R. U. 1964. Redox systems in submerged soils. Trans. 8th Int. Congr. Soil Sci. 3: 379-386.

— , LOY, T. A. \& TIANCO, E. M. 1969. Redox equilibria in flooded soils: II. The manganese oxide systems. Soil Sci. 108: 48-57.

PRATT, P. F., BAIR, F. L. \& McLEAN, G. W. 1964. Nickel and copper chelation capacities of soil organic matter. Trans. 8th Int. Congr. Soil Sci. 3: 243-248.

RANDALL, G. W., SCHULTE, E. E. \& COREY, R. B. 1976. Correlation of plant manganese with extractable soil manganese and soil factors. Soil Sci. Soc. Amer. J. 40: 282-287.

RANDHAWA, N. S. \& BROADBENT, F. E. 1965. Soil organic matter-metal complexes: 6. Stability constants of zinc-humic acid complexes at different $\mathrm{pH}$ values. Soil Sci. 99: 362-366.

RANKAMA, K. \& SAHAMA, T. G. 1950. Geochemistry. 912 p. Chicago.

REHAB, F. I. \& WALLACE, A. 1978. Excess trace metal effects on cotton. 1. Copper, zinc, cobalt and manganese in solution culture. Comm. Soil Sci. Plant Anal. 9: 507-518.

ROBERGE, M. R. \& KNOWLES, R. 1968. Factors affecting urease activity in a black spruce humus sterilized by gamma radiation. Can J. Soil Sci. 48: 355-361.

ROBERTS, J. D. \& CASERIO, M. C. 1967. Modern organic chemistry. 844 p. New York.

ROBINSON, R. A. \& BOWER, V. E. 1961. The ionization constant of hydroxylamine. J. Phys. Chem. 65: $1279-1280$.

ROBINSON, W. O. 1929. Detection and significance of manganese dioxide in the soil. Soil Sci. 27: 335-350.

ROORDA van EYSINGA, J. P. N. L., DIJK, P. A. van \& BES, S. S. de 1978. The available manganese content of soils in the Netherlands determined by various methods. Comm. Soil Sci. Plant Anal. 9: 141-151.

ROSS, S. J., Jr., FRANZMEIER, D. P. \& ROTH, C. B. 1976. Mineralogy and chemistry of manganese oxides in some Indiana soils. Soil Sci. Soc. Amer. J. 40: 137-143.

RYTI, R. 1965. On the determination of soil pH. J. Scient. Agric. Soc. Finl. 37: 51-60.

SANCHEZ, C. \& KAMPRATH, E. J. 1959. Effect of liming and organic matter content on the availability of native and applied manganese. Soil Sci. Soc. Amer. Proc. 23: 302-304.

SCHACHTSCHABEL, P. 1956. Die Bestimmung des Manganversorgungsgrades der Böden. Proc. 6th Int. Congr. Soil Sci. 4: 113-118.

- 1957. Die Bestimmung des Manganversorgungsgrades von Böden und seine Beziehung zum Auftreten der Dörrfleckenkrankheit bei Hafer. Z. Pflanzenernähr. Bodenk. 78: 147-167.

SCHLICHTING, E. \& ELGALA, A. M. 1975. Schwermetalverbindung und Tongehalte in Böden. Z. Pflanzenernähr. Bodenk.: 563-571.

SCHMITZ, G. W. \& PRATT, P. F. 1953. Exchangeable and nonexchangeable potassium as indexes to yield increases and potassium absorption by corn in the greenhouse. Soil Sci. 76: 345-353.

SCHNITZER, M. 1969. Reactions between fulvic acid, a soil humic compound and inorganic soil constituents. Soil Sci. Soc. Amer. Proc. 33: 75-81.

- \& HANSEN, E. H. 1970. Organo-metallic interactions in soils: 8. An evaluation of methods for the determination of stability constants of metal-fulvic acid complexes. Soil Sci. 109: 333-340.

- \& SKINNER, S. I. M. 1967. Organo-metallic interactions in soils: 7. Stability constants of $\mathrm{Pb}^{++}-$, $\mathrm{Ni}^{++}, \mathrm{Mn}^{++}-, \mathrm{Co}^{++}, \mathrm{Ca}^{++}$, and $\mathrm{Mg}^{++}$-fulvic acid complexes. Soil Sci. 103: 247-252.

SCHÜTZ, E. 1978. Über die Verfügbarkeit verschiedener Manganfraktionen eines Moorbodens. Schw. landw. Forsch. 17: 165-178.

- 1980. Über die Verfügbarkeit verschiedener Manganfraktionen eines Mineralbodens. Schw. landw. Forsch. 19: 63-70.

SEMB, G. \& ØIEN, A. 1970. Orienterende undersøkelser over manganmangel i relasjon til pH og manganinnholdet i jorda. Forsk. Fors. Landbr. 21: 125-137.

SERDOBOLSKII, I. P. \& SINYAGINA, M. G. 1953. Acid-base conditions of the formation of soluble organic compounds of manganese. Pochvovedenie 8: 42-50. (Ref. Soils and Fertilizers 17: 42). 
SHELDRICK, B. H. \& McKEAGUE, J. A. 1975. A comparison of extractable Fe and Al data using methods followed in the U.S.A and Canada. Can. J. Soil Sci. 55: 77-78.

SHERMAN, G. D. \& HARMER, P. M. 1942. The manganous - manganic equilibrium of soils. Soil Sci. Soc. Amer. Proc. 7: 398-405.

— , McHARGUE, J. S. \& HODGKISS, W. S. 1942. Determination of active manganese in soil. Soil Sci. 54: 253-257.

SHUMAN, L. M. 1980. Effects of soil temperature, moisture and air-drying on extractable manganese, iron, copper, and zinc. Soil Sci. 130: 336-343.

SIBBESEN, E. 1977. A simple ion-exchange resin procedure for extracting plant-available elements from soil. Plant and Soil 46: 665-669.

- 1978. An investigation of the anion-exchange resin method for soil phosphate extraction. Plant and Soil 50: 305-321.

- 1981. Some new equations to describe phosphate sorption by soils. J. Soil Sci. 32: 67-74.

SILLANPÄÄ, M. 1962. Trace elements in Finnish soils as related to soil texture and organic matter content. J. Scient. Agric. Soc. Finl. 34: 34-40.

-1975 . Hivenaineet suoprofiilissa. Summary: Distribution of trace elements in peat profiles. Suo 26: 83-86.

- 1977. Maanäytteiden varastointiajan, kosteustilan ja uuttolämpötilan vaikutus viljavuusanalyysin tuloksiin. Referat: Inverkan av förvaringstid, fuktighet och extraheringstemperatur på resultaten vid markkarteringsanalys. Kehittyvä Maatalous 35: 13-23.

- \& RINNE, S.-L. 1975. The effect of heavy nitrogen fertilization on the uptake of nutrients and on some properties of soils cropped with grasses. Ann. Agric. Fenn. 14: 210-226.

SIMS, J. L. \& PATRICK, W. H., Jr. 1978. The distribution of micronutrient cations in soil under conditions of varying redox potential and pH. Soil Sci. Soc. Amer. J. 42: 258-262.

SIPPOLA, J. 1974. Mineral composition and its relation to texture and to some chemical properties in Finnish subsoils. Ann. Agric. Fenn. 13: 169-234.

— \& KURKI, M. 1981. Maasta eri uuttomenetelmillä uuttuvat hivenainemäärät ja niiden korrelointi timotein hivenainepitoisuuden kanssa. Maantutkimuslaitoksen tiedote 13: 1-14.

— \& TARES, T. 1978. The soluble content of mineral elements in cultivated Finnish soils. Acta Agric. Scand. Suppl. 20: 11-25.

SKUJINS, J. J. \& McLAREN, A. D. 1969. Assay of urease activity using ${ }^{14} \mathrm{C}$-urea in stored geologically preserved and irradiated soils. Soil Biol. Biochem. 1: 89-99.

SMITH, F. 1954. Ascorbic acid. II. Chemistry. The Vitamins. Chemistry, physiology, pathology I: 180-208. New York.

SNEDECOR, G. W. \& COCHRAN, W. G. 1978. Statistical methods. 6th Ed. 593 p. Ames.

SOLTANPOUR, P. N., KHAN, A. \& LINDSAY, W. L. 1976. Factors affecting DTPA-extractable Zn, $\mathrm{Fe}, \mathrm{Mn}$ and $\mathrm{Cu}$ from soils. Comm. Soil Sci. Plant Anal. 7: 797-821.

STEENBJERG, F. 1933. Undersøgelser over manganindholdet i dansk jord. I. Det ombyttelige mangan. Tidsskr. Planteavl. 39: 401-436.

STEVENSON, D. S. \& MUNN, D. M. 1970. A simple automatic waterer for growth room or greenhouse. Can. J. Soil Sci. 50: 461-462.

STEVENSON, F. J. 1976. Stability constants of $\mathrm{Cu}^{2+}, \mathrm{Pb}^{2+}$ and $\mathrm{Cd}^{2+}$ complexes with humic acids. Soil Sci. Soc. Amer. J. 40: 665-672.

- 1977. Nature of divalent transition metal complexes of humic acids as revealed by a modified potentiometric titration method. Soil Sci. 123: 10-17.

STUMM, W. \& MORGAN, J. J. 1970. Aquatic chemistry. An introduction emphasizing chemical equilibria in natural waters. 583 p. New York.

STÅHLBERG, S. \& SOMBATPANIT, S. 1974. Manganese relationships of soil and plant. I. Investigation and classification of Swedish manganese-deficient soils. Acta Agric. Scand. 24: 179-194.

- , SOMBATPANIT, S. \& STÅHLBERG, J. 1976. Manganese relationships of soil and plant. II. Studies on manganese fixation. Acta Agric. Scand. 26: 65-81.

TAKAI, Y. \& KAMURA, T. 1966. The mechanism of reduction in waterlogged paddy soil. Folia Microbiol. 11: 304-313.

TAYLOR, R. M. \& McKENZIE, R. M. 1966. The association of trace elements with manganese minerals in Australian soils. Aust. J. Soil Res. 4: 29-39.

- , McKENZIE, R. M. \& NORRISH, K. 1964. The mineralogy and chemistry of manganese in some Australian soils. Aust. J. Soil Res. 2: 235-248. 
TILLER, K. G. 1963. Weathering and soil formation on dolerite in Tasmania with particular reference to several trace elements. Aust. J. Soil Res. 1: 74-90.

TISDALE, S. L. \& BERTRAMSON, B. R. 1950. Elemental sulfur and its relationship to manganese availability. Soil Sci. Soc. Amer. Proc. 14: 131-137.

TURNER, F. T. \& PATRICK, W. H., Jr. 1968. Chemical changes in waterlogged soils as a result of oxygen depletion. Trans. 9th Int. Congr. Soil Sci. 4: 53-65.

ULMGREN, P. \& WAHLBERG, O. 1971. Equilibrium studies of L-ascorbate ions. II. Metal-ascorbate complex formed in aqueous solution, an introduction. Acta Chem. Scand. 25: 1000-1010.

UREN, N. C. \& LEEPER, G. W. 1978. Microbial oxidation of divalent manganese. Soil Biol. Biochem. $10: 85-87$.

VASARI, Y., KOLJONEN, T. \& LAAKSO, K. 1972. A case of manganese precipitate in the Taviharju esker, Kuusamo, North East Finland. Bull. Geol. Soc. Finl. 44: 133-140.

VETTER, K. J. 1952. Überspannung und Kinetik der Chinhydronelektrode. Z. Electrochem. 56: 797-806.

VORM, P. D. J. van der \& DIEST, A. van 1979. Aspects of the Fe- and Mn nutrition of rice plants. Plant and Soil 51: 233-246.

VUORINEN, J. 1958. On the amounts of minor elements in Finnish soils. J. Scient. Agric. Soc. Finl. 30: 30-35.

WADDY, J. A. \& VIMPAY, I. A. 1970. Estimation of non-exchangeable potassium in soils using a cation-exchange resin. J. Sci. Food Agric. 21: 113-115.

WAHLBERG, O. \& ULMGREN, P. 1967. Equilibrium studies of L-ascorbate ions. I. Equilibria between ascorbate ions and protons in $3 \mathrm{M} \mathrm{Na}\left(\mathrm{ClO}_{4}\right)$ medium. Acta Chem. Scand. 21: 2759-2772.

WALKER, J. M. \& BARBER, S. A. 1960. The availability of chelated Mn to millet and its equilibria with other forms of $\mathrm{Mn}$ in the soil. Soil Sci. Soc. Amer. Proc. 24: 485-488.

WARTIOVAARA, V. 1943. Mikrobiviljelmien elektrodipotentiaalin mittaamisesta. Suomen Kemistilehti A $16: 68-73$.

WEBER, J. R., MUNCH, J. C. \& OTTOW, J. C. G. 1979. Einfluss der Teilchengrösse auf die bacterielle Reduzierbarkeit pedogener Eisenoxide. Mitt. Deut. Bodenkundl. Ges. 29: 465-472.

WELLS, C. F. \& KURITSYN, L. V. 1970. Kinetics of the oxidation of quinol by aquovanadium(V) ions in perchlorate media. J. Chem. Soc. A: 1372-1376.

WHITE, R. P. 1970. Effects of lime upon soil and plant manganese levels in an acid soil. Soil Sci. Soc. Amer. Proc. 34: 625-629.

WILLARD, H. H. \& GREATHOUSE, L. H. 1917. The colorimetric determination of manganese by oxidation with periodate. J. Amer. Chem. Soc. 39: 2366-2377.

YAALON, D. H., JUNGREIS, C. \& KOYUMDJISKY, H. 1972. Distribution and reorganization of manganese in three catenas of Mediterranean soils. Geoderma 7: 71-78.

ZAHER, E. A. H. 1979. Adsorption and movement of manganese in some soils of Western Germany. 125 p. Göttingen.

ZoBELL, C. E. 1946. Studies on redox potential of marine sediments. Bull. Amer. Assoc. Petrol. Geol. 30: 477-513.

Ms received June 18, 1982. 
Appendix 1. Soil samples in the basic material.

$\mathrm{a}=0-20 \mathrm{~cm}, \mathrm{~b}=20-40 \mathrm{~cm}, \mathrm{~V}=$ virgin soil.

\begin{tabular}{|c|c|c|c|c|c|c|c|c|}
\hline \multirow{2}{*}{$\begin{array}{c}\text { Soil } \\
\text { sample }\end{array}$} & \multirow{2}{*}{$\begin{array}{c}\text { Bulk } \\
\text { density, } \\
\mathrm{kg} / \mathrm{dm}^{3}\end{array}$} & \multirow{2}{*}{$\underset{\mathrm{CaCl}_{2}}{\mathrm{pH}}$} & \multirow{2}{*}{$\underset{\%}{\text { Org. C, }}$} & \multicolumn{5}{|c|}{ Particle-size distribution, \% } \\
\hline & & & & $\begin{array}{l}<2 \\
\mu \mathrm{m}\end{array}$ & $\begin{array}{c}2-20 \\
\mu \mathrm{m}\end{array}$ & $\begin{array}{c}20-60 \\
\mu \mathrm{m}\end{array}$ & $\begin{array}{c}60-200 \\
\mu \mathrm{m}\end{array}$ & $\begin{array}{c}>200 \\
\mu \mathrm{m}\end{array}$ \\
\hline 1a V & 0,74 & 4,5 & 7,8 & 23 & 22 & 37 & 15 & 3 \\
\hline $1 \mathrm{~b} \mathrm{~V}$ & 1,23 & 4,3 & 1,0 & 8 & 7 & 28 & 53 & 4 \\
\hline $2 a \mathrm{~V}$ & 0,58 & 4,5 & 10,6 & 40 & 21 & 25 & 12 & 2 \\
\hline $2 \mathrm{~b} \mathrm{~V}$ & 0,95 & 3,4 & 2,8 & 17 & 15 & 35 & 30 & 3 \\
\hline $3 a$ & 1,10 & 6,4 & 4,1 & 35 & 22 & 21 & 19 & 3 \\
\hline $3 \mathrm{~b}$ & 1,12 & 6,2 & 1,0 & 71 & 20 & 1 & 7 & 1 \\
\hline $4 a$ & 0,99 & 5,9 & 5,3 & 47 & 20 & 19 & 11 & 3 \\
\hline $4 \mathrm{~b}$ & 1,03 & 5,6 & 2,0 & 37 & 13 & 14 & 32 & 4 \\
\hline $5 a$ & 0,93 & 5,5 & 5,6 & 38 & 22 & 28 & 10 & 2 \\
\hline $5 b$ & 1,04 & 5,1 & 1,9 & 50 & 21 & 15 & 13 & 1 \\
\hline $6 a$ & 1,25 & 5,4 & 3,0 & 8 & 6 & 20 & 60 & 6 \\
\hline $6 b$ & 1,25 & 5,4 & 1,1 & 12 & 7 & 23 & 57 & 1 \\
\hline $7 \mathrm{a}$ & 1,24 & 5,9 & 4,6 & 8 & 5 & 11 & 68 & 8 \\
\hline $7 b$ & 1,25 & 5,2 & 1,1 & 10 & 5 & 16 & 66 & 3 \\
\hline $8 a$ & 1,04 & 5,7 & 5,6 & 12 & 11 & 23 & 45 & 9 \\
\hline $8 \mathrm{~b}$ & 1,21 & 5,3 & 1,0 & 12 & 7 & 21 & 55 & 5 \\
\hline $9 a$ & 1,33 & 5,4 & 0,7 & 22 & 12 & 20 & 43 & 3 \\
\hline $9 b$ & 1,17 & 5,7 & 0,6 & 45 & 21 & 17 & 16 & 1 \\
\hline $10 \mathrm{a}$ & 1,12 & 4,7 & 1,7 & 46 & 23 & 15 & 13 & 3 \\
\hline $10 \mathrm{~b}$ & 1,08 & 5,6 & 0,9 & 74 & 14 & 4 & 7 & 1 \\
\hline $11 \mathrm{a}$ & 1,16 & 4,8 & 1,6 & 61 & 12 & 8 & 18 & 1 \\
\hline $11 \mathrm{~b}$ & 1,12 & 5,6 & 0,6 & 60 & 12 & 11 & 18 & 0 \\
\hline $12 \mathrm{a}$ & 1,05 & 4,5 & 3,4 & 15 & 45 & 14 & 19 & 7 \\
\hline $12 \mathrm{~b}$ & 1,04 & 4,7 & 0,7 & 14 & 51 & 13 & 16 & 6 \\
\hline $13 \mathrm{a}$ & 1,04 & 4,5 & 4,0 & 15 & 40 & 11 & 19 & 15 \\
\hline $13 \mathrm{~b}$ & 0,98 & 4,8 & 1,0 & 16 & 39 & 8 & 16 & 21 \\
\hline $14 a$ & 1,09 & 4,6 & 3,7 & 6 & 15 & 14 & 47 & 18 \\
\hline $14 \mathrm{~b}$ & 1,16 & 4,6 & 1,6 & 3 & 10 & 12 & 54 & 21 \\
\hline $15 a$ & 1,07 & 6,0 & 3,8 & 25 & 46 & 19 & 7 & 3 \\
\hline $15 \mathrm{~b}$ & 1,10 & 6,0 & 0,9 & 32 & 44 & 16 & 6 & 2 \\
\hline $16 a$ & 1,06 & 5,7 & 3,7 & 22 & 43 & 26 & 4 & 5 \\
\hline $16 \mathrm{~b}$ & 1,14 & 5,5 & 0,9 & 18 & 45 & 32 & 3 & 2 \\
\hline $17 \mathrm{a}$ & 1,06 & 5,4 & 4,6 & 23 & 40 & 17 & 9 & 11 \\
\hline $17 \mathrm{~b}$ & 1,09 & 5,3 & 1,1 & 26 & 47 & 17 & 6 & 4 \\
\hline $18 \mathrm{a}$ & 1,06 & 4,9 & 2,7 & 17 & 13 & 16 & 37 & 17 \\
\hline $19 a$ & 1,00 & 5,3 & 4,2 & 50 & 33 & 3 & 9 & 5 \\
\hline $20 \mathrm{a}$ & 1,19 & 4,9 & 3,0 & 6 & 3 & 3 & 30 & 58 \\
\hline $21 a$ & 1,21 & 5,3 & 3,1 & 6 & 3 & 4 & 30 & 57 \\
\hline $22 \mathrm{~b} \mathrm{~V}$ & 1,26 & 4,7 & 0,4 & 15 & 19 & 4 & 21 & 41 \\
\hline $23 \mathrm{~b} \mathrm{~V}$ & 0,75 & 3,9 & 9,6 & 36 & 45 & 13 & 4 & 2 \\
\hline $24 a$ & 1,18 & 4,7 & 2,6 & 6 & 12 & 14 & 41 & 27 \\
\hline $24 \mathrm{~b}$ & 1,15 & 4,9 & 1,5 & 5 & 9 & 13 & 43 & 30 \\
\hline $25 a$ & 0,96 & 4,6 & 3,1 & 51 & 37 & 9 & 2 & 1 \\
\hline $25 b$ & 0,92 & 4,6 & 1,9 & 52 & 36 & 9 & 2 & 1 \\
\hline $26 a$ & 0,97 & 4,9 & 3,9 & 17 & 41 & 35 & 6 & 1 \\
\hline $26 \mathrm{~b}$ & 0,83 & 4,6 & 2,8 & 14 & 39 & 38 & 7 & 2 \\
\hline $27 a$ & 0,63 & 4,8 & 15,8 & 9 & 32 & 40 & 15 & 4 \\
\hline $27 \mathrm{~b}$ & 0,50 & 4,7 & 18,4 & 9 & 26 & 43 & 15 & 7 \\
\hline
\end{tabular}


Appendix 1. (Continued).

\begin{tabular}{|c|c|c|c|c|c|c|c|c|}
\hline $\begin{array}{c}\text { Soil } \\
\text { sample }\end{array}$ & $\begin{array}{c}\text { Bulk } \\
\text { density, } \\
\mathrm{kg} / \mathrm{dm}^{3}\end{array}$ & $\begin{array}{c}\mathrm{pH} \\
\mathrm{CaCl}_{2}\end{array}$ & $\begin{array}{c}\text { Org. C, } \\
\%\end{array}$ & $\begin{array}{l}<2 \\
\mu \mathrm{m}\end{array}$ & $\begin{array}{c}\text { Particle } \\
2-20 \\
\mu \mathrm{m}\end{array}$ & $\begin{array}{c}\text { ze distri } \\
20-60 \\
\mu \mathrm{m}\end{array}$ & $\begin{array}{c}\text { ution, } \% \\
60-200 \\
\mu \mathrm{m}\end{array}$ & $\begin{array}{c}>200 \\
\mu \mathrm{m}\end{array}$ \\
\hline $28 \mathrm{a}$ & 0,96 & 4,7 & 4,6 & 65 & 12 & 6 & 5 & 12 \\
\hline $28 \mathrm{~b}$ & 0,87 & 4,7 & 3,6 & 61 & 12 & 6 & 6 & 15 \\
\hline $29 a$ & 0,50 & 4,7 & 32,4 & & & & & \\
\hline $29 b$ & 0,37 & 4,3 & 33,1 & & & & & \\
\hline $30 \mathrm{a}$ & 0,63 & 5,9 & 13,9 & 24 & 36 & 36 & 3 & 1 \\
\hline $30 \mathrm{~b}$ & 0,77 & 5,9 & 3,5 & 19 & 33 & 40 & 5 & 3 \\
\hline $31 \mathrm{a}$ & 1,07 & 5,6 & 2,4 & 15 & 23 & 40 & 20 & 2 \\
\hline $31 \mathrm{~b}$ & 1,02 & 5,5 & 1,2 & 15 & 29 & 39 & 16 & 1 \\
\hline $32 a$ & 1,09 & 4,4 & 3,2 & 9 & 25 & 24 & 26 & 16 \\
\hline $32 \mathrm{~b}$ & 1,03 & 4,4 & 2,8 & 8 & 22 & 24 & 28 & 18 \\
\hline $33 a$ & 0,75 & 4,3 & 8,2 & 40 & 29 & 13 & 6 & 12 \\
\hline $33 b$ & 0,72 & 4,3 & 6,9 & 51 & 31 & 10 & 3 & 5 \\
\hline $34 a$ & 1,07 & 7,2 & 2,1 & 48 & 35 & 10 & 2 & 5 \\
\hline $34 b$ & 1,06 & 7,2 & 1,6 & 56 & 34 & 3 & 2 & 5 \\
\hline $35 a$ & 0,93 & 5,2 & 2,6 & 42 & 41 & 11 & 4 & 2 \\
\hline $35 b$ & 0,90 & 5,2 & 1,3 & 41 & 45 & 9 & 3 & 2 \\
\hline $36 a$ & 0,65 & 5,1 & 12,1 & 18 & 20 & 14 & 26 & 22 \\
\hline $36 b$ & 0,81 & 4,6 & 6,0 & 15 & 8 & 12 & 38 & 27 \\
\hline $37 a$ & 1,26 & 4,7 & 1,2 & 6 & 4 & 6 & 51 & 33 \\
\hline $37 \mathrm{~b}$ & 1,27 & 4,9 & 0,5 & 5 & 2 & 4 & 50 & 39 \\
\hline $38 a$ & 1,10 & 5,3 & 2,6 & 8 & 24 & 48 & 18 & 2 \\
\hline $38 \mathrm{~b}$ & 1,00 & 4,9 & 2,3 & 8 & 23 & 47 & 20 & 2 \\
\hline $39 a$ & 1,20 & 5,7 & 1,6 & 14 & 38 & 23 & 14 & 11 \\
\hline $39 \mathrm{~b}$ & 1,10 & 5,4 & 1,3 & 17 & 42 & 18 & 13 & 10 \\
\hline $40 \mathrm{a}$ & 1,20 & 5,2 & 2,0 & 6 & 10 & 29 & 46 & 9 \\
\hline $40 \mathrm{~b}$ & 1,15 & 5,1 & 1,3 & 6 & 12 & 35 & 40 & 7 \\
\hline $41 \mathrm{a}$ & 1,19 & 4,6 & 2,0 & 6 & 8 & 21 & 54 & 11 \\
\hline $41 \mathrm{~b}$ & 1,11 & 4,7 & 1,7 & 4 & 9 & 27 & 52 & 8 \\
\hline $42 a$ & 1,02 & 6,2 & 2,0 & 10 & 33 & 49 & 7 & 1 \\
\hline $42 \mathrm{~b}$ & 1,01 & 6,0 & 1,0 & 7 & 31 & 51 & 6 & 5 \\
\hline $43 a$ & 1,11 & 4,9 & 2,3 & 9 & 11 & 29 & 48 & 3 \\
\hline $43 b$ & 1,13 & 4,4 & 0,7 & 9 & 11 & 60 & 15 & 5 \\
\hline $44 a$ & 1,01 & 5,5 & 2,1 & 36 & 40 & 11 & 10 & 3 \\
\hline $44 b$ & 0,96 & 5,4 & 2,1 & 36 & 38 & 12 & 11 & 3 \\
\hline $45 a$ & 0,96 & 4,7 & 3,0 & 4 & 18 & 55 & 20 & 3 \\
\hline $45 b$ & 1,09 & 4,7 & 1,1 & 4 & 15 & 55 & 25 & 1 \\
\hline $46 a$ & 1,23 & 6,1 & 0,6 & 4 & 31 & 42 & 10 & 13 \\
\hline $46 b$ & 1,20 & 5,3 & 0,4 & 5 & 33 & 40 & 11 & 11 \\
\hline $47 a$ & 1,15 & 4,9 & 1,9 & 17 & 16 & 33 & 26 & 8 \\
\hline $47 \mathrm{~b}$ & 1,12 & 5,0 & 1,3 & 22 & 19 & 28 & 24 & 7 \\
\hline $48 a$ & 1,04 & 5,7 & 1,8 & 21 & 30 & 28 & 16 & 5 \\
\hline $48 \mathrm{~b}$ & 1,07 & 5,0 & 0,9 & 28 & 30 & 27 & 13 & 2 \\
\hline $49 a$ & 0,84 & 5,0 & 6,2 & 24 & 38 & 36 & 1 & 1 \\
\hline $49 b$ & 1,01 & 4,8 & 1,4 & 30 & 42 & 27 & 1 & 0 \\
\hline $50 \mathrm{a}$ & 0,82 & 4,7 & 4,1 & 26 & 54 & 11 & 4 & 5 \\
\hline $50 \mathrm{~b}$ & 0,82 & 4,7 & 2,9 & 25 & 55 & 11 & 5 & 4 \\
\hline $51 \mathrm{a}$ & 1,12 & 4,8 & 1,3 & 6 & 9 & 37 & 43 & 5 \\
\hline $51 \mathrm{~b}$ & 1,15 & 4,7 & 0,7 & 10 & 12 & 40 & 36 & 2 \\
\hline $52 a$ & 0,69 & 4,5 & 10,1 & 6 & 11 & 24 & 48 & 11 \\
\hline $52 \mathrm{~b}$ & 0,74 & 4,5 & 3,9 & 5 & 8 & 28 & 51 & 8 \\
\hline $53 a$ & 1,02 & 5,5 & 3,1 & 11 & 14 & 11 & 56 & 8 \\
\hline
\end{tabular}


Appendix 1. (Continued).

\begin{tabular}{|c|c|c|c|c|c|c|c|c|}
\hline \multirow{2}{*}{$\begin{array}{c}\text { Soil } \\
\text { sample }\end{array}$} & \multirow{2}{*}{$\begin{array}{c}\text { Bulk } \\
\text { density, } \\
\mathrm{kg} / \mathrm{dm}^{3}\end{array}$} & \multirow{2}{*}{$\underset{\mathrm{CaCl}_{2}}{\mathrm{pH}}$} & \multirow{2}{*}{$\underset{\%}{\text { Org. C, }}$} & \multicolumn{5}{|c|}{ Particle-size distribution, \% } \\
\hline & & & & $\begin{array}{l}<2 \\
\mu \mathrm{m}\end{array}$ & $\begin{array}{c}2-20 \\
\mu \mathrm{m}\end{array}$ & $\begin{array}{c}20-60 \\
\mu \mathrm{m}\end{array}$ & $\begin{array}{c}60-200 \\
\mu \mathrm{m}\end{array}$ & $\begin{array}{c}>200 \\
\mu \mathrm{m}\end{array}$ \\
\hline $53 \mathrm{~b}$ & 0,97 & 4,2 & 1,5 & 27 & 21 & 17 & 31 & 4 \\
\hline $54 a$ & 0,74 & 4,7 & 6,2 & 42 & 36 & 14 & 7 & 1 \\
\hline $54 \mathrm{~b}$ & 0,78 & 4,5 & 3,8 & 35 & 40 & 19 & 6 & 0 \\
\hline $55 a$ & 0,80 & 4,1 & 4,6 & 22 & 30 & 36 & 10 & 2 \\
\hline $55 b$ & 0,84 & 3,9 & 2,1 & 17 & 24 & 43 & 14 & 2 \\
\hline $56 a$ & 0,96 & 5,0 & 3,1 & 37 & 39 & 13 & 5 & 6 \\
\hline $56 \mathrm{~b}$ & 0,90 & 4,9 & 3,6 & 39 & 38 & 11 & 5 & 7 \\
\hline $57 a$ & 1,10 & 5,0 & 2,4 & 29 & 19 & 19 & 17 & 14 \\
\hline $57 \mathrm{~b}$ & 1,04 & 4,9 & 1,3 & 40 & 24 & 12 & 12 & 12 \\
\hline $58 \mathrm{a}$ & 0,93 & 4,7 & 4,9 & 46 & 27 & 16 & 9 & 2 \\
\hline $58 \mathrm{~b}$ & 1,07 & 4,9 & 2,1 & 31 & 30 & 26 & 13 & 0 \\
\hline $59 a$ & 1,07 & 5,3 & 2,3 & 17 & 34 & 26 & 22 & 1 \\
\hline $59 \mathrm{~b}$ & 1,12 & 5,2 & 1,2 & 15 & 34 & 30 & 20 & 1 \\
\hline $60 a$ & 1,14 & 5,3 & 1,7 & 14 & 19 & 13 & 27 & 27 \\
\hline $60 \mathrm{~b}$ & 1,11 & 5,1 & 1,0 & 15 & 20 & 13 & 21 & 31 \\
\hline $61 \mathrm{a}$ & 0,93 & 4,5 & 2,4 & 21 & 59 & 16 & 2 & 2 \\
\hline $61 \mathrm{~b}$ & 0,98 & 4,7 & 1,9 & 21 & 60 & 15 & 2 & 2 \\
\hline $62 a$ & 0,87 & 5,3 & 3,7 & 38 & 44 & 12 & 5 & 1 \\
\hline $62 \mathrm{~b}$ & 0,90 & 4,3 & 1,2 & 39 & 49 & 10 & 1 & 1 \\
\hline $63 a$ & 1,06 & 4,7 & 1,8 & 16 & 58 & 21 & 3 & 2 \\
\hline $63 \mathrm{~b}$ & 1,12 & 4,7 & 0,6 & 14 & 60 & 23 & 2 & 1 \\
\hline $64 a$ & 1,11 & 4,6 & 1,6 & 10 & 29 & 36 & 21 & 4 \\
\hline $64 \mathrm{~b}$ & 1,13 & 4,8 & 0,8 & 10 & 34 & 42 & 13 & 1 \\
\hline $65 a$ & 1,31 & 4,7 & 1,7 & 6 & 25 & 27 & 14 & 28 \\
\hline $65 \mathrm{~b}$ & 1,43 & 5,0 & 1,4 & 3 & 15 & 19 & 11 & 52 \\
\hline $66 a$ & 1,00 & 4,4 & 4,0 & 5 & 17 & 25 & 30 & 23 \\
\hline $66 \mathrm{~b}$ & 1,18 & 4,7 & 1,1 & 5 & 19 & 25 & 28 & 23 \\
\hline $67 a$ & 1,08 & 3,9 & 2,5 & 5 & 18 & 34 & 41 & 2 \\
\hline $67 \mathrm{~b}$ & 0,98 & 3,9 & 2,5 & 4 & 17 & 33 & 43 & 3 \\
\hline $68 \mathrm{a}$ & 0,75 & 3,9 & 6,2 & 4 & 10 & 43 & 41 & 2 \\
\hline $68 \mathrm{~b}$ & 0,95 & 4,0 & 3,4 & 3 & 8 & 47 & 41 & 1 \\
\hline $69 a$ & 1,08 & 5,6 & 1,7 & 20 & 52 & 21 & 5 & 2 \\
\hline $69 \mathrm{~b}$ & 1,07 & 5,7 & 0,9 & 15 & 53 & 28 & 3 & 1 \\
\hline $70 \mathrm{a}$ & 0,95 & 5,9 & 4,1 & 20 & 41 & 33 & 4 & 2 \\
\hline $70 \mathrm{~b}$ & 0,96 & 5,6 & 2,8 & 19 & 40 & 36 & 4 & 1 \\
\hline $71 a$ & 1,21 & 5,9 & 1,3 & 5 & 7 & 51 & 35 & 2 \\
\hline $71 \mathrm{~b}$ & 1,18 & 5,7 & 0,3 & 4 & 5 & 50 & 41 & 0 \\
\hline $72 a$ & 0,43 & 4,4 & 36,8 & & & & & \\
\hline $72 b$ & 0,36 & 4,5 & 44,9 & & & & & \\
\hline $73 a$ & 0,81 & 4,6 & 3,2 & 10 & 23 & 33 & 30 & 4 \\
\hline $73 b$ & 0,93 & 4,5 & 12,0 & 10 & 23 & 38 & 28 & 1 \\
\hline $74 a$ & 0,61 & 3,7 & 22,1 & & & & & \\
\hline $74 \mathrm{~b}$ & 0,32 & 3,7 & 50,5 & & & & & \\
\hline $75 a$ & 1,06 & 4,7 & 2,2 & 8 & 45 & 29 & 16 & 2 \\
\hline $75 b$ & 1,15 & 4,9 & 0,4 & 8 & 44 & 32 & 15 & 1 \\
\hline $76 a$ & 0,90 & 4,8 & 4,4 & 9 & 43 & 36 & 7 & 5 \\
\hline $76 \mathrm{~b}$ & 0,82 & 5,0 & 4,1 & 9 & 44 & 36 & 7 & 4 \\
\hline $77 a$ & 1,02 & 5,3 & 2,7 & 33 & 48 & 9 & 5 & 5 \\
\hline $77 \mathrm{~b}$ & 0,95 & 5,2 & 1,3 & 30 & 47 & 11 & 6 & 6 \\
\hline $78 a$ & 1,00 & 4,8 & 2,3 & 45 & 34 & 9 & 9 & 3 \\
\hline $78 \mathrm{~b}$ & 0,87 & 5,6 & 2,4 & 44 & 34 & 10 & 9 & 3 \\
\hline
\end{tabular}


Appendix 1. (Continued).

\begin{tabular}{|c|c|c|c|c|c|c|c|c|}
\hline \multirow{2}{*}{$\begin{array}{c}\text { Soil } \\
\text { sample }\end{array}$} & \multirow{2}{*}{$\begin{array}{c}\text { Bulk } \\
\text { density, } \\
\mathrm{kg} / \mathrm{dm}^{3}\end{array}$} & \multirow{2}{*}{$\begin{array}{c}\mathrm{pH} \\
\mathrm{CaCl}_{2}\end{array}$} & \multirow{2}{*}{$\begin{array}{l}\text { Org. C, } \\
\%\end{array}$} & \multicolumn{5}{|c|}{ Particle-size distribution, $\%$} \\
\hline & & & & $\begin{array}{l}<2 \\
\mu \mathrm{m}\end{array}$ & $\begin{array}{c}2-20 \\
\mu \mathrm{m}\end{array}$ & $\begin{array}{c}20-60 \\
\mu \mathrm{m}\end{array}$ & $\begin{array}{c}60-200 \\
\mu \mathrm{m}\end{array}$ & $\begin{array}{c}>200 \\
\mu \mathrm{m}\end{array}$ \\
\hline $79 a$ & 0,80 & 4,9 & 6,8 & 43 & 29 & 15 & 9 & 4 \\
\hline $79 b$ & 0,88 & 4,8 & 3,9 & 41 & 26 & 19 & 10 & 4 \\
\hline $80 a$ & 1,13 & 5,9 & 2,2 & 48 & 25 & 18 & 7 & 2 \\
\hline $80 \mathrm{~b}$ & 1,08 & 6,1 & 1,8 & 57 & 24 & 15 & 4 & 0 \\
\hline $81 a$ & 1,10 & 4,9 & 2,6 & 19 & 28 & 26 & 22 & 5 \\
\hline $81 \mathrm{~b}$ & 1,07 & 4,9 & 0,6 & 39 & 33 & 1 & 22 & 5 \\
\hline $82 a$ & 0,86 & 4,5 & 4,1 & 41 & 48 & 5 & 2 & 4 \\
\hline $82 \mathrm{~b}$ & 0,89 & 4,8 & 2,3 & 39 & 52 & 5 & 2 & 2 \\
\hline $83 a$ & 0,50 & 4,6 & 21,9 & & & & & \\
\hline $83 b$ & 0,48 & 4,3 & 26,4 & & & & & \\
\hline $84 a$ & 0,87 & 4,5 & 3,3 & 26 & 52 & 20 & 2 & 0 \\
\hline $84 b$ & 0,77 & 4,4 & 2,5 & 26 & 49 & 23 & 2 & 0 \\
\hline $85 a$ & 0,45 & 3,8 & 33,1 & & & & & \\
\hline $85 b$ & 0,30 & 3,9 & 49,6 & & & & & \\
\hline $86 a$ & 0,71 & 3,9 & 20,8 & & & & & \\
\hline $86 b$ & 0,56 & 3,6 & 24,8 & & & & & \\
\hline $87 a$ & 0,93 & 4,4 & 2,9 & 36 & 41 & 18 & 4 & 1 \\
\hline $87 b$ & 0,97 & 4,6 & 0,9 & 35 & 40 & 19 & 4 & 2 \\
\hline $88 a$ & 1,22 & 4,3 & 1,7 & 4 & 12 & 4 & 37 & 43 \\
\hline $88 \mathrm{~b}$ & 1,23 & 4,4 & 0,9 & 5 & 8 & 5 & 39 & 43 \\
\hline $89 a$ & 1,04 & 4,4 & 3,4 & 4 & 13 & 22 & 31 & 30 \\
\hline $89 b$ & 1,01 & 4,4 & 2,6 & 5 & 14 & 20 & 31 & 30 \\
\hline $90 \mathrm{a}$ & 1,00 & 5,2 & 2,1 & 29 & 58 & 6 & 5 & 2 \\
\hline $90 \mathrm{~b}$ & 0,97 & 5,4 & 0,9 & 22 & 66 & 5 & 5 & 2 \\
\hline $91 \mathrm{a}$ & 0,77 & 5,6 & 6,0 & 25 & 48 & 25 & 1 & 1 \\
\hline $91 b$ & 0,67 & 4,9 & 6,6 & 26 & 49 & 23 & 1 & 1 \\
\hline $92 a$ & 0,93 & 6,4 & 5,3 & 35 & 52 & 10 & 2 & 1 \\
\hline $92 \mathrm{~b}$ & 0,98 & 6,5 & 3,6 & 40 & 48 & 9 & 2 & 1 \\
\hline $93 a$ & 1,00 & 5,2 & 3,0 & 29 & 24 & 16 & 28 & 3 \\
\hline $93 \mathrm{~b}$ & 0,91 & 4,2 & 1,7 & 35 & 28 & 19 & 17 & 1 \\
\hline $94 a$ & 1,14 & 5,3 & 2,0 & 4 & 4 & 5 & 85 & 2 \\
\hline $94 \mathrm{~b}$ & 1,18 & 5,5 & 0,9 & 3 & 3 & 5 & 87 & 2 \\
\hline $95 a$ & 1,02 & 4,6 & 2,2 & 37 & 38 & 8 & 9 & 8 \\
\hline $95 b$ & 1,00 & 4,8 & 1,7 & 38 & 39 & 8 & 8 & 7 \\
\hline $96 a$ & 1,14 & 5,3 & 4,4 & 42 & 18 & 13 & 9 & 18 \\
\hline $96 \mathrm{~b}$ & 0,99 & 5,3 & 1,9 & 54 & 32 & 5 & 3 & 6 \\
\hline $97 a$ & 0,16 & 3,6 & 49,6 & & & & & \\
\hline $98 a$ & 0,56 & 4,1 & 28,7 & & & & & \\
\hline $98 \mathrm{~b}$ & 0,23 & 3,7 & 55,8 & & & & & \\
\hline $99 a$ & 1,07 & 5,2 & 3,6 & 5 & 10 & 49 & 35 & 1 \\
\hline $99 \mathrm{~b}$ & 1,10 & 5,0 & 1,0 & 3 & 11 & 53 & 33 & 0 \\
\hline $100 \mathrm{a}$ & 0,42 & 4,4 & 33,4 & & & & & \\
\hline $100 \mathrm{~b}$ & 0,25 & 3,8 & 46,9 & & & & & \\
\hline $101 \mathrm{a} \mathrm{V}$ & 0,59 & 4,6 & 9,3 & 14 & 32 & 34 & 17 & 3 \\
\hline $101 \mathrm{~b} \mathrm{~V}$ & 0,73 & 4,5 & 4,4 & 19 & 41 & 17 & 21 & 2 \\
\hline $102 a \mathrm{~V}$ & 0,95 & 4,8 & 2,9 & 11 & 26 & 20 & 15 & 28 \\
\hline $102 \mathrm{~b} \mathrm{~V}$ & 1,70 & 4,6 & 1,7 & 8 & 20 & 20 & 13 & 39 \\
\hline $103 a \mathrm{~V}$ & 0,64 & 4,2 & 16,4 & 36 & 24 & 13 & 15 & 12 \\
\hline $103 \mathrm{~b} \mathrm{~V}$ & 0,53 & 3,9 & 8,6 & 53 & 22 & 9 & 10 & 6 \\
\hline $104 a$ & 1,01 & 5,4 & 2,9 & 8 & 20 & 12 & 20 & 40 \\
\hline $104 b$ & 1,09 & 5,6 & 2,4 & 8 & 20 & 11 & 21 & 40 \\
\hline
\end{tabular}


Appendix 1. (Continued).

\begin{tabular}{|c|c|c|c|c|c|c|c|c|}
\hline $\begin{array}{c}\text { Soil } \\
\text { sample }\end{array}$ & $\begin{array}{c}\text { Bulk } \\
\text { density, } \\
\mathrm{kg} / \mathrm{dm}^{3}\end{array}$ & $\begin{array}{c}\mathrm{pH} \\
\mathrm{CaCl}_{2}\end{array}$ & $\begin{array}{c}\text { Org. C, } \\
\%\end{array}$ & $\begin{array}{l}<2 \\
\mu \mathrm{m}\end{array}$ & $\begin{array}{c}\text { Particle } \\
2-20 \\
\mu \mathrm{m}\end{array}$ & $\begin{array}{c}\text { ze distril } \\
20-60 \\
\mu \mathrm{m}\end{array}$ & $\begin{array}{c}\text { ation, } \% \\
60-200 \\
\mu \mathrm{m}\end{array}$ & $\begin{array}{c}>200 \\
\mu \mathrm{m}\end{array}$ \\
\hline $105 a$ & 0,55 & 4,2 & 8,9 & 34 & 44 & 12 & 5 & 5 \\
\hline $105 b$ & 0,56 & 3,9 & 6,8 & 34 & 44 & 12 & 5 & 5 \\
\hline $106 a$ & 1,02 & 5,6 & 3,8 & 33 & 16 & 6 & 22 & 23 \\
\hline $106 b$ & 1,06 & 5,8 & 3,1 & 31 & 14 & 5 & 24 & 26 \\
\hline $107 \mathrm{a}$ & 1,00 & 4,7 & 1,5 & 60 & 14 & 7 & 12 & 7 \\
\hline $107 \mathrm{~b}$ & 0,99 & 5,0 & 2,3 & 45 & 10 & 11 & 18 & 16 \\
\hline $108 \mathrm{a}$ & 0,93 & 5,3 & 4,4 & 7 & 8 & 6 & 33 & 46 \\
\hline $108 \mathrm{~b}$ & 1,31 & 4,5 & 1,0 & 2 & 3 & 3 & 42 & 50 \\
\hline $109 a$ & 1,01 & 4,4 & 6,4 & 23 & 12 & 24 & 34 & 7 \\
\hline
\end{tabular}


Appendix 2. Exchangeable, hydroquinone-reducible, hydroxylammonium chloride-reducible, ascorbic acid-reducible and total manganese and total iron in the soil samples.

\begin{tabular}{|c|c|c|c|c|c|c|}
\hline \multirow{2}{*}{$\begin{array}{l}\text { Soil } \\
\text { sample }\end{array}$} & \multirow{2}{*}{$\begin{array}{l}\text { Exchangeable } \\
\mathrm{Mn}, \mathrm{mg} / \mathrm{kg}\end{array}$} & \multicolumn{3}{|c|}{ Reducible manganese, $\mathrm{mg} / \mathrm{kg}$} & \multirow{2}{*}{$\begin{array}{l}\text { Total } \\
\mathrm{Mn}, \mathrm{mg} / \mathrm{kg}\end{array}$} & \multirow{2}{*}{$\begin{array}{l}\text { Total } \\
\mathrm{Fe}, \mathrm{g} / \mathrm{kg}\end{array}$} \\
\hline & & $\mathrm{C}_{6} \mathrm{H}_{4}(\mathrm{OH})_{2}$ & $\mathrm{HONH}_{3} \mathrm{Cl}$ & $\mathrm{C}_{6} \mathrm{H}_{8} \mathrm{O}_{6}$ & & \\
\hline
\end{tabular}

\begin{tabular}{|c|c|c|c|c|c|c|}
\hline 1a & 12,8 & 2,2 & 2,2 & 3,2 & 314 & 19,7 \\
\hline $1 \mathrm{~b}$ & 2,5 & 0,5 & 1,0 & 1,0 & 222 & 10,9 \\
\hline $2 a$ & 14,9 & 1,1 & 1,1 & 1,1 & 343 & 27,9 \\
\hline $2 \mathrm{~b}$ & 32,6 & 0,8 & 3,4 & 3,4 & 307 & 21,8 \\
\hline $3 a$ & 3,0 & 11,0 & 23,0 & 28,0 & 386 & 30,6 \\
\hline $3 b$ & 1,5 & 4,0 & 18,5 & 18,5 & 518 & 57,0 \\
\hline $4 a$ & 5,1 & 9,9 & 27,4 & 31,9 & 458 & 42,2 \\
\hline $4 b$ & 1,2 & 1,3 & 6,3 & 9,3 & 356 & 40,6 \\
\hline $5 a$ & 8,5 & 4,5 & 15,0 & 19,5 & 378 & 25,4 \\
\hline $5 b$ & 0,8 & 0,7 & 1,2 & 2,2 & 348 & 39,0 \\
\hline $6 a$ & 2,3 & 5,2 & 10,7 & 15,2 & 320 & 18,8 \\
\hline $6 b$ & 2,0 & 12,3 & 34,0 & 33,0 & 297 & 19,9 \\
\hline $7 a$ & 2,8 & 5,8 & 14,3 & 22,8 & 354 & 19,0 \\
\hline $7 b$ & 1,4 & 2,1 & 4,0 & 5,4 & 269 & 20,0 \\
\hline $8 a$ & 6,0 & 18,0 & 40,0 & 47,4 & 442 & 40,6 \\
\hline $8 \mathrm{~b}$ & 2,0 & 7,7 & 20,0 & 20,7 & 255 & 19,4 \\
\hline $9 a$ & 2,4 & 6,1 & 11,1 & 15,6 & 351 & 25,6 \\
\hline $9 b$ & 1,1 & 9,9 & 30,9 & 40,4 & 454 & 42,4 \\
\hline $10 a$ & 8,4 & 12,6 & 26,1 & 43,9 & 566 & 33,1 \\
\hline $10 \mathrm{~b}$ & 1,3 & 5,7 & 28,7 & 30,2 & 538 & 58,4 \\
\hline $11 \mathrm{a}$ & 2,0 & 4,0 & 11,5 & 15,0 & 504 & 49,3 \\
\hline $11 \mathrm{~b}$ & 2,0 & 8,5 & 34,5 & 41,6 & 552 & 51,7 \\
\hline $12 a$ & 9,0 & 23,0 & 32,0 & 45,9 & 609 & 30,1 \\
\hline $12 \mathrm{~b}$ & 1,0 & 2,5 & 4,0 & 14,5 & 458 & 34,7 \\
\hline $13 a$ & 14,0 & 30,2 & 45,2 & 72,2 & 562 & 30,5 \\
\hline $13 \mathrm{~b}$ & 2,5 & 5,1 & 10,3 & 23,9 & 539 & 38,5 \\
\hline $14 a$ & 5,5 & 16,9 & 23,3 & 30,3 & 454 & 24,5 \\
\hline $14 \mathrm{~b}$ & 2,0 & 11,6 & 20,2 & 37,8 & 367 & 21,4 \\
\hline $15 a$ & 5,7 & 28,3 & 85,5 & 125,5 & 970 & 39,1 \\
\hline $15 b$ & 1,8 & 14,2 & 112,2 & 100,2 & 661 & 48,0 \\
\hline $16 a$ & 4,7 & 23,7 & 75,5 & 109,7 & 918 & 36,2 \\
\hline $16 \mathrm{~b}$ & 1,2 & 9,2 & 31,2 & 54,8 & 530 & 36,4 \\
\hline $17 \mathrm{a}$ & 14,4 & 44,2 & 119,4 & 172,2 & 936 & 35,1 \\
\hline $17 \mathrm{~b}$ & 4,3 & 13,7 & 39,1 & 75,9 & 642 & 44,5 \\
\hline $18 \mathrm{a}$ & 6,0 & 5,7 & 7,8 & 13,6 & 383 & 25,0 \\
\hline $19 \mathrm{a}$ & 6,2 & 15,2 & 67,4 & 103,7 & 808 & 36,0 \\
\hline $20 \mathrm{a}$ & 21,2 & 53,0 & 130,4 & 162,8 & 526 & 16,8 \\
\hline $21 a$ & 11,1 & 58,9 & 112,5 & 175,1 & 654 & 11,6 \\
\hline $22 \mathrm{~b}$ & 5,2 & 10,5 & 31,4 & 43,4 & 510 & 28,8 \\
\hline $23 \mathrm{~b}$ & 33,2 & 0,0 & 0,0 & 0,0 & 349 & 38,9 \\
\hline $24 a$ & 16,8 & 80,4 & 153,8 & 179,2 & 498 & 16,3 \\
\hline $24 \mathrm{~b}$ & 10,7 & 47,3 & 88,5 & 109,3 & 378 & 16,4 \\
\hline $25 a$ & 6,8 & 17,7 & 35,2 & 58,0 & 404 & 34,4 \\
\hline $25 b$ & 12,4 & 13,2 & 38,0 & 49,4 & 331 & 36,1 \\
\hline $26 a$ & 4,0 & 9,5 & 14,8 & 19,0 & 306 & 20,2 \\
\hline $26 \mathrm{~b}$ & 3,0 & 6,1 & 7,2 & 9,8 & 267 & 20,0 \\
\hline $27 a$ & 141,0 & 517,6 & 718,4 & 680,7 & 2196 & 26,7 \\
\hline $27 \mathrm{~b}$ & 138,0 & 400,3 & 770,3 & 647,0 & 2481 & 24,5 \\
\hline $28 \mathrm{a}$ & 13,0 & 30,3 & 50,6 & 69,2 & 1158 & 101,4 \\
\hline
\end{tabular}


Appendix 2. (Contunued).

\begin{tabular}{|c|c|c|c|c|c|c|}
\hline \multirow{2}{*}{$\begin{array}{l}\text { Soil } \\
\text { sample }\end{array}$} & \multirow{2}{*}{$\begin{array}{l}\text { Exchangeable } \\
\mathrm{Mn}, \mathrm{mg} / \mathrm{kg}\end{array}$} & \multicolumn{3}{|c|}{ Reducible manganese, $\mathrm{mg} / \mathrm{kg}$} & \multirow{2}{*}{$\begin{array}{l}\text { Total } \\
\mathrm{Mn}, \mathrm{mg} / \mathrm{kg}\end{array}$} & \multirow{2}{*}{$\begin{array}{r}\text { Total } \\
\mathrm{Fe}, \mathrm{g} / \mathrm{kg}\end{array}$} \\
\hline & & $\mathrm{C}_{6} \mathrm{H}_{4}(\mathrm{OH})_{2}$ & $\mathrm{HONH}_{3} \mathrm{Cl}$ & $\mathrm{C}_{6} \mathrm{H}_{8} \mathrm{O}_{6}$ & & \\
\hline $28 \mathrm{~b}$ & 11,5 & 24,1 & 62,5 & 66,3 & 1628 & 111,2 \\
\hline $29 a$ & 57,0 & 54,5 & 98,7 & 112,7 & 335 & 15,7 \\
\hline $29 b$ & 64,1 & 45,0 & 71,8 & 68,3 & 230 & 17,8 \\
\hline $30 a$ & 2,0 & 9,0 & 22,4 & 28,0 & 280 & 23,9 \\
\hline $30 \mathrm{~b}$ & 0,9 & 3,3 & 10,1 & 11,1 & 272 & 23,8 \\
\hline $31 \mathrm{a}$ & 2,7 & 16,3 & 36,7 & 41,7 & 455 & 29,9 \\
\hline $31 \mathrm{~b}$ & 2,0 & 9,0 & 20,2 & 29,1 & 401 & 33,1 \\
\hline $32 a$ & 34,4 & 77,1 & 102,7 & 112,0 & 619 & 19,0 \\
\hline $32 \mathrm{~b}$ & 30,6 & 73,9 & 131,8 & 124,0 & 541 & 18,6 \\
\hline $33 a$ & 5,9 & 8,1 & 10,6 & 13,6 & 237 & 31,0 \\
\hline $33 b$ & 4,2 & 3,4 & 4,9 & 6,8 & 236 & 33,2 \\
\hline $34 a$ & 1,2 & 18,3 & 41,5 & 48,7 & 742 & 46,6 \\
\hline $34 \mathrm{~b}$ & 1,5 & 28,5 & 89,0 & 68,6 & 655 & 47,5 \\
\hline $35 a$ & 4,6 & 24,3 & 43,1 & 74,9 & 841 & 45,2 \\
\hline $35 b$ & 2,4 & 11,6 & 49,1 & 79,2 & 756 & 46,4 \\
\hline $36 a$ & 10,5 & 21,2 & 40,5 & 58,5 & 336 & 20,7 \\
\hline $36 \mathrm{~b}$ & 4,8 & 12,2 & 21,3 & 28,5 & 237 & 15,0 \\
\hline $37 a$ & 7,1 & 22,9 & 34,0 & 43,9 & 236 & 9,8 \\
\hline $37 b$ & 3,0 & 6,6 & 13,0 & 12,0 & 161 & 8,3 \\
\hline $38 \mathrm{a}$ & 3,2 & 9,3 & 18,5 & 22,4 & 340 & 19,0 \\
\hline $38 \mathrm{~b}$ & 3,2 & 6,8 & 10,8 & 13,8 & 275 & 18,9 \\
\hline $39 a$ & 5,6 & 29,4 & 62,4 & 74,4 & 427 & 17,9 \\
\hline $39 b$ & 6,3 & 25,9 & 71,0 & 84,2 & 404 & 19,4 \\
\hline $40 \mathrm{a}$ & 12,5 & 62,8 & 93,2 & 118,9 & 490 & 18,3 \\
\hline $40 \mathrm{~b}$ & 4,6 & 18,7 & 33,7 & 42,5 & 377 & 19,1 \\
\hline $41 a$ & 11,0 & 67,8 & 92,6 & 124,7 & 744 & 27,9 \\
\hline $41 \mathrm{~b}$ & 6,4 & 48,3 & 90,7 & 146,5 & 646 & 26,6 \\
\hline $42 a$ & 4,8 & 100,9 & 186,6 & 233,3 & 868 & 26,9 \\
\hline $42 b$ & 3,0 & 58,2 & 126,3 & 128,4 & 619 & 28,7 \\
\hline $43 a$ & 3,6 & 10,4 & 19,2 & 23,6 & 342 & 15,9 \\
\hline $43 b$ & 1,0 & 1,4 & 1,0 & 2,1 & 332 & 14,4 \\
\hline $44 a$ & 7,0 & 62,4 & 139,4 & 139,8 & 1087 & 24,7 \\
\hline $44 b$ & 5,8 & 44,8 & 132,1 & 150,3 & 1048 & 45,9 \\
\hline $45 a$ & 3,5 & 3,7 & 7,0 & 41,2 & 326 & 18,6 \\
\hline $45 b$ & 1,3 & 1,3 & 2,3 & 3,2 & 360 & 23,4 \\
\hline $46 a$ & 4,2 & 54,6 & 105,8 & 122,9 & 664 & 28,0 \\
\hline $46 b$ & 5,0 & 43,2 & 66,2 & 76,8 & 497 & 29,4 \\
\hline $47 a$ & 2,8 & 2,9 & 8,2 & 11,7 & 291 & 20,7 \\
\hline $47 \mathrm{~b}$ & 1,9 & 3,7 & 15,1 & 20,3 & 280 & 26,2 \\
\hline $48 \mathrm{a}$ & 1,4 & 9,6 & 23,0 & 35,3 & 410 & 27,0 \\
\hline $48 b$ & 1,3 & 4,7 & 8,7 & 12,7 & 312 & 35,9 \\
\hline $49 a$ & 5,2 & 25,9 & 46,6 & 63,0 & 538 & 33,9 \\
\hline $49 b$ & 2,4 & 10,6 & 27,6 & 33,7 & 400 & 31,1 \\
\hline $50 \mathrm{a}$ & 9,1 & 16,7 & 30,3 & 42,9 & 475 & 32,9 \\
\hline $50 \mathrm{~b}$ & 7,6 & 23,0 & 36,7 & 45,9 & 504 & 36,9 \\
\hline 51 a & 7,4 & 24,8 & 42,6 & 57,9 & 604 & 28,9 \\
\hline $51 \mathrm{~b}$ & 7,1 & 29,0 & 60,6 & 76,9 & 543 & 31,4 . \\
\hline $52 a$ & 17,0 & 18,6 & 26,2 & 28,3 & 322 & 11,3 \\
\hline $52 \mathrm{~b}$ & 6,4 & 7,1 & 13,1 & 13,6 & 261 & 9,9 \\
\hline $53 a$ & 3,6 & 9,4 & 18,6 & 23,1 & 404 & 23,6 \\
\hline
\end{tabular}


Appendix 2. (Contunued).

\begin{tabular}{|c|c|c|c|c|c|c|}
\hline \multirow{2}{*}{$\begin{array}{l}\text { Soil } \\
\text { sample }\end{array}$} & \multirow{2}{*}{$\begin{array}{l}\text { Exchangeable } \\
\mathrm{Mn}, \mathrm{mg} / \mathrm{kg}\end{array}$} & \multicolumn{3}{|c|}{ Reducible manganese, $\mathrm{mg} / \mathrm{kg}$} & \multirow{2}{*}{$\begin{array}{l}\text { Total } \\
\mathrm{Mn}, \mathrm{mg} / \mathrm{kg}\end{array}$} & \multirow{2}{*}{$\begin{array}{l}\text { Total } \\
\mathrm{Fe}, \mathrm{g} / \mathrm{kg}\end{array}$} \\
\hline & & $\mathrm{C}_{6} \mathrm{H}_{4}(\mathrm{OH})_{2}$ & $\mathrm{HONH}_{3} \mathrm{Cl}$ & $\mathrm{C}_{6} \mathrm{H}_{8} \mathrm{O}_{6}$ & & \\
\hline $53 \mathrm{~b}$ & 4,4 & 3,9 & 5,6 & 7,1 & 353 & 31,8 \\
\hline $54 a$ & 20,6 & 78,7 & 98,0 & 132,3 & 770 & 38,3 \\
\hline $54 \mathrm{~b}$ & 7,7 & 22,9 & 29,5 & 52,3 & 555 & 30,4 \\
\hline $55 a$ & 10,5 & 6,0 & 6,5 & 8,5 & 405 & 36,4 \\
\hline $55 \mathrm{~b}$ & 4,9 & 1,4 & 1,4 & 2,0 & 363 & 27,7 \\
\hline $56 a$ & 3,5 & 24,8 & 69,7 & 119,4 & 1080 & 50,8 \\
\hline $56 \mathrm{~b}$ & 5,0 & 31,7 & 81,4 & 117,9 & 951 & 50,6 \\
\hline $57 a$ & 4,0 & 6,5 & 11,0 & 20,4 & 341 & 29,8 \\
\hline $57 b$ & 2,6 & 4,0 & 7,4 & 10,9 & 346 & 44,2 \\
\hline $58 \mathrm{a}$ & 5,5 & 16,7 & 23,4 & 39,2 & 498 & 40,3 \\
\hline $58 \mathrm{~b}$ & 4,0 & 13,5 & 23,2 & 31,6 & 489 & 38,8 \\
\hline $59 a$ & 3,6 & 10,9 & 19,7 & 27,5 & 414 & 25,6 \\
\hline $59 \mathrm{~b}$ & 2,1 & 6,8 & 14,4 & 18,5 & 364 & 27,4 \\
\hline $60 \mathrm{a}$ & 5,0 & 16,1 & 38,2 & 52,9 & 312 & 18,4 \\
\hline $60 \mathrm{~b}$ & 3,1 & 7,9 & 14,9 & 24,7 & 286 & 21,1 \\
\hline $61 a$ & 11,5 & 27,4 & 35,9 & 48,5 & 559 & 34,7 \\
\hline $61 b$ & 6,4 & 19,2 & 28,6 & 48,3 & 631 & 36,4 \\
\hline $62 a$ & 2,0 & 5,5 & 14,0 & 24,7 & 346 & 35,7 \\
\hline $62 \mathrm{~b}$ & 3,8 & 6,7 & 16,2 & 19,5 & 403 & 38,4 \\
\hline $63 a$ & 10,5 & 30,0 & 43,2 & 57,4 & 522 & 30,5 \\
\hline $63 \mathrm{~b}$ & 4,5 & 19,7 & 29,7 & 38,7 & 517 & 29,2 \\
\hline $64 a$ & 5,3 & 10,2 & 11,3 & 17,4 & 354 & 26,5 \\
\hline $64 \mathrm{~b}$ & 3,3 & 8,2 & 11,2 & 28,4 & 407 & 28,8 \\
\hline $65 a$ & 6,5 & 34,1 & 46,4 & 54,7 & 308 & 16,9 \\
\hline $65 b$ & 2,0 & 5,0 & 9,5 & 11,5 & 253 & 16,6 \\
\hline $66 a$ & 16,5 & 44,7 & 61,5 & 74,2 & 305 & 16,8 \\
\hline $66 \mathrm{~b}$ & 3,3 & 10,7 & 15,7 & 19,5 & 221 & 15,2 \\
\hline $67 a$ & 20,0 & 2,8 & 5,0 & 4,4 & 357 & 24,5 \\
\hline $67 b$ & 17,0 & 3,6 & 7,4 & 18,0 & 404 & 22,2 \\
\hline $68 a$ & 3,3 & 0,3 & 0,8 & 1,4 & 244 & 12,4 \\
\hline $68 \mathrm{~b}$ & 1,3 & 0,4 & 0,4 & 0,5 & 429 & 13,9 \\
\hline $69 a$ & 6,5 & 28,5 & 49,4 & 55,3 & 424 & 32,1 \\
\hline $69 \mathrm{~b}$ & 2,2 & 11,8 & 23,4 & 34,5 & 443 & 29,5 \\
\hline $70 \mathrm{a}$ & 2,7 & 11,8 & 25,1 & 32,9 & 347 & 30,7 \\
\hline $70 \mathrm{~b}$ & 2,0 & 6,9 & 11,0 & 13,5 & 324 & 25,2 \\
\hline $71 \mathrm{a}$ & 4,8 & 35,2 & 53,3 & 54,0 & 338 & 18,9 \\
\hline $71 \mathrm{~b}$ & 2,9 & 18,8 & 26,5 & 28,8 & 393 & 17,7 \\
\hline $72 a$ & 20,8 & 0,5 & 1,7 & 3,0 & 183 & 22,4 \\
\hline $72 b$ & 18,8 & 6,2 & 21,2 & 21,2 & 197 & 21,3 \\
\hline $73 a$ & 14,0 & 23,2 & 34,8 & 38,9 & 237 & 23,0 \\
\hline $73 b$ & 3,9 & 7,1 & 7,6 & 10,1 & 359 & 27,8 \\
\hline $74 a$ & 26,3 & 1,2 & 2,5 & 3,7 & 267 & 24,0 \\
\hline $74 b$ & 62,5 & 1,4 & 1,4 & 4,2 & 170 & 18,5 \\
\hline $75 a$ & 7,8 & 16,9 & 21,6 & 33,4 & 383 & 23,4 \\
\hline $75 b$ & 3,9 & 21,4 & 35,5 & 64,9 & 448 & 26,7 \\
\hline $76 a$ & 11,0 & 39,1 & 57,8 & 63,9 & 482 & 23,5 \\
\hline $76 \mathrm{~b}$ & 9,9 & 39,7 & 66,1 & 74,5 & 365 & 18,0 \\
\hline $77 a$ & 4,2 & 26,6 & 63,7 & 100,2 & 905 & 41,3 \\
\hline $77 b$ & 3,6 & 19,1 & 54,6 & 92,0 & 765 & 43,0 \\
\hline $78 a$ & 11,0 & 44,2 & 91,2 & 120,1 & 821 & 50,5 \\
\hline $78 \mathrm{~b}$ & 21,1 & 35,6 & 81,1 & 103,3 & 664 & 54,1 \\
\hline
\end{tabular}


Appendix 2. (Contunued).

\begin{tabular}{|c|c|c|c|c|c|c|}
\hline \multirow{2}{*}{$\begin{array}{l}\text { Soil } \\
\text { sample }\end{array}$} & \multirow{2}{*}{$\begin{array}{l}\text { Exchangeable } \\
\mathrm{Mn}, \mathrm{mg} / \mathrm{kg}\end{array}$} & \multicolumn{3}{|c|}{ Reducible manganese, $\mathrm{mg} / \mathrm{kg}$} & \multirow{2}{*}{$\begin{array}{l}\text { Total } \\
\text { Mn, } \mathrm{mg} / \mathrm{kg}\end{array}$} & \multirow{2}{*}{$\begin{array}{l}\text { Total } \\
\mathrm{Fe}, \mathrm{g} / \mathrm{kg}\end{array}$} \\
\hline & & $\mathrm{C}_{6} \mathrm{H}_{4}(\mathrm{OH})_{2}$ & $\mathrm{HONH}_{3} \mathrm{Cl}$ & $\mathrm{C}_{6} \mathrm{H}_{8} \mathrm{O}_{6}$ & & \\
\hline $79 a$ & 5,5 & 18,3 & 29,6 & 39,1 & 309 & 28,5 \\
\hline $79 b$ & 4,7 & 12,3 & 27,2 & 33,1 & 318 & 31,3 \\
\hline $80 a$ & 2,4 & 11,1 & 31,1 & 39,1 & 459 & 50,5 \\
\hline $80 \mathrm{~b}$ & 1,8 & 11,2 & 45,3 & 55,9 & 455 & 48,0 \\
\hline $81 \mathrm{a}$ & 7,8 & 15,4 & 24,6 & 30,6 & 202 & 13,5 \\
\hline $81 \mathrm{~b}$ & 5,6 & 16,0 & 37,9 & 48,6 & 287 & 25,5 \\
\hline $82 a$ & 8,4 & 16,9 & 31,6 & 47,9 & 809 & 47,6 \\
\hline $82 \mathrm{~b}$ & 3,8 & 16,2 & 31,5 & 75,7 & 772 & 46,2 \\
\hline $83 a$ & 9,8 & 14,2 & 20,2 & 25,2 & 152 & 19,8 \\
\hline $83 b$ & 13,3 & 11,7 & 16,7 & 16,7 & 178 & 18,6 \\
\hline $84 a$ & 9,7 & 16,1 & 30,8 & 24,0 & 362 & 28,3 \\
\hline $84 \mathrm{~b}$ & 8,5 & 14,1 & 15,7 & 18,9 & 382 & 29,5 \\
\hline $85 a$ & 28,8 & 0,2 & 5,0 & 3,7 & 178 & 19,9 \\
\hline $85 b$ & 51,3 & 9,2 & 14,5 & 11,9 & 191 & 16,9 \\
\hline $86 a$ & 54,7 & 5,8 & 12,7 & 13,7 & 151 & 4,4 \\
\hline $86 \mathrm{~b}$ & 48,4 & 3,2 & 7,4 & 8,4 & 253 & 21,8 \\
\hline $87 a$ & 9,7 & 19,3 & 28,7 & 43,5 & 379 & 34,1 \\
\hline $87 \mathrm{~b}$ & 4,3 & 11,7 & 47,8 & 47,3 & 460 & 41,1 \\
\hline $88 a$ & 20,0 & 94,3 & 130,7 & 156,4 & 450 & 13,3 \\
\hline $88 \mathrm{~b}$ & 11,0 & 63,2 & 86,1 & 122,6 & 426 & 13,7 \\
\hline $89 a$ & 16,0 & 61,9 & 68,3 & 72,6 & 323 & 14,0 \\
\hline $89 b$ & 12,0 & 43,8 & 50,1 & 64,3 & 320 & 14,1 \\
\hline $90 \mathrm{a}$ & 12,0 & 72,3 & 132,3 & 206,2 & 1296 & 36,1 \\
\hline $90 \mathrm{~b}$ & 10,1 & 49,9 & 140,6 & 267,2 & 1108 & 40,0 \\
\hline $91 \mathrm{a}$ & 4,3 & 13,2 & 26,8 & 32,0 & 291 & 16,9 \\
\hline $91 b$ & 5,5 & 11,0 & 16,6 & 23,5 & 306 & 18,8 \\
\hline $92 \mathrm{a}$ & 4,6 & 31,7 & 74,9 & 96,8 & 592 & 32,6 \\
\hline $92 \mathrm{~b}$ & 3,3 & 43,5 & 111,0 & 136,7 & 763 & 52,5 \\
\hline $93 a$ & 7,6 & 21,4 & 32,4 & 46,4 & 493 & 29,2 \\
\hline $93 \mathrm{~b}$ & 9,2 & 11,9 & 14,5 & 22,9 & 465 & 34,1 \\
\hline $94 a$ & 4,6 & 17,5 & 45,1 & 47,2 & 292 & 9,0 \\
\hline $94 \mathrm{~b}$ & 1,9 & 6,3 & 14,6 & 21,3 & 272 & 10,1 \\
\hline $95 a$ & 10,5 & 32,6 & 56,7 & 95,2 & 860 & 37,6 \\
\hline $95 \mathrm{~b}$ & 7,2 & 27,5 & 66,7 & 119,9 & 804 & 38,7 \\
\hline $96 a$ & 5,8 & 16,3 & 43,4 & 47,5 & 453 & 30,0 \\
\hline $96 \mathrm{~b}$ & 3,6 & 14,9 & 45,1 & 58,4 & 545 & 46,9 \\
\hline $97 a$ & 12,8 & 0,8 & 1,3 & 2,2 & 80 & 3,5 \\
\hline $98 \mathrm{a}$ & 47,5 & 18,3 & 39,3 & 28,8 & 321 & 22,1 \\
\hline $98 \mathrm{~b}$ & 51,3 & 35,5 & 66,7 & 66,7 & 194 & 8,3 \\
\hline $99 a$ & 5,6 & 35,4 & 66,7 & 93,7 & 372 & 18,2 \\
\hline $99 \mathrm{~b}$ & 0,9 & 1,6 & 3,1 & 5,7 & 306 & 24,1 \\
\hline $100 \mathrm{a}$ & 75,0 & 1,3 & 30,3 & 40,5 & 237 & 12,6 \\
\hline $100 \mathrm{~b}$ & 60,5 & 0,0 & 38,2 & 46,0 & 208 & 5,8 \\
\hline $101 \mathrm{a}$ & 17,0 & 50,7 & 112,3 & 144,4 & 584 & 22,9 \\
\hline $101 \mathrm{~b}$ & 11,0 & 34,1 & 64,4 & 86,1 & 550 & 7,9 \\
\hline $102 \mathrm{a}$ & 2,6 & 8,4 & 17,4 & 22,7 & 303 & 20,3 \\
\hline $102 \mathrm{~b}$ & 1,4 & 4,6 & 7,8 & 11,6 & 339 & 21,3 \\
\hline $103 a$ & 10,0 & 0,5 & 9,5 & 11,1 & 177 & 17,5 \\
\hline $103 \mathrm{~b}$ & 2,8 & 0,6 & 1,3 & 1,6 & 313 & 31,3 \\
\hline $104 a$ & 8,5 & 65,4 & 165,8 & 185,1 & 684 & 25,6 \\
\hline $104 \mathrm{~b}$ & 3,8 & 48,5 & 140,5 & 166,2 & 688 & 26,4 \\
\hline
\end{tabular}


Appendix 2. (Contunued).

\begin{tabular}{|c|c|c|c|c|c|c|}
\hline \multirow{2}{*}{$\begin{array}{l}\text { Soil } \\
\text { sample }\end{array}$} & \multirow{2}{*}{$\begin{array}{l}\text { Exchangeable } \\
\mathrm{Mn}, \mathrm{mg} / \mathrm{kg}\end{array}$} & \multicolumn{3}{|c|}{ Reducible manganese, $\mathrm{mg} / \mathrm{kg}$} & \multirow{2}{*}{$\begin{array}{l}\text { Total } \\
\mathrm{Mn}, \mathrm{mg} / \mathrm{kg}\end{array}$} & \multirow{2}{*}{$\begin{array}{c}\text { Total } \\
\mathrm{Fe}, \mathrm{g} / \mathrm{kg}\end{array}$} \\
\hline & & $\mathrm{C}_{6} \mathrm{H}_{4}(\mathrm{OH})_{2}$ & $\mathrm{HONH}_{3} \mathrm{Cl}$ & $\mathrm{C}_{6} \mathrm{H}_{8} \mathrm{O}_{6}$ & & \\
\hline $105 a$ & 7,7 & 2,3 & 3,3 & 3,8 & 231 & 37,0 \\
\hline $105 b$ & 6,6 & 0,3 & 0,5 & 0,4 & 275 & 47,9 \\
\hline $106 a$ & 10,0 & 61,8 & 244,6 & 253,6 & 811 & 32,9 \\
\hline $106 \mathrm{~b}$ & 4,7 & 45,0 & 218,0 & 231,7 & 755 & 32,0 \\
\hline $107 a$ & 8,5 & 10,5 & 16,3 & 26,2 & 603 & 54,0 \\
\hline $107 b$ & 11,0 & 10,6 & 20,6 & 24,3 & 491 & 44,4 \\
\hline $108 \mathrm{a}$ & 2,1 & 11,4 & 26,3 & 29,5 & 465 & 19,5 \\
\hline $108 b$ & 0,0 & 1,5 & 2,1 & 2,7 & 601 & 17,4 \\
\hline $109 a$ & 8,6 & 3,2 & 4,8 & 10,1 & 318 & 21,3 \\
\hline
\end{tabular}




\title{
Kasville käyttökelpoisen maan mangaanin määrittämisestä
}

\author{
Väinö Mäntylahti \\ Yliopiston maanviljelyskemian laitos, Helsinki
}

Tutkimuksen tarkoituksena oli märïttää kasville käyttökelpoista maan mangaania. Maasta määritettiin vaihtuvaa ja pelkistyvää mangaania ja tutkittiin, miten ne muiden maa-analyysitulosten ohella kuvasivat sadon mangaanin ottoa ja mangaanipitoisuutta. Lisäksi tutkittiin mistä tekijöistä maan uuttuvan mangaanin pitoisuuden vaihtelut johtuvat ja miten niihin voidaan vaikuttaa. Aineistona oli 193 kivennäismaata ja 17 eloperäistä maata. Kivennäismaista oli pintamaita 98 ja eloperäisistä maista 9. Astiakokeissa käytettiin koekasvina kauraa (Avena sativa L.), Italian raiheinää (Lolium multiflorum Lam.) ja rypsiä (Brassica campestris oleifera $\mathrm{L}$.).

Maan mangaanin uuttamiseksi kehitettiin kationinvaihtohartsimenetelmä, jolla voitiin tyydyttävällä toistettavuudella määrittää maan vaihtuvaa ja pelkistyvää mangaania. Vaihtuva mangaani koostui maanesteen kationimuotoisesta mangaanista ja maan vaihtuvasta kationimuotoisesta mangaanista. Pelkistyvä mangaani oli hydrokinonin, hydroksyyliammoniumkloridin ja askorbiinihapon vaikutuksesta pelkistynyttä kationimuotoista mangaania.

Maan kokonaismangaanin pitoisuuden vaihtelua selitti ensisijaisesti maan kokonaisraudan pitoisuus (30-66 \%). Vähäisessä määrin vaihtelua selittivät savespitoisuus, $\mathrm{pH}$ kivennäismaiden muokkauskerroksessa ja kun kivennäismaita käsiteltiin yhtenä ryhmänä, sekä orgaanisen hiilen pitoisuus kivennäismaiden muokkauskerroksessa. Maan vaihtuvan mangaanin pitoisuuden vaihtelusta pelkistyvän mangaanin pitoisuus, $\mathrm{pH}$ ja orgaanisen hiilen pitoisuus selittivät 53-67\%. Pelkistyvän mangaanin pitoisuus oli hieman tärkeämpi riippumaton muuttuja kuin $\mathrm{pH}$. Orgaanisen hiilen pitoisuuden merkitys riippumattomana muuttujana oli vähäinen muihin muuttujiin verrattuna. Hydrokinoni-, hydroksyyliammoniumkloridi- ja askorbiinihappopelkisteisen mangaanin pitoisuudet olivat lähes samanarvoisia vaihtuvan mangaanin pitoisuuden vaihtelun kuvaajia. Pelkistyvän mangaanin pitoisuuden vaihtelua selitti vähäisessä määrin (18-34 \%) maan "kokonais"mangaanin pitoisuus.

Maan vaihtuvan mangaanin pitoisuus ei rïppunut maan kosteudesta, mikäli kosteus oli kenttäkapasiteettia pienempi. Sen sijaan kasvuston vaikutuksesta maan vaihtuvan mangaanin pitoisuus kohosi, kun vertailukohteena käytettiin muhitettuja maita. Maan hapetus-pelkistyspotentiaalimittausten perusteella todettiin, että maan kosteus alensi potentiaalia vasta, kun kosteus oli kenttäkapasiteettia suurempi. Kasvin juuristolla oli huomattava potentiaalia alentava vaikutus. Maan vaihtuvan mangaanin pitoisuus alkoi kohota, kun hapetus-pelkistyspotentiaali laski alle $0,59 \mathrm{~V}$. Tosin vaihtuvan mangaanin pitoisuus ei kohonnut potentiaaliyksikköä kohti läheskään niin paljon, kuin synteettisten mangaanioksidien teoreettinen pelkistyminen olisi edellyttänyt. Maan mikrobitoiminnan inaktivoinnin ja glukoosilisäyksen vaikutuksesta vaihtuvan mangaanin pitoisuus kohosi riippumatta kovinkaan suuresti inaktivoinnin asteesta. Mangaanin pelkistymisen pääteltiin olevan luonteeltaan sekä biologista että ei-biologista. Helposti hapettuva orgaaninen yhdiste pelkisti nopeasti maan mangaania.

Maan vaihtuvan mangaanin pitoisuus selitti $23 \%$ ensimmäisen raiheinäsadon mangaanin oton ja 34 \% mangaanipitoisuuden vaihtelusta. Mitä useampi sato korjattiin, sitä vähäisemmäksi osoittautui vaihtuvan mangaanin pitoisuuden merkitys sadon mangaanin oton ja pitoisuuden vaihtelun kuvaajana. Sen sijaan pelkistyvän mangaanin pitoisuuden merkitys korostui sitä mukaa, mitä useampi sato korjattiin. Neljännen sadon mangaanin oton vaihtelusta hydroksyyliammoniumkloridipelkisteisen mangaanin pitoisuus selitti $68 \%$ ja mangaanipitoisuuden vaihtelusta $69 \%$. Riippumattomana muuttujana hydroksyyliammoniumkloridipelkisteisen mangaanin pitoisuus oli parempi selittäjä kuin hydrokinonipelkisteisen ja askorbiinihappopelkisteisen mangaanin pitoisuus. Raiheinän juuriston mangaanipitoisuuden vaihtelusta maan vaihtuvan mangaanin pitoisuus ja askorbiinihappopelkisteisen mangaanin pitoisuus selittivät $73 \%$.

Maan vaihtuvan mangaanin pitoisuuden katsottiin kuvaavan maan mangaanin intensiteettitekijää. Vastaavasti pelkistyvän mangaanin pitoisuuden katsottiin kuvaavan maan mangaanin kapasiteettitekijää.

Mangaanilannoitus kohotti sadon ja maan uuttuvan mangaanin pitoisuutta. Toisaalta kalkitus vähensi sadon mangaanin ottoa ja alensi siten sadon mangaanipitoisuutta. Kun kalkitus ja mangaanilannoitus suoritettiin samana keväänä, säilyi mangaanilannoituksen teho tyydyttävänä, mikäli kalkitusainemärä oli 
ollut pieni. Seuraavana kasvukautena lisätyllä mangaanilla ei ollut juuri lainkaan jälkivaikutusta, jos kalsiittia oli edellisenä vuotena käytetty noin $7 \mathrm{t} / \mathrm{ha} \cdot 20 \mathrm{~cm}$. Suuri mangaanimäärä $(51,5 \mathrm{~kg} / \mathrm{ha} \cdot 20 \mathrm{~cm})$ riitti vaivoin kumoamaan kalkituksen aiheuttaman sadon mangaanin oton ja mangaanipitoisuuden alenemisen. Kalkituksen vaikutuksesta tapahtunut maan vaihtuvan mangaanin pitoisuuden aleneminen oli suurempi kuin maan $\mathrm{pH}: \mathrm{n}$ muutoksen perusteella oli pääteltävissä. Vaihtuvan mangaanin pitoisuuden väheneminen merkitsi samalla pelkistyvän mangaanin pitoisuuden kohoamista.

Kun pyritään määrittämään kasville käyttökelpoista maan mangaania tarkoituksena ennakoida sadon mangaanin ottoa ja mangaanipitoisuutta, näyttäisi olevan tarkoituksenmukaista määrittää mangaanin intensiteettiä ja kapasiteettia kuvaavia muuttujia. Intensiteettiä kuvaava muuttuja saattaisi olla puskuroimattomasta uuttosuspensiosta määritetty kationimuotoinen vaihtuva mangaani. Kapasiteettia sopinee kuvaamaan hydroksyyliammoniumkloridilla hapetusasteelle $\mathrm{Mn}^{2+}$ pelkistyvä mangaani. 